UNIVERSIDADE DE SÃO PAULO

FACULDADE DE ECONOMIA, ADMINISTRAÇÃO E CONTABILIDADE DE RIBEIRÃO PRETO

DEPARTAMENTO DE ADMINISTRAÇÃO

PROGRAMA DE PÓS-GRADUAÇÃO EM ADMINISTRAÇÃO DE ORGANIZAÇÕES

MAYARA SEGATTO

O desenvolvimento local a partir da teoria da complexidade: uma abordagem fenomenológica

ORIENTADOR: PROF. DR. DANTE PINHEIRO MARTINELLI

RIBEIRÃO PRETO

2013 
Prof. Dr. João Grandino Rodas

Reitor da Universidade de São Paulo

Prof. Dr. Sigismundo Bialoskorski Neto

Diretor da Faculdade de Economia, Administração e Contabilidade de Ribeirão Preto

Profa. Dra. Sonia Valle Walter Borges de Oliveira Chefe do Departamento de Administração 


\section{MAYARA SEGATTO}

O desenvolvimento local a partir da teoria da complexidade: uma abordagem fenomenológica

Dissertação apresentada ao Programa de PósGraduação em Administração de Organizações da Faculdade de Economia, Administração e Contabilidade de Ribeirão Preto da Universidade de São Paulo, para obtenção do título de Mestra em Ciências. Versão Corrigida. A original encontra-se disponível no Serviço de Pós-Graduação da FEARP/USP.

ORIENTADOR: PROF. DR. DANTE PINHEIRO MARTINELLI 
Autorizo a reprodução e divulgação total ou parcial deste trabalho, por qualquer meio convencional ou eletrônico, para fins de estudo e pesquisa, desde que citada a fonte.

\section{FICHA CATALOGRÁFICA}

Segatto, Mayara

O desenvolvimento local a partir da teoria da complexidade: uma abordagem fenomenológica. Ribeirão Preto, 2013.

92 f. : il. ; $30 \mathrm{~cm}$

Dissertação de Mestrado, apresentada à Faculdade de Economia, Administração e Contabilidade de Ribeirão Preto/USP. Área de concentração: Administração de Organizações.

Orientador: Martinelli, Dante Pinheiro.

1. Desenvolvimento local. 2. Complexidade. 3. Fenomenologia. 4. Dinâmica. 
Às queridas

Adelina, Isabel, Vânia e Samara. Aos queridos

Lineu, Tony, Matheus e Leandro. 



\section{AGRADECIMENTOS}

Ao Prof. Dante Pinheiro Martinelli, pesquisador renomado, professor dedicado e excelente orientador. Agradeço pelo seu tempo e paciência, pelos conselhos e pela honra de me permitir desfrutar de sua amizade. Agradeço pela influência positiva em muitos sentidos, sem a qual esse trabalho não seria possível.

A todos os docentes da Faculdade de Economia, Administração e Contabilidade de Ribeirão Preto (FEA-RP), que, direta ou indiretamente, contribuíram para minha formação pessoal e profissional. Aos professores: Silvia Inês Dallavalle de Pádua, Charbel José Chiappetta Jabbour e Lara Bartocci Liboni Amui, sempre acessíveis e prestativos. À Prof. Dra. Carla Aparecida Arena Ventura e ao Prof. Dr. João Luiz Passador, cujas críticas e sugestões na etapa de qualificação e ao longo do desenvolvimento do trabalho foram essenciais para o resultado final.

Aos meus colegas de estudo da FEA-RP, por participarem das discussões e se envolverem com meus dilemas ao longo do processo de pesquisa. Agradecimentos especiais a Leonardo Augusto Amaral Terra, pelas sugestões e também por permitir que seu trabalho seja utilizado como modelo. Agradecimentos aos colegas do Grupo de Sistemas da FEA-RP, pelo apoio e compreensão nos momentos de ausência.

À minha família e amigos, que compreenderam minhas ausências e mantiveram apoio incondicional às minhas escolhas. Às amigas Beatriz e Letícia, que foram parte de mim a cada passo desta jornada, mesmo quando a presença física não era possível. Ao meu noivo Leandro, que apoiou minha decisão e incentivou cada etapa do meu curso de mestrado.

Ao Conselho Nacional de Desenvolvimento Científico e Tecnológico (CNPq), pelo apoio financeiro.

Aos funcionários da FEA-RP/USP que forneceram todo o apoio necessário. Aos funcionários da ESALQ/USP que contribuíram para que este trabalho continuasse possível à distância.

Meus sinceros agradecimentos a todos que fizeram parte dessa jornada, seria impossível citar aqui todos os nomes das pessoas que me incentivaram e me fortaleceram. Muito obrigada a todos que puderam compreender o valor deste desafio, ou que, mesmo não compreendendo, apoiaram incondicionalmente todo o esforço despendido. 

O maior esforço é aquele necessário para reconhecer quando é o bastante. 



\section{RESUMO}

SEGATTO, M. O desenvolvimento local a partir da teoria da complexidade: uma abordagem fenomenológica. 2013. 92 f. Dissertação de Mestrado, Faculdade de Economia, Administração e Contabilidade de Ribeirão Preto, Universidade de São Paulo, Ribeirão Preto, 2013.

O desenvolvimento local é um assunto controverso e pouco estudado no Brasil, assim como no debate internacional. A despeito das opiniões divergentes, autores da área concordam com a emergência do tema do desenvolvimento de localidades e regiões, impulsionado pelo novo contexto globalizado, marcado por paradoxos, incerteza e complicações, em que os benefícios gerados permanecem restritos a poucas regiões. Assumindo a relevância do tema acerca do desenvolvimento, é crescente a atenção às abordagens em âmbito local, já que nessa esfera os problemas são mais bem identificados, além de haver maior possibilidade de integração entre os diferentes setores e atores envolvidos. Nesse contexto, a complexidade é apontada como característica das dinâmicas de desenvolvimento, o que exige um tratamento a partir de um fundamento epistemológico coerente. Somente com a compreensão da dinâmica que envolve o próprio processo de desenvolvimento é que se pode pensar em formas de impulsioná-lo por meio das ações dos seus atores. Assim, este esforço de pesquisa busca verificar se a dinâmica do desenvolvimento local envolve características que justifiquem seu tratamento tendo por base uma abordagem epistemológica compatível com os paradigmas científicos contemporâneos acerca da teoria da complexidade. Partindo de uma discussão teórica, este trabalho realiza uma revisão conceitual, embasado em uma análise do problema, segundo a fenomenologia de Husserl. Os resultados foram submetidos a um processo analógico, realizado por meio de pesquisa bibliográfica em obras que tratam da teoria da complexidade, em busca de conceitos básicos fundamentais, que foram transpostos à essência do desenvolvimento local. Como resultado, a essência do fenômeno do desenvolvimento foi descrita em um esboço, configurando uma rede formada pelas interações entre seus subsistemas. Esta configuração foi analisada a partir dos conceitos da teoria da complexidade, em uma descrição de sua dinâmica que caracteriza o desenvolvimento local como um fenômeno complexo, considerando esta base teórica como abordagem adequada ao seu tratamento.

Palavras chave: 1. Desenvolvimento local; 2. Complexidade; 3. Fenomenologia; 4. Dinâmica. 


\begin{abstract}
SEGATTO, M. The local development from the complexity theory: a phenomenological approach. 2013. 92 f. Dissertação de Mestrado, Faculdade de Economia, Administração e Contabilidade de Ribeirão Preto, Universidade de São Paulo, Ribeirão Preto, 2013.

Local development is a controversial and poorly studied matter in Brazil, as well as in the international debate. Despite differing opinions, authors agree that the emergence of the theme of development of localities and regions has been driven by the new globalized context, characterized by paradoxes, uncertainty and complications, in which the generated benefits remain restricted to a few regions. Assuming the relevance of the development issue, there is growing attention to approaches at the local extent, since in the local scope problems are better identified, beyond the greater possibility of integration between different sectors and stakeholders. In this sense, complexity is seen as a feature of the development dynamics, requiring a coherent epistemological foundation for studies. The only alternative for finding ways to promote the development process through the actions of agents/actors, such as business organizations, is by understanding the dynamics surrounding it. Thus, this research aims at verifying if the local development dynamics involve characteristics that justify its treatment based on an epistemological approach consistent with the contemporary scientific paradigms of complexity theory. From a theoretical discussion, this work performs a conceptual revision, based on an analysis of the problem, according to Husserl's phenomenology. Results were submitted to an analog procedure, performed through a bibliographic research in literature dealing with the complexity theory, in pursuit of fundamental basic concepts, transposed to the essence of the local development. As a partial result, the essence of the development phenomenon was described in a sketch, setting up a network constituted by interactions between its subsystems. This configuration was analyzed based on the concepts of complexity theory, in a description of the dynamics that characterizes the local development as a complex phenomenon, considering this theoretical basis as a suitable approach to its treatment.
\end{abstract}

Keywords: 1. Local development; 2. Complexity; 3. Phenomenology; 4. Dynamic. 


\section{LISTA DE FIGURAS}

Figura 1 - Estrutura não-linear do trabalho e objetivos específicos .....................................21

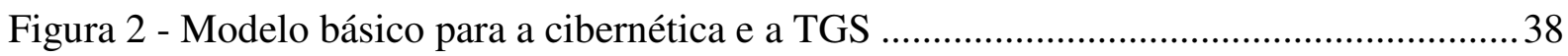

Figura 3 - Etapas do método proposto por Terra e Passador (2011) .................................... 131

Figura 4 - Procedimentos de pesquisa nesta dissertação ...................................................... 132

Figura 5 - Esboço da essência primeira do subsistema de desenvolvimento local.................138

Figura 6 - Esboço da essência primeira do desenvolvimento.............................................. 139

Figura 7 - Indivíduos e grupos informais no desenvolvimento local .................................. 154

Figura 8 - Organizações no desenvolvimento local ....................................................... 155

\section{LISTA DE QUADROS}

Quadro 1 - Procedimentos de pesquisa relacionados aos objetivos do trabalho ...................... 19

Quadro 2 - Diferenças entre os enfoques cartesiano e sistêmico ............................................ 30

Quadro 3 - Síntese dos principais paradigmas do desenvolvimento após 1950 ........................ 82

Quadro 4 - Conceitos de desenvolvimento territorial comparados ....................................... 107

Quadro 5 - Conceitos de desenvolvimento regional comparados ........................................ 108

Quadro 6 - Conceitos de desenvolvimento local comparados............................................. 109

Quadro 7 - Fundamentos epistemológicos da complexidade adotados pelo presente estudo 126

Quadro 8 - Conceitos fundamentais da teoria da complexidade resultantes da revisão da

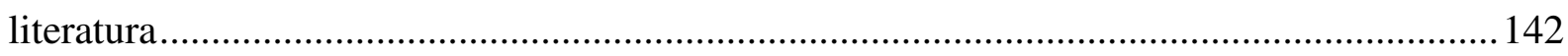

Quadro 9 - Proposta inicial dos termos de busca para pesquisa bibliográfica ........................ 143

Quadro 10 - Termos de busca para pesquisa bibliográfica..................................................... 143

Quadro 11 - Seleção final de artigos para atualização do conhecimento sobre a teoria da

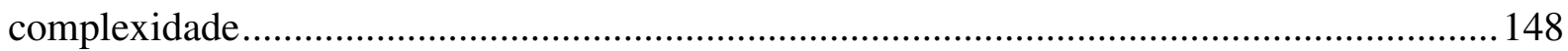

Quadro 12 - Relação das questões de análise com os conceitos fundamentais da Complexidade 152

Quadro 13 - Características da Complexidade apresentadas pelo desenvolvimento local ..... 165

Quadro 14 - Dinâmicas da Complexidade às quais o desenvolvimento local está sujeito..... 166 


\section{LISTA DE TABELAS}

Tabela 1 - Resultado das buscas preliminares nas bases de dados ..................................... 145

Tabela 2 - Estudos selecionados para análise …............................................................... 145 


\section{LISTA DE ABREVIATURAS E SIGLAS}

ALP - Arranjo Local de Produção

CAPES - Coordenação de Aperfeiçoamento de Pessoal de Nível Superior CE - Critério de Exclusão

Cepal - Comissão Econômica para a América Latina e o Caribe

CI - Critério de Inclusão

Dlis - Desenvolvimento Local Integrado e Sustentável

ECO-92 - II Conferência Mundial do Meio Ambiente e Desenvolvimento

F - Filtro de pesquisa

FMI - Fundo Monetário Internacional

Ipea - Instituto de Pesquisa Econômica Aplicada

NUP - New Urban Policy School (Escola da Nova Política Urbana)

ONG - Organização Não-Governamental

ONU - Organização das Nações Unidas

PME - Pequena e Média Empresa

SIBiUSP - Sistema Integrado de Bibliotecas da Universidade de São Paulo

SIG - Sistema Integrado de Gestão

SLI/P - Sistema Local de Inovação e Produção

SLP - Sistema Local de Produção

TGS - Teoria Geral de Sistemas

VSM - Viable System Model (Modelo de Sistema Viável) 



\section{SUMÁRIO}

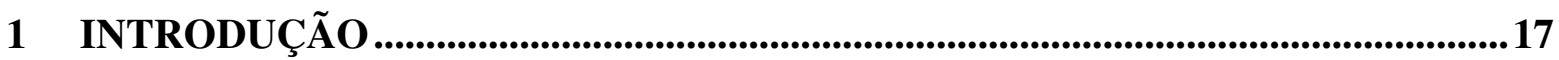

1.1. PROBLEMA DE PESQUISA ……………………............................... 18

1.2. OBJETIVO GERAL ……………………………….............................. 18

1.3. OBJETIVOS ESPECÍFICOS ................................................................. 18

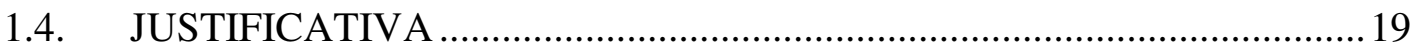

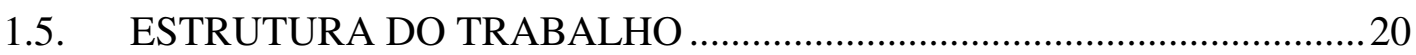

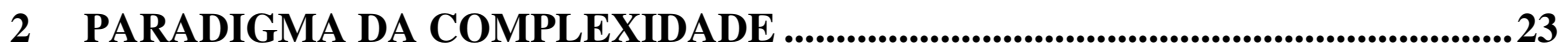

2.1. ABORDAGEM SISTÊMICA ……………………………………............ 31

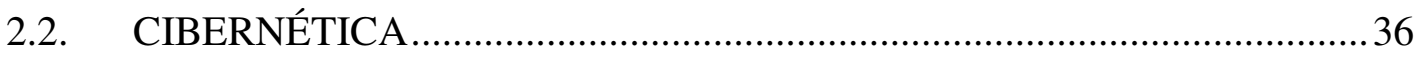

2.3. CAOS E COMPLEXIDADE …………………………………………..... 41

2.4. COMPLEXIDADE E DESENVOLVIMENTO..............................................63

3 DESENVOLVIMENTO .................................................................................................79

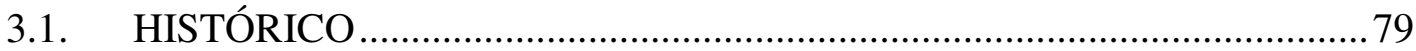

3.2. CONCEITO DE DESENVOLVIMENTO ……………………………........ 89

3.2.1. Desenvolvimento local ........................................................................96

3.2.2. Desenvolvimento regional ................................................................ 100

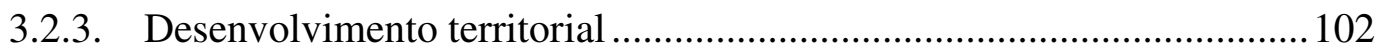

3.2.4. Comparação dos conceitos de desenvolvimento ......................................106

3.3. ATORES DO DESENVOLVIMENTO ……………………………........110

3.4. REQUISITOS DO DESENVOLVIMENTO ..............................................119

4 PROCEDIMENTOS DE PESQUISA E ANÁLISE DOS RESULTADOS..............125

4.1. MÉTODO DE COLETA DE EVIDÊNCIAS ................................................133

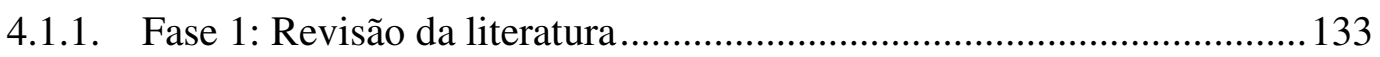

4.1.2. Fase 2: Captura da essência do fenômeno …………………………….... 134

4.1.3. Fase 3: Pesquisa bibliográfica ……………………………………...... 140

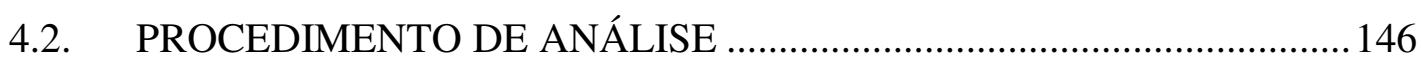

4.3. ORGANIZAÇÃO DOS RESULTADOS ……………………………........ 148 
5 DESENVOLVIMENTO LOCAL PELA VISÃO DA TEORIA DA COMPLEXIDADE .......................................................................................................... 151

6 CONSIDERAÇÕES FINAIS................................................................................... 165

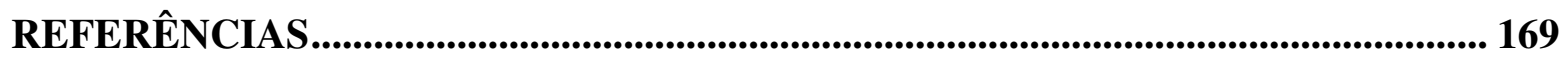




\section{INTRODUÇÃO}

A questão do desenvolvimento de localidades e regiões tem ganhado força no debate acadêmico e prático, embora resulte de um esforço relativamente recente de pesquisa. Apesar de admitirem contribuições anteriores, há divergências entre os autores acerca do momento em que as discussões sobre desenvolvimento em âmbito local e regional se destacaram, sendo que Siedenberg (2010) aponta a década de 1950, Navarro (2001) enfatiza dois momentos: a década de 1950 e, depois, meados da década de 1990, enquanto Moraes (2010) define o início dos anos 1980 e Dallabrida e Becker (2010) indicam os anos 1980 e 1990 como marcantes para as preocupações com o desenvolvimento.

A despeito das opiniões divergentes, autores da área concordam com a emergência do tema impulsionada pelo novo contexto global (BIRKNER, 2008; WITTMANN; RAMOS, 2004) marcado por paradoxos, incerteza e complexidade (AXLEY; MACMAHON, 2006; CLOSS; ANTONELLO, 2010). A complexidade tem sido apontada por diversos autores como característica das dinâmicas de desenvolvimento (ALBUQUERQUE, 1998; BECKER, 2010a; CANEVER et al., 2010; CAPRA, 2006; MARTINS; VAZ; CALDAS, 2010; MORAES, 2010; OLIVEIRA; WITTMANN, 2010; SACHS, 2008; SOTARAUTA, 2009; SOTO, 2010), exigindo um posicionamento coerente acerca do fenômeno.

Nesse contexto, o equilíbrio entre as demandas e tendências globais com as potencialidades regionais é o grande desafio contemporâneo dos agentes dos processos de desenvolvimento, além da falta de uma abordagem sistêmica de gestão para que os interesses distintos das partes envolvidas sejam integrados (OLIVEIRA; WITTMANN, 2010). Fatores como a necessidade de modelar instituições, combinada com a complexidade crescente e a rápida velocidade das mudanças têm aumentado as demandas dos responsáveis pelo desenvolvimento local (SOTARAUTA, 2009). Uma forma de encarar essa complexidade, segundo Martins, Vaz e Caldas (2010), é pela articulação simultânea entre instrumentos e atores, por meio de estratégias de desenvolvimento que ressaltem o caráter multidimensional e multiescalar desses processos. Entretanto, os atores nem sempre compreendem a real sistemicidade envolvida nas dinâmicas do desenvolvimento, o que ocorre devido à insuficiência das abordagens tradicionais cartesianas para lidar com esse desafio. Somente a partir da compreensão da dinâmica complexa que envolve o desenvolvimento local, é que se pode pensar em formas de impulsioná-lo por meio das ações de seus agentes. Portanto, este 
esforço de pesquisa busca verificar a adequabilidade da teoria da complexidade como fundamento conceitual para o tratamento do desenvolvimento local.

\subsection{PROBLEMA DE PESQUISA}

O contexto apresentado demonstra a necessidade de uma avaliação do desenvolvimento a partir de uma perspectiva compatível com sua natureza, em alternativa às abordagens tradicionais cartesianas. Assim, o problema de pesquisa foi definido: O paradigma da Complexidade consiste em uma abordagem adequada para o tratamento da dinâmica do desenvolvimento local?

\subsection{OBJETIVO GERAL}

O objetivo da pesquisa é verificar se a dinâmica do desenvolvimento local envolve características que justifiquem seu tratamento tendo por base uma abordagem epistemológica compatível com os paradigmas científicos contemporâneos acerca da Complexidade.

\subsection{OBJETIVOS ESPECÍFICOS}

A partir do objetivo geral, os objetivos específicos do presente esforço de pesquisa foram definidos:

- Compreender a base teórica e os conceitos envolvidos nos paradigmas emergentes ligados à Complexidade;

- Identificar as perspectivas contemporâneas acerca do desenvolvimento e as concepções, processos e atores a ele relacionados;

- Descrever as características da dinâmica básica do desenvolvimento local que possuam relações com as perspectivas referentes à teoria da complexidade. 
O quadro 1 representa as relações entre os objetivos específicos e o objetivo geral do trabalho, assim como os procedimentos a serem adotados para que estes sejam atingidos.

\begin{tabular}{|c|c|c|}
\hline Objetivo geral & Objetivos específicos & Procedimentos de pesquisa \\
\hline \multirow[b]{3}{*}{ 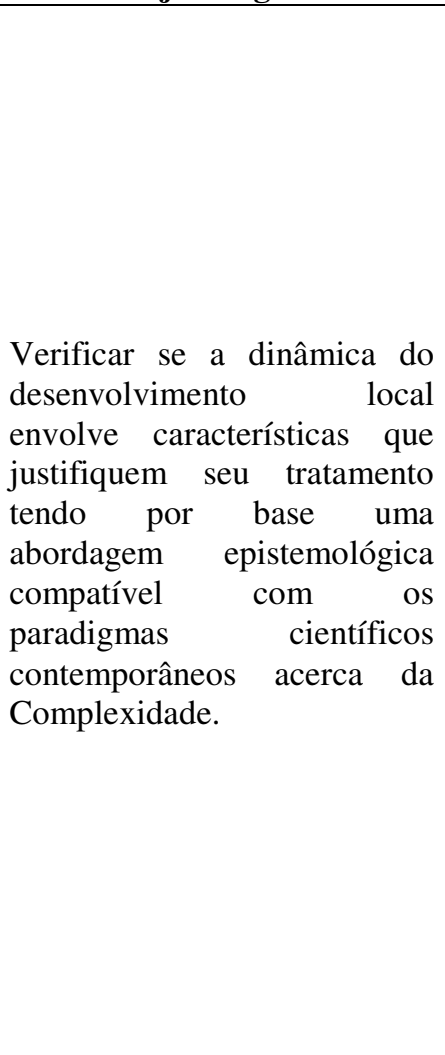 } & $\begin{array}{l}\text { Compreender a base teórica e os } \\
\text { conceitos envolvidos nos paradigmas } \\
\text { emergentes ligados à Complexidade. }\end{array}$ & $\begin{array}{l}\text { - Revisão da literatura sobre a } \\
\text { Complexidade, buscando conceitos } \\
\text { fundamentais. }\end{array}$ \\
\hline & $\begin{array}{l}\text { Identificar as } \begin{array}{c}\text { perspectivas } \\
\text { contemporâneas }\end{array} \text { acerca do } \\
\text { desenvolvimento e as concepções, } \\
\text { processos e atores a ele relacionados. }\end{array}$ & $\begin{array}{l}\text { - Revisão da literatura sobre } \\
\text { desenvolvimento, verificando os } \\
\text { conceitos e definições, descrições } \\
\text { do processo, atores e requisitos; } \\
\text { - Seleção da definição de } \\
\text { desenvolvimento a ser utilizada no } \\
\text { trabalho. }\end{array}$ \\
\hline & $\begin{array}{l}\text { Descrever as características da } \\
\text { dinâmica básica do desenvolvimento } \\
\text { local que possuam relações com as } \\
\text { perspectivas referentes à teoria da } \\
\text { complexidade. }\end{array}$ & $\begin{array}{l}\text { - Esboço da essência primeira do } \\
\text { desenvolvimento local baseada na } \\
\text { interpretação e experiência quanto } \\
\text { ao fenômeno; } \\
\text { - Pesquisa bibliográfica utilizando os } \\
\text { conceitos fundamentais encontrados } \\
\text { na revisão da literatura sobre } \\
\text { Complexidade, buscando } \\
\text { atualizações de definições e } \\
\text { conceitos que possam ser } \\
\text { relacionados ao fenômeno do } \\
\text { desenvolvimento local; } \\
\text { - Descrição das características da } \\
\text { dinâmica do desenvolvimento local } \\
\text { relacionando-as aos conceitos } \\
\text { teóricos da Complexidade. }\end{array}$ \\
\hline
\end{tabular}

Quadro 1 - Procedimentos de pesquisa relacionados aos objetivos do trabalho

\subsection{JUSTIFICATIVA}

Diante do contexto em que a complexidade é apontada como característica do desenvolvimento (ALBUQUERQUE, 1998; BECKER, 2010a; CANEVER et al., 2010; CAPRA, 2006; MARTINS; VAZ; CALDAS, 2010; MORAES, 2010; OLIVEIRA; WITTMANN, 2010; SACHS, 2008; SOTARAUTA, 2009; SOTO, 2010) justifica-se um estudo que busque verificar a adequabilidade dos paradigmas científicos emergentes para a compreensão da dinâmica envolvida no desenvolvimento local. Para que os distintos atores do desenvolvimento possam contribuir, faz-se necessária a compreensão do fenômeno e de seus processos. Esses processos - particularmente as interações entre as dimensões econômica e social e entre fatores físicos e humanos - ainda não são compreendidos apesar de anos de 
pesquisa e investimentos em esforços de desenvolvimento (TISCH; WALLACE, 1994). A partir da compreensão da dinâmica inerente ao desenvolvimento, seus atores podem planejar suas ações, equilibrando os objetivos individuais aos coletivos, a fim de propiciar um desenvolvimento sustentável em suas mais variadas dimensões.

A motivação para explorar a nova abordagem baseada na complexidade surgiu da frustração com outras abordagens tradicionais cartesianas que, com frequência, falham. Além disso, a motivação para este trabalho decorre do desejo de contribuir com o avanço do conhecimento, trazendo benefícios diretos para a sociedade. Portanto, o foco se deu sobre um tema diretamente ligado à sociedade, e principalmente, às comunidades locais. O contato com o tema do desenvolvimento local foi resultado de uma disciplina cursada durante o mestrado que, juntamente com o interesse pelo assunto, trouxe indagações acerca da dinâmica do fenômeno. A busca pela compreensão do desenvolvimento local é o reflexo de uma preocupação em entender as possibilidades de ação dos atores desse fenômeno. Logo, a motivação para o trabalho surgiu do desejo de contribuição efetiva para o desenvolvimento da sociedade, uma vez que, a partir da compreensão do fenômeno, os atores do processo podem atuar em prol da melhoria das condições de vida e da sustentabilidade do desenvolvimento.

\subsection{ESTRUTURA DO TRABALHO}

A primeira seção deste trabalho de pesquisa consiste nesta introdução. Ela é dividida em uma apresentação e mais cinco subseções, cujo conteúdo envolve o problema de pesquisa, os objetivos, a justificativa para a elaboração deste estudo e a presente estrutura do trabalho. Além desta introdução, este trabalho é composto por mais cinco seções, sendo que uma delas trata dos procedimentos de pesquisa, a última apresenta as considerações finais e as outras três estão relacionadas aos objetivos específicos, conforme a figura 1.

A seção denominada "Paradigma da Complexidade" apresenta os aspectos principais acerca da Complexidade e as implicações para a abordagem epistemológica e metodológica adotada neste estudo.

A seção denominada "Desenvolvimento" discute a multiplicidade dos conceitos acerca do desenvolvimento. Esta seção contempla uma apresentação e mais quatro subseções, com o objetivo de apresentar o processo de desenvolvimento a partir das diversas perspectivas encontradas e compará-las. 


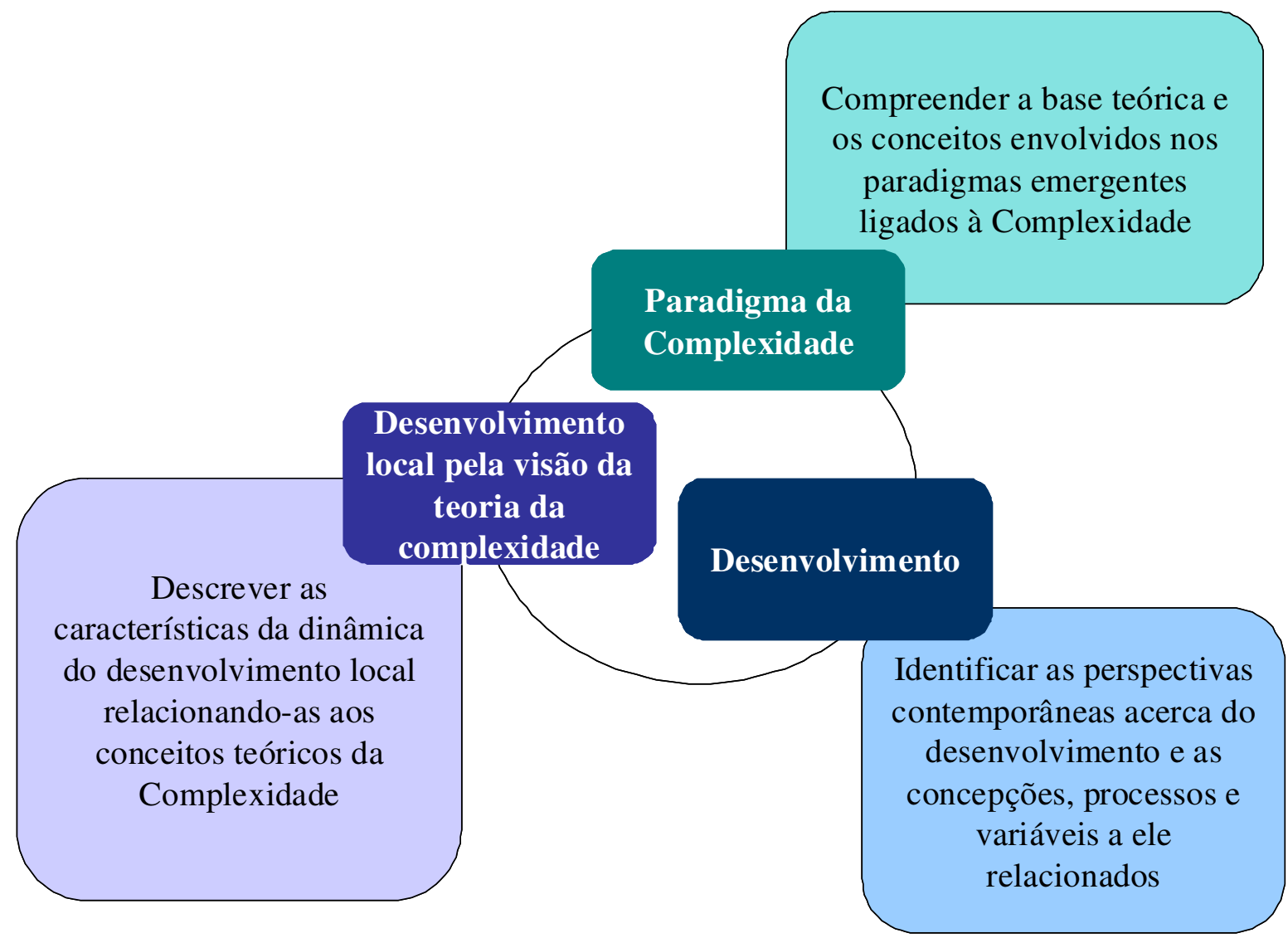

Figura 1 - Estrutura não-linear do trabalho e objetivos específicos

A seção designada de "Procedimentos de pesquisa e análise dos resultados" apresenta o método utilizado para se atingir o objetivo deste trabalho. Esta seção é dividida em três subseções, contemplando os detalhes a respeito da coleta e análise dos dados e já apresentando alguns resultados parciais.

Já a seção "Desenvolvimento local pela visão da teoria da complexidade" contempla a descrição das características da dinâmica do desenvolvimento local relacionando-as aos conceitos fundamentais da Complexidade.

Por fim, são apresentadas as considerações finais. Elas sintetizam os aspectos mais importantes encontrados, analisando suas implicações para os estudos na área de desenvolvimento local e para os atores do fenômeno, apresentando, por fim, a contribuição e as limitações decorrentes da abordagem utilizada. 


\section{PARADIGMA DA COMPLEXIDADE}

A visão do mundo e os valores que formam a base de nossa cultura foram formulados em suas linhas essenciais nos séculos XVI e XVII, substituindo uma visão orgânica do mundo, dominante antes de 1500 (CAPRA, 2006). Essa visão de um universo orgânico, vivo e espiritual foi substituída pela visão do mundo como uma máquina, resultado de mudanças revolucionárias na física e na astronomia, marcadas pelas realizações de Copérnico, Galileu e Newton (CAPRA, 2006).

A ciência do século XVII baseou-se num novo método de investigação, defendido vigorosamente por Francis Bacon, o qual envolvia a descrição matemática da natureza e o método analítico de raciocínio concebido pelo gênio de Descartes. Reconhecendo o papel crucial da ciência na concretização dessas importantes mudanças, os historiadores chamaram os séculos XVI e XVII de a Idade da Revolução Científica (CAPRA, 2006, p. 50).

Segundo Capra (2006, p. 50), “a revolução científica começou com Nicolau Copérnico, que se opôs à concepção geocêntrica de Ptolomeu e da Bíblia”, destituindo a Terra de sua posição central no universo. Já Galileu Galilei tem papel destacado na revolução científica devido à utilização da experimentação científica e da descrição matemática da natureza, que se tornaram as características dominantes da ciência no século XVII, criando a obsessão pela medição e pela quantificação (BAUER, 1999; CAPRA, 2006).

Francis Bacon, por sua vez, descreveu o método empírico da ciência, formulando uma teoria clara do procedimento indutivo ("realizar experimentos e extrair deles conclusões gerais, a serem testadas por novos experimentos"), mudando a natureza e o objetivo da investigação científica para o conhecimento usado como forma de controle e domínio da natureza (BAUER, 1999; CAPRA, 2006, p. 51).

O cartesianismo, responsável pela construção do método filosófico posterior à visão orgânica de mundo dos gregos, teve início com Descartes (1596-1650), lançando as bases para a ciência clássica (WITTMANN; MAEHLER, 2008) e fundando o racionalismo moderno (BAUER, 1999). De acordo com Capra (2006), René Descartes, considerado o fundador da filosofia moderna, influenciou o desenvolvimento subsequente da civilização ocidental a partir de sua crença na certeza do conhecimento científico, base da filosofia cartesiana. Para Descartes, "ciência era sinônimo de matemática" e ela era a chave para a compreensão do universo, desenvolvendo um método de raciocínio cuja proposição inicial era a de levar à verdade científica (CAPRA, 2006, p. 53). Como afirma Capra (2006), o foco do 
método de Descartes é a dúvida, ou seja, ele duvida de tudo, até chegar a si mesmo como pensador, do que não pode duvidar. Assim, baseado na afirmação "penso, logo existo", concebendo o pensamento como a essência da natureza humana, ele define o conhecimento certo como resultado da intuição e da dedução (CAPRA, 2006).

Para Descartes, o único conhecimento válido era o que podia ser expresso por regras eternas, livres do contexto e precisas, que capturassem padrões gerais (DEVLIN, 1996). Conforme Capra (2006), o método de Descartes é analítico, ou seja, decompõe problemas em partes componentes, dispondo-as em sua ordem lógica, utilizando-se do raciocínio dedutivo. Apesar do seu método analítico de raciocínio ser provavelmente sua maior contribuição à ciência, também resultou na fragmentação característica do pensamento contemporâneo em geral e das disciplinas acadêmicas, levando à atitude generalizada de reducionismo e à separação entre mente e matéria, considerando aquela superior à última (CAPRA, 2006). Segundo Wittmann e Maehler (2008), a filosofia de Descartes vê a natureza como uma divisão entre a mente e a matéria, com ênfase para a fragmentação, estudando as partes sem perceber o todo. "O pensamento cartesiano implementou a concepção mecanicista do universo, que consiste em objetos separados, os quais, uma vez reduzidos em seus componentes e interações, podem ser usados para o conhecimento do todo" (WITTMANN; MAEHLER, 2008, p. 22).

Além disso, nessa percepção mecanicista do mundo os fenômenos eram regidos pela causalidade (HOLANDA, 2001) - os efeitos têm causas definidas -, cujo principal entusiasta também foi Descartes (BAUER, 1999). Ele criou quatro regras: conhecer a fundo o que se quer estudar; dividir o objeto de estudo no máximo de partes possíveis; conduzir os pensamentos em ordem, começando dos mais simples aos mais complexos; e fazer para cada caso a enumeração completa e as revisões sem omissões (WITTMANN; MAEHLER, 2008). Assim, através da redução dos fenômenos complexos aos seus componentes básicos, eles poderiam ser compreendidos. Essa prática, conhecida como reducionismo, confunde-se com o próprio método científico (VERGARA; BRANCO, 1993), devido a suas influências sobre a cultura científica, uma vez que a ciência tradicional foi originada e estruturada nos moldes do cartesianismo (PRIGOGINE, 1996).

O paradigma cartesiano considera seu método científico como única abordagem válida de conhecimento; a concepção do universo como uma máquina, composta por unidades elementares; a crença do progresso material ilimitado e a ideia da vida como luta pela existência (CAPRA, 2006). Essa concepção cartesiana do mundo, fortalecida pela ciência newtoniana, levou à fragmentação nas disciplinas acadêmicas, bem como nas entidades 
governamentais, servindo como fundamento lógico para o tratamento do meio ambiente natural de maneira também fragmentada, sendo que diferentes grupos de interesse exploram cada peça separada (CAPRA, 2006).

Acreditava-se que os fenômenos complexos podiam ser sempre entendidos desde que se os reduzisse a seus componentes básicos e se investigasse os mecanismos através dos quais esses componentes interagem. Essa atitude, conhecida como reducionismo, ficou tão profundamente arraigada em nossa cultura, que tem sido frequentemente identificada com o método científico (CAPRA, 2006, p. 44).

Como afirma Capra (2006, p. 56), "toda a elaboração da ciência mecanicista nos séculos XVII, XVIII e XIX, incluindo a grande síntese de Newton, nada mais foi do que o desenvolvimento da ideia cartesiana”. Isaac Newton completou a revolução científica cartesiana, desenvolvendo a formulação matemática da concepção mecanicista do mundo, fornecendo a base do pensamento científico até boa parte do século XX. Ele formulou as leis exatas para descrever o movimento de todos os corpos sob a influência da força da gravidade, confirmando a visão cartesiana da natureza como um sistema mecânico que obedece a leis matemáticas exatas (CAPRA, 2006).

Além disso, Newton unificou as duas tendências apresentadas por Bacon e Descartes, respectivamente: o método empírico e indutivo; e o método racional e dedutivo; mostrando que eles são métodos complementares e fornecendo os fundamentos da metodologia em que a ciência natural passou a basear-se. Conforme Capra (2006, p. 62), "os séculos XVIII e XIX serviram-se da mecânica newtoniana com enorme sucesso. [...] O sistema matemático do mundo elaborado por Newton estabeleceu-se rapidamente como a teoria correta da realidade", confirmando a convicção de que o universo era um sistema mecânico que funcionava de acordo com as leis newtonianas do movimento (BAUER, 1999).

A abordagem mecanicista foi aplicada a uma diversidade de áreas do conhecimento, incluindo a física, química, astronomia, biologia, psicologia, medicina e ciências sociais. Entretanto, durante o século XIX, novas descobertas evidenciaram as limitações do modelo newtoniano e prepararam o caminho para as revoluções científicas do século XX (CAPRA, 2006).

A tendência para adotar a física newtoniana como modelo para teorias e conceitos, apesar dos benefícios, trouxe também uma série de desvantagens para muitas áreas, em especial para as ciências sociais, já que a estrutura cartesiana é "inteiramente inadequada para o fenômeno que esses cientistas descrevem", tornando, assim, seus modelos menos realistas, o que é "particularmente evidente na economia" (CAPRA, 2006, p. 180). 
Capra (2006, p. 46) alerta ainda para as limitações da visão de mundo cartesiana, defendendo enfoques holísticos e ecológicos, assim, "os cientistas não terão por que relutar em adotar uma estrutura holística, como frequentemente o fazem hoje em dia, por temor de serem anticientíficos”. Da mesma forma, Vergara e Branco (1993, p. 21) defendem a insuficiência da visão mecanicista de mundo para explicar os fenômenos, descrevendo a situação em que "debatemo-nos entre a sensação de impotência e a imposição por novas visões de mundo". Assim, Capra (2006, p. 28) enfatiza a mudança de paradigma, ou seja, a "mudança profunda no pensamento, percepção e valores que formam uma determinada visão da realidade". Ele enfatizava a necessidade dessa mudança, afirmando que "[...] a substituição do paradigma cartesiano por uma visão holística e ecológica não tornará as novas abordagens menos científicas, mas, pelo contrário, as fará mais compatíveis com as novas conquistas nas ciências naturais" (CAPRA, 2006, p. 185).

A visão sistêmica da vida é uma base apropriada tanto para as ciências do
comportamento e da vida quanto para as ciências sociais e, especialmente, a
economia. A aplicação de conceitos sistêmicos para descrever processos e atividades
econômicos é particularmente urgente porque virtualmente todos os nossos
problemas econômicos atuais são problemas sistêmicos que já não podem ser
entendidos dentro do âmbito da visão de mundo da ciência cartesiana (CAPRA,
2006, p. 380).

Descobertas como as que culminaram com o desenvolvimento da eletrodinâmica enfatizavam a incapacidade do modelo mecanicista de descrever e explicar adequadamente certos fenômenos e forças, como os fenômenos elétricos e magnéticos. Nesse contexto, conforme Capra (2006), surgiu uma nova tendência do pensamento que dominaria toda a ciência futura e não apenas o século XIX, sugerindo a ideia de evolução, ou seja, mudança, crescimento e desenvolvimento, consolidada com a teoria da evolução das espécies, em biologia. O passo inicial para essa mudança foi dado por Jean-Baptiste Lamarck no começo do século XIX, fortalecida e adaptada por Charles Darwin, com a teoria da seleção natural, constituindo as bases do moderno pensamento evolucionista (CAPRA, 2006).

Assim, os cientistas seriam obrigados a abandonarem a concepção cartesiana do mundo, uma vez que, segundo a teoria evolucionista, o universo deveria ser descrito como um sistema em evolução e mudança, com o desenvolvimento de estruturas complexas a partir de formas mais simples. Na física, esse movimento ocorreu no sentido de uma crescente desordem, levando os estudiosos à formulação da termodinâmica, conhecida como a "ciência da complexidade" (CAPRA, 2006, p. 67).

Além disso, duas descobertas na física no século XX, resultando na teoria da relatividade e na teoria quântica, enfraqueceram todos os principais conceitos da visão de 
mundo cartesiana e da mecânica newtoniana, sendo que seus conceitos não poderiam mais ser estendidos aos novos domínios da física (CAPRA, 2006; PRIGOGINE, 1996). O paradigma cartesiano-newtoniano só começou a ser realmente questionado nas três primeiras décadas do século XX, por meio de descobertas no campo da Física Quântica que pulverizaram seus principais alicerces: a) a noção de espaço e tempo absolutos; b) a noção de partículas sólidas elementares; c) a noção de matéria como substância fundamental; d) a natureza estritamente causal dos fenômenos; e e) a descrição objetiva da natureza (BAUER, 1999).

O início da física moderna foi marcado pelos feitos de Albert Einstein, cujas realizações acerca da teoria da relatividade e da radiação eletromagnética, fornecendo subsídios para o posterior desenvolvimento da teoria quântica, marcaram o começo do pensamento do século XX, incluindo drásticas modificações nos conceitos de espaço e tempo (CAPRA, 2006).

Além disso, no século $\mathrm{XX}$, os físicos descobriram propriedades e fenômenos relacionados com a estrutura dos átomos, como os raios $\mathrm{X}$ e a radiatividade, inexplicáveis em termos da visão de mundo cartesiana, forçando os cientistas a pensarem de uma maneira nova. "Em sua luta para apreenderem essa nova realidade, os cientistas ficaram profundamente conscientes de que seus conceitos básicos, sua linguagem e toda a sua forma de pensar eram inadequados para descrever fenômenos atômicos" (CAPRA, 2006, p. 71).

A teoria quântica, ou mecânica quântica, também chamada de nova física por Capra (2006), exigia profundas mudanças nos conceitos de espaço, tempo, matéria, objeto e causa e efeito, causando grande choque, devido a esses conceitos serem fundamentais. Logo, segundo Capra (2006), uma nova visão de mundo e de forma de pensar começa a surgir caracterizadas por palavras como orgânica, holística, ecológica e multidisciplinar, podendo ser denominada como visão sistêmica, no sentido da Teoria Geral dos Sistemas (TGS). Assim, Capra (2006, p. 72) descreve a nova visão do mundo em que

[...] o universo deixa de ser visto como uma máquina, composta por uma infinidade de objetos, para ser descrito como um todo dinâmico, indivisível, cujas partes estão essencialmente inter-relacionadas e só podem ser entendidas como modelos de um processo cósmico.

A nova física, assim como a nova visão do mundo, não lidam com "coisas", mas sim com interconexões, ou seja, não é possível decompor o universo em unidades ínfimas com existência independente, a natureza é uma "teia complicada de relações entre as várias partes de um todo unificado" (CAPRA, 2006, p. 75). Para Capra (2006, p. 76) "essa mudança de objetos para relações tem implicações de longo alcance para a ciência como um todo". 
Como enfatiza Capra (2006, p. 81), "na física atômica, não pode mais ser mantida a divisão cartesiana entre matéria e mente, entre o observado e o observador. Nunca podemos falar da natureza sem, ao mesmo tempo, falarmos sobre nós mesmos". Portanto, a física moderna invalidou a possibilidade de uma descrição objetiva da natureza, além de mostrar a inviabilidade de uma ciência isenta de valores, uma vez que os conceitos, pensamentos e valores do cientista estão intimamente relacionados com os modelos que ele observa (CAPRA, 2006). Conforme Vergara e Branco (1993, p. 27), “verifica-se um nítido movimento em direção à percepção das interdependências, ao entendimento da complementaridade entre os opostos e ao reconhecimento da complexidade da natureza humana".

Foi nesse contexto que a física moderna passou, a partir dos trabalhos de Einstein, Neils Bohr, Werner Heisenberg e outros, de um universo determinístico para a consideração da incerteza dentro de uma realidade probabilística. Nem mesmo a matéria e a radiação passaram incólumes, admitindo serem tratadas ora como partículas, ora como ondas. Outras pesquisas, como as desenvolvidas pela equipe do físico Alain Aspect, chegam a apontar para o fato de não ter significado falarmos de coisas e objetos como sendo reais além da mente do observador. Na mesma direção aponta David Bohm, ao falar de duas ordens no universo, que se interpenetram. Da ordem implicada, dobrada, não-manifesta, emerge a explicada, desdobrada, manifesta, que se traduz no que vemos à nossa volta (VERGARA; BRANCO, 1993, p. 27).

A nova concepção do universo resultante da física moderna não significa que a concepção cartesiana está errada, mas sim que a ciência moderna percebeu que todas as teorias científicas são aproximações da realidade, sendo que cada uma delas é válida em situações específicas. Apesar do paradigma cartesiano ainda dominar as ciências, os diversos campos do conhecimento percebem suas limitações e verificam a necessidade de uma nova estrutura conceitual (CAPRA, 2006).

O método mecanicista de análise busca a explicação do funcionamento de um todo em termos do funcionamento de suas partes. Já o método organicista focaliza o todo como ponto de partida da investigação. A TGS pode ser entendida como um esforço para fundir tais enfoques, utilizando as vantagens de cada um. Nesse caso, a ênfase está na complexidade organizada, ou seja, "na circunstância de que a adição de uma nova entidade introduz não apenas a relação dessa entidade para com as outras, mas também modifica as relações entre todas as outras entidades" (BERTALANFFY et al., 1976, p. 27).

O "procedimento analítico", princípio fundamental da ciência "clássica”, significa que uma entidade pode ser estudada a partir de suas partes e pode ser constituída ou reconstituída pela reunião dessas partes. Sua aplicação depende de duas condições: (a) inexistência ou fraqueza suficiente de interações entre as partes; e (b) linearidade das relações que descrevem 
o comportamento das partes. Tais condições não são satisfeitas pelos sistemas, pois estes consistem de partes em fortes interações não lineares (BERTALANFFY, 2012).

Contrapondo-se à visão cartesiana, a abordagem sistêmica proporcionou uma nova visão da ciência e à maneira de ver e interpretar a realidade (WITTMANN; MAEHLER, 2008). Para Cavalcanti e Paula (2012), a abordagem sistêmica abrange diversas estruturas especializadas, entre elas a TGS, a cibernética, a análise sistêmica e a engenharia de sistemas. O biólogo alemão Ludwig von Bertalanffy é reconhecido como o fundador da TGS (BERTALANFFY, 2012; CAVALCANTI; PAULA, 2012; DONAIRES, 2012; HOLANDA, 2001; MORGAN, 2009), sendo que esta foi concebida em 1937, culminando no livro General Systems Theory, em 1968 (CAVALCANTI; PAULA, 2012). A TGS foi constituída "anteriormente à cibernética, à engenharia dos sistemas e ao surgimento de campos afins" (BERTALANFFY, 2012, p. 30), embora haja opiniões divergentes a respeito. De acordo com Bertalanffy (2012, p. 32), seus primeiros enunciados "datam de 1925-1926”, e ele explica o surgimento da teoria de sistemas:

[...] a necessidade resultou do fato do esquema mecanicista das séries causais isoláveis e do tratamento por partes terem se mostrado insuficientes para atender aos problemas teóricos, especialmente nas ciências biossociais, e aos problemas práticos propostos pela moderna tecnologia (BERTALANFFY, 2012, p. 31).

Bertalanffy et al. (1976) explicam que a abordagem de sistemas leva a uma perspectiva macro, mais global, considerando os elementos que compõem um organismo ou fenômeno a partir de suas partes até a totalidade, reconhecendo as subdivisões e seu funcionamento, para um exame das finalidades para as quais o organismo funciona. $\mathrm{Na}$ mesma direção, a visão sistêmica ou abordagem sistêmica é definida por Cavalcanti e Paula (2012) como a visão do todo, em vez de utilizar de uma análise específica das partes, sendo uma alternativa à metodologia analítica empregada em problemas simples. Apesar de os esforços pioneiros da análise de sistemas terem nascido das ciências físicas e biológicas, a teoria dos sistemas é promissora como um modelo alternativo (KOGETSIDIS, 2011) para estudar a sociedade, uma vez que possui a capacidade de lidar com as relações dinâmicas entre as partes (BERTALANFFY et al., 1976).

Holanda (2001) diferencia o enfoque sistêmico do analítico pela técnica de solução dos problemas: o enfoque analítico, ao solucionar um problema complexo, tenta dividi-lo para compreender as partes; enquanto o enfoque sistêmico busca compreender o problema como um todo relacionando as partes, para só então buscar uma solução. O quadro 2 contrapõe os dois enfoques. 


\begin{tabular}{|c|c|}
\hline ENFOQUE CARTESIANO (analítico) & ENFOQUE SISTÊMICO \\
\hline Isola e se concentra nos elementos. & Unifica e se concentra na interação entre os elementos. \\
\hline Enfatiza a precisão dos detalhes. & Enfatiza a percepção global. \\
\hline Modifica uma variável de cada vez. & Modifica grupos de variáveis simultaneamente. \\
\hline $\begin{array}{l}\text { Valida fatos por meio de prova experimental dentro do } \\
\text { corpo de uma teoria. }\end{array}$ & $\begin{array}{l}\text { Valida fatos por comparação do comportamento do } \\
\text { modelo com a realidade. }\end{array}$ \\
\hline $\begin{array}{l}\text { Utiliza modelos precisos e detalhados, porém pouco } \\
\text { úteis para explicar realidades complexas. }\end{array}$ & $\begin{array}{l}\text { Utiliza modelos que são insuficientes para serem } \\
\text { usados como bases de conhecimento, mas úteis em } \\
\text { decisão e ação. }\end{array}$ \\
\hline $\begin{array}{l}\text { Apresenta uma aproximação eficiente quando as } \\
\text { interações são lineares e fracas. }\end{array}$ & $\begin{array}{l}\text { Apresenta uma aproximação eficiente quando as } \\
\text { interações são não-lineares e fortes. }\end{array}$ \\
\hline $\begin{array}{l}\text { Conduz a educação para a segmentação } \\
\text { disciplinariedade. }\end{array}$ & $\mathrm{Cc}$ \\
\hline
\end{tabular}

Quadro 2 - Diferenças entre os enfoques cartesiano e sistêmico Fonte: adaptado de HOLANDA (2001).

Foi criada em 1954, portanto, uma "Sociedade da Teoria Geral dos Sistemas", cujo nome foi mudado para "Sociedade de Pesquisa Geral dos Sistemas" (Society for General Systems Research) posteriormente e, atualmente, é conhecido como "Sociedade Internacional para as Ciências dos Sistemas" (International Society for the Systems Sciences). O objetivo era impulsionar o desenvolvimento dos sistemas teóricos aplicáveis a mais de um campo do conhecimento (BERTALANFFY, 2012).

Suas principais funções são: (1) investigar a isomorfia de conceitos, leis e modelos em vários campos e promover a transferência útil de um campo para outro; (2) encorajar a criação de modelos teóricos adequados em campos onde atualmente não existem; (3) reduzir ao mínimo a duplicação do esforço teórico em diferentes campos; (4) promover a unidade da ciência mediante a melhoria da comunicação entre os especialistas (BERTALANFFY, 2012, p. 35).

A partir da semelhança estrutural dos modelos e do isomorfismo em diferentes campos, revelaram-se problemas centrais de ordem, organização, totalidade, teleologia etc., excluídos dos programas da ciência mecanicista. Como muitos problemas e soluções semelhantes surgiram em diferentes campos do conhecimento de maneira independente, foi identificada a necessidade de uma teoria de princípios universais aplicáveis aos sistemas de uma forma geral. Assim, foi postulada a disciplina chamada de TGS, cujo conteúdo é a formulação e derivação dos princípios válidos para os sistemas em geral (BERTALANFFY, 2012). Conforme Abraham (2011) resume, as ideias principais da TGS incluem o holismo, o organicismo e os sistemas abertos, a serem tratados adiante neste trabalho. A natureza da teoria dos sistemas consistia na tentativa de uma interpretação e a criação de uma teoria científica em assuntos nos quais anteriormente não existiam, com generalização mais alta do que a das ciências especiais.

Uma consequência da existência de propriedades gerais dos sistemas é o aparecimento de semelhanças estruturais ou isomorfismos em diferentes campos. Há correspondência entre princípios que governam o comportamento de entidades que são intrinsecamente de todo diferentes (BERTALANFFY, 2012, p. 57) 
Apesar de diversos exemplos de fórmulas e equações matemáticas aplicáveis a campos distintos, os isomorfismos dos sistemas aparecem também em problemas não quantificáveis. Assim, nos fenômenos complexos, a "explicação em princípio" (HAYEK, 1955) mediante modelos qualitativos é preferível à ausência de qualquer explicação. Segundo Bertalanffy (2012), um exemplo são as isomorfias entre os sistemas biológicos e as comunidades animais ou também as sociedades humanas. A crença de que a essência do procedimento científico consiste na descoberta de novas afirmações que possam ser testadas pode ser uma séria barreira para a compreensão de certos campos em que um procedimento diferente talvez seja o único meio efetivo como guia acerca dos fenômenos complexos (HAYEK, 1955).

"São características da organização quer de um organismo vivo quer de uma sociedade noções como as de crescimento, diferenciação, ordem hierárquica, dominância, controle, competição, etc. [...] A teoria dos sistemas é capaz de tratar dessas matérias". (BERTALANFFY, 2012, p. 74). Dessa forma, Bertalanffy (2012) chegou a uma concepção denominada perspectivismo, por oposição ao reducionismo. "Não podemos reduzir os níveis biológicos, social e do comportamento ao nível mais baixo, o das construções e leis da física. [...] O princípio unificador é que encontramos organização em todos os níveis" (BERTALANFFY, 2012, p. 76) a partir da abordagem sistêmica.

\subsection{ABORDAGEM SISTÊMICA}

A abordagem sistêmica foi elaborada para atender uma série de demandas: generalização, simplificação, integração, otimização, avaliação, planejamento e controle (MARTINELLI; VENTURA, 2012). Beer (1994b) explicita a complexidade da rede resultante das mudanças sociais e tecnológicas, em que coisas pequenas tornam-se maiores, coisas simples tornam-se mais elaboradas e a velocidade aumenta significativamente. Além disso, a taxa de mudança aumenta e a natureza da mesma faz com que itens separados cada vez mais sejam conectados. Bertalanffy (2012) já alertava para o surgimento de diversos problemas na produção, no comércio, nos armamentos e na política, tornando necessária a aplicação do enfoque sistêmico a problemas urgentes. 
Um primeiro-ministro canadense (MANNING, $1967^{1}$ apud BERTALANFFY, 2012, p. 22-23) inclui a abordagem por meio de sistemas em sua plataforma política, dizendo que

existe uma relação entre todos os elementos e constituintes da sociedade. Os fatores essenciais dos problemas públicos, das questões e programas a adotar devem sempre ser considerados e avaliados como componentes interdependentes de um sistema total.

A gestão está ficando mais complexa, desde o gerenciamento que o próprio indivíduo faz de si mesmo e todo tipo e tamanho de agregação até a gestão da Terra. Recebendo interferências mais complexas de todos os outros níveis, a complexidade se prolifera, impossibilitando a gestão por meio das ferramentas existentes (BEER, 1994b). Segundo Bertalanffy (2012), trata-se de uma transformação nas categorias básicas de pensamento e, de alguma maneira, tratamos com complexos, com "totalidades" ou "sistemas" em todos os campos de conhecimento, exigindo-se novas conceituações, novas ideias e categorias, centralizadas na definição de sistema, de uma forma ou de outra.

Há diversas definições para o conceito de sistema. De acordo com Bauer (1999, p. 44, grifo do autor) "um sistema é um conjunto de elementos em interação". Da mesma forma, para Bertalanffy et al. (1976, p. 1, grifo do autor) "um sistema se define como um complexo de elementos em interação, interação essa de natureza ordenada (não fortuita)". Para Beer (1994b, p. 7, tradução livre), "um sistema consiste de um grupo de elementos relacionados dinamicamente no tempo de acordo com algum padrão coerente". Cavalcanti e Paula (2012) definem sistema como as partes, ou elementos de um todo, coordenados entre si, que funcionam como uma estrutura organizada. Donaires (2012, p. 16), por sua vez, define um sistema como "um conjunto de elementos independentes em interação, com vistas a atingir um objetivo". De acordo com Bertalanffy (2012), há um consenso entre os teóricos dos sistemas de que esse conceito não se limita às entidades materiais, mas pode ser aplicado a qualquer totalidade constituída por componentes interatuantes.

Para Cavalcanti e Paula (2012), elementos importantes extraídos do conceito de sistema incluem: objetos (elementos do sistema), relacionamentos (fronteiras que ligam os objetos), atributos (características dos objetos e dos relacionamentos), ambiente (o que está fora do sistema) e o todo (partes agregadas formando um todo que se torna uma estrutura independente, com papel distinto das partes). Donaires (2012) aponta os três elementos básicos essenciais na conceituação de sistemas: subsistemas, relações e propósito. Os subsistemas são elementos que compõem o sistema, possuindo uma existência e uma

\footnotetext{
${ }^{1}$ MANNING, H. E. C. Political realignment - a challenge to thoughtful canadians. Toronto/Montreal:
} McClelland \& Steward, 1967. 
identidade próprias que os destacam como partes individuais. As interações ou relações dinâmicas entre os elementos podem impor restrições aos subsistemas, reduzindo a complexidade potencial, ou podem também levar à sinergia, fazendo surgir propriedades emergentes no sistema que não existiam nos subsistemas individualmente. $\mathrm{O}$ terceiro aspecto envolve o objetivo ou propósito do sistema, revelando fatos decisivos acerca da sua identidade (DONAIRES, 2012).

A concepção sistêmica considera o mundo em termos de relações e de integração, isto é, em função da inter-relação e interdependência dos fenômenos. Os sistemas são totalidades integradas, organizados formando estruturas de múltiplos níveis, cada nível dividido em subsistemas; portanto, organismos vivos, sociedades e ecossistemas são sistemas (CAPRA, 2006). Conforme Capra (2006, p. 40) descreve, "todas essas entidades - das moléculas aos seres humanos e destes aos sistemas sociais - podem ser consideradas 'todos' no sentido de serem estruturas integradas, e também 'partes' de 'todos' maiores, em níveis superiores de complexidade".

Dessa forma, os mesmos aspectos de totalidade que caracterizam os organismos individuais como sistemas são apresentados por sistemas sociais e por ecossistemas "que consistem numa variedade de organismos e matérias inanimadas em interação mútua" (CAPRA, 2006, p. 260). Apesar da dificuldade em definir as entidades socioculturais, a abordagem de sistemas pode fornecer a base de uma estrutura mais capaz de fazer justiça às complexidades e propriedades dinâmicas do sistema sociocultural. Nesse caso, a dificuldade repousa, além da complexidade envolvida nos fenômenos, também na definição das entidades consideradas, uma vez que as ciências sociais tratam de sistemas socioculturais, envolvendo questões culturais, valores e símbolos (BERTALANFFY, 2012).

Aspectos dos sistemas envolvem sua atividade, que se caracteriza por um processo de transação, ou seja, interação simultânea e mutuamente interdependente entre diversos componentes; além disso, os sistemas possuem natureza dinâmica, apresentando formas flexíveis (CAPRA, 2006). Para Capra (2006, p. 261), “o pensamento sistêmico é pensamento de processo; a forma torna-se associada ao processo, a inter-relação à interação, e os opostos são unificados através da oscilação".

Bertalanffy (2012) defende que a aplicação prática da teoria de sistemas aos problemas que surgem nas ciências sociais, como nos negócios, governo, política internacional e outros, demonstra sua adequabilidade, conduzindo à compreensão e à predição. Além disso, sua 
aplicabilidade a entidades parcialmente imateriais e altamente heterogêneas fica demonstrada também, podendo oferecer respostas definidas e indicações práticas.

Ao tratarem sobre a teoria dos sistemas aplicada, Bertalanffy et al. (1976) enfatizam que uma análise sistêmica auxiliaria na solução de problemas, sugerindo a necessidade de maior planejamento, gastando mais tempo e energia no uso mais efetivo de recursos, e levantando questões-chave no início do processo, e não posteriormente. Além disso, a variável de limite também é apontada como beneficiária da abordagem geral de sistemas. Ela considera a permeabilidade de limite, em uma tentativa de calcular como as forças externas exercem influência sobre os aspectos internos e políticas de um sistema.

A tomada de decisões também pode ser beneficiada pela análise sistêmica, uma vez que a visão do indivíduo sobre a natureza da sociedade determina em grande parte a lógica pela qual ele toma suas decisões. Dessa forma, a partir de uma perspectiva dos sistemas, são considerados conjuntos de dados diferentes e mais ricos, chegando à essência do problema, gerando uma variedade de alternativas e pesando a melhor decisão na visão do conjunto. "Em resumo, a ideia de uma abordagem mais global pode estimular uma melhor identificação e inventário de recursos possuídos por uma sociedade para um pensamento melhor e mais criativo sobre seus sistemas" (BERTALANFFY et al., 1976, p. XXI).

Além da sociologia e da história estudando as organizações informais, foi desenvolvida a teoria das organizações formais, ou seja, estruturas planejadas, tais como um exército, a burocracia, uma empresa comercial etc. Nesse contexto, a organização é tratada como um sistema de variáveis mutuamente dependentes. A abordagem sistêmica enfatiza princípios básicos de organização ao invés de se concentrar nos elementos do fenômeno estudado (CAPRA, 2006), conduzindo, dessa forma, à transdisciplinaridade, influenciando todos os tipos de organizações, que passaram a ser estudadas como sistemas paradoxais, ou seja, os que são simultaneamente abertos e fechados, em constante interação (WITTMANN; MAEHLER, 2008).

O fato das simples leis do crescimento demonstrarem aplicação às entidades sociais e a aplicação fundamentada dos modelos teóricos, em particular o modelo dos sistemas dinâmicos, abertos e adaptativos aos processos históricos, indicam que os princípios dos sistemas se aplicam a ambos esses campos. Apesar disso, é importante atentar ao fato de que modelos espelham apenas certos aspectos ou facetas da realidade (BERTALANFFY, 2012).

Nesse sentido, foi proposta a teoria dos sistemas abertos, uma das contribuições mais significativas da TGS, baseada no fato de que o organismo é um sistema aberto, isto é, um sistema em que são estabelecidas trocas com o ambiente (DONAIRES, 2012). Um sistema é 
"fechado" se nenhum material entra nele ou sai dele. Um sistema "aberto" é aquele em que há importação e exportação de matéria, realizando trocas com o ambiente, com construção e demolição dos materiais que o compõem (BERTALANFFY, 2012). Conforme Bousquet e Curtis (2011), um sistema aberto possui fronteiras porosas e que se deslocam, trocando informação e energia com seu ambiente. A base do modelo do sistema aberto é a interação dinâmica de seus componentes. De acordo com Bauer (1999, p. 45),

[...] um sistema aberto é um conjunto de partes interdependentes e em permanente interação, constituindo dessa forma um todo sinérgico, voltado à consecução de propósitos dados, e interdependente também em relação a seu meio ambiente, sendo tanto por ele influenciado como influenciando-o.

Conforme Donaires (2012), as características distintivas dos sistemas abertos incluem: entradas e saídas (trocas de material, energia e/ou informação entre sistema e ambiente); transformação (lei, regra ou processo que explica como, a partir das entradas, o sistema produz as saídas); estados (os estados internos do sistema, ou a memória, interferem no processo de transformação); fronteiras (separação entre o que está no domínio do sistema e tudo o mais que há no ambiente); e ambiente (tudo que extrapola as fronteiras do sistema). Cavalcanti e Paula (2012) também listam as propriedades dos sistemas abertos: inter-relação e interdependência dos seus objetos e atributos; holismo (todo é a soma de partes interdependentes); busca pela consecução dos objetivos; entradas e saídas; processo de transformação; entropia (energia para trabalho útil); regulação; hierarquia; diferenciação; e equifinalidade.

Utilizando-se desses conceitos, Capra (2006, p. 269) caracteriza os organismos vivos como sistemas abertos:

os organismos vivos, sendo sistemas abertos, mantêm-se vivos e em funcionamento
através de intensas transações com seu meio ambiente, que também consiste,
parcialmente, em organismos. Assim, a totalidade da biosfera - nosso ecossistema
planetário - é uma teia dinâmica e altamente integrada de formas vivas e não-vivas.
Embora essa teia possua múltiplos níveis, as transações e interdependências existem
em todos os seus níveis.

Visando à perenidade, os sistemas abertos se utilizam de mecanismos de regulação a fim de manter o equilíbrio interno, apesar das turbulências ambientais; e tais mecanismos são o domínio da cibernética (DONAIRES, 2012), que pode fornecer a base necessária para a compreensão de sistemas complexos diante das mudanças na sociedade (BEER, 1994a). 


\subsection{CIBERNÉTICA}

De acordo com Bauer (1999), ainda à época em que surgia a teoria dos sistemas, Wiener desenvolvia esforços semelhantes de interdisciplinaridade que resultaram na cibernética, do grego kybernytiky, que significa algo como "a arte de governar navios" em analogia à função do piloto, que deve controlar o navio por meio da comunicação com os outros envolvidos. A cibernética é uma ciência da comunicação que visa ao controle, representando um processo de transformação de informação que visa à consecução de ações (BAUER, 1999).

Em 1948 surgiu o livro Cybernetics, or Control and Communication in the Animal and the Machine, de Norbert Wiener (CAVALCANTI; PAULA, 2012), que levou os conceitos cibernéticos de retroação e informação muito além dos campos da tecnologia e generalizou-os nos domínios biológico e social. Apesar da cibernética apresentar precursores, sua popularidade é devida a Wiener (BERTALANFFY, 2012).

Bertalanffy (2012) defende que a cibernética, enquanto teoria dos mecanismos de controle é apenas uma parte da TGS. Já Holanda (2001) defende que ela, assim como uma série de outras abordagens, tem suas raízes na TGS. Para Costa, Wittmann e Grzybovski (2008), é improvável compreender a TGS sem revisar o conceito de cibernética, em virtude da ligação estreita entre ambas. "De certo modo, pode-se dizer que os campos da cibernética e da teoria dos sistemas praticamente se fundiram", uma vez que o campo principal de aplicação teórica da cibernética é justamente o sistema (BAUER, 1999, p. 47). Já para Abraham (2011), a TGS pode ser entendida como a resposta européia ao movimento americano da cibernética. Independente das diferenças de opinião a respeito da ordem de influência é possível observar sinergia entre ambas as abordagens.

Ao contrário da explicação causal, a explicação cibernética é sempre negativa, isto é, se considera quais possibilidades poderiam possivelmente ter ocorrido e então se pergunta por que muitas das alternativas não foram seguidas, fazendo com que o evento específico seja um dos poucos que, de fato, poderiam ocorrer (BATESON, 1967).

A cibernética tem como foco o estudo da informação, da comunicação e do controle (CAVALCANTI; PAULA, 2012; MORGAN, 2009), seja na máquina ou no animal (DONAIRES, 2012; HOLANDA, 2001). Beer (1985) aborda a cibernética como a ciência da organização efetiva. Ela aborda modos de comportamento (HOLANDA, 2001), ao invés de abordar coisas; sendo assim, funcional e comportamental (ASHBY, 1970). O foco da 
cibernética não está nos eventos ou objetos, mas sim na informação que eles carregam (BATESON, 1967). De acordo com Costa, Wittmann e Grzybovski (2008, p. 72), "a tarefa da cibernética é tornar explícitas as leis que governam o comportamento dos sistemas, sejam eles de natureza elétrica, orgânica, geológica, econômica ou social”. Para Holanda (2001), o principal objetivo da cibernética envolve a compreensão dos mecanismos circulares que permitem aos sistemas complexos se manterem, adaptarem e se auto-organizarem, sendo viáveis.

De acordo com Beer (1985), uma organização é viável se pode sobreviver em um tipo particular de ambiente; entretanto, apesar de sua existência separada com certa autonomia, ou seja, apesar de sua identidade própria, ela não pode sobreviver no vácuo. Assim, um sistema viável é caracterizado pelo equilíbrio entre integração e auto-afirmação, sendo que este equilíbrio existe em uma interação dinâmica, tornando todo o sistema flexível e aberto à mudança (CAPRA, 2006).

Para que o conceito de sistema viável seja compreendido, deve ser considerado um critério de "viabilidade independente", mesmo que todo sistema faça parte de um sistema maior e nunca esteja completamente isolado, completamente autônomo ou livre. O sistema viável é reconhecido por possuir identidade própria. Quando o sistema viável morre, ele continua a existir fisicamente e a interagir com sistemas contíguos. Entretanto, ele perdeu sua identidade, precisamente em termos de sua coerência como uma entidade viável. Como exemplo, é possível citar a compra de uma empresa por uma corporação, em que é assegurado aos stakeholders que a identidade da empresa será preservada, isto é, seu nome será mantido e a diretoria continuará exercendo controle. Porém, isso não ocorre de fato. A corporação possui um nome que representa maior valor, então o nome da empresa comprada aparece gradativamente submisso ao daquela, e geralmente é substituído depois de alguns anos. Quanto à diretoria, ela logo percebe que sua liberdade de ação é restrita, até que ela se torna um grupo de gestão. Em resumo, a empresa tornou-se uma das unidades da nova totalidade, perdendo sua identidade (BEER, 1994a). Beer (1985) também exemplifica a viabilidade com outros tipos de organização, como um ser vivo, e até uma vila, que é uma organização viável, com sua igreja, sua escola, seus açougues e padarias, sendo incorporada a uma sociedade que a sustenta, e em um contexto maior, sendo parte de um sistema social que garante sua identidade cultural. Seguindo o conceito de viabilidade, Beer (1985) apresenta o Modelo de Sistema Viável (Viable System Model - VSM) como uma maneira alternativa (cibernética) de 
estudar a estrutura organizacional (seja de uma empresa, um conglomerado, um serviço social, um departamento governamental ou uma economia nacional).

A cibernética é uma teoria de sistemas cujos fundamentos são a comunicação, ou troca de informações entre o sistema e o ambiente e dentro do próprio sistema, e o controle, ou regulação do funcionamento do sistema sob influência do ambiente (BERTALANFFY, 2012). Essa dinâmica é representada na figura 2.

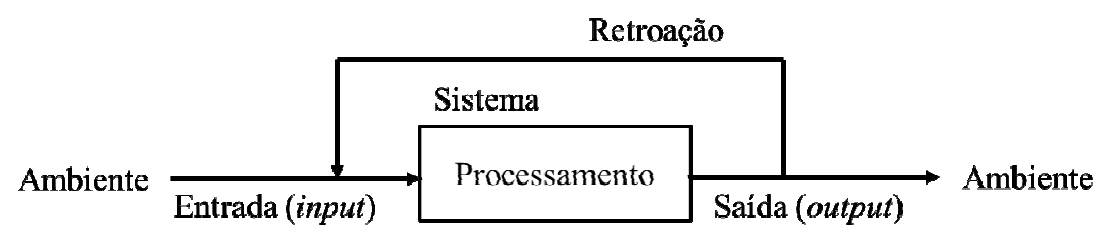

Figura 2 - Modelo básico para a cibernética e a TGS Fonte: BAUER (1999, p. 47).

Há três componentes fundamentais em qualquer sistema de controle: a entrada, a saída, e a rede que as conecta (BEER, 1994a). O primeiro princípio do controle, definido como "o que facilita a existência e a operação dos sistemas", é que o controlador é parte do sistema controlado, ele não está à parte do mesmo, tendo sua existência inferida pelo comportamento do sistema (BEER, 1994a, p. 27, tradução livre).

Outro conceito, considerado o mais importante para a cibernética, é o de feedback ou retroalimentação. Entretanto, o termo é utilizado tão livremente que quase qualquer coisa que apresente uma reação a ela mesma é frequentemente relacionada ao conceito. Apesar disso, o real significado é fundamental para o pensamento cibernético. Feedback, conforme Beer (1994a), refere-se a uma medição que detecta o desvio do sistema de alguma norma definida, comparando a saída com o resultado esperado. Essa medição, que pode ela mesma ter que sofrer modificações, é retroalimentada para ajustar a entrada para que a transformação (ou processo de transformação) leve a uma saída corrigida (BEER, 1994a). Quando existe circularidade de ação entre as partes de um sistema dinâmico, isto é, cada parte afeta a outra, pode-se afirmar que há retroalimentação ou feedback (ASHBY, 1970). No modelo, a retroalimentação ou feedback, corresponde ao uso que o sistema faz, sob forma de input, do output ou de parcela do input, verificando se os resultados estão ou não em conformidade com o previsto. No caso da existência de desvios, estes são corrigidos pela regulação do input até que atinja o resultado esperado, pela homeostase ou auto-regulação interna. A homeostase corresponde à manutenção de um equilíbrio dinâmico, mantendo determinadas variáveis operando dentro de limites aceitáveis (BAUER, 1999). 
A preocupação central dos sistemas viáveis consiste nos mecanismos que permitem aos sistemas manter esse equilíbrio interno (BEER, 1985; DONAIRES, 2012). A homeostase, na biologia, é o mecanismo que os sistemas vivos utilizam para manter as características vitais dentro de limites plausíveis; ela ocorre por meio de estratégias de retroalimentação negativa, isto é, quando as características apresentam desvios das condições ideais elas são corrigidas para manter o equilíbrio (DONAIRES, 2012). O sistema viável é necessariamente um produtor da organização (sistema em estudo), e não apenas adjunto a ela, embora importante. Todos os outros sistemas que não são recursões em outro nível são dedicados a estabilizar o ambiente interno (do sistema em foco). Assim, na definição dos sistemas viáveis em um nível mais baixo de recursão eles devem construir/produzir a organização, não sendo apenas facilitadores ou apoios; eles devem produzir a si mesmos, continuamente e regenerativamente, para manter suas identidades, como qualquer outro sistema viável (BEER, 1985).

Segundo Donaires (2012), da mesma forma que a retroalimentação negativa está para o mecanismo de regulação, a aprendizagem está para o mecanismo de adaptação. Sistemas regulados apresentam retroalimentação negativa, enquanto os sistemas capazes de aprender são chamados de auto-organizáveis ou adaptativos. No campo da cibernética, a autoorganização é tida como o conceito que deflagrou as primeiras pesquisas sobre complexidade (SERVA; DIAS; ALPERSTEDT, 2010).

De forma análoga ao mecanismo de regulação, em que foi preciso mover-se para fora do sistema e entrar novamente pela retroalimentação negativa, o organizador cria um mecanismo de aprendizagem diante de perturbações externas e modifica o regulador para que ele seja capaz de manter sua capacidade de regulação (DONAIRES, 2012). Assim, os sistemas se adaptam para que, mesmo diante de mudanças no ambiente, possam se manter sob controle. A adaptação pode envolver, além de aprendizagem, também mutações, resultando em evolução; e os sistemas ditos evolutivos passam por um processo contínuo, lento e gradual (DONAIRES, 2012).

De acordo com Ashby (1970, p. 3, grifo do autor) "a cibernética trata tipicamente qualquer máquina dada, particular, perguntando não 'que ação individual ela produzirá aqui e agora?', mas 'quais são os possíveis comportamentos que pode produzir?’”. Ashby (1970, p. 5) destaca a contribuição da cibernética para o estabelecimento de paralelismos entre diferentes campos do conhecimento:

[...] verificou-se repetidamente na ciência que a descoberta de uma relação entre dois de seus ramos leva cada ramo a ajudar no desenvolvimento do outro. [...] Nenhum deles, sem dúvida, pode fornecer provas acerca das leis do outro, mas cada um pode 
propiciar sugestões que eventualmente serão de maior ajuda e fecundidade. [...] A cibernética deverá, provavelmente, revelar grande número de paralelismos interessantes e sugestivos entre a máquina, o cérebro e a sociedade.

A cibernética oferece um método para o tratamento de sistemas complexos (ASHBY, 1970), cuja complexidade deriva do número de estados internos do sistema (DONAIRES, 2012). Em sistemas complexos é impossível variar os fatores um de cada vez, necessitando de nova abordagem, pois os fatores "são tão dinâmicos e interligados que a alteração de um fator imediatamente atua como causa para suscitar alterações em outros, talvez em inúmeros outros" (ASHBY, 1970, p. 6); ou seja, os fatores configuram o que se denominou de complexidade organizada. Ashby (1970, p. 6) explica que no estudo de alguns sistemas a complexidade não pode ser totalmente evitada:

o córtex cerebral do organismo de vida livre, o formigueiro como uma sociedade em funcionamento e o sistema econômico humano eram salientes tanto na sua importância prática como na impossibilidade de serem tratados pelos métodos mais antigos.

Bertalanffy et al. (1976, p. 25, grifo dos autores) explicam o conceito de complexidade organizada, apontando a cibernética como um método matemático desenvolvido para descrevê-la:

uma complexidade organizada pode ser considerada como um conjunto de objetos ou eventos cuja descrição inclui muitas variáveis, entre as quais existem fortes interdependências mútuas, de modo que o sistema de equações resultante não pode ser resolvido parceladamente.

Os sistemas naturais possuem uma capacidade inerente de se auto-organizarem de formas que não são propriamente compreendidas. Eles não são necessariamente otimizados sob um ponto de vista matemático, mas possuem um mecanismo que seleciona modos particulares de organização viáveis para a sobrevivência. Um algoritmo é uma técnica, ou mecanismo, que especifica como alcançar um objetivo completamente definido. Já o método heurístico, ou simplesmente heurística, define um comportamento que tende a um objetivo que não pode ser precisamente definido, pois se sabe "qual" é o objetivo mas não "onde" ele está. Beer (1994a) exemplifica essa situação supondo que o objetivo é chegar ao topo de uma montanha cônica envolta em nuvens. Ela deve ter um ponto mais alto, mas não se sabe exatamente o rumo. Assim, a instrução "continue subindo" leva ao destino, embora ele não seja conhecido. Isso é heurística, que prescreve regras gerais para atingir objetivos gerais, não prescrevendo uma rota exata para um objetivo definido como faz um algoritmo. Há diversos caminhos até o topo da montanha, e não importa muito qual caminho é escolhido (embora alguns sejam mais rápidos). Essas duas noções são fundamentais para a cibernética, uma vez que ao lidar com "sistemas impensáveis" é geralmente impossível prover uma especificação completa de um objetivo, e assim, impossível prescrever um algoritmo (BEER, 1994a). 
Essas duas técnicas de organização do controle em um sistema de alta variedade são muito distintas, entretanto, a sociedade tende a viver sob a heurística e tentar controlar a vida por meio de algoritmos. A dificuldade em compreender o papel da heurística em sistemas complexos pode ser atribuída ao planejamento da educação em torno da análise detalhada e especificações (BEER, 1994a). De acordo com Marchi e Wittmann (2008), o novo cenário mundial, cada vez mais dinâmico e ambíguo, exige um novo modelo de pensamento. Nesse sentido, Pádua (2008, p. 22) enfatiza as mudanças que impulsionaram a nova maneira de pensar a realidade:

as novas teorias da física sobre o cosmos, a Terra, o caos, bem como os desafios postos pela biologia molecular, que desde o início dos anos 1960 se ocupa da complexidade das reorganizações genéticas, das mutações, dos acasos, trouxeram à tona a existência dos processos desordenados, imprevisíveis, indemonstráveis, indeterminados.

Mikulecky (2001) afirma que o mundo real é formado por complexidades. Assim, o pensador Edgar Morin, considerado pai da teoria da complexidade, propõe uma modificação na forma de pensar (MORIN, 2010), explorada na próxima subseção.

\subsection{CAOS E COMPLEXIDADE}

O trabalho de Morin $(2010,2011)$ propõe a construção de um novo paradigma, em que o conhecimento deve, simultaneamente, detectar a ordem e a desordem, reconhecendo as relações de complexidade entre elas (PÁDUA, 2008). A complexidade consiste num fenômeno quantitativo, isto é, na extrema quantidade de interações e de interferências entre um número muito grande de unidades (MORIN, 2011). Uma epistemologia orientada pela complexidade favorece a compreensão dos fenômenos como parte de um tecido de relações (ALHADEFF-JONES, 2008). Entretanto, ela é mais do que apenas quantidades de unidade e interações que desafiam as possibilidades de cálculo, ela consiste também de incertezas, indeterminações e fenômenos aleatórios, apresentando relação com o acaso. Logo, a complexidade coincide com uma parte de incerteza, ela é a incerteza em sistemas ricamente organizados, estando ligada a uma mistura de ordem e desordem (MORIN, 2011).

O ponto de partida da teoria dos sistemas complexos consiste exatamente nas limitações dos procedimentos analíticos do enfoque reducionista para a investigação científica (MIKULECKY, 2001), já que ela busca fornecer métodos para a compreensão da dinâmica 
dos sistemas para os quais os métodos convencionais falham (JOHNSON, 2010). Apesar da fixação desse ponto de partida, não há unanimidade na formulação do conceito de sistema complexo, sendo possível observar muitas definições diferentes (GOULIELMOS, 2005; JOHNSON, 2010; MIGUÉLEZ, 2011; MIKULECKY, 2001; PRADO, 2009). É possível observar ainda, certa confusão com as noções de caos e de complicação.

Então, o que se entende pelos conceitos de complexidade e de caos deve ser definido. Segundo Ferreira (1986, p. 440), a complexidade "abrange ou encerra muitos elementos ou partes" ou pode ser entendida como um "grupo ou conjunto de coisas, fatos ou circunstâncias que têm qualquer ligação ou nexo entre si”. Houaiss e Villar (2009, p. 505) definem algo complexo como algo ou "conjunto, tomado como um todo mais ou menos coerente, cujos componentes funcionam entre si em numerosas relações de interdependência ou de subordinação, de apreensão muitas vezes difícil pelo intelecto, e que geralmente apresentam diversos aspectos".

Já caos significa, de acordo com Ferreira (1986, p. 339), o "vazio obscuro e ilimitado que precede e propicia a geração do mundo; abismo" ou "grande confusão ou desordem". Para Houais e Villar (2009, p. 390), caos significa "mistura de coisas ou ideias em total desarmonia; confusão" ou, no campo da física:

$$
\begin{aligned}
& \text { [...] comportamento de um sistema dinâmico que evolui no tempo, de acordo com } \\
& \text { uma lei determinista, e é regido por equações cujas soluções são extremamente } \\
& \text { sensíveis às condições iniciais, de modo que pequenas diferenças acarretarão estados } \\
& \text { posteriores extremamente diferentes. }
\end{aligned}
$$

Neste trabalho, complexidade e caos são utilizados com um significado mais amplo, embora a referência de descrição mais ampla para caos esteja relacionada ao campo da física no dicionário consultado.

Katopes (2011) afirma que é mais fácil reconhecer a complexidade do que definir seu conceito. Conforme Howard (2010), complexidade descreve um ambiente de complicação composta, sendo função do número, ambiguidade, taxa de mudança e do entrelaçamento das variáveis envolvidas em um problema. A complexidade, para a teoria de sistemas, é definida por meio da grande quantidade de partes e interações, enquanto a teoria da complexidade tem como premissa básica que muito do comportamento agregado complexo surge das atividades relativamente simples e localizadas de seus agentes, isto é, ela é como uma ilusão, algo que emerge quando vários de seus agentes seguem regras simples (PHELAN, 1999).

Apesar do conceito de complexidade incluir a noção de completude, ele reconhece a incerteza e, consequentemente, o fato de que o saber total é inatingível: "a totalidade é a não verdade" (MORIN, 2011, p. 69). Da mesma maneira como não se pode confundir 
complexidade com completude, ela também é diferente de complicação (ALHADEFFJONES, 2008; MORIN, 2011; SERVA; DIAS; ALPERSTEDT, 2010). Segundo Morin (2011), a complicação, entendida como o emaranhamento extremo das inter-retroações, é um dos elementos constituintes da complexidade. A teoria da complexidade criou o reconhecimento e a aceitação da desordem, da incerteza e da imprevisibilidade (GOULIELMOS, 2005). Ela vê o mundo físico não como um conjunto de relações consecutivas e lineares entre os elementos, mas sim como uma rede pluralística de relacionamentos que exibe comportamento dinâmico, criativo e complexo, seguindo um conjunto de leis simples, embora não determinadas (DENNIS, 2007).

Segundo Giovannini (2002a), a Complexidade ou teoria da complexidade envolve uma série de conceitos originados nas chamadas hard sciences. A teoria de sistemas (ABRAHAM, 2011; BAUER, 1999; BOUSQUET; CURTIS, 2011; CAPRA, 2006; GIOVANNINI, 2002a; GIOVANNINI, 2002b; MANSON, 2001; MORIN, 2011; PÁDUA, 2008; WITTMANN; MAEHLER, 2008), a cibernética (ABRAHAM, 2011; BAUER, 1999; BOUSQUET; CURTIS, 2011; GIOVANNINI, 2002a; MANSON, 2001; MORIN, 2011; PÁDUA, 2008; SERVA; DIAS; ALPERSTEDT, 2010), a teoria da informação (MORIN, 2011; PÁDUA, 2008; SERVA; DIAS; ALPERSTEDT, 2010), a abordagem neural (MANSON, 2001; WITTMANN; MAEHLER, 2008) e a dinâmica de sistemas (ABRAHAM, 2011; BOUSQUET; CURTIS, 2011) são apontadas como as principais referências teóricas que constituem as bases do pensamento complexo, embora não haja consenso acerca da ordem cronológica de surgimento e desenvolvimento dessas abordagens.

Entretanto, a relação entre a TGS e a Complexidade é mostrada por Bertalanffy (2012, p. 124), que já se referia, de maneira preliminar, à ideia de sistema dinâmico: "na ciência moderna, a interação dinâmica parece ser o problema central em todos os campos da realidade. Seus princípios gerais estão para ser definidos pela teoria de sistemas". Manson (2001), no entanto, enfatiza as diferenças entre a Complexidade e a teoria de sistemas: (a) a Complexidade trata de relacionamentos não-lineares entre entidades em constante mudança, enquanto a teoria de sistemas estuda entidades estáticas ligadas por relacionamentos lineares; (b) a Complexidade examina características qualitativas, enquanto a abordagem de fluxos e trocas da teoria de sistemas enfatiza quantidades; (c) a Complexidade aborda a emergência ou evolução de comportamentos complexos a partir de interações simples entre os componentes do sistema ao longo do tempo, e a teoria de sistemas favorece a simplificação e parametrização dos fluxos e trocas, assumindo que o sistema existe em equilíbrio e, portanto, 
negando a necessidade de examinar os relacionamentos em mudança entre os elementos. Da mesma forma, Phelan (1999) ressalta as diferenças em termos de tópicos de pesquisa e metodologia entre essas duas abordagens. Segundo esse autor, a teoria de sistemas enfatiza a previsão, o controle e a solução de problemas em geral, tendo como foco a melhoria de um sistema por meio de sua análise. Já na Complexidade, o trabalho possui natureza exploratória na tentativa de explicar o comportamento agregado de um sistema. Ademais, Phelan (1999) concorda com Manson (2001), ao afirmar que a teoria de sistemas enfatiza quantidades por meio de fluxos e trocas ao invés de qualidades ou atributos de um elemento.

Apesar das distinções apontadas pelos autores, a abordagem de sistemas e a Complexidade compartilham diversos aspectos, como o foco no anti-reducionismo e a apreciação holística da interconexão do sistema (MANSON, 2001), além da visão de mundo compartilhada (PHELAN, 1999). A cibernética, por sua vez, possui muitas interligações com a abordagem sistêmica e, portanto, ambas foram tratadas neste esforço de pesquisa visando delinear a base teórica para o estudo da Complexidade. Como a teoria da informação e a abordagem neural envolvem campos de conhecimento mais específicos, elas não serão tratadas neste trabalho.

Independentemente da ordem em que as abordagens surgiram e influenciaram umas as outras, elas compartilham diversos conceitos e ideias. Alhadeff-Jones (2008) divide a Complexidade em três gerações com diversas correntes teóricas, argumentando que a redução a uma forma singular (teoria da complexidade ou ciência da complexidade) pode levar à negligência de uma série de teorias diferentes que lidam com as implicações relacionadas à noção de complexidade. Conforme Barabási (2007), uma teoria completa da Complexidade ainda não existe, apesar dos avanços conceituais de várias abordagens. Alguns autores (BURNES, 2005; KLIJN, 2008; MANSON, 2001; MATHEWS; WHITE; LONG, 1999) argumentam que há uma variedade de teorias, desenvolvidas por diferentes áreas científicas, que se encontram sob a denominação geral de Complexidade. No entanto, a literatura não apresenta uma divisão bem definida entre os conceitos e/ou correntes teóricas, e o presente esforço de pesquisa busca conceitos fundamentais acerca dessa forma de encarar o mundo e os problemas. De forma geral, todas as correntes da Complexidade estão interessadas em como a natureza de um sistema pode ser caracterizada a partir de suas partes constituintes de uma maneira não reducionista (MANSON, 2001). As interligações entre essas bases teóricas aumentaram e, eventualmente, o complexo sistema de ideias tornou-se um sistema maior (ABRAHAM, 2011; MATHEWS; WHITE; LONG, 1999). Conforme Bousquet e Curtis (2011), a Complexidade é mais um conjunto de conceitos ferramentais do que um corpo 
teórico definitivo. Por essas razões, esse conjunto de conceitos será aqui tratado, apesar das críticas, como Complexidade ou teoria da complexidade, para facilitar a referência a tais ferramentas conceituais. O termo "Complexidade", quando utilizado sozinho para tratar desse conjunto como um corpo de conhecimento, será apresentado neste trabalho com letra inicial maiúscula, com o único objetivo de diferenciá-lo de seu significado usual caracterizando um fenômeno ou algo complexo.

Kogetsidis (2011) classifica a teoria da complexidade como uma abordagem estruturalista, em que a modelagem de todas as interações envolvidas é impossível, buscando, assim, identificar os aspectos estruturais mais importantes que governam o comportamento dos elementos ou subsistemas, e que determinam a viabilidade e desempenho do sistema. Essa base teórica contribui para o entendimento e para que se possa lidar com o ambiente caótico e incerto em que o ser humano está inserido, ilustrado por Prigogine (1996, p. 194): "o universo é um sistema termodinâmico gigante. Em todos os níveis, encontramos instabilidades e bifurcações". Dessa forma, os ambientes de instabilidade passam a ser compreendidos através de conceitos para os quais a existência do caos seria uma condição importante e necessária à evolução (WITTMANN; MAEHLER, 2008).

Nesse contexto, Donaires (2012, p. 32) enfatiza a complexidade dos fenômenos sociais, com ênfase para o comportamento humano: "os fenômenos sociais são extremamente complexos, tanto no que se refere ao número de variáveis relevantes quanto a da natureza variada dos dados". As entidades complexas incluem não somente tudo que é vivo, desde as células até os seres humanos, mas também organizações, desde uma colônia de formigas até corporações (BLOCH, 2005). A teoria da complexidade introduz uma orientação que permite a consideração dos sistemas sociais tanto em termos das trocas de informação como de comunicação, que os tornam diferentes de suas bases biológicas (HORN, 2008).

Prigogine (1996) ainda salienta o fato do mundo não ser estático e previsível, mas sim composto de níveis com flutuações, bifurcações e instabilidades, ressaltando noções como a de caos. Sistemas complexos são modelos de desequilíbrio, mudando continuamente por meio de mecanismos contraditórios que competem entre si por efetividade (AGAR, 1999). Já segundo Rickles, Hawe e Shiell (2007), os sistemas complexos são altamente compostos, construídos por grandes quantidades de subunidades mutuamente interativas (que são geralmente compostas também), cujas interações repetitivas resultam em um comportamento coletivo rico, que retroalimenta o comportamento das partes individuais. Para Sanger e Giddings (2012) um sistema complexo consiste em numerosos subsistemas interagindo entre 
si por meio de múltiplos ciclos de retroalimentação não-lineares e recursivos. Em contraste, um sistema simples pode ter muitas partes que interagem entre si, mas qualquer retroalimentação entre as partes é linear e não recursiva (SANGER; GIDDINGS, 2012).

Portanto, a mudança de uma ordem estática, concreta e palpável dá lugar a uma visão complexa e aleatória e origina escolhas múltiplas com um horizonte de previsões ilimitadas, em virtude de um ambiente mais complexo e caótico (WITTMANN; MAEHLER, 2008). Bloch (2005) aponta a compreensão dos relacionamentos, da estrutura e de sua função como o caminho para a compreensão das entidades complexas. Porém, Sanger e Giddings (2012) defendem que a complexidade depende da interpretação de quem estuda o sistema, isto é, o sistema pode ser simples e complexo, dependendo do observador.

O tetragrama defendido por Morin (2011) - ordem/desordem/interações/organização orienta todo o trabalho de construção do pensamento complexo (PÁDUA, 2008). Sua análise é concentrada nos três grandes pilares da ciência: a ordem, a separabilidade e a razão absoluta, ou seja, o caráter absoluto que a ciência atribui à lógica indutiva-dedutiva-identitária (PÁDUA, 2008). Para Wittmann e Maehler (2008), a teoria da complexidade deriva do fato de que a abordagem de causa-efeito é ineficaz para compreender a essência de certas manifestações, uma vez que em determinados sistemas dinâmicos a incerteza e o caos são fatores internos devidos à não-linearidade, e não externos. Essa evolução foi estimulada pela constatação de que sistemas perfeitamente lineares eram raros na natureza e nos sistemas humanos (AGAR, 1999; GIOVANNINI, 2002a).

De acordo com Morin (2011, p. 68), há várias espécies de complexidade, como as complexidades ligadas à desordem e outras que são ligadas a contradições lógicas: "pode-se dizer que o que é complexo diz respeito, por um lado, ao mundo empírico, à incerteza, à incapacidade de ter certeza de tudo, de formular uma lei, de conceber uma ordem absoluta. Por outro lado diz respeito [...] à incapacidade de evitar contradições". A complexidade, ainda, implica o senso da solidariedade (não se podem isolar os objetos uns dos outros) e o senso do caráter multidimensional de toda realidade (MORIN, 2011). Nesse sentido, o engajamento, ou compromisso, além de ser apontado como um princípio fundamental, também é indicado como necessário para que o pensamento complexo se sustente, já que ele representa um nível de interação em que uma parte permite a completa participação da outra na criação de possibilidades (BOKENO, 2008).

O presente esforço de pesquisa foi desenvolvido, desde sua concepção até o tratamento dado ao sistema em foco, com base nos sete princípios apontados por Morin (2010) para uma iniciação ao pensamento complexo: 
1. Princípio sistêmico: O todo é maior que a soma das partes, expondo o conceito de sinergia;

2. Princípio holográfico: complementar ao princípio sistêmico, pois não apenas a parte está no todo, como o todo está inscrito na parte;

3. Princípio do circuito retroativo: feedbacks positivos ou negativos, as múltiplas retroações em um sistema são inter-relacionadas e sofrem o efeito da incerteza;

4. Princípio do circuito recursivo: circuito gerador em que os produtos e os efeitos são, eles mesmos, produtores e causadores daquilo que produzem;

5. Princípio da auto-organização: seres vivos como seres auto-organizadores não param de autoproduzirem e, para isso, dependem da energia para manutenção da autonomia;

6. Princípio dialógico: pode-se conceber um mesmo fenômeno complexo por vias contraditórias, mas inseparáveis;

7. Princípio da reintrodução do conhecimento em todo conhecimento: a lucidez do indivíduo depende da complexidade do modo como organiza suas ideias, adequação e readequação do conhecimento.

Segundo Morin (2011, p. 74), o princípio dialógico pode ajudar a pensar a complexidade, isso porque ele permite manter a dualidade no seio da unidade, isto é, ele associa dois termos ao mesmo tempo complementares e antagônicos: "um suprime o outro, mas ao mesmo tempo, em certos casos, eles colaboram e produzem organização e complexidade".

O princípio de recursão organizacional também pode ajudar nesse sentido, um processo recursivo é aquele em que os produtos e os efeitos são ao mesmo tempo causas e produtores do que os produz. Um exemplo é o próprio indivíduo, a espécie e a reprodução: os indivíduos são produtores de um processo de reprodução que é anterior a eles, mas uma vez que são produtos, tornam-se os produtores do processo que vai continuar. A ideia recursiva rompe com a ideia linear, já que o que é produzido volta-se sobre o que o produz num ciclo autoconstitutivo, auto-organizador e autoprodutor (MORIN, 2011). A recursividade consiste na reaplicação das mesmas regras ao longo do tempo, resultando na ampliação dos efeitos das alterações (GIOVANNINI, 2002b).

Conforme Beer (1985), o estudo de um sistema tem início com a determinação precisa de qual organização se deseja estudar e a definição de suas fronteiras, mesmo que elas mudem conforme a adaptação da organização. Em seguida, as partes viáveis do sistema devem ser 
especificadas, e o sistema viável maior do qual ele, por sua vez, é parte. Ou seja, as recursões do sistema devem ser consideradas, de forma que o sistema viável seja autorreferenciado (sua lógica se mantém em si mesma). Nessa característica reside a explicação para a manutenção da identidade, a facilidade de autorreparação, a autoconsciência e a própria recursividade (BEER, 1985).

A própria definição de sistemas ilustra a recursividade, uma vez que um sistema complexo é composto de subsistemas que têm, por sua vez, seus próprios subsistemas, e assim por diante (DONAIRES, 2012). Beer (1994b, p. 118, tradução livre) consolida o teorema do sistema recursivo: "em uma estrutura organizacional recursiva, qualquer sistema viável contém, e está contido em, um sistema viável”. Da mesma forma, qualquer sistema viável existe em uma variedade de dimensões recursivas, isto é, um sistema viável existe em várias cadeias de sistemas (BEER, 1985). Um indivíduo, por exemplo, pertence a uma família, que pertence a um bairro e assim por diante; mas esse indivíduo também tem um emprego, que o inclui em uma empresa ou serviço, modificando a cadeia de sistemas. Esse mesmo indivíduo pode pertencer a uma igreja, a um clube de esportes etc. Cada uma dessas cadeias de sistemas pode ser chamada de dimensão recursiva (BEER, 1985). Logo, a decisão sobre o nível (sistema maior, sistema em foco e subsistemas) e a dimensão recursiva considerados depende do objetivo do estudo.

De acordo com Ashby (1970), duas "máquinas" ou sistemas podem ser acoplados, ou seja, pode ser feita sua junção, de modo a formar um todo. Assim, um sistema também pode ser entendido pelo acoplamento de suas partes ou subsistemas. Entretanto, compreender o comportamento das partes não é suficiente para determinar o do todo, já que o próprio acoplamento influencia esse comportamento (ASHBY, 1970). A recursividade é um mecanismo utilizado para lidar com a complexidade, auxiliando na definição ou na representação formal que permite a expressão lógica de modelos ilimitados de forma sucinta (DONAIRES, 2012).

Outro princípio que pode ajudar na lógica da complexidade é o princípio hologramático ou, como apresentado previamente, holográfico. Num holograma físico, o menor ponto da imagem contém a quase totalidade da informação do objeto representado. Assim, a parte está no todo e o todo está na parte, enriquecendo o conhecimento das partes pelo todo e o do todo pelas partes (MORIN, 2011). É a partir dessa concepção que Bokeno (2008) aponta o holismo como um princípio fundamental do pensamento complexo: tudo é dual, simultaneamente todo e parte, demonstrando tanto tendências auto-assertivas (proeminência/expressão individual) como integrativas (ser parte de um todo maior). 
Quanto ao princípio de auto-organização, Murray (1998) argumenta que ele não foi claramente demonstrado como necessário para a definição da Complexidade. Entretanto, para esse autor, os princípios apresentados por qualquer sistema que demonstre comportamento complexo e que, portanto, definem a teoria da complexidade são: (a) comportamento caótico ou não-linearidade; (b) adaptabilidade complexa; (c) auto-organização; e (d) (co)evolução. O comportamento caótico consiste nas grandes mudanças que podem ocorrer, dada uma pequena mudança no estado inicial do sistema; e outra característica do comportamento caótico é a possibilidade de surgimento de eventos aleatórios devido à presença de um atrator (esse conceito será tratado mais detalhadamente adiante). A adaptabilidade complexa se refere à adaptação mútua entre grupos e indivíduos, tanto dentro do grupo como em relação ao ambiente. A auto-organização está ligada ao comportamento emergente dos sistemas complexos, já que a organização do todo não pode ser prevista a partir do comportamento das partes (MURRAY, 1998). Rickles, Hawe e Shiell (2007) afirmam que os sistemas complexos frequentemente exibem auto-organização, que acontece quando os sistemas se organizam espontaneamente, sem influência externa.

A (co)evolução refere-se ao não-equilíbrio do sistema, que não atinge um estado de equilíbrio, mas continua a evoluir; e evolução aqui deve ser entendida a partir da noção de irreversibilidade em um sistema complexo, isto é, a evolução não implica progresso, mas simplesmente que o sistema não pode voltar ao seu estado anterior, mudando sempre para estados que podem ou não ser considerados "melhores" pelos grupos que exercem influência sobre o sistema. A co-evolução significa que todos os subsistemas que influenciam o sistema são também influenciados pelo mesmo, formando uma rede de sistemas em evolução (MURRAY, 1998). Para Rickles, Hawe e Shiell (2007), a co-evolução descreve a maneira como os organismos criam seu ambiente e são moldados pelo mesmo, devido ao feedback ou ciclo de retroalimentação positivo.

Portanto, tais princípios foram considerados ao longo do desenvolvimento e escrita do trabalho, em uma tentativa de seguir essa abordagem até mesmo nas etapas de pesquisa, assim como durante a reflexão acerca do fenômeno em estudo, buscando aplicar esses princípios ou identificá-los na dinâmica do sistema de desenvolvimento local.

Devido aos mecanismos de retroalimentação desenvolvidos pela cibernética, o uso da teoria de sistemas para o entendimento da organização foi ampliado na direção dos sistemas dinâmicos não-lineares, sendo que a TGS e a cibernética consolidaram tal ideia (GIOVANNINI, 2002a). A teoria da complexidade preocupa-se com a emergência de ordem 
em sistemas dinâmicos não-lineares operando nos limites do caos, ou "edge of chaos" (BURNES, 2005), que seria onde o sistema alcança um estado de equilíbrio dinâmico, entre a ordem e o caos, ou estabilidade e mudança (LINDSAY, 2005). A dinâmica resulta na impossibilidade de compreensão dos sistemas complexos por meio de sua observação em um único momento no tempo; devido às não-linearidades (ciclos múltiplos interconectados de retroalimentação) não se pode ter certeza de sua evolução até que ele atinja seu destino (AGAR, 1999). A não-linearidade é um princípio básico do pensamento complexo, caracterizando um sistema não-linear como aquele cujas saídas não podem ser previstas a partir das condições iniciais ao longo de uma trajetória reta ou estável, ou seja, um sistema cuja resposta não é proporcional ao estímulo aplicado, e que permitem várias soluções (BAUER, 1999; BOKENO, 2008; LONGA, 2004). Enquanto os processos lineares possuem uma natureza previsível e determinística, os processos não-lineares são imprevisíveis e nãodeterminísticos (LONGA, 2004).

A não-linearidade é uma propriedade fundamental dos sistemas complexos, assim como do mundo que se busca compreender. Ela refere-se a múltiplos ciclos sobrepostos de retroalimentação e densamente conectados que se conectam, soltam e conectam novamente (AGAR, 1999). As relações não-lineares são relações em rede, já que as redes têm a nãolinearidade como propriedade básica e os relacionamentos em padrão de rede são nãolineares, seguindo todas as direções (BOUSQUET; CURTIS, 2011). Assim, a Complexidade pode auxiliar a compreensão das interações em rede das entidades estudadas.

Os sistemas não-lineares alternam períodos de comportamento previsível com períodos de situação caótica, sofrendo perturbações internas e externas que amplificam as interações não-lineares. Esses movimentos levam os sistemas a patamares mais elevados de organização, tornando-os mais complexos e aptos a interagirem com o meio ambiente (WITTMANN; MAEHLER, 2008).

A complexidade afirma que os resultados, para entidades complexas como
empresas, mercados ou economias não são passíveis de serem pré-conhecidos, uma
vez que as relações entre as ações e seus resultados são não-lineares. Através de
intrincados feedbacks, as causas podem se transformar em efeitos e os efeitos em
causas, de maneira que, na prática, ligações causais não podem ser traçadas
(WITTMANN; MAEHLER, 2008, p. 34).

O foco deste esforço de pesquisa é um tipo específico de sistema dinâmico não-linear que potencialmente possui características similares às das localidades em busca do desenvolvimento. A primeira característica específica é a adaptabilidade, isto é, a capacidade de aprender com a experiência e alterar seu comportamento com base nisso. As entidades ou sistemas complexos são adaptativos, possuindo a habilidade de se manterem e aprender da 
experiência (BOUSQUET; CURTIS, 2011; MIGUÉLEZ, 2011), embora seus componentes e até sua forma possam mudar, isto é, eles têm vida, são auto-organizados, adaptando-se internamente às mudanças ambientais (BLOCH, 2005). A co-evolução e a auto-organização são características importantes dos sistemas adaptativos complexos (BOUSQUET; CURTIS, 2011; KLIJN, 2008; LINDSAY, 2005). A segunda característica específica é que seja um sistema aberto, mais especificamente, uma estrutura dissipativa, isto é, que absorve e dissipa energia e matéria do ambiente (PRIGOGINE, 1996). Os sistemas complexos são abertos, se mantendo por meio do fluxo contínuo e das trocas de componentes ou energia (BLOCH, 2005; BOUSQUET; CURTIS, 2011). Segundo Giovannini (2002b), estas duas características são necessárias para que o sistema possa ser autônomo e para que potencialmente possa se desenvolver de acordo com os conceitos aqui abordados. Assim, o termo sistema dinâmico não-linear deve ser entendido como a descrição acima, ou seja, sistema estruturalmente dissipativo, dinâmico, não-linear e adaptativo.

Para lidar com esses sistemas, a teoria da complexidade trouxe como solução um novo determinismo, o caos determinístico. Conforme Fiedler-Ferrara e Prado (1994), o caos determinístico se deve, essencialmente, à dependência sensitiva às condições iniciais que, por sua vez, resulta das não-linearidades presentes no sistema, amplificando exponencialmente pequenas diferenças nas condições iniciais. Dessa forma, leis de evolução determinísticas podem levar a comportamentos caóticos, inclusive na ausência de ruído ou flutuações externas (FIEDLER-FERRARA; PRADO, 1994). Como consequência, um prognóstico de longo prazo é impossível, uma vez que as condições iniciais exatas nunca são conhecidas (POSER, 2007).

Complexidade refere-se à impossibilidade de atingir a completude do conhecimento, reconhecendo e aceitando a incerteza (BAUER, 1999). Como exposto previamente, em determinados sistemas dinâmicos, a incerteza e o caos são gerados internamente, pelo próprio sistema, devido à sua não-linearidade, e não exclusivamente por fatores externos. A complexidade e o caos podem surgir, nesses casos, de regras relativamente simples aplicadas continuamente de forma recursiva. Para tratar desses sistemas, a solução baseia-se, então, na compreensão das regras básicas que regem seus comportamentos, que tipo de feedback existe, como ele atua no sistema e o tipo e duração dos ciclos de retroalimentação (GIOVANNINI, 2002b).

A teoria da complexidade estuda os sistemas adaptativos complexos, ou seja, estuda qualquer conjunto de elementos que interagem dinamicamente entre si, reproduzindo seu 
próprio comportamento (DEMO, 2002). Buscando a compreensão dos sistemas complexos, Donaires (2012) lista os cinco atributos que os caracterizam:

1. Complexidade, frequentemente, supõe hierarquia, ou seja, o sistema complexo é composto de subsistemas inter-relacionados;

2. A escolha de quais componentes de um sistema são primitivos é arbitrária, dependendo do entendimento do observador;

3. Conexões intracomponentes são geralmente mais fortes que conexões intercomponentes;

4. Sistemas hierárquicos são compostos de apenas alguns poucos tipos diferentes de subsistemas em várias combinações e arranjos;

5. Um sistema complexo que funciona é invariavelmente descoberto como tendo evoluído de um sistema simples que funcionava.

De acordo com Bloch (2005), os sistemas complexos compartilham certas características: (a) possuem a habilidade de se manterem, são auto-organizados; (b) são abertos, realizando trocas de componentes e energia; (c) nessas trocas, eles são parte de redes; (d) são também partes ou fractais de outras entidades ou sistemas, possuindo a totalidade do sistema em si mesmos; (e) são dinâmicos, movendo-se entre a ordem e o caos, e são exatamente essas fases de transição que se configuram como a oportunidade para a criatividade e a emergência de novas formas; (f) durante essas fases de transição, eles buscam picos de adaptabilidade, isto é, o ponto que proporcionará a melhor chance de sobrevivência; (g) possuem uma dinâmica não-linear, já que as transições entre ordem e caos derivam de múltiplas causas de múltiplos relacionamentos em rede, de uma interação contínua entre o externo e o interno; (h) possuem dependência sensitiva, em que mudanças pequenas resultam em efeitos consideráveis; (i) à medida que o sistema muda através das transições, ele sobrevive e mantém sua forma em resposta a vários tipos de atratores que limitam seu movimento e crescimento; (j) são emergentes, ou seja, eles mantém a vida por meio da criação de novas formas; $(\mathrm{k})$ são interdependentes, existindo apenas como parte de uma rede inseparável.

Já para Johnson (2010), os sistemas complexos apresentam: muitas partes heterogêneas; leis de transição complicadas; emergência imprevisível ou inesperada; dependência sensitiva às condições iniciais; dinâmica dependente da trajetória; conexões em rede e múltiplos subsistemas dependentes; dinâmica emergente das interações dos agentes autônomos; auto-organização em novas estruturas e padrões de comportamento; dinâmica do não-equilíbrio ou distante do equilíbrio; dinâmica discreta com explosão combinatória; 
adaptação a ambientes mutantes; subsistemas co-evolutivos; fronteiras mal definidas; dinâmica multiníveis. Qualquer dessas características pode fazer um sistema parecer complexo, mas juntas, essas características podem dificultar sua compreensão e controle (JOHNSON, 2010).

Fenômenos, comportamentos ou sistemas que exibem complexidade são marcados por instabilidades, flutuações, sinergia, emergência, auto-organização, não-linearidade, ciclos de retroalimentação positiva e negativa, equilíbrios dinâmicos, rupturas de simetria ou fases de proximidade do caos (MIGUÉLEZ, 2011). Assim, Bauer (1999, p. 19, grifo do autor) aponta os sistemas complexos em ciência, mostrando a diversidade de conceitos associados a essa concepção:

Quais seriam, porém, os sistemas complexos em ciência? Hoje, eles atendem por
cada vez mais diversas denominações: complexidade por auto-organização pelo
ruído, autopoiesis, estruturas dissipativas, ordem estratificada, irreversibilidade do
tempo, caos determinístico, atratores, fractais, criticalidade, vidros de spin,
percolação, dinâmica de populações, complexidade algorítmica, holística,
transdisciplinaridade etc.

Para Larsen-Freeman (2012), os sistemas complexos seguem alguns princípios: (1) são abertos e dinâmicos; (2) operam sob condições fora do equilíbrio; (3) são considerados sistemas por abrangerem muitos elementos que interagem; (4) são dinâmicos, se adaptando tanto por interações com o ambiente como pela reorganização interna, ou auto-organização; (5) a força das interações muda com o tempo; (6) sua complexidade é emergente; (7) é nãolinear, ou seja, uma ocorrência inesperada pode surgir a qualquer momento; (8) sua estrutura se mantém apesar de mudanças em seus componentes; (9) o ambiente em que eles operam é parte de um sistema complexo; (10) apresentam comportamento em uma variedade de escalas de tempo e em diferentes níveis de complexidade; (11) podem apresentar variação caótica; e (12) são iterativos, isto é, revisitam o mesmo território diversas vezes, o que significa que o nível presente de desenvolvimento é dependente do que o precedeu.

Manson (2001), por sua vez, explora alguns conceitos que definem os sistemas complexos a partir da abordagem da complexidade agregada (focada nos interrelacionamentos):

a) Relacionamentos entre entidades: um sistema complexo é definido mais pelos relacionamentos do que pelas partes constituintes, estando limitados às interações locais, isto é, não há onisciência (as partes não necessariamente têm consciência do que as outras estão fazendo); 
b) Estrutura interna: relacionamentos de diferentes forças entre as partes definem a estrutura interna de um sistema, sendo que os mesmos componentes, com relações realinhadas, podem formar subsistemas diferentes. Além disso, qualquer componente pode pertencer a múltiplos subsistemas;

c) Meio ambiente: definido como tudo que está fora do sistema (embora a divisão não seja necessariamente definida), o relacionamento com o meio ambiente é essencial para a existência do sistema complexo. Independente da real fronteira, o sistema passa informação, matéria e energia através de sua estrutura interna; e as ações e interações entre seus componentes eventualmente criam um fluxo de volta ao ambiente;

d) Aprendizado e memória: um sistema complexo não é dependente do ambiente, ele se estrutura, reage e antecipa ativamente, "lembrando" por meio da persistência da estrutura interna. Os componentes e subsistemas com capacidade de acomodar o influxo de energia, informação e matéria do ambiente crescem; e relacionamentos externos regulares encorajam 0 crescimento do mesmo conjunto de componentes e subsistemas. Deparado com uma situação nova, algum conjunto de componentes do sistema deve ter a capacidade de lidar com tal situação. Nas raras situações em que essa capacidade não existe, o sistema não responde ao ambiente, podendo sofrer consequências catastróficas;

e) Emergência: existe em função da sinergia, já que as características do sistema como um todo não resultam da sobreposição, mas das interações entre os componentes. Essa característica impossibilita a previsão e o controle, uma vez que mudanças em um subsistema visando à mudança do todo podem não obter o resultado esperado, já que os outros componentes do sistema mudam para se adaptar à intervenção, além de outras mudanças no ambiente;

f) Mudança e evolução: um sistema complexo muda constantemente, seja devido à auto-organização (mudança da estrutura interna para melhor interagir com o ambiente), à propriedade dissipativa (forças externas ou perturbações internas levam o sistema a um estado altamente desorganizado antes de levá-lo repentinamente a um de maior organização) ou à criticidade auto-organizativa (habilidade dos sistemas complexos de equilíbrio entre a aleatoriedade e a estática, ao invés de enfrentar uma crise o sistema atinge um ponto crítico em 
que sua estrutura interna encontra-se à beira do colapso sem, no entanto, atingilo).

Logo, é possível perceber a variedade de conceitos e ideias abrangidos pela teoria da complexidade, buscando maneiras de lidar com os fenômenos e problemas contemporâneos. As características da complexidade também são listadas por Demo (2002), incluindo noções como:

- Dinâmica: por envolver um "campo de forças contrárias", em que a estabilidade é sempre provisória;

- Não-linearidade: complicado e complexo são conceitos distintos, em um todo complexo, a decomposição das partes desconstrói o todo, sendo, entretanto, impraticável refazer o mesmo todo a partir das partes;

- Reconstrutividade: a complexidade permanece a mesma, se reconfigurando conforme o fluxo do tempo e as circunstâncias encontradas e, já que é marcada pela "flecha do tempo" de Prigogine (1996), tornando-se irreversível;

- Processo dialético evolutivo: envolve a capacidade dos fenômenos complexos de aprender, isto é, seus processos podem incluir criatividade autêntica;

- Irreversibilidade: determinada pela inserção temporal, ou seja, qualquer depois é diferente do antes. Além disso, todo fenômeno complexo possui sua individualidade, entendida como condição distintiva;

- Intensidade: possuindo dimensões produtivas imprevisíveis e incontroláveis;

- Ambiguidade/ambivalência: a ambiguidade refere-se à estrutura, devido à composição também desencontrada de seus componentes. Já a ambivalência refere-se à dinâmica dos fenômenos complexos, constituída de valores contrários, estabelecendo-se entre eles campos contrários de força.

Para lidar com a complexidade, o pensamento sistêmico está fundamentado sobre conceitos intimamente relacionados, são eles: emergência e hierarquia, e comunicação e controle (DONAIRES, 2012). Ou seja, são conceitos cujo desenvolvimento é atribuído à abordagem sistêmica, mas que também são citados como parte da teoria da complexidade, mostrando as sinergias e inter-relações entre as abordagens. A ideia de controle está associada à imposição de restrições, que excluem uma variedade de comportamentos dinâmicos, selecionando-os e fazendo emergir a nova funcionalidade desejada no nível mais alto (DONAIRES, 2012). Da mesma forma, como citado anteriormente, a noção de controle é preocupação central da cibernética. 
Já as propriedades emergentes referem-se às propriedades particulares de cada nível hierárquico, ou seja, elas emergem de cada um deles e fazem sentido apenas no nível de abstração em que aparecem (BOUSQUET; CURTIS, 2011; DONAIRES, 2012). As propriedades emergentes são propriedades imprevisíveis a partir do conhecimento das partes e de seus acoplamentos, isto é, propriedades apresentadas pelo todo que não eram encontradas em nenhuma das partes isoladamente (AGAR, 1999; ASHBY, 1970; KLIJN, 2008; LONGA, 2004; MASON, 2008). A partir disso, nem sempre as propriedades do todo reproduzem as propriedades das partes, e vice-versa. O conceito de emergência está ligado à idéia de um todo maior que a soma de suas partes (GIOVANNINI, 2002b; MASON, 2008; MIKULECKY, 2001). A complexidade emerge em sistemas em que a interação dos agentes forma padrões de organização mais complexos que os padrões dos próprios agentes. Ou seja, o sistema complexo apresenta dinâmicas que não se poderia prever ou esperar dado o conhecimento dos agentes individuais que o compõem (AGAR, 1999).

A emergência é um princípio fundamental do pensamento complexo, referindo-se ao surgimento de fenômenos e estruturas novas e inesperadas que não poderiam ser previstas a partir das condições iniciais de sua dinâmica; assim, a emergência é um produto de sistemas auto-organizados (BOKENO, 2008). Como exemplo, é possível citar a própria concepção de vida: embora suas partes sejam apenas componentes químicos, a propriedade emergente possui uma característica diferente - estar viva -, algo imprevisível a partir do comportamento de cada componente (LONGA, 2004; MASON, 2008). Assim, o surgimento de diferenças qualitativas claras entre os níveis é a característica básica das propriedades emergentes (LONGA, 2004).

Uma vez que o sistema atinge um determinado nível crítico de complexidade, ocorre a fase de transição, ou bifurcação (PUDDIFOOT, 2000), que torna possível a emergência de novas propriedades e comportamentos (MIKULECKY, 2001). Ela consiste na mudança de um padrão para outro no sistema, isto é, na mudança do atrator do sistema (PUDDIFOOT, 2000). Essa fase de transição consiste em uma lei fundamental para o aumento da complexidade, mas seus detalhes (quando e como ela ocorre, que propriedades e que comportamentos emergem) são contingentes em fatores contextuais específicos e provavelmente únicas para esse contexto particular (MASON, 2008). A emergência é auxiliada e até estimulada à medida que os sistemas deixam um domínio estável e se aproximam do caos (MIKULECKY, 2001).

Murray (1998) lista três características dos sistemas complexos: (1) emergência; (2) recursividade; e (3) abordagem baseada em processos. A teoria da complexidade possui foco 
nos processos de emergência e adaptabilidade ao invés de analisar situações específicas. Logo, a Complexidade, em geral, resulta em uma percepção qualitativa ou uma analogia para alguns aspectos da situação em estudo, e não em previsões detalhadas e prescrições (MURRAY, 1998).

Prado (2009) apresenta três concepções de Complexidade. A Complexidade busca compreender o todo considerando não só os seus elementos, mas também o modo como estão organizados e como interagem no interior dessa organização. A primeira configura-se na obra de Bertalanffy, que argumenta acerca das insuficiências do método reducionista, isto é, para o emprego do procedimento analítico duas condições devem ser satisfeitas: interações entre as partes devem ser fracas para serem negligenciadas e, assim, considerar o todo como a agregação das partes; e os vínculos de causa e efeito devem ser lineares entre as partes e o todo para que se possa pensar que o comportamento do todo segue o padrão do comportamento das partes. Entretanto, Bertalanffy argumentou que tais condições nunca ocorrem nos sistemas (PRADO, 2009).

A partir disso, as três concepções de sistema complexo apresentadas por Prado (2009) possuem cada uma sua noção específica de emergência. A primeira, denominada dedutivista, está baseada na ideia de que esse tipo de objeto científico pode ser apreendido suficientemente com base na construção de sistemas dinâmicos; ou seja, emergência é o padrão macroscópico resultante das interações microscópicas dos elementos do sistema. A segunda, chamada de saltacionista, considera que emergência consiste nas mudanças qualitativas manifestadas nos sistemas complexos ao longo de seu processo evolutivo; logo, essas propriedades inéditas não são dedutíveis a partir dos estados iniciais e das regras de interação dos elementos do sistema.

E a terceira concepção, ou estrutural, defende que os nexos entre os elementos são constitutivos tanto dos elementos enquanto tais quanto do todo sistêmico; dessa forma, os sistemas são objetos com estrutura de relações e posições e, assim, as propriedades emergentes são manifestações dessas estruturas subjacentes (PRADO, 2009). De acordo com essa concepção, Giovannini (2002a, 2002b) apresenta alguns dos principais conceitos da teoria da complexidade: dependência sensitiva às condições iniciais, caos, atratores estranhos, padrões fractais e estabilidade dinâmica.

A incerteza, ou caos determinístico, segundo Giovannini (2002b), é inerente aos sistemas dinâmicos não-lineares, não sendo eliminada, nem necessariamente diminuída, com um maior controle sobre os parâmetros do sistema. Nesse sentido, Prigogine (1996, p. 32) 
apresenta os sistemas caóticos: "os sistemas caóticos são um exemplo extremo de sistema instável, pois as trajetórias que correspondem a condições iniciais tão próximas quanto quisermos divergem de maneira exponencial ao longo do tempo". Sistemas caóticos podem ter poucas subunidades em interação, mas elas interagem de tal forma que produzem uma dinâmica muito intricada. O comportamento de um sistema caótico parece aleatório, mas é gerado por processos determinísticos simples e não-aleatórios (RICKLES; HAWE; SHIELL, 2007). Este comportamento imprevisível de tais sistemas é originado na sua dependência sensitiva às condições iniciais (FIEDLER-FERRARA; PRADO, 1994), isto é, pequenas variações nos parâmetros do sistema podem ter consequências não-lineares (MANSON, 2001) desproporcionais sobre a evolução do sistema (LONGA, 2004; PUDDIFOOT, 2000; SANGER; GIDDINGS, 2012). A sensibilidade às condições iniciais é comumente ilustrada pela parábola do "efeito borboleta" (BOUSQUET; CURTIS, 2011; GLEICK, 2008; MANSON, 2001; PUDDIFOOT, 2000; SANGER; GIDDINGS, 2012), em que a batida das asas de uma borboleta na bacia amazônica pode afetar o tempo que fará nos Estados Unidos (PRIGOGINE, 1996). Conforme Rickle, Hawe e Shiell (2007) a sensibilidade às condições iniciais, devida à não-linearidade, é condição necessária tanto do caos como da complexidade.

A Complexidade demonstrou que esta relação desproporcional é causada pela recursividade dos sistemas dinâmicos não-lineares. A recursividade, de acordo com Giovannini (2002b), é a reaplicação das mesmas regras ao longo do tempo. Esse mecanismo de retroalimentação (baseado na mútua causalidade) dos sistemas não-lineares amplifica o efeito de pequenas alterações (GIOVANNINI, 2002b). Um sistema amplifica qualquer perturbação ou nova entrada por meio de ciclos de recursão ou iteração, por isso a noção de retroalimentação é de importância particular para fenômenos não-lineares (BOUSQUET; CURTIS, 2011).

Agar (1999) enfatiza a distinção entre caos e complexidade, embora tanto sistemas caóticos como complexos sejam exemplos de sistemas dinâmicos não-lineares (RICKLES; HAWE; SHIELL, 2007). O caos mostra como um único (ou simples) conjunto de equações não-lineares pode produzir resultados que parecem desordenados, aleatórios, ou caóticos na superfície. Na verdade, os resultados, ao longo do tempo, formam padrões de acordo com os chamados atratores estranhos (AGAR, 1999), a serem explorados adiante. O caos consiste em comportamentos complicados, aperiódicos e aparentemente aleatórios a partir de iterações de uma regra simples (RICKLES; HAWE; SHIELL, 2007). Já a complexidade se refere a sistemas com agentes múltiplos interagindo e mudando conforme as interações. O sistema tende a se auto-organizar ao invés de produzir comportamentos aparentemente aleatórios 
(AGAR, 1999). A complexidade é o surgimento de comportamentos coletivos ricos e dinâmicos a partir de interações simples entre um grande número de subunidades (RICKLES; HAWE; SHIELL, 2007). Até no sistema mais complexo, a emergência de ordem se manifesta por meio do processo de auto-organização (BURNES, 2005). Assim, sistemas caóticos possuem atratores estranhos, enquanto os sistemas complexos possuem uma série de possíveis atratores (RICKLES; HAWE; SHIELL, 2007). Conforme Rickles, Hawe e Shiell (2007), sistemas caóticos não são necessariamente complexos, e sistemas complexos não são necessariamente caóticos (embora possam ser para alguns valores das variáveis ou parâmetros de controle).

A teoria dos sistemas dinâmicos é um ramo amplo da matemática, ficando conhecida como teoria do caos (ABRAHAM, 2011). Ela se diferencia da Complexidade à medida que está centrada no comportamento complexo que surge das interações não-lineares entre poucos elementos; enquanto a Complexidade busca mostrar que interações altamente complexas em sistemas com uma rede de muitos elementos criam padrões em uma escala maior, a qual possui uma natureza qualitativamente distinta, embora os padrões em si sejam simples (LONGA, 2004). A teoria do caos sugere que mesmo um ínfimo grau de incerteza a respeito das condições iniciais pode crescer inexoravelmente e causar flutuações substanciais no comportamento de um fenômeno particular (MASON, 2008).

O fato de haver muitas variáveis no ambiente das localidades em busca do desenvolvimento e de ser impossível conhecer e controlar todas elas não está relacionado com caos e complexidade. A visão de que, se fosse possível conhecê-las e controlá-las seria possível prever o comportamento dos sistemas de desenvolvimento local, é uma típica visão determinístico-mecanicista. Ela é adequada a sistemas complicados, que é algo distinto de sistemas complexos. Além disso, comportamento caótico não é o mesmo que comportamento aleatório, que não está sujeito a nenhum tipo de determinismo (GIOVANNINI, 2002b).

De acordo com Giovannini (2002b), o comportamento caótico possui um determinismo subjacente, chamado de determinismo caótico, o qual não permite previsões precisas (que são objeto do determinismo mecanicista). Contudo, nem todos os sistemas dinâmicos não-lineares apresentam comportamento caótico; tais sistemas podem evoluir para três situações: (a) estabilidade em torno de um atrator definitivo; (b) alternância de forma periódica entre dois ou mais atratores; e (c) simplesmente "morrer" por falta de viabilidade (GIOVANNINI, 2002b). 
Caos, no contexto da Complexidade, se refere ao comportamento de sistemas dinâmicos resultante da dependência sensitiva às condições iniciais (FIEDLER-FERRARA; PRADO, 1994); isto é, o comportamento caótico não é originado por fatores externos, mas tem origem interna ao próprio sistema (GIOVANNINI, 2002b). Para Burnes (2005), o caos pode ser visto como uma forma diferente de ordem: o caos descreve uma desordem complexa, imprevisível e ordenada em que padrões de comportamento se revelam em formas similares, embora irregulares. Na teoria do caos, o comportamento caótico do sistema importa, enquanto na teoria da complexidade o que importa é o abandono desse comportamento caótico em favor de um regime ordenado, encontrado no sistema como um todo devido à emergência (LONGA, 2004). Por isso, neste esforço de pesquisa, o foco é a teoria da complexidade.

Ademais, para compreensão das possibilidades de evolução dos sistemas é importante considerar a questão da autonomia. Para Prigogine (1996), nas últimas décadas, houve o nascimento de uma nova ciência, a física dos processos do não-equilíbrio, levando a novos conceitos, como a auto-organização e as estruturas dissipativas. Os desenvolvimentos da física e das matemáticas do caos e da instabilidade nos permitem perceber os problemas sob um ângulo renovado (PRIGOGINE, 1996). Sob essa abordagem, Serva, Dias e Alperstedt (2010) defendem que a complexidade consiste na contínua autoprodução, auto-organização e autonomia dos sistemas. Autonomia, em um sistema, significa que a parte ou função indicada é responsável pela sua própria regulação, mantendo a estabilidade interna (BEER, 1994a).

Em um sistema viável, sua dinâmica envolve a gestão da complexidade. A complexidade, por sua vez, deve ser balanceada, e para isso, ela deve ser medida. Ela é o resultado da maneira como os sistemas se comportam e interagem. Como os sistemas são fenômenos subjetivos, a determinação de uma medida objetiva para a complexidade torna-se problemática. Entretanto, as medidas consideradas objetivas apenas o são porque houve um acordo acerca de um grupo de convenções sobre suas aplicações. Beer (1994b) exemplifica com a altura do Monte Everest, que não é a distância de uma viagem desde a base para escalálo, e também não é a medida tirada de uma régua do tamanho do braço quando se olha para ele. Essas duas convenções poderiam ter sido utilizadas, ambas funcionariam dadas outras condições definidas. Logo, de acordo com Beer (1994b), medidas objetivas, assim como sistemas objetivos, apenas existem como cristalizações convencionadas de uma entre um número infinito de possibilidades subjetivas. $\mathrm{O}$ mesmo pode ser considerado para a medida definida de complexidade: a variedade.

O termo "variedade" é uma medida de complexidade, porque conta o número de estados possíveis de um sistema (BEER, 1985). O conceito de variedade foi introduzido pelo 
ciberneticista britânico Ross Ashby, que a define como o número de elementos distintos de um conjunto (ASHBY, 1970). Novamente, é possível perceber as conexões entre a cibernética e a Complexidade. Conforme Beer (1994a) e Donaires (2012), variedade consiste no número de itens distinguíveis (ou estados possíveis) do objeto de estudo.

Segundo a Lei de Variedade Requerida, também conhecida como lei de Ashby, "somente variedade absorve variedade", isto é, somente variedade pode destruir variedade (ASHBY, 1970). Uma aplicação da Lei de Variedade Requerida de Ashby consiste na determinação de que a variedade da saída deve, ao menos, ser igual à variedade da entrada para o sistema como um todo (BEER, 1994a). A consequência é que a variedade do regulador tem que pelo menos ser igual, se não puder superar, à do sistema controlado (DONAIRES, 2012). Ashby (1970) explica que a função do regulador é bloquear o fluxo de variedade das perturbações para as variáveis essenciais. Se o regulador apresentar variedade menor que a requerida, o sistema controlado pode fugir ao controle (DONAIRES, 2012). A medida de variedade de um sistema, entretanto, só pode ser determinada quando se define as fronteiras do sistema, delimitando-o, definindo-o. E o que o sistema é, ou sua definição, depende de seu propósito, interligando os conceitos de maneira estreita (BEER, 1994b). Contrariando a Lei de Variedade Requerida, Pina e Cunha e Rego (2010) defendem que a simplicidade, da qual a complexidade emerge, não deve ser menosprezada, isto é, deve-se considerar a co-existência da simplicidade com a complexidade, argumentando que uma iniciativa simples pode facilitar a emergência do comportamento complexo e adaptativo de uma coletividade. Ou seja, para lidar com um sistema complexo, não se deve buscar, necessariamente, tornar-se tão complexo quanto o sistema em foco (PINA E CUNHA; REGO, 2010).

Em sistemas complexos, a dinâmica não-linear implica mudanças abruptas entre as partes do sistema consideradas de maneira isolada e o todo; essas mudanças são impulsionadas por atratores (LONGA, 2004). O comportamento de sistemas dinâmicos nãolineares pode, em determinadas condições, possuir um atrator, que é um conjunto invariante para o qual órbitas próximas convergem depois de um tempo (FIEDLER-FERRARA; PRADO, 1994). Longa (2004) define um atrator como uma área que captura um sistema próximo que possui as propriedades relevantes, isto é, por meio dos atratores, o sistema se estabelece em áreas que favorecem a emergência, pois seu papel é assegurar a evolução ótima dos sistemas complexos, evitando a necessidade de que o sistema explore aleatoriamente as possibilidades. É o potencial de que as variáveis do sistema mudem abruptamente de um atrator para outro que é chamado de bifurcação (MANSON, 2001). Para analisar e 
compreender os sistemas que apresentam o determinismo caótico são utilizados os conceitos de atratores estranhos e padrões fractais recursivos. Em sistemas que evoluem em caos determinístico, pode-se provar que os atratores têm dimensões fractais (FIEDLERFERRARA; PRADO, 1994), sendo assim, chamados de atratores estranhos (GIOVANNINI, 2002b).

O atrator estranho, segundo Manson (2001), é definido como um valor ou um conjunto de valores para os quais as variáveis do sistema tendem, mas nunca os alcançam exatamente. Assim como os atratores normais são valores para os quais as variáveis do sistema tendem, os atratores estranhos delimitam de maneira aproximada os possíveis valores das variáveis (MANSON, 2001; PUDDIFOOT, 2000). O conceito de atrator estranho cria a condição para a compreensão do equilíbrio dinâmico, mostrando como é possível ter estabilidade suficiente em um sistema para sua existência e, ao mesmo tempo, preservar a possibilidade endógena de adaptação e mudança. Os atratores estranhos indicam uma condição de equilíbrio procurada pelo sistema; essa procura é garantida pela recursividade dos mecanismos de feedback dos sistemas (GIOVANNINI, 2002b).

Os padrões fractais de evolução são encontrados em uma variedade de fenômenos e áreas (física, química, biologia, economia), sendo resultado de sistemas dinâmicos nãolineares (GIOVANNINI, 2002a). Ferreira (1986) define fractal como forma geométrica de aspecto irregular ou fragmentado, que pode ser subdividida indefinidamente em partes, que são cópias reduzidas do todo. Assim, Gleick (2008, p. 94) define fractal por meio da autosemelhança, que é a simetria através das escalas, significando recorrência, isto é, um padrão dentro de outro padrão: "para a imaginação, um fractal é uma maneira de ver o infinito". Conforme Fiedler-Ferrara e Prado (1994), os fractais consistem em estruturas geométricas complexas e com dimensões não-inteiras. Para Manson (2001), fractais são padrões complicados auto-referenciados, que também são atratores estranhos cujos padrões se mantêm imutáveis independentemente da escala de observação. Este mesmo autor exemplifica o conceito por meio da estrutura de uma árvore, que é fractal porque a mesma distribuição ramificada é encontrada desde a escala da árvore como um todo até as veias de suas folhas. Os fractais mostram que é possível alcançar formas e comportamentos complexos mesmo partindo-se de regras simples aplicadas de forma recursiva. Assim, a compreensão da lógica dos fractais permite entender melhor os sistemas através de seus componentes recursivos e, assim, entender seu comportamento ao longo do tempo (GIOVANNINI, 2002b).

Sistemas dinâmicos não-lineares possuem razoável capacidade de absorver instabilidades ou ruídos de origem externa, isso ocorre devido à interação contínua de padrões 
recursivos que levam o sistema à sua condição original de equilíbrio dinâmico em torno de um atrator. São necessários ruídos substanciais, aplicados por diversos ciclos, para modificar a posição dos atratores ou para inviabilizar o sistema (GIOVANNINI, 2002b).

As implicações da estabilidade dinâmica dos sistemas complexos para os sistemas de desenvolvimento local devem-se, principalmente, ao reforço da importância da compreensão de sua dinâmica antes de atuar sobre eles, principalmente antes de dedicar recursos para proteger o sistema de ruídos externos. Isso porque a incerteza é característica intrínseca do sistema e, ao mesmo tempo, ele possui capacidade de absorver instabilidades de origem externa. Incertezas e ruídos externos, dentro de determinados limites, não afetam os atratores do sistema e, portanto, sua evolução (GIOVANNINI, 2002b).

À medida que o sistema se aproxima dos limites, o caos determinístico é a característica predominante gerando novos comportamentos e configurações do sistema. As alternativas que funcionam são adotadas e assumem a forma de novos atratores: situações de estabilidade dinâmica sujeitas a novas mudanças à medida que o processo continua. Este processo é eficaz, na medida em que, para sobreviver, o sistema não precisa encontrar a melhor alternativa possível, mas sim, aquela que funciona (GIOVANNINI, 2002b). No contexto do desenvolvimento, isso explica a diversidade de localidades que convivem, sobrevivem e se desenvolvem, apresentando especificidades que nem sempre podem ser reaplicadas em outra situação/local. Assim, essa perspectiva pode auxiliar na gestão da complexidade envolvida na dinâmica do desenvolvimento local.

\subsection{COMPLEXIDADE E DESENVOLVIMENTO}

A mudança de paradigma refletida no surgimento de novas abordagens científicas é constantemente justificada pela necessidade de lidar com a complexidade e transdisciplinaridade dos problemas contemporâneos. "[...] Desde o começo do século XX os cientistas pressentiram a necessidade de procurar alternativas para o reducionismo, procurando novos pressupostos com base nos quais pudessem pensar" (BAUER, 1999, p. 44).

Kuhn (1996) consolidou o termo "paradigma" como realizações que possuem duas características essenciais: 1) seus feitos foram sem precedentes, atraindo um grupo duradouro de partidários, afastando-os de outras formas de atividade científica; e 2) suas realizações 
eram abertas para que esse grupo redefinido de praticantes da ciência pudesse resolver toda a espécie de problemas. Conforme Kuhn (1996), paradigmas são realizações científicas universalmente reconhecidas que, por determinado período, fornecem modelos para uma comunidade de praticantes da ciência. Ou seja, um paradigma envolve uma estrutura para a geração de teorias, envolve a aceitação e o comprometimento com tais estruturas, provendo modelos, padrões e exemplos (BAUER, 1999). Kuhn (1996) concebe um paradigma como uma premissa fundamental entre os pesquisadores que o compartilham, sendo um modelo ou padrão aceito.

$\mathrm{O}$ estudo dos paradigmas prepara o estudante para tornar-se pesquisador, garantindo que sua prática não confronte os pontos fundamentais estabelecidos (KUHN, 1996). Dessa forma, paradigmas compartilhados garantem regras e padrões para a prática científica, mantendo sua tradição. Ao longo do tempo, os paradigmas sofrem alterações ou são substituídos e, nesse sentido, Capra (2006) já alertava para o fato de estarmos vivendo uma mudança de paradigma. As transformações de paradigmas são revoluções científicas, e a transição sucessiva entre paradigmas, por meio da revolução, constitui o desenvolvimento da ciência amadurecida (KUHN, 1996).

De acordo com Morin (2010, p. 14), “os desenvolvimentos próprios de nosso século e de nossa era planetária nos confrontam, inevitavelmente e com mais e mais frequência, com os desafios da complexidade”. Nesse sentido, Vergara e Branco (1993, p. 21) alertam para a complexidade dos problemas e para a transdisciplinaridade a eles inerente, justificando a necessidade de transformação:

[...] os grandes problemas com os quais nos vemos envolvidos, que inadequadamente classificamos como sendo, exclusivamente, de natureza econômica, social ou política, demonstram ter em comum uma complexidade sem precedentes e o fato de fazerem parte de uma teia de relacionamentos interdependentes.

Capra (2006) enfatiza um sinal da crise em que a sociedade se encontra e, conforme Prigogine (1996, p. 193), “vivemos o fim das certezas". Toffler (1995) também analisa o ambiente confuso, com mudanças violentas, enfatizando a inter-relação entre os eventos ou tendências aparentemente desconexos; entretanto, o autor apresenta uma perspectiva menos negativa que a de Capra (2006, p. 22-23), para quem os indivíduos considerados especialistas em diversos campos já não estão capacitados para lidar com os problemas urgentes que acometem suas respectivas áreas de especialização:

[...] os economistas são incapazes de entender a inflação, os oncologistas estão totalmente confusos acerca das causas do câncer, os psiquiatras são mistificados pela esquizofrenia, a polícia vê-se impotente em face da criminalidade crescente, e a lista vai por aí afora. 
O problema fica explícito também no meio acadêmico, uma vez que a elite intelectual admite a inexistência de consenso, confirmando que a corrente principal das ideias se dividiu em diversas vertentes; assim, o verdadeiro problema consiste nas percepções estreitas da realidade pelos acadêmicos, inadequadas para enfrentar os principais problemas (CAPRA, 2006). Toffler (1995) também alerta para o choque entre as especialidades, com dados fragmentados e foco na análise micrométrica. Vários autores (CAPRA, 2006; CARDOSO JUNIOR; SIQUEIRA, 2011; DEMO, 2002; DOMINGUES; FERNÁNDEZ, 2011; MORIN, 2010) defendem a necessidade de se superar o conhecimento fragmentado pelas disciplinas, afirmando que a realidade é deturpada quando é reduzida ao olhar de apenas uma disciplina, sendo essa abordagem insuficiente para lidar com problemas complexos.

Na mesma direção, Morin (2011, p. 68-69) critica a visão "não complexa" das ciências humanas e sociais, que consideram as dimensões separadamente (econômica, social, política...):

[...] acredita-se que essas categorias criadas pelas universidades sejam realidades, mas esquece-se que no econômico, por exemplo, há as necessidades e os desejos humanos. Atrás do dinheiro, há todo um mundo de paixões, há a psicologia humana. Mesmo nos fenômenos econômicos stricto sensu atuam os fenômenos de multidão, os fenômenos ditos de pânico [...]. A dimensão econômica contém as outras dimensões e não se pode compreender nenhuma realidade de modo unidimensional.

Capra (2006) argumenta que os problemas não podem ser entendidos no âmbito da metodologia fragmentada característica de nossas disciplinas acadêmicas, uma vez que eles são sistêmicos, estão intimamente interligados e são interdependentes. Pádua (2008, p. 36-37) também enfatiza a complexidade dos problemas reais:

[...] cada vez mais, foi se compreendendo a complexidade multidimensional da realidade social, que é, ao mesmo tempo, individual e coletiva, local, nacional, multinacional e transnacional, em que convivem ordem/desordem/organização, determinismo e liberdade/criação, repetição e inovação, dependência e autonomia.

$\mathrm{O}$ enfrentamento de um ambiente globalizado e caracterizado pela interdependência entre os fenômenos ainda é um desafio, dado que a formação humana privilegia o pensamento reducionista e fragmentado (VERGARA; BRANCO, 1993). A abordagem reducionista, apesar de ser considerada por Bauer (1999) como o principal entre todos os paradigmas, é insuficiente para lidar com a totalidade dos problemas, atrofiando as possibilidades de compreensão e reflexão (MORIN, 2010). Axley e Macmahon (2006) defendem que o paradigma cartesiano-newtoniano possivelmente alcançou seus limites de efetividade diante da dinâmica e incerteza do mundo.

Donaires (2012) também defende que o modelo causal falha diante da complexidade, uma vez que, devido ao grande número de estados internos, as relações causais são tantas e 
tão intrincadas que sua abordagem leva ao colapso do processo de análise por excesso de detalhes. Assim, a concepção tradicional científica, baseada na causalidade e no determinismo, se mostra ineficaz diante de alguns dos novos desafios atuais, já que o reducionismo é inadequado em situações com grande complexidade (DONAIRES, 2012).

\footnotetext{
É preciso buscar formas alternativas de exploração da realidade que sejam menos reducionistas, mais holísticas, e que possibilitam driblar a complexidade para dar agilidade ao progresso do conhecimento, ao desenvolvimento das sociedades, à melhoria da eficiência das instituições públicas, e da competitividade das empresas (DONAIRES, 2012, p. 24).
}

Apresenta-se a necessidade de uma visão globalizante da realidade, em que as partes devem ser tratadas segundo os seus mútuos relacionamentos e o relacionamento com o todo (VERGARA; BRANCO, 1993). Morin defende que o indivíduo, a sociedade e a espécie são elementos indissociáveis que não podem ser tomados como absolutos independentemente, isto é, as interações entre os indivíduos permitem a organização da cultura ou a autoorganização da sociedade, ao mesmo tempo em que preservam a existência da diversidade humana dentro da espécie (PÁDUA, 2008). Segundo Morin (2010, p. 89), a reforma do pensamento deve gerar um pensamento do contexto e do complexo: "é preciso substituir um pensamento que isola e separa por um pensamento que distingue e une”. Tornou-se necessário encontrar maneiras de compreender e avaliar padrões crescentes de conflito, imprevisibilidade, fluxos, equilíbrio dinâmico, colapsos, descobertas e relações transnacionais (DENNIS, 2007). Nesse sentido, a Complexidade critica a divisão do conhecimento em disciplinas, pois em cada parte do todo, existe outra parte desconhecida (SERVA; DIAS; ALPERSTEDT, 2010). Para Bauer (1999), essa abordagem é um paradigma em ascensão, configurando uma mudança de paradigma, isto é, uma mudança de mentalidade (GOULIELMOS, 2005).

No contexto em que as tradicionais abordagens compartimentadas e estritamente disciplinares são insuficientes para a compreensão e o tratamento da complexidade de nosso tempo (CARDOSO JUNIOR; SIQUEIRA, 2011), o tema do desenvolvimento não é exceção, exigindo também novas abordagens. Conforme Cardoso Junior e Siqueira (2011), devido à heterogeneidade da realidade, o entendimento, a interpretação e as aplicações de conceitos referentes ao desenvolvimento não são tarefas simples.

O foco dado ao tema do desenvolvimento de localidades, regiões, países e do globo na área acadêmica e na agenda política e econômica global tem variado ao longo do tempo. $\mathrm{O}$ desenvolvimento local é um assunto controverso e pouco estudado no Brasil, assim como no debate internacional (MARTINS; CALDAS, 2009; MARTINS; VAZ; CALDAS, 2010). Martins, Vaz e Caldas (2010) afirmam que o desenvolvimento perdeu parte do vigor e de seu 
sentido vetorial devido ao excesso de adjetivos a ele atribuídos (local, sustentável, territorial, sustentado, integrado, democrático, participativo, entre outros). Entretanto, a relevância do estudo do assunto fica clara ao verificar as desigualdades gritantes encontradas em quase todos os países e regiões.

Sachs (2008) aponta a desigualdade presente globalmente, com a distribuição desequilibrada de riqueza entre minorias ricas e maiorias pobres. Nesse sentido, Rocha Neto e Borges (2011) criticam o desenvolvimento capitalista, uma vez que as iniciativas instituem-se em localidades já naturalmente "privilegiadas", ampliando ainda mais as desigualdades e desequilíbrios. De acordo com Sachs (2008), a ideia de desenvolvimento implica a expiação e a reparação de desigualdades passadas, trazendo a promessa de modernidade propiciada pela mudança estrutural.

Em um contexto em que a globalização gerou muitos benefícios, além de crescimento e desenvolvimento, essas vantagens permanecem restritas a poucas regiões do globo. A economia global, apesar de afetar indiretamente a vida de toda a humanidade, não é planetária, isto é, sua operação e estrutura reais se referem a segmentos de estruturas econômicas, países e regiões, variando conforme a posição do país ou região na divisão internacional do trabalho. Ou seja, a globalização segue um padrão seletivo (CASTELLS, 1999).

Dowbor, Ianni e Resende (2000) afirmam que a visão da globalização como abertura de fronteiras e geração de espaço mundial comum é simplificada. De acordo com Santos (2001), a globalização deve ser considerada a partir de dois processos: o de produção da materialidade que nos cerca e o da produção de novas relações sociais entre países, classes e pessoas. Já Magnoli (2003, p. 11) trabalha com um foco prioritariamente econômico da globalização, em que ela "é o processo pelo qual o espaço mundial adquire unidade", realizada pela intensificação e pelo aprofundamento dos fluxos econômicos; ou seja, "o comércio internacional, os investimentos de capitais no exterior e os fluxos de informações integram as economias e os mercados nacionais numa economia-mundo que abrange todo o planeta" (MAGNOLI, 2003, p. 23). No mesmo sentido, Santos (2001, p. 23) afirma que "a globalização é, de certa forma, o ápice do processo de internacionalização do mundo capitalista".

A definição de Singer (2000, p. 21) tem como foco as relações de trabalho: "a globalização é um processo de reorganização da divisão internacional do trabalho, acionado em parte pelas diferenças de produtividade e de custos de produção entre países". Albagli 
(1999, p. 185) a define como o "alongamento das relações entre o local/presente e o distante/ausente, por meio das redes, que estabelecem interações e conexões que perpassam o conjunto do planeta". Ultramari e Duarte (2009), por sua vez, entendem a globalização como a intensificação das relações e dependências em nível global. Robertson (1999) define a globalização como a compressão do mundo e a intensificação da consciência do mundo como um todo; sua concepção é mais ampla, com foco na crescente aceleração da interdependência global e da consciência da totalidade global. Assim, as definições mais amplas de Albagli (1999), Ultramari e Duarte (2009) e de Robertson (1999) atendem de maneira mais coerente a abordagem deste esforço de pesquisa, enfatizando as inter-relações e interdependências.

Apesar da criação de oportunidades, a globalização impulsionou desigualdades, gerando também empobrecimento, insegurança no trabalho, enfraquecimento de instituições, dos sistemas de apoio social e o desgaste das identidades e valores estabelecidos (STREETEN, 2001). De acordo com Santos (2001), os benefícios advindos da globalização não podem ser generalizados, uma parte minoritária da sociedade, os chamados "atores hegemônicos", é privilegiada pela utilização das novas técnicas avançadas, isto é, o sistema é efetivamente excludente em termos sociais, e assegura exclusividades. Por exemplo, a informação transmitida à maioria da humanidade é manipulada e, em lugar de esclarecer, confunde. E "é desse modo que a periferia do sistema capitalista acaba se tornando ainda mais periférica" (SANTOS, 2001, p. 39).

Birkner (2008) defende que a globalização provocou o empobrecimento das economias periféricas. Com a mesma postura, Stiglitz (2007) afirma que a globalização não é benéfica para os países pobres, sendo caracterizada por resultados desequilibrados, tanto entre países como dentro deles. Da mesma opinião, Sunkel (2001) exemplifica enfatizando a desigualdade ou polarização presente na América Latina em relação aos serviços sociais, em que uma minoria desfruta de condições de atenção social semelhantes às dos países industrializados, enquanto a maioria da população não tem acesso ou recebe cuidados mínimos e de ínfima qualidade. Isso ocorre quanto se trata de saúde, educação, produtividade, emprego e renda. "Os que possuem capacidade técnica e bens materiais beneficiam-se da abertura para a globalização; os outros são deixados para trás” (STREETEN, 2001, p. 78-79).

Segundo Santos (2001), a fome deixou de ser um fato isolado e passou a ser um dado generalizado e permanente atingindo 800 milhões de pessoas espalhadas por todos os continentes, sem exceção. Santos (2001) também alerta para o fato de que, apesar dos progressos da medicina, 14 milhões de pessoas morrem todos os dias, antes do quinto ano de vida. Dois bilhões de pessoas sobrevivem sem água potável, além do maior número de 
deslocados e refugiados da história e do desemprego, fenômeno tornado comum. A pobreza também aumenta e o analfabetismo continua sendo um problema (SANTOS, 2001). Tisch e Wallace (1994) enfatizam a disparidade presente no mundo, afirmando que a lacuna entre os ricos e os pobres é enorme e está aumentando. Segundo os mesmo autores, os níveis de saúde e educação também variam muito entre países.

Santos (2001) alerta para as "perversidades" da globalização, defendendo que existe uma "ideologização maciça" sustentando os benefícios aparentes dos processos de globalização, que acabam por ocultar a realidade negativa gerada pelos mesmos processos para a maior parte da humanidade. Assim, Santos (2001) enfatiza o desemprego crescente que se torna crônico, o aumento da pobreza, a redução da qualidade de vida das classes médias, a generalização da fome e do desabrigo, o surgimento de novas doenças e proliferação de outras, a manutenção da mortalidade infantil, a inacessibilidade à educação de qualidade e o alastramento e aprofundamento de "males espirituais e morais", como os egoísmos, cinismos e a corrupção. A responsabilidade por essa evolução negativa da humanidade pode ser atribuída à adesão desenfreada aos comportamentos competitivos (SANTOS, 2001).

Singer (2000) aponta o crescimento do desemprego no Brasil, defendendo que a globalização ocasiona desemprego estrutural nos países exportadores de capital e importadores de produtos industriais. Esse tipo de desemprego ocorre porque os trabalhadores que são vítimas da desindustrialização em geral não têm pronto acesso a novos postos de trabalho criados para suprir a exportação de capital, uma vez que estes vão sendo ocupados por mão-de-obra mais barata (feminina ou menos qualificada, muitas vezes em tempo parcial). Assim, o desemprego estrutural não aumenta necessariamente o número de pessoas sem trabalho, mas contribui para deteriorar o mercado de trabalho para quem vende sua capacidade de produzir (SINGER, 2000). De forma geral, é possível falar em precarização do trabalho, isto é, os postos de trabalho criados em função das transformações tecnológicas e da divisão internacional do trabalho não oferecem, em sua maioria, as compensações usualmente garantidas (SINGER, 2000).

O Brasil, que experimentou em passado recente um considerável crescimento econômico, também foi um dos países a apresentar maior distância entre o crescimento econômico e o desenvolvimento social, apresentando concentração de renda e desigualdade social (MARTINELLI; JOYAL, 2004). Veiga (2005a, p. 22) enfatiza a "brutal desigualdade de renda vigente no Brasil" e a necessidade de uma série de mudanças institucionais para a 
redução da mesma. Dowbor (1997) também enfatiza as desigualdades, a concentração de renda no Brasil e no mundo e a pobreza excessiva. Singer (2000, p. 84) afirma que

[...] o Brasil é a terra da desigualdade. Aqui o grau de disparidade entre ricos e pobres, brancos e não brancos, homem e mulher, moradores do campo e da cidade, indivíduos de alta e de baixa escolaridade é provavelmente maior que em qualquer outro lugar.

Dowbor (1997, p. 16) alerta para a necessidade de "um desenvolvimento socialmente justo, economicamente viável e ambientalmente sustentável”. Entretanto, a diferença de objetivos entre os atores desse processo dificulta esse resultado, já que o poder público executa políticas públicas, as organizações empresariais produzem, e as Organizações NãoGovernamentais (ONG) ou comunitárias batalham por questões ambientais (DOWBOR, 1997).

Nesse cenário, a fim de minimizar o efeito da concentração de renda e das desigualdades encontradas dentro e entre localidades e países, o principal objetivo das atuais políticas de desenvolvimento é a criação de condições endógenas de desenvolvimento (BIRKNER, 2008), isto é, a criação de condições para que o desenvolvimento seja baseado em capacidades próprias de cada região ou localidade, prezando sua autonomia e suas singularidades.

Assumindo a relevância do tema acerca do desenvolvimento, é crescente a atenção às abordagens em âmbito local. O "local", nesta pesquisa, é considerado a partir da formação socioterritorial, baseada na noção de identidade e pertencimento criada em dada localidade, definindo seus limites; isto é, o local não necessariamente se refere à noção de "pequeno", podendo ser formado por alguns bairros, um município ou um conjunto deles, formando uma região, dependendo da necessidade de análise.

De acordo com Ferreira et al. (2011, p. 520), “o argumento básico a favor do desenvolvimento local é que na esfera local os problemas são mais bem identificados e, portanto, torna-se mais fácil encontrar a solução mais adequada". Além disso, "uma vantagem muito significativa das políticas locais é o fato de poderem integrar os diferentes setores e articular os diversos atores" (DOWBOR, 2001, p. 217). Albuquerque (1998, p. 50) defende que "frente ao modelo de crescimento polarizado, hierarquizado e concentrador se destaca a necessidade do desenvolvimento territorialmente mais equilibrado, que impulsione a descentralização e potencialize as comunidades locais e regionais" a assumirem um papel decisivo no desenvolvimento. Além disso, o controle social nas mãos das classes dominantes leva à necessidade de um controle democrático exercido pelas comunidades locais e regionais e, em síntese, pela sociedade civil (ALBUQUERQUE, 1998). 
Martinelli e Joyal (2004) enfatizam a descida na escala espacial como princípio básico para a criação de uma iniciativa de desenvolvimento, dada a impossibilidade de se articular iniciativas eficazes em uma perspectiva nacional ou mesmo nas macrorregiões do país. "O local, enquanto espaço e território permeável à produção de experiências de resistência e/ou contra hegemônicas, caracteriza-se por produzir espaços nos quais predominam os princípios da igualdade, solidariedade e respeito à natureza" (MARTINS; CALDAS, 2009, p. 216). Assim, a valorização do local, pelo capitalismo, permite a participação social no desenvolvimento regional, garantindo adaptação às mudanças do ambiente (OLIVEIRA; WITTMANN, 2010). Segundo Martinelli e Joyal (2004), o enfoque local permite a criação de políticas mais realistas e baseadas em consenso devido à proximidade entre os atores sociais locais e problemas, necessidades e recursos.

Houve uma mudança nas dimensões, embora de modo desigual: "enquanto algumas coisas se globalizam, outras se tornam mais locais, com o renascer de tradições regionais, dinamização das políticas municipais, descentralização da educação e da saúde. As cidades adquiriram papel mais importante" (DOWBOR; IANNI; RESENDE, 2000, p. 7). O regionalismo volta a receber mais atenção, representando um diferencial competitivo frente à homogeneidade do mundo. A globalização reforça a importância do desenvolvimento local, já que cria a necessidade de formação de identidades e diferenciação entre regiões e comunidades, permitindo sua inserção em um contexto de alta competitividade (MARTINELLI; JOYAL, 2004). Além disso, esse contexto de competitividade e diferenciação pode levar ao foco exagerado em questões econômicas, gerando a necessidade de considerar preocupações com os aspectos sociais nas estratégias de desenvolvimento em nível local (MARTINELLI; JOYAL, 2004). Com as mudanças observadas no sentido de fragmentação territorial, devidas à globalização, as identidades culturais e políticas no nível regional e no local voltam ao foco, sendo pertinente desenvolver interesse por estratégias de desenvolvimento no âmbito local (MARTINELLI; JOYAL, 2004).

Entretanto, apesar da valorização do local, Miranda e Magalhães (2001) destacam que os temas e projetos locais devem considerar o debate e a pertinência da incidência sobre a ordem mais ampla da sociedade, do governo e da economia brasileira, considerando o contexto e as influências recíprocas.

Com o retorno das atenções ao âmbito local, há ainda questões sociais e estruturais que justificam a importância da abordagem nesse nível. Miranda e Magalhães (2001) apontam quatro justificativas para se recorrer ao desenvolvimento local no Brasil: 
- Desigualdade como fenômeno estrutural;

- Caráter fragmentado e descontinuado das iniciativas e políticas públicas;

- Desconsideração do espaço e da política nacional e sua influência sobre os projetos locais;

- Risco de criar sistemas "paralelos" ou "informais", como suposta forma de inclusão de questões outrora excluídas dos sistemas oficiais de geração e distribuição de renda e riqueza.

A desigualdade estrutural, a evolução do desenvolvimento no país (ou do não desenvolvimento) e suas causas fundadas na história de um indisciplinado poder minoritário que exerceu um patronato político são objeto de reflexão de autores como Faoro $(1975,1976)$ e Prado Júnior (2001). De acordo com Faoro (1976), o patronato não consiste na aristocracia, no estamento superior, mas sim no aparelhamento, no instrumento em que aquela se expande e se sustenta. Faoro (1975, p. 737) confirma a existência de um sistema de forças políticas "sobre a sociedade, acima das classes, o aparelhamento político [...] impera, rege e governa, em nome próprio, num círculo impermeável de comando" que não representa a nação. "A minoria governa sempre, em todos os tempos, em todos os sistemas políticos" (FAORO, 1975, p. 741).

Graziano da Silva $(1994,1996)$ também aborda o tema da desigualdade, embora ressalte o problema a partir da dimensão agrária e da agricultura. Miranda e Magalhães (2001) justificam a consideração da desigualdade como fenômeno estruturante da sociedade brasileira porque ela está presente e interfere desde no vocabulário usado até na forma como se atribui significado a ações cotidianas simples. Além disso, qualquer tentativa de implementação ou facilitação de processos em locais predominantemente habitados por populações em situação de pobreza enfrenta uma série de dificuldades inesperadas. Tais dificuldades decorrem da diferença de entendimento do que seja "participação" ou "desenvolvimento" e também da diferença extrema de acesso a condições básicas de vida (MIRANDA; MAGALHÃES, 2001).

Apesar das camadas mais pobres da população serem "tolerantes" com a iniquidade, elas possuem a percepção da injustiça da ordem econômica e social do país, além de desconfiarem do sentido, da continuidade e do compromisso das iniciativas governamentais. Por isso, a reação geral a muitas iniciativas de desenvolvimento é permeada por uma atitude hostil. Essa desconfiança se justifica pela não inclusão de uma opção política que envolvesse as elites e os governantes em um compromisso massivo com a população nos processos de 
estabilização econômica, de desenvolvimento ou de crescimento econômico (MIRANDA; MAGALHÃES, 2001).

Assim, segundo Miranda e Magalhães (2001), os projetos de desenvolvimento local enfrentam o desafio de construir elos entre sua ação local e concepções que orientem intervenções mais amplas, com o objetivo de enfrentar a desigualdade e obter a participação das populações pobres. Contribuindo para a desconfiança está o elitismo da formação acadêmica e técnica, que ignora outras formas de saber e conhecimento; ou seja, as tentativas de combate à pobreza, por exemplo, são baseadas em conhecimento teórico das elites do país em vez de considerarem a participação política das camadas diretamente envolvidas no cotidiano da pobreza (MIRANDA; MAGALHÃES, 2001).

Os projetos de desenvolvimento local constituem alternativas de inserção do "local" na economia e, consequentemente, na ordem "global". Entretanto, o estado nacional deve ser conhecido para estabelecer essa ligação, uma vez que as políticas de combate à pobreza estão vinculadas a políticas macroeconômicas. Portanto, os projetos e iniciativas em âmbito local não podem desconsiderar questões referentes às opções de política e economia do país; há que se "consolidar vínculos políticos e econômicos, fortalecendo sujeitos políticos capazes de disputar recursos, discursos e concepções” (MIRANDA; MAGALHÃES, 2001, p. 111). Ademais, é necessário um ambiente público mais politizado, com possibilidade de acompanhamento e controle das iniciativas por parte da sociedade. Consequentemente, a ação política da sociedade pode garantir que a ação dos governos não seja descontinuada e espasmódica, e que haja articulação entre os diferentes órgãos governamentais.

Miranda e Magalhães (2001, p. 112) apontam que "as formas tradicionais e oficiais de estimular o desenvolvimento não foram planejadas nem desenhadas para atingir parcelas mais pobres da população", gerando a necessidade de uma atuação pública inovadora que evite a criação de sistemas "paralelos" de atendimento às necessidades de crédito, de capacitação ou de comercialização das camadas populares. Segundo Furtado (1974), a política de desenvolvimento voltada à satisfação dos altos níveis de consumo de uma minoria privilegiada da população, tal como a brasileira, tende a agravar as desigualdades sociais e a elevar o custo social de um sistema econômico. O mercado produz exclusões, com uma liberdade seletiva, implicando a sua inevitável transformação e também da ordem global a fim de estabelecer um mundo com riquezas mais compartilhadas e garantir a entrada dos excluídos. Logo, as iniciativas de desenvolvimento local não podem ser instrumentos de simples apaziguamento dos pobres, mantendo-os em sistemas alternativos ou paralelos; mas 
sim permitirem a articulação política mais ampla, impactando e redesenhando as políticas públicas (MIRANDA; MAGALHÃES, 2001).

Mesmo em âmbito local, a complexidade tem sido apontada como inerente aos processos de desenvolvimento. Sachs (2008, p. 25) enfatiza a multidimensionalidade e complexidade do desenvolvimento que, por isso, não pode ser "encapsulado em fórmulas simples". Segundo Canever et al. (2010), o desenvolvimento é um fenômeno complexo, difícil de mensurar e cujo conceito pode variar de significado de acordo com a base teórica em consideração, assunto a ser explorado adiante neste trabalho. A complexidade das relações entre as diferentes localidades tem sido ampliada devido à globalização do mundo através dos sistemas de comunicação e transporte, que as têm aproximado, facilitando as ligações em rede por meio da maior disponibilidade de informações (MORAES, 2010). Segundo Albuquerque (1998), a dinâmica do mundo real é heterogênea, em oposição à hegemonia das frações globalizadas do capital, gerando a necessidade de adotar estratégias de desenvolvimento que considerem tal complexidade no processo de acumulação de capital nos âmbitos local e regional.

Para Martins, Vaz e Caldas (2010), a compreensão das dinâmicas locais demanda a contextualização do local e de seu relacionamento com outras instâncias (regional, nacional e internacional), o que não se configura como trabalho trivial por envolver articulações complexas. Uma forma de encarar essa complexidade é pela articulação simultânea entre instrumentos e atores, por meio de estratégias situacionais de desenvolvimento local, singular no tempo e no espaço, ressaltando o caráter multidimensional e multiescalar desses processos (MARTINS; VAZ; CALDAS, 2010). O ritmo de mudança contemporâneo é mais rápido e as mudanças são mais amplas, envolvendo o globo inteiro (CAPRA, 2006). Soto (2010) reafirma a natureza complexa da dinâmica do desenvolvimento capitalista, que exige uma análise pluralista, interdisciplinar e dialética.

Becker (2010a, p. 68) alerta para a complexidade proveniente dos determinantes e desafios das dinâmicas de desenvolvimento regional, defendendo que "a complexidade decorrente da multiplicidade de determinantes e desafios contemporâneos do desenvolvimento regional esbarra, frontalmente, com a crescente especialização da análise disciplinar". Diante das abordagens reducionistas utilizadas para análise, a compreensão das dinâmicas de desenvolvimento torna-se inatingível.

Nesse contexto, o equilíbrio entre as demandas e tendências globais com as potencialidades regionais é o grande desafio contemporâneo dos agentes dos processos de desenvolvimento; e a falta de uma abordagem sistêmica de gestão, integrando os diferentes 
interesses das partes envolvidas é um dos fatores a inibir a sinergia nos processos econômicos e organizacionais de desenvolvimento regional (OLIVEIRA; WITTMANN, 2010).

As ações humanas e organizacionais provocam significativas transformações no ambiente, centro de atenção no discurso global contemporâneo devido ao aquecimento global e suas consequências (TERRA, 2010). Uma vez que o ambiente é resultante de interações, percebe-se uma crise de relevância acerca do conhecimento sobre os processos de desenvolvimento, que não contempla os pressupostos capazes de levar os seus atores a perceberem a real sistemicidade envolvida.

Diversos autores (BECKER, 2010a; CANEVER et al., 2010; CAPRA, 2006; MARTINS; VAZ; CALDAS, 2010; MORAES, 2010; OLIVEIRA; WITTMANN, 2010; SOTARAUTA, 2009; SOTO, 2010) têm reconhecido as restrições da abordagem tradicional cartesiana para tratamento dos aspectos do desenvolvimento. A realidade enfrentada pelos atores do desenvolvimento, mutável e imprevisível, porém frequentemente mantida em estabilidade dinâmica parece alinhar-se com essa interpretação. $\mathrm{O}$ foco das atenções para a Complexidade nas ciências sociais foi direcionado, em parte, pela globalização e pela crescente percepção de que os relacionamentos sociais não-lineares em rede caracterizam boa parte do mundo contemporâneo; a Complexidade, por sua vez, oferece ferramentas para compreender esse ambiente (BOUSQUET; CURTIS, 2011).

Então, faz sentido procurar na teoria da complexidade algumas respostas para os problemas de compreensão e descrição dos sistemas do desenvolvimento. A proposta deste estudo envolve o tratamento do desenvolvimento a partir de uma visão transdisciplinar, que atravesse as disciplinas, ou que, ao menos, ocupe suas zonas obscuras (SIQUEIRA, 2011), sob o paradigma da Complexidade.

Segundo Terra (2010), em uma rede interligada, como nossa sociedade, as abordagens estruturadas de forma fragmentada e baseadas na linearidade não contemplam os impactos transformadores das ações dos agentes sobre o próprio ambiente que os cercam. Thiollent (1983) destaca que todo pesquisador deve ser responsável por uma reflexão metodológica e epistemológica, considerando a base teórica e social a ser tratada diante da tecnologia que se propõem a desenvolver. Por esse motivo, este esforço de pesquisa busca uma abordagem que permita lidar com o fenômeno do desenvolvimento local considerando sua multiplicidade de variáveis, processos e dinâmicas. 
Permitindo uma melhor compreensão do contexto, a teoria da complexidade fornece conceitos que podem auxiliar na gestão e na tomada de decisões em diferentes áreas. Ela não somente implica que os processos globais sejam sustentados por interconexões múltiplas, mas também que os eventos, tanto locais quanto globais, não existam de maneira isolada, mas produzam efeitos por meio de inter-relacionamentos não-lineares (DENNIS, 2007). Wittmann e Maehler (2008, p. 36) enfatizam o impacto da abordagem da Complexidade para os gestores públicos e privados, uma vez que

[...] a concepção da teoria da complexidade visa a dar subsídios aos administradores e planejadores públicos para tomarem suas decisões, considerando as múltiplas variáveis interligadas, em que não há uma única causa específica e, muitas vezes, o próprio sistema, internamente, causa desequilíbrio e caos na busca de novos patamares de sustentabilidade e equilíbrio.

No contexto do desenvolvimento, observam-se a dinâmica do mercado, o aumento das relações entre diferentes localidades com envolvimento de maiores redes de relacionamento e diferentes interesses, além da competição global, a conectividade e a comunicação instantânea, políticas e negociações globais. Então é possível dizer que a Complexidade talvez possa ser uma forma mais adequada para permitir uma leitura mais próxima do real da dinâmica do desenvolvimento elucidando relações que, até então, outras teorias não explicaram.

Giovannini (2002a) explicita algumas das principais críticas realizadas à teoria de sistemas, mostrando a adequabilidade dos conceitos da Complexidade para responder a elas. Motta e Vasconcelos (2008), por exemplo, criticam a análise de organizações a partir de instrumentos das ciências naturais (da biologia, mais especificamente), afirmando que o teórico passa a acreditar que seu objeto de estudo, de natureza social, tende a tornar-se tão previsível quanto os sistemas biológicos. Diante disso, Giovannini (2002a, p. 62) defende a explicação encontrada na teoria da complexidade:

[...] a Complexidade mostrou que sistemas biológicos e físicos são, em sua maioria, imprevisíveis após certo número de ciclos, e que essa imprevisibilidade, entretanto, pode ser tratada com rigor científico e utilizada para o entendimento desses sistemas. Atualmente, a teoria da complexidade tem inúmeras aplicações práticas, não somente em experimentos controlados. Não há razões para excluir, a priori, a possibilidade de importar esses instrumentos das ciências naturais para estudar as organizações. Não se trata de eliminar a incerteza, mas de entendê-la.

"O que a ciência contemporânea vem comprovando pelas teorias do Caos e da Complexidade é que tanto o equilíbrio quanto a proporcionalidade entre causas e efeitos são antes exceção do que regra" (CASSANEGO JUNIOR, 2008, p. 90). Assim como a incerteza, a estabilidade dinâmica também é característica inerente do sistema. "Fica, dessa forma, reforçada a necessidade de compreender a dinâmica dos sistemas antes de atuar sobre eles, em 
especial antes de dedicar recursos para proteger o sistema dos ruídos externos" (GIOVANNINI, 2002a, p. 64). De acordo com Costa, Wittmann e Grzybovski (2008, p. 78),

[...] afirma-se que as sociedades humanas são sistemas (sociais) que, por serem complexos e profundamente subjetivos (próprios do ser humano), organizam-se a partir da desordem. No entanto, a desordem também tem uma ordem intrínseca, existindo um equilíbrio ordem/desordem/interação/organização.

Segundo Giovannini (2002a), a abordagem sistêmica permitiu a elaboração de modelos das organizações que podem representar as inter-relações e o todo à medida que o tempo passa, visualizando-as como entidades dinâmicas, compostas por elementos dinâmicos (as pessoas). A teoria de sistemas aplicada a organizações foi utilizada no sentido de criação de uma base conceitual para sua análise e a criação de modelos; entretanto, mesmo os modelos mais simples apresentam interações não-lineares, dificultando a predição de comportamentos e a proposição de intervenções em busca de resultados (GIOVANNINI, 2002a). "O comportamento complexo e caótico é inerente a determinados tipos de sistemas, muito comuns na natureza", como os ambientes em que as organizações estão inseridas, em busca do desenvolvimento (GIOVANNINI, 2002a, p. 61).

Para Giovannini (2002a), devido ao princípio de incerteza intrínseco aos sistemas dinâmicos não-lineares, as organizações podem ser estudadas a partir dos conceitos da Complexidade. Seguindo essa lógica, é possível afirmar que estudar o desenvolvimento local (considerado a partir da rede de inter-relações entre suas partes, vistas como formas organizacionais) a partir da Complexidade é coerente:

o princípio da incerteza da ciência da Complexidade tem a vantagem [...] de estar inserido em um quadro conceitual que permite entender e tratar a incerteza de forma objetiva e racional e, portanto, melhorar a capacidade de compreensão e atuação sobre os sistemas organizacionais (GIOVANNINI, 2002a, p. 60).

Entretanto, a ideia de que a incerteza e a instabilidade têm origem na grande quantidade de variáveis que as afetam configura uma barreira para o estudo desses sistemas a partir dos conceitos da Complexidade (GIOVANNINI, 2002a). Os efeitos da não-linearidade são encobertos pelas influências do ambiente externo, sendo tentador utilizar tal explicação para os efeitos.

Assim como as decisões acerca das organizações e as iniciativas de desenvolvimento local, Morin (2011, p. 13) argumenta que a estratégia política deve ser baseada na Complexidade: "a estratégia política requer o conhecimento complexo, porque ela se constrói na ação com e contra o incerto, o acaso, o jogo múltiplo das interações e retroações". No entanto, Giovannini (2002a) afirma que a Complexidade não é prescritiva, mas sim descritiva e explicativa, já que ela consiste em um conjunto de ideias que ainda não são completamente 
coerentes e estruturadas (MURRAY, 1998). Portanto, espera-se que a Complexidade possa prover, até este ponto, somente uma abordagem para a compreensão dos fenômenos complexos em termos gerais ao invés de uma prescrição detalhada (MURRAY, 1998).

Diante do exposto e do ambiente de complicações, incerteza e não-linearidade, utilizar os paradigmas emergentes como base para os estudos dos fenômenos, buscando sua compreensão, parece adequado. Entre as razões pelas quais se busca descrever e entender a complexidade tão precisamente e tão bem quanto possível está o desejo de reduzir e o de aumentar a complexidade. Isto é, busca-se construir níveis mais altos de complexidade porque eles são meios mais eficientes de ação e, ao mesmo tempo, busca-se reduzi-la com o objetivo de minimizar efeitos indesejados e ser capaz de lidar com os crescentes níveis de complexidade (NOWOTNY, 2005). Logo, é possível que o paradigma da Complexidade configure uma alternativa coerente para entender a incerteza de tal dinâmica e descrevê-la. 


\section{DESENVOLVIMENTO}

\subsection{HISTÓRICO}

De acordo com Siedenberg (2010), é basicamente a partir da II Guerra Mundial, quando os países mais pobres passam a buscar alcançar o nível de vida similar ao dos países mais ricos e ditos desenvolvidos, que a implementação de políticas e estratégias de desenvolvimento, assim como as discussões teóricas a respeito do desenvolvimento socioeconômico de países e regiões destacaram-se na academia, nos meios políticos e na mídia. Segundo o autor, apesar de existirem contribuições teóricas importantes surgidas antes de 1950, é a partir dessa década que o termo desenvolvimento ocupa lugar de destaque nas ciências sociais aplicadas. Sachs (2008) afirma que a reflexão sobre o desenvolvimento começou na década de 1940 no contexto da preparação dos anteprojetos para a reconstrução da periferia devastada da Europa no pós-guerra. Para Navarro (2001), a noção de "desenvolvimento" alcançou singularidade histórica em dois momentos: o primeiro foi a partir da década de 1950, estendendo-se até o final dos anos 1970; e o segundo ocorreu a partir de meados da década de 1990, incitado por uma percepção acerca da aparente impossibilidade do desenvolvimento, ou pelo menos, suas dificuldades de materialização.

Apesar das diferenças de opinião acerca do período em que as discussões sobre o desenvolvimento alcançaram destaque, existe certo consenso de que o avanço do processo de globalização contribuiu para o aumento do interesse pela temática regional e local, com debates e disputas sociais agora em escala global (ALBUQUERQUE, 1998; NAVARRO, 2001; ULTRAMARI; DUARTE, 2009; WITTMANN; RAMOS, 2004). Com a intensificação da concorrência, houve preocupação em determinar os motivos de vantagens competitivas das organizações empresariais. Dessa forma, estudos das décadas de 1980 e 1990 evidenciaram a influência de fatores de abrangência local ou regional nesse contexto (WITTMANN; DOTTO; BOFF, 2004). Conforme Moraes (2010), é a partir do início dos anos 80 que o debate sobre a possibilidade de gestão local do desenvolvimento se intensificou na Europa, nos Estados Unidos e na América Latina.

No Brasil, segundo Ultramari e Duarte (2009), foi nos anos 1990 que surgiu uma preocupação com a pequena escala, diferente dos planos econômicos nacionais, marcantes até 
os anos 1970. Birkner (2008) confirma a multiplicação do número de experiências e políticas públicas voltadas à promoção do desenvolvimento local-regional desde a década de 1990 no Brasil. Entretanto, para alguns autores (FONSECA et al., 2007; FRANÇA; CALDAS, VAZ, 2004; MARTINS; CALDAS, 2009; MARTINS; VAZ; CALDAS, 2010) a valorização do local como instância privilegiada para planejar e executar políticas públicas governamentais remonta aos anos 70 no Brasil. Nessa época, no âmbito local, tratava-se de experiências buscando a descentralização da gestão e a democratização das relações do Estado com a sociedade (FRANÇA; CALDAS, VAZ, 2004; MARTINS; CALDAS, 2009). Essa mudança também resulta de transformações macroeconômicas internacionais e do enfraquecimento do papel do Estado como único responsável por políticas econômicas, cujos efeitos foram sentidos nas economias locais e regionais (ULTRAMARI; DUARTE, 2009).

Albuquerque (1998) afirma que, a partir dos anos 1970 e 1980, houve um maior interesse sobre as iniciativas de desenvolvimento econômico local fomentado pela crise do modelo fordista. O processo de mudança dos modelos econômicos e sociais enfatizou a discussão do local como cenário econômico, político e social, exigindo um redirecionamento integrado das políticas públicas (ALBUQUERQUE, 1998). Assim, um maior conhecimento sobre processos de desenvolvimento local realçou aspectos qualitativos, territoriais e ambientais, enfatizando as possibilidades e iniciativas de desenvolvimento econômico endógeno (MARTINELLI; JOYAL, 2004). Martinelli e Joyal (2004, p. 10-11) explicam o conceito de desenvolvimento endógeno como um "processo interno de ampliação contínua de agregação de valor na produção, bem como da capacidade de absorção da região", sendo um modelo estruturado a partir dos próprios atores locais, e não mais pelo planejamento centralizado, isto é, trata-se de um desenvolvimento realizado de baixo para cima, partindo das potencialidades socioeconômicas originais do próprio local.

\footnotetext{
A literatura passou a enfatizar a importância da dinâmica endógena das regiões inclusive em termos políticos e sociais - como elemento determinante da competitividade das empresas nelas localizadas. $\mathrm{O}$ novo enfoque atribui peso importante às instituições formais e informais, às características culturais e à composição das redes sociais e econômicas das regiões (WITTMANN; DOTTO; BOFF, 2004, p. 7).
}

De acordo com Dallabrida e Becker (2010), a partir dos anos 1980 e 1990 a região foi destacada como objeto de investigação das ciências sociais, retomando o interesse sobre questões territoriais. A região passou a ser vista a partir de seus potenciais específicos, ou seja, suas regras, hábitos e convenções informais que contribuem para a regulação da atividade econômica, denominando os "meios inovadores" (DALLABRIDA; BECKER, 2010). Na década de 1990, as intervenções relacionadas ao desenvolvimento regional recebem 
uma conotação mais setorial, dificultando o ordenamento do território (ROCHA NETO; BORGES, 2011). Martinelli e Joyal (2004), embora não definam uma data específica, afirmam que o debate sobre desenvolvimento local tomou corpo no Brasil há apenas alguns anos.

Assim, o desenvolvimento local e regional passou a receber atenção internacionalmente a partir da década de 1950, recebendo maior ênfase durante as décadas de 1980 e 1990. Da mesma forma, a falta de consenso a respeito do período em que os âmbitos local e regional foram enfatizados nas discussões sobre desenvolvimento no Brasil é clara. Entretanto, a maioria das opiniões estudadas pertence ao intervalo de tempo entre a década de 1970 e a de 1990 para que o desenvolvimento local e regional tome lugar de destaque no meio acadêmico e prático.

Siedenberg (2010) lista os diferentes enfoques a que o conceito de desenvolvimento já se adaptou, sendo acrescido de diferentes adjetivos. De acordo com Sachs (2008), a ideia de desenvolvimento evoluiu, tornando-se mais complexa, o que é representado pela adição de sucessivos adjetivos, tais como econômico, social, político, cultural, sustentável, e pelas novas problemáticas. A partir de meados da década de 70, o substantivo "desenvolvimento" passou a ser associado com mais frequência a adjetivos como humano, social e sustentável, e com o radical "eco", voltando a ocupar lugar de destaque nas políticas públicas, na academia, na mídia, em projetos de preservação ambiental e junto a grupos e organizações sociais (SIEDENBERG, 2010).

Após 1950 o termo desenvolvimento já esteve associado a diversas concepções, que vão desde o mero crescimento econômico ou da dissociação ao ecodesenvolvimento e desenvolvimento sustentável, até a discussão sobre a 'governança global', entre outras (SIEDENBERG, 2010). O quadro 3 sintetiza as principais concepções e estratégias de desenvolvimento hegemônicas durante determinados períodos tanto na aplicação de planos quanto na reflexão teórica global, configurando "os principais paradigmas ou ideias predominantes de desenvolvimento após 1950" (SIEDENBERG, 2010, p. 162).

De acordo com Almeida Filho (2011), a Economia do Desenvolvimento, como disciplina, surge no período do pós-guerra, sendo parte do esforço internacional liderado pelos Estados Unidos de consolidar o desenvolvimento capitalista como hegemônico e pretensamente vantajoso para as economias ditas subdesenvolvidas. Nesse contexto, as diferenças entre os países pobres e os países ricos eram enfatizadas por desigualdades que geraram uma preocupação claramente econômica. A modernização por industrialização 
(também chamada de desenvolvimento tardio) foi implementada por muitos países no pósguerra, ou seja, a partir de 1950 (com ênfase para os latino-americanos), no contexto da nova ordem mundial. Ela pode ser subdividida em três grandes estratégias básicas: a) a política de substituição das importações, que tem como pano de fundo a crise de abastecimento decorrente do pós-guerra e, como objetivo, a modernização do mercado interno; b) o fomento à exportação, que tem como pano de fundo a nova divisão internacional do trabalho e, como objetivo, o aproveitamento das vantagens comparativas, e c) o fomento de pólos de desenvolvimento setoriais, ou regionais (SIEDENBERG, 2010). Desde o final da Segunda Guerra Mundial até aproximadamente o começo dos anos de 1970, a palavra "desenvolvimento" se confundia com o conceito de "crescimento econômico", pois era entendido, fundamentalmente, como o processo pelo qual o sistema econômico criava e incorporava progresso técnico e ganhos de produtividade ao nível, sobretudo, das firmas (CARDOSO JUNIOR, 2011).

\begin{tabular}{|l|l|l|l|}
\hline \multicolumn{1}{|c|}{ Estratégia básica } & \multicolumn{1}{|c|}{ Período } & \multicolumn{1}{c|}{ Principais elementos } & \multicolumn{1}{c|}{ Dimensão enfatizada } \\
\hline Modernização & Década de 50 & $\begin{array}{l}\text { Industrialização, substituição das } \\
\text { importações e fomento das } \\
\text { exportações, revolução verde }\end{array}$ & $\begin{array}{l}\text { Setorial, econômica, } \\
\text { orientada para o } \\
\text { crescimento }\end{array}$ \\
\hline Dissociação & Década de 60 & $\begin{array}{l}\text { Desenvolvimento do mercado } \\
\text { interno, self reliance }\end{array}$ & Política \\
\hline $\begin{array}{l}\text { Equacionamento das } \\
\text { necessidades básicas }\end{array}$ & Década de 70 & $\begin{array}{l}\text { Orientação para a miséria e } \\
\text { grupos marginalizados } \\
\text { específicos, participação }\end{array}$ & Regional e social \\
\hline $\begin{array}{l}\text { Ajuste estrutural } \\
\text { Desenvolvimento } \\
\text { sustentável }\end{array}$ & Década de 90 & $\begin{array}{l}\text { Desregulamentação, } \\
\text { flexibilização, equacionamento } \\
\text { da dívida, balanço e inflação } \\
\text { internos }\end{array}$ & Econômica \\
\hline Governança global & Fim dos anos 90 & $\begin{array}{l}\text { Desenvolvimento } \\
\text { socioeconômico participativo e } \\
\text { dos recursos naturais }\end{array}$ & $\begin{array}{l}\text { Regional, ambiental e } \\
\text { global, Conferências Mundiais }\end{array}$ \\
\hline
\end{tabular}

Quadro 3 - Síntese dos principais paradigmas do desenvolvimento após 1950 Fonte: Adaptado de Coy (1998 ${ }^{2}$ apud SIEDENBERG, 2010, p. 162).

Esse modelo fortemente influenciado pelo pensamento anglo-saxão era fundamentalmente baseado no conceito de crescimento (ALMEIDA FILHO, 2011), como defendido por Rostow (1974), por exemplo, que trata o desenvolvimento como sinônimo de industrialização e crescimento econômico. A despeito de diferenças pontuais, esse esforço

${ }^{2}$ COY, M. Materialien zur geographie der entwicklungsländer. Geographisches institute der eberhartd KarlsUniversität Tübingen, 1998. [Manuscrito]. 
teórico buscou superar o subdesenvolvimento pela aceleração das transformações da economia em direção a um modelo de economia desenvolvida, tomando como modelo a americana (ALMEIDA FILHO, 2011). Conforme Rostow (1974), as condições para esse crescimento, de forma geral, foram resultantes de uma intromissão externa por sociedades mais adiantadas, ao invés de surgidas endogenamente.

Apesar dos avanços, sobretudo de crescimento econômico, gerados pela modernização por industrialização, surgiram críticas e controvérsias. Mesmo buscando oferecer propostas condizentes com as especificidades de cada formação social, todas as correntes buscavam a superação do subdesenvolvimento pela industrialização, tomando como base a experiência das nações capitalistas pioneiras (ALMEIDA FILHO, 2011). Devido à insuficiência constatada dos projetos de industrialização frente à inclusão social, à pobreza estrutural e às desigualdades, buscou-se a diferenciação entre crescimento e desenvolvimento, incorporando qualificativos com o objetivo de preencher as lacunas do conceito (CARDOSO JUNIOR, 2011).

De forma geral, a Comissão Econômica para a América Latina e o Caribe ou Comissão Económica para a América Latina e Caraíbas (Cepal) serviu aos propósitos de difusão da teoria do desenvolvimento, pois ela postulava que a industrialização era o principal caminho para superação do subdesenvolvimento dos países da América Latina; entretanto, seus debates são marcados pela contestação da divisão internacional do trabalho (ALMEIDA FILHO, 2011). Assim, essa concepção de desenvolvimento foi substituída, com maior ou menor ênfase, em alguns países (China, Cuba, Egito, Peru e Chile, entre outros), por outra estratégia: de desenvolvimento endógeno ou da dissociação como tentativa de isolamento dos efeitos dinâmicos do desenvolvimento global e desigual, fomentando o mercado interno e subsidiando o aumento da produção agrícola (SIEDENBERG, 2010).

É comum registrar-se o declínio da Economia do Desenvolvimento nos anos 1970 (ALMEIDA FILHO, 2011). As estratégias de crescimento implementadas pela modernização via industrialização tardia contribuíram para o aumento das disparidades regionais internas, gerando insatisfação social. Havia a crença generalizada do desenvolvimento econômico (capitalista) como panaceia para os problemas da sociedade. A ligação com o contexto da Guerra Fria é direta à medida que essa ideologia garantia a manutenção da ordem sistêmica, constituindo uma resposta às promessas geradas do outro lado da "cortina de ferro" (ALMEIDA FILHO, 2011). 
Entretanto, nos anos 1960 ficou claro que, apesar do crescimento econômico percebido, ele não era distribuído. Isso ficou evidente quando o vigor do crescimento começou a se esgotar em meados dos anos 1960. Nos anos 1970 foi estabelecida a crise da estagflação, combinando baixas taxas de crescimento com altas taxas de inflação (ALMEIDA FILHO, 2011).

As desigualdades sociais ficaram ainda mais evidentes, sem que as diferenças de desenvolvimento entre os países tivessem sido diminuídas (ALMEIDA FILHO, 2011). Portanto, o foco nas necessidades básicas (necessidades essenciais para uma vida saudável) emergiu durante a década de 1970 seguindo a tomada de consciência de que o desenvolvimento burocraticamente implementado não resultaria em benefícios para a maioria da população que de fato precisa de melhorias na qualidade de vida (TISCH; WALLACE, 1994). Nesse contexto, o conceito de desenvolvimento foi atualizado para incluir a busca do atendimento das necessidades básicas das pessoas e da redução das disparidades entre países e regiões, dando espaço para políticas de erradicação da miséria, de priorização de enfoques regionais (em detrimento dos setoriais), de participação dos envolvidos e de adoção de estratégias tipo bottom-up (de baixo para cima), em substituição às medidas do tipo top-down (de cima para baixo), caracterizando as chamadas estratégias de equacionamento das necessidades básicas (SIEDENBERG, 2010). Uma abordagem de baixo para cima (desenvolvimento participativo que envolve os beneficiários no projeto e na implementação das atividades) foi defendida, focando o auxílio em garantir aos indivíduos as necessidades básicas de alimentação, água limpa, vestimenta, abrigo, educação básica e acesso a tratamento de saúde (TISCH; WALLACE, 1994).

Nenhum desses três paradigmas conseguiu consolidar-se com resultados plenamente satisfatórios. Devido à crise de endividamento público da década de 80 as políticas de desenvolvimento tiveram que ser reorientadas: buscou-se o ajuste financeiro por meio da desestatização (privatizações) e de outras medidas, como a abertura gradual da economia, a liberalização de mercados, os cortes nos subsídios públicos e o consequente aumento dos custos sociais. Assim, na década de 80, prevaleceram as estratégias de ajuste estrutural, cuja prioridade era o ajuste das finanças públicas e o controle de índices de inflação (SIEDENBERG, 2010). Os programas de ajuste estrutural têm foco nas políticas (política de preços de alimentos, de crédito, regulamentações de importação e exportação, política de investimentos, educação, saúde). Tais programas foram criados pelo Fundo Monetário Internacional (FMI) e pelo Banco Mundial durante a década de 1980 em resposta à crise nos países em desenvolvimento. A magnitude das dificuldades enfrentadas por tais países devido 
ao aumento no preço do petróleo dos anos 1970 demandou uma reação mais coerente e compreensiva das principais instituições financeiras internacionais (TISCH; WALLACE, 1994).

A estratégia de ajuste estrutural abrange políticas macro e microeconômicas, baseada na crença de que a falta de atenção às políticas tem dificultado os esforços de desenvolvimento. Seus principais objetivos consistem na melhoria do ambiente de políticas macroeconômicas para atrair investimentos, estimular o mercado e os incentivos individuais. Tal estratégia presume um nível de relações setoriais internas e coesão entre as economias nacionais afetadas; entretanto, tais relações raramente existem nos países realmente pobres (TISCH; WALLACE, 1994).

Então, as ideias neoliberais ganham espaço, sendo que a década de 1980 foi caracterizada pela disseminação do neoliberalismo para grande parte dos países capitalistas avançados. A derrubada do Muro de Berlim em 1989 foi um marco histórico, como se o mundo aceitasse o capitalismo. Assim, consolida-se um novo ciclo de expansão do capitalismo de alcance mundial, chamado de globalização (ALMEIDA FILHO, 2011).

A globalização traria consigo o declínio do Estado-nação (OHMAE, 1996), a intensificação do papel e do poder dos organismos multilaterais ao ditar a agenda global e a consolidação de blocos regionais. Esses fenômenos acabam por obscurecer a existência de diferenças e hierarquias globais (ALMEIDA FILHO, 2011). Dessa forma, o foco muda para temáticas de âmbito global. Antes as preocupações estavam voltadas para a desigualdade entre os países. A partir desse momento, as atenções se voltam para outras formas de desigualdade (individual e espacial). Além disso, os debates sobre meio ambiente ganham espaço (ALMEIDA FILHO, 2011).

Conforme Siedenberg (2010), com o ajuste realizado surgiu espaço para um novo paradigma: devido aos indicadores de poluição crescente e à devastação ambiental desenfreada, o foco da sociedade global recaiu sobre a ideia do desenvolvimento sustentável. O mesmo, entendido como aquele que busca garantir que a capacidade local possa continuar com os esforços de desenvolvimento, emergiu do aumento da consciência ambiental (TISCH; WALLACE, 1994). A ideia se consolidou definitivamente, como compromisso coletivo, na II Conferência Mundial do Meio Ambiente e Desenvolvimento (também conhecida como ECO92), no Rio de Janeiro, em 1992 (SIEDENBERG, 2010). Assim, desde os anos 1970, houve uma reconceitualização do desenvolvimento impulsionada pela atenção dada à questão ambiental, passando pelo ecodesenvolvimento (SACHS, 1986), renomeado recentemente 
desenvolvimento sustentável (SACHS, 2008). Essa abordagem sugere que o desenvolvimento no longo prazo exige não apenas que a tecnologia seja sustentável, mas também que o treinamento dos indivíduos e a construção de instituições são aspectos críticos para a manutenção do progresso (TISCH; WALLACE, 1994).

A implementação de diretrizes mundiais de desenvolvimento sustentável acabou incentivando um novo paradigma de desenvolvimento: o paradigma da governança global. A tentativa de regulação internacional se deu via diversas negociações, criação de órgãos de regulação internacional, além de conferências mundiais a respeito de assuntos como: direitos humanos, população e desenvolvimento, desenvolvimento sustentável, direitos das mulheres, habitação e alimentação, entre outros (SIEDENBERG, 2010). O desenvolvimento pensado de maneira mais holística cede lugar a diversos debates paralelos, cada um deles voltado para uma dimensão do fenômeno, isto é, o debate torna-se difuso, fragmentado, considerando suas múltiplas dimensões (ALMEIDA FILHO, 2011).

Exemplos da incorporação dessas temáticas no pensamento convencional são as bases teóricas das proposições de políticas dos organismos multilaterais, como o Banco Mundial e o FMI, e os chamados modelos de crescimento endógeno, incorporando variáveis como capital humano, capital social e até mesmo capital natural (ALMEIDA FILHO, 2011).

Seguindo a evolução dos paradigmas de desenvolvimento, no ano de 1986 foi aprovada pela Organização das Nações Unidas (ONU) a Declaração sobre o Direito ao Desenvolvimento, estabelecendo o marco para a ampliação das políticas de desenvolvimento. Essa declaração reconhece o desenvolvimento como um processo econômico, social, cultural e político abrangente, cujo objetivo é a melhoria do bem-estar da população. Ou seja, o reconhecimento de que o exercício do desenvolvimento está ligado aos direitos humano passa a ser formalizado com a aprovação da ONU (NWAUCHE; NWOBIKE, 2005).

Esses são, em suma, os principais paradigmas que influenciaram as mais diversas estratégias e políticas de desenvolvimento nos últimos anos (SIEDENBERG, 2010). Siedenberg (2010) afirma que essa diversidade reflete a insatisfação com os resultados e a incerteza em relação à estratégia mais adequada para levar ao desenvolvimento, seja ele local, regional, social, econômico ou sustentável (ou qualquer outro adjetivo que se convencione).

De acordo com Polanyi (2000) a dinâmica da sociedade moderna é governada por dois movimentos: um destrutivo, definido pela dinâmica da economia de mercado; e um contramovimento, ditado "por um comportamento defensivo de uma sociedade que enfrenta mudanças" (BECKER, 2010b, p. 41). Esse é o resultado da transformação do homem em mão de obra (ou recursos humanos, ou capital humano) e da natureza em terra (ou recursos 
naturais, ou capital natural), sendo mediados pelo dinheiro (POLANYI, 2000). Becker (2010b) enfatiza esses dois movimentos, afirmando que a primeira é definida por aspectos econômicos, devastando nações e regiões; enquanto a outra consiste na reação das sociedades regionais e nacionais à devastação.

Segundo Belluzzo (1980, p. 89), há uma inversão nos objetivos finais do processo, uma vez que o trabalho, a natureza e a organização produtiva deixaram de ter como propósito o atendimento das necessidades humanas, não estando ligados a limitações das necessidades e atendendo prioritariamente, senão unicamente, às "necessidades de autovalorização do capital".

Assim, para atender esse propósito, ocorre a interligação de regiões estratégicas economicamente, formando redes, organizadas e estruturadas segundo a capacidade técnicoeconômica de cada região ou lugar de orientação e direcionamento de fluxos financeiros, desenvolvendo habilidades regionais diretamente associadas à influência de grandes grupos econômico-financeiros multinacionalizados (BECKER, 2010b). "Assim, a transnacionalização dos espaços econômicos leva as regiões a se tornarem alternativas à valorização do capital financeiro" (BECKER, 2010b, p. 43). Nesse contexto, as regiões passam a competir entre si para atração de investimentos, uma vez que o capital financeiro caracteriza-se por sua volatilidade e mobilidade, migrando conforme seus interesses em cada região (BECKER, 2010b). Já no contramovimento do social, com a crescente regionalização dos espaços sociais, ocorre a interligação de áreas contíguas, com vistas à continuidade territorial, desenvolvendo relações de cooperação entre os agentes locais do desenvolvimento (BECKER, 2010b). A partir desse movimento, o capitalismo global renova seus interesses pelas particularidades do local, reconhecendo a importância da região para a produção da sobrevivência humana (BECKER, 2010b).

Surge, assim, a possibilidade de existência e coexistência de múltiplos modelos de desenvolvimento local. Por um lado, destaca-se a necessidade de uma região econômica especializada e hierarquizada de acordo com os interesses econômico-corporativos multinacionalizados da valorização do capital. Por outro lado, existe a possibilidade de uma região social e ambiental especializada e horizontalizada de acordo com os interesses locais de reprodução da vida (BECKER, 2010b). Assim, são configuradas as dinâmicas diferenciadas dos distintos processos de desenvolvimento local/regional (BECKER, 2010b).

Apesar da dinâmica de desenvolvimento global e as oportunidades dela geradas serem as mesmas, as regiões respondem de maneira diferente aos desafios da globalização. Segundo 
Becker (2010b), isso ocorre, provavelmente, porque algumas regiões reagem passivamente, não desenvolvendo seu modelo próprio e específico de desenvolvimento, enquanto outras (re)agem ativamente e o desenvolvem. Da mesma forma, Siedenberg (2010) defende que dificilmente existirá um conceito universal para desenvolvimento, assim como não existe uma única dinâmica de desenvolvimento, sendo que os processos regionais de desenvolvimento se diferenciam entre si. Além disso, Siedenberg (2010) afirma que apenas uma pequena parte dos aspectos capazes de desencadear um processo de desenvolvimento é passível de influência e controle; assim, quaisquer respostas e análises serão sempre parciais e imperfeitas.

Apesar de considerar que dificilmente existirá um conceito universal para desenvolvimento, Siedenberg (2010, p. 169) defende a validade de um esboço de um conceito ideal de desenvolvimento como desdobramento de especificidades, embora não suficiente:

[...] considerando que processos regionais de desenvolvimento se diferenciam entre si exatamente porque abordam aspectos específicos, porque envolvem diferentes atores e agentes em múltiplos contextos e tempos e em relações e interesses diversos, toda análise, por mais abrangente que seja, será sempre apenas uma contribuição parcial e exclusiva; poderá ser uma resposta aceitável, mas não suficiente (SIEDENBERG, 2010, p. 169).

Já para Martins, Vaz e Caldas (2010), a busca de caminhos para solução das questões acerca do desenvolvimento exige uma abertura para análise e avaliação de resultados que descarta modelos preconcebidos ou a eleição de melhores práticas.

Alguns estudos a respeito do desenvolvimento analisam o local com foco no global e, na opinião de Bassan e Siedenberg (2010, p. 147), esse tratamento é dado "como se existisse um único modelo de desenvolvimento, ou uma receita única de desenvolvimento local, ou como se fosse possível homogeneizar esse processo". Bagnasco (2001) também afirma que não há uma receita de desenvolvimento que possa ser replicada de maneira idêntica em outra localidade, região ou país, não existe o melhor caminho, mesmo nesta era de globalização. Ademais, Martinelli e Joyal (2004) enfatizam a necessidade de considerar as especificidades de cada dinâmica e de cada localidade, alertando para a impossibilidade de replicar iniciativas de sucesso. Da mesma forma, Prado Júnior (2001) afirma que a especificidade histórica dos países é subestimada na tentativa de análise do desenvolvimento.

É necessário enfatizar que o objetivo deste estudo não é de "homogeneizar o processo" de desenvolvimento, ou encontrar "um único modelo", como criticam os autores. Este estudo busca compreender, de maneira detalhada, se as características da dinâmica básica do desenvolvimento local configuram-no como complexo e, assim, verificar se a Complexidade consiste em abordagem coerente para seu tratamento. Busca-se entender como funcionam as 
dinâmicas básicas do desenvolvimento, identificando as variáveis envolvidas e suas interrelações essenciais, notando que as especificidades desenvolvidas por cada localidade ou região definem novas variáveis e inter-relações, agregando novas dinâmicas ao fenômeno em sua essência e, por sua vez, alterando-o.

\subsection{CONCEITO DE DESENVOLVIMENTO}

Não existe uma definição universalmente aceita de desenvolvimento (SOUZA, 1995). Siedenberg (2010) afirma que o conceito de desenvolvimento, do ponto de vista histórico e semântico, já sofreu diversas metamorfoses, adaptando-se aos diferentes enfoques e sendo acrescido dos mais diferentes adjetivos, como exposto previamente. O conceito de desenvolvimento tem sido utilizado, muitas vezes, para "indicar um contexto relativamente impreciso, aproximado, indefinido, ambíguo e que permite as mais diversas interpretações", sem definição clara e precisa das dimensões essenciais ou das relações concretas do conceito (SIEDENBERG, 2010, p. 161). Conforme Tisch e Wallace (1994), a definição de desenvolvimento é um problema técnico e conceitual difícil, ela tem evoluído continuamente, e a natureza dos relacionamentos estáticos e dinâmicos entre seus vários aspectos (infraestrutura física, desenvolvimento dos recursos humanos, e a política ambiental) pode jamais ser totalmente esclarecida.

Diversos autores alertam para a falta de consenso conceitual ou metodológico quanto ao desenvolvimento local tanto nacional como internacionalmente, como apresentado adiante (FRANÇA; CALDAS; VAZ, 2004; MARCUZZO; AREND; RAMOS, 2004; MARTINS; CALDAS, 2009; MARTINS; VAZ; CALDAS, 2010; ULTRAMARI; DUARTE, 2009). Da mesma forma, há grande diversidade conceitual a respeito de desenvolvimento regional, uma vez que a maioria dos autores considera que "região" é uma categoria analítica do espaço, sendo diferenciada conforme a visão e formação ideológica (ULTRAMARI; DUARTE, 2009).

O conceito de desenvolvimento baseou-se, por muito tempo, exclusivamente nos aspectos econômicos (VEIGA, 2005b). Consultando dicionários da língua portuguesa, é possível verificar definições muito voltadas para questões de crescimento e progresso. Michaelis (1998, p. 686) define desenvolvimento como "crescimento ou expansão gradual" 
ou “adiantamento, progresso". Desenvolvimento é definido, segundo Ferreira (1986, p. 561), como o "estágio econômico, social e político de uma comunidade, caracterizado por altos índices de rendimento dos fatores de produção, i. e., os recursos naturais, o capital e o trabalho". Na mesma linha, Houaiss e Villar (2009, p. 649) definem desenvolvimento como “crescimento econômico, social e político de um país, região, comunidade etc.”, considerando outros aspectos além do econômico.

Furtado (1963) apresenta a evolução da teoria do desenvolvimento na ciência econômica, desde a economia clássica até o enfoque neoclássico, analisando as contribuições para a formação desta teoria. Nesse caso, o foco é a vertente econômica do desenvolvimento, focando as relações de produção, divisão do trabalho e acumulação de capital. Entretanto, para Marcuzzo, Arend e Ramos (2004, p. 176), "no que se refere ao conceito de desenvolvimento, embora esse esteja ainda em construção, com opiniões diversas entre os autores, em uma versão moderna já se entende que desenvolvimento é muito mais do que o simples crescimento econômico". Na pesquisa de França, Caldas e Vaz (2004), apesar do foco para a dimensão econômica, ela não se sobrepõe, mas está intrinsecamente vinculada às dimensões sociais, ambientais, culturais e políticas.

Martinelli e Joyal (2004) argumentam que, ao invés da ênfase excessiva no aspecto econômico, uma sociedade deveria ser considerada desenvolvida quando passa a viver melhor e aperfeiçoando a vida de seus membros. Seguindo a mesma argumentação, Tisch e Wallace (1994) defendem que o desenvolvimento não é unidimensional, não podendo ser medido por meio de um indicador estatístico, como a renda per capita, por exemplo. Ademais, distintos tipos de desenvolvimento são importantes para países diferentes, que têm bases de recursos humanos e naturais diferentes e estruturas sociais e políticas distintas. Entretanto, seres humanos têm necessidades e desejos semelhantes, fazendo com que as características gerais do desenvolvimento sejam geralmente reconhecidas: altos níveis de renda, altas taxas de alfabetização, baixa mortalidade infantil, expectativa de vida longa, um ambiente limpo, e liberdade política. $\mathrm{O}$ bem estar pessoal é comumente definido em termos de renda, educação, saúde e ambiente de vida; entretanto, a qualidade de vida é complexa demais para ser totalmente compreendida a partir de alguns poucos indicadores, proporcionando uma visão limitada do bem estar pessoal e social (TISCH; WALLACE, 1994).

Um país desenvolvido deveria ser considerado aquele em que a população desfruta de bem-estar, saúde, educação, segurança e perspectivas de crescimento em termos pessoais (MARTINELLI; JOYAL, 2004). Assim, os autores definem desenvolvimento como "um processo de aperfeiçoamento em relação a um conjunto de valores ou uma atitude 
comparativa com respeito a esse conjunto, sendo esses valores condições e/ou situações desejáveis para a sociedade" (MARTINELLI; JOYAL, 2004, p. 51).

Para Martinelli e Joyal (2004), o desenvolvimento deve refletir o progresso da sociedade em suas múltiplas dimensões, incluindo vertentes políticas, tecnológicas, sociais, ambientais e de qualidade de vida da população. Segundo Tisch e Wallace (1994), desenvolvimento socioeconômico envolve melhorias em diversas áreas: produção de alimentos, serviços de saúde, educação, infraestrutura de transporte e comunicação, e mercados para todos esses bens e serviços. Também inclui avanços na capacidade de manufatura industrial. Para que cada uma das melhorias citadas seja alcançada, muitas outras realizações físicas são necessárias, melhorando o bem estar humano e proporcionando a base para as economias modernas. O desenvolvimento socioeconômico envolve oportunidades, incluindo o ambiente político em que indivíduos e organizações conduzem suas vidas profissionais e pessoais (TISCH; WALLACE, 1994).

Seguindo a mesma abordagem, Cardoso Junior (2011) considera um conceito amplo de desenvolvimento, considerando as sete grandes dimensões ou eixos estruturantes para o conceito de acordo com o planejamento estratégico do Instituto de Pesquisa Econômica Aplicada (Ipea): (1) inserção internacional soberana; (2) macroeconomia para o pleno emprego; (3) infraestrutura econômica, social e urbana; (4) estrutura tecnoprodutiva avançada e regionalmente articulada; (5) sustentabilidade ambiental; (6) proteção social, garantia de direitos e geração de oportunidades; e (7) fortalecimento do Estado, das instituições e da democracia. Cardoso Junior (2011) define desenvolvimento como um processo contínuo de aprendizado e conquistas, cujas dimensões ou qualificativos se agregam teórica e politicamente.

Nesse sentido mais amplo, Albuquerque (1998) destaca a importância das estratégias de desenvolvimento "desde baixo", sobretudo em termos de emprego e espaço territorial. Tais estratégias possuem caráter mais difuso e são sustentadas por fatores não somente econômicos, mas também sociais, culturais e territoriais. Desenvolvimento socioeconômico consiste em mais do que desenvolvimento social e econômico; seu foco está na transformação humana individual e, para que mudanças de longo prazo ocorram, a crença no progresso individual e social deve substituir o conformismo frente ao fatalismo (TISCH; WALLACE, 1994). Como afirmam Oliveira e Wittmann (2010, p. 296), os processos de desenvolvimento são cada vez mais complexos, sendo que mudanças qualitativas no modo de vida da população, nas instituições e nas estruturas produtivas, buscando a melhoria dos indicadores 
sociais, devem ser preocupações básicas das iniciativas de desenvolvimento. Da mesma forma, Sachs (2008) defende a noção de desenvolvimento includente, isto é, um desenvolvimento que requer a garantia do exercício dos direitos civis, cívicos e políticos.

Desenvolvimento socioeconômico consiste, para Tisch e Wallace (1994), num processo complexo de melhoria da vida dos indivíduos. Ele envolve, no mínimo, avanços na renda, saúde e educação. Entretanto, o desenvolvimento é mais que a soma das partes: interações entre realizações e equidade na distribuição são importantes da mesma forma e a participação dos indivíduos no alcanço de melhores padrões de vida também é crítica para a sustentabilidade do desenvolvimento ao longo do tempo (TISCH; WALLACE, 1994).

Segundo Marcuzzo, Arend e Ramos (2004), é necessário que os avanços sejam sustentáveis. Conforme Tisch e Wallace (1994), desenvolvimento de longo prazo é autosustentável por ser autocapacitante para os indivíduos, instituições e para a sociedade. Casarotto Filho e Pires (1998) enfatizam a adesão social, a manutenção e a internalização do conceito de sustentabilidade como os maiores desafios de um processo estruturado e participativo de desenvolvimento, apresentando as quatro dimensões do desenvolvimento sustentável (econômico-social, científico-tecnológica, geoambiental e político-institucional); além de definir suas características como: (a) garantia da sustentabilidade do desenvolvimento; (b) visão de longo prazo; e (c) descentralização e participação social.

Conforme Sachs (2008), o conceito de desenvolvimento sustentável foi refinado com o tempo, levando à inclusão da sustentabilidade social como componente essencial, isto é, a noção de geração de empregos e contribuição para a redução da pobreza e das desigualdades passa a ter papel central. A sustentabilidade abrange objetivos sociais, ambientais e econômicos, pensando na geração atual e nas futuras, trabalhando com escalas múltiplas de tempo e espaço (VEIGA, 2005b). Segundo Frey e Frey (2004), governos, empresas e sociedade organizam-se visando a um desenvolvimento sustentável, que englobe tanto os aspectos econômicos como os sociais e ambientais.

No mesmo sentido, Ricupero (2001) entende que a economia, ou o desenvolvimento, precisam de um sentido que deve ser determinado pelos homens, uma vez que não é inerente. Assim, Ricupero (2001) indica que o sentido deve abranger aspectos como a diminuição da desigualdade, a eliminação da pobreza absoluta, a tentativa de criação de um mundo menos desigual, em que o mal feito aos mais pobres, tanto em termos individuais como em termos de países e continentes, seja corrigido. De acordo com essa concepção, Ramos e Mariño (2010, p. 217) utilizam a definição de desenvolvimento como a atualização histórica das condições econômicas e de qualidade de vida para toda uma população. Prado Júnior (2001) defende, 
analisando o caso brasileiro, a influência da história como determinante do desenvolvimento de um país ou localidade, condicionando a formação, a evolução e a maneira particular de ser de um povo.

Bassan e Siedenberg (2010) afirmam que para compreender o desenvolvimento, se faz necessário o entendimento de crescimento, relacionando-os. Segundo a visão de Souza (1995), há uma corrente que considera o crescimento e o desenvolvimento como sinônimos. Entretanto, há uma segunda corrente que defende a indispensabilidade do crescimento para o desenvolvimento, embora alegue sua insuficiência para este (BASSAN; SIEDENBERG, 2010). Existe também uma terceira corrente para a qual o crescimento econômico é uma "simples variação quantitativa do produto", e o desenvolvimento "envolve mudanças qualitativas no modo de vida das pessoas, nas instituições e nas estruturas produtivas" (BASSAN; SIEDENBERG, 2010, p. 142).

Para Veiga (2005b), até o início dos anos 1960, desenvolvimento era considerado sinônimo de crescimento econômico, já que as nações desenvolvidas eram aquelas que se tornaram ricas pela industrialização. Assim, é a partir dessa época que surgiu a necessidade de distinguir tais noções. Segundo Souza (1995), desenvolvimento se define pela existência de crescimento econômico contínuo, em ritmo superior ao crescimento demográfico, envolvendo mudanças de estruturas e melhoria de indicadores econômicos e sociais per capita; como um fenômeno de longo prazo, implicando o fortalecimento da economia nacional, a ampliação da economia de mercado e a elevação geral da produtividade. Para Veiga (2005b), crescimento significa expansão quantitativa, enquanto desenvolvimento envolve transformações qualitativas. Segundo Siqueira (2011), desenvolvimento e crescimento não podem ser confundidos, e da mesma forma, uma única das dimensões do desenvolvimento não deve ser privilegiada, uma vez que há riscos de desequilíbrios entre classes e grupos sociais.

Veiga (2005b) ressalta que o crescimento econômico não se traduz necessariamente em maior acesso de populações pobres a bens materiais e culturais, com o acesso à saúde e à educação, por exemplo. Assim, crescimento econômico não pode ser visto como sinônimo de desenvolvimento (VEIGA, 2005a, p. 61):

quando os frutos do crescimento são utilizados para reforçar a matriz institucional herdada de uma sociedade oligárquica e escravocrata, em vez de servir para transformá-la, seus benefícios não chegam sequer a melhorar o acesso das populações mais vulneráveis àquilo que foi estabelecido na velha Declaração dos Direitos do Homem.

Furtado (1963) define uma região desenvolvida como aquela em que, não havendo desocupação de fatores, só é possível aumentar a produtividade introduzindo novas técnicas; 
isto é, o processo de desenvolvimento, segundo ele, se dá por meio de combinações novas dos fatores existentes ou pela introdução de novas técnicas. Furtado $(1963,1974)$ trata o desenvolvimento exclusivamente a partir do ponto de vista econômico, considerando-o um conceito relacionado com elementos quantificáveis. Arbix e Zilbovicius (2001, p. 56, grifo dos autores) enfatizam a visão limitada da concepção do desenvolvimento tomando como base aspectos basicamente econômicos:

a redução do desenvolvimento a alguns poucos componentes econômicos e a sua transformação em coadjuvante dos processos de crescimento da produtividade esvaziaram completamente seu conteúdo de busca de um ordenamento civilizado da vida em sociedade.

Veiga (2005a, p. 45) diferencia desenvolvimento de crescimento econômico, defendendo que "só há desenvolvimento quando os benefícios do crescimento servem à ampliação das capacidades humanas", isto é, "o desenvolvimento está na maneira como os frutos do crescimento econômico são utilizados pelas sociedades”. Essas capacidades humanas abrangem quatro aspectos: vida longa e saudável, instrução, acessibilidade aos recursos necessários a um nível de vida digno e capacidade de participação da vida da comunidade (VEIGA, 2005a). Sachs (2001) reforça a ideia de que o crescimento, por si só, não resulta em desenvolvimento, ou seja, não é suficiente. Para Sachs (2008), o crescimento é uma condição necessária, mas insuficiente para alcançar a meta de uma vida melhor, mais feliz e mais completa. Entretanto, crescimento e desenvolvimento não são conceitos opostos, uma vez que

\footnotetext{
o crescimento econômico, se repensado de forma adequada, de modo a minimizar os impactos ambientais negativos, e colocado a serviço de objetivos socialmente desejáveis, continua sendo uma condição necessária para o desenvolvimento (SACHS, 2001, p. 158).
}

Dowbor (2001, p. 197) também argumenta a respeito da insuficiência do crescimento econômico, devendo haver "investimento no ser humano, na sua formação, na sua saúde, na sua cultura, no seu lazer, na sua informação”, ou seja, na dimensão social, que necessita, devido suas especificidades, de uma gestão específica. Para Sachs (2001), o equilíbrio ou "reconciliação" entre crescimento econômico e desenvolvimento social reside na política. Sachs (2001) aponta três questões para que se alcance o equilíbrio entre as abordagens voltadas para as necessidades e as ditadas pelo mercado: (1) a harmonização dos objetivos sociais, ambientais e econômicos; (2) a promoção de parcerias entre todos os interessados no processo de desenvolvimento: os cidadãos e as organizações da sociedade civil; o mundo empresarial e um Estado enxuto, mas operante (a chamada economia negociada); e, por fim, (3) a articulação dos espaços de desenvolvimento, partindo dos locais até chegar ao global, passando pelos regionais e nacionais. 
Arbix e Zilbovicius (2001, p. 56) alertam para a necessidade de redefinição dos contornos e do conteúdo das políticas de desenvolvimento a fim de "resgatar a noção original de desenvolvimento como processo de busca do bem-estar humano". Para os autores, os programas sociais (educação, bem-estar infantil, dispositivos de combate à pobreza, saúde e outros) devem ser o foco de toda e qualquer estratégia de desenvolvimento. Nesse sentido, Veiga (2005a) trata do desenvolvimento de maneira ampla, incluindo dimensões como a cívica, a cultural e a ambiental, enfatizando a necessidade de sustentabilidade do mesmo. De acordo com Passador e Nalle Jr. (2007), o conceito de desenvolvimento deve ser abrangente, incluindo aspectos como o desenvolvimento do ser humano, sua integridade e condições de vida. Assim, o desenvolvimento é caracterizado pelo seu projeto social subjacente, priorizando a efetiva melhoria das condições de vida da população (FURTADO, 2004; VEIGA, 2005b). Entretanto, essa mudança é fruto da expressão de uma vontade política orientada para a formação de uma sociedade apta a assumir um papel dinâmico no processo de desenvolvimento (FURTADO, 2004).

Furtado (2004, p. 485) define desenvolvimento como "o caminho de acesso a formas sociais mais aptas a estimular a criatividade humana e responder às aspirações da coletividade", mais do que simplesmente um processo de acumulação e aumento de produtividade. O desenvolvimento também pode ser conceituado em termos da apropriação efetiva dos direitos humanos: (a) direitos políticos, civis e cívicos; (b) direitos econômicos, sociais e culturais; e (c) direitos coletivos ao meio ambiente e ao desenvolvimento (SACHS, 2008). Para Santos (2002), o desenvolvimento consiste em uma forma de promover melhores condições de vida para a população em geral, e para os setores marginalizados em particular, considerando os valores da igualdade e cidadania como base para uma abordagem "de baixo para cima" que atenda, além da dimensão econômica, as dimensões sociais, políticas, culturais e naturais.

Logo, o conceito de desenvolvimento inclui o conceito de crescimento, superando sua ideia, uma vez que ele é qualitativo, buscando, além do aumento da produção, aspectos de qualidade de vida, distribuição de renda, satisfação das necessidades humanas e atendimento dos objetivos das sociedades (BASSAN; SIEDENBERG, 2010). Conforme Bassan e Siedenberg (2010, p. 145), "ele se refere ao crescimento de um conjunto de estrutura complexa. Essa complexidade traduz as diversidades das formas sociais e econômicas". Portanto, o desenvolvimento do homem e do seu meio, a sociedade, estão no centro da 
questão, sendo que os demais fatores seriam condições necessárias para que os objetivos possam ser alcançados (PASSADOR; NALLE JR., 2007).

De forma resumida, as conceituações tradicionais de desenvolvimento tinham o crescimento como foco, enfatizando aspectos econômicos como indicadores da evolução das sociedades. Já nas perspectivas mais recentes, o desenvolvimento é considerado como a evolução de uma sociedade de uma forma mais ampla e multifacetada, como um processo de longo prazo que inclui aspectos como a qualidade de vida, redução das desigualdades, satisfação das necessidades, garantia do bem-estar, justiça, equidade, segurança, saúde, educação, perspectivas de crescimento e desenvolvimento pessoal, igualdade de participação política, além da preocupação ambiental a fim de garantir esse desenvolvimento de maneira sustentável, para que as gerações futuras tenham suas necessidades garantidas da mesma forma. Ao analisar um nível mais micro, é possível encontrar diferentes adjetivos ligados à noção de desenvolvimento e as palavras "local", "regional" e "territorial" constantemente complementam tais definições. Assim, as diferentes perspectivas são analisadas em seguida.

\subsubsection{Desenvolvimento local}

De acordo com Navarro (2001), a expressão desenvolvimento local é recente e deriva de duas grandes mudanças nas últimas décadas: a multiplicação de ONGs que enfatizam uma estratégia de ação local e os processos de descentralização em curso que valorizaram essa instância. O termo local ganhou destaque graças às oportunidades decorrentes da reestruturação do modo produtivo industrial e à realocação das infraestruturas produtivas (MARTINELLI; JOYAL, 2004). Martinelli e Joyal (2004) afirmam ainda que o enfoque local surgiu como consequência de iniciativas territoriais geradas nas bases, que impulsionaram atividades de fomento produtivo e empresarial em um momento de mudança radical das condições.

O "local", quando se trata de desenvolvimento local, não é entendido a partir de um recorte administrativo, então nem sempre se sobrepõe ao município. Há casos em que o termo refere-se a uma região inteira, em outros trata de apenas alguns bairros de um conjunto de municípios (FRANÇA, CALDAS, VAZ, 2004). O termo local, ao tratar de desenvolvimento, não é sinônimo de pequeno e não se refere necessariamente à diminuição ou redução, ganhando uma conotação socioterritorial para o processo de desenvolvimento (MARTINELLI; JOYAL, 2004). Conforme Fonseca et al. (2007, p. 196), "frente à idéia de global, o local pode referir-se a uma dada localidade (cidade, bairro e rua), região ou nação, 
formando subespaços, criando alguma delimitação ou recorte territorial que se expressa em termos econômicos, políticos e culturais". Entretanto, no Brasil, quando se pensa em desenvolvimento local, de forma geral se refere ao nível municipal ou regional (MARTINELLI; JOYAL, 2004). De acordo com essa concepção, Ultramari e Duarte (2009) consideram o desenvolvimento local no Brasil como o desenvolvimento do município, ou seja, um desenvolvimento realizado a partir da maior autonomia e responsabilidade do poder local e da sociedade civil em diferentes esferas: econômica, política, social, cultural e ambiental.

Conforme Martinelli e Joyal (2004), a noção de local baseada no conceito de região gera polêmica, uma vez que as divisões administrativas são muitas vezes arbitrárias e não possuem correspondência com a geografia humana. Logo, tais autores recomendam que o desenvolvimento local seja iniciado nas regiões que correspondam a um "espaço de solidariedade", em que os indivíduos possuem uma história em comum e onde pretendam construir um futuro comum.

Para a definição de um local, alguns autores (ALBAGLI, 1999; MARTINELLI; JOYAL, 2004; PAULA, 2001) enfatizam a existência de identidade, cooperação e solidariedade, podendo configurar-se em qualquer recorte socioterritorial pluridimensional, ou seja, o local pode envolver uma dimensão econômica, cultural e/ou político-territorial. O local não se refere ao tamanho, mas envolve o conjunto de relações que existem em um determinado ambiente territorial, seja ele uma microrregião ou uma cidade, considerando as heterogeneidades e especificidades deste território (SANTOS, 2002). O local e seus limites não correspondem a um espaço geográfico definido, mas a uma construção social, enfatizando os laços territoriais, econômicos e culturais envolvidos. A ideia de local está ligada às noções de identidade e pertencimento, uma vez que depende da percepção das pessoas quanto ao que é o seu local (MARTINS; CALDAS, 2009).

Consideram-se também os atores sociais e institucionais desta localidade, com sua diversidade e potencialidades econômicas, sociais, ambientais e institucionais e as diferentes alternativas de atuação para a transformação e o desenvolvimento do local (MARTINS; CALDAS, 2009, p. 209).

Ultramari e Duarte (2009, p. 27) alertam para o fato de que a dimensão global deve ser considerada ao defender o desenvolvimento local, "reconhecendo interesses externos ao espaço menor trabalhado". Da mesma forma, "a abordagem nacional também deve ser considerada na busca de melhores padrões de desenvolvimento" (ULTRAMARI; DUARTE, 2009, p. 27). Entretanto, de acordo com Martinelli e Joyal (2004, p. 55), "por definição, o desenvolvimento local se apresenta em forma regional", não sendo uma alternativa aos 
enfoques desumanizadores das economias globalizadas, mas sim criando uma complementaridade local/global como lógicas inter-relacionadas.

Para Ultramari e Duarte (2009), as políticas maiores, nacionais, podem potencializar recursos e esforços locais. Entretanto, os autores alertam para o que consideram o maior desafio imposto aos agentes do desenvolvimento local: trabalhar as questões econômicas, se submetendo aos interesses do mercado e da necessidade de renda por parte da população, e garantir o objetivo de caráter social, reconhecendo a limitação do poder de intervenção do município nas questões relativas à economia e a falta de recursos em suas administrações.

Com um enfoque para as capacidades produtivas, Coelho (2001) define o desenvolvimento econômico local como a construção de um ambiente produtivo inovador, em que cooperação e integração são institucionalizadas, visando à ampliação de oportunidades locais, gerando trabalho e renda, atraindo novos negócios e criando condições para um desenvolvimento humano sustentável. Já para Martinelli e Joyal (2004), a característica central do desenvolvimento baseado localmente está na ênfase da política de desenvolvimento endógeno, isto é, uma política em que os potenciais locais são priorizados. O desenvolvimento endógeno pode ser visto como um processo iniciado de dentro das localidades, mobilizando os atores locais para otimizar os recursos de capital, de trabalho e de instituições locais, assim como de infraestruturas físicas, em vez de atrair investimentos externos para impulsionar o desenvolvimento local e gerar empregos (MARTINELLI; JOYAL, 2004). A novidade nessas abordagens locais de desenvolvimento é o fato de estarem centradas na compreensão das dinâmicas endógenas dos territórios, ou, como preferem Dallabrida e Becker (2010), na dinâmica territorial do desenvolvimento. Dessa forma, o foco está nas relações, nas interações entre as empresas e destas com os outros atores institucionais do desenvolvimento (DALLABRIDA; BECKER, 2010).

Como afirmam Dallabrida e Becker (2010), as abordagens contemporâneas do desenvolvimento local/regional não mais consideram a região, ou território, apenas como "suporte passivo de recursos", mas como geradoras de recursos a partir das complexas interações entre os atores locais. O meio passa a ser visto como o criador das inovações e se expressa, "principalmente, por formas de organização cooperativas/participativas e pela sua maior capacidade de mobilização e inovação local" (DALLABRIDA; BECKER, 2010, p. 191).

Para Passador e Nalle Jr. (2007), o desenvolvimento local está baseado em fatores como o capital social, o capital humano, a cidadania, as capacidades territoriais e as condições de sustentabilidade, fatores esses que devem ser determinados dentro da região, e não de fora 
para dentro. O capital social está relacionado ao ambiente social propício ao desenvolvimento, ou seja, ele envolve as redes de relações, as normas de comportamento, laços de confiança e obrigações mútuas. O capital humano é definido como a capacidade do homem de fazer coisas novas e construir seu futuro, sendo um instrumento de mudança social. A cidadania consiste na participação, fundamental para a promoção da articulação dos atores, fortalecendo a coesão da comunidade. As capacidades territoriais, por sua vez, configuram as qualidades necessárias para que o território funcione como catalisador das outras variáveis do desenvolvimento, auxiliando o processo. Já a sustentabilidade refere-se à preocupação de promover o desenvolvimento satisfazendo os interesses da geração presente sem comprometer a geração futura. Porém, a sustentabilidade não se limita à questão ecológica e ambiental, devendo ser ampliada a todas as dimensões da vida humana, mantendo um padrão de organização nos territórios, ou seja, um sistema que possua a capacidade de se auto-organizar, de se reproduzir e de autocriar as condições para sua continuidade (PASSADOR; NALLE JR., 2007).

Conforme Silveira (2001), não há unanimidade entre os autores em relação à importância atribuída ao desenvolvimento local. Há opiniões que o consideram apenas como foco de reflexão, outros autores o vêem como um campo efetivo de práticas transformadoras e outros ainda afirmam que não existe desenvolvimento local, defendendo que o desenvolvimento ocorre articulado a processos gerais e que a incorporação de novos espaços subordinados à lógica do centro dominante é da natureza específica das sociedades capitalistas (SILVEIRA, 2001). Já Martinelli e Joyal (2004) defendem o desenvolvimento local como uma resposta às alternativas de desenvolvimento, apresentando um potencial transformador no contexto de globalização e reestruturação produtiva.

Apesar das discussões sobre a efetividade das mudanças em nível local, na prática são observadas iniciativas com resultados comprovados, com exemplos na área de geração de renda, pela valorização do produtor rural; no desenvolvimento do turismo, capacitando a população de áreas rurais ou a partir da conservação ambiental; na valorização do artesanato regional; na criação de "Bancos do Povo", concedendo empréstimos sem comprovação de renda e formalidades; e no desenvolvimento de incubadoras de indústrias, entre outras (ULTRAMARI; DUARTE, 2009). De acordo com Martinelli e Joyal (2004), o desenvolvimento local trata de iniciativas implantadas para estimular as economias de coletividades locais, não se baseando em um quadro teórico rigorosamente definido, ao contrário do desenvolvimento regional. 


\subsubsection{Desenvolvimento regional}

A expressão "desenvolvimento regional" é utilizada sem muito critério, para evocar tudo o que se relacione com o desenvolvimento econômico (MARTINELLI; JOYAL, 2004). Seguindo outra abordagem, a definição de Becker (2010a, p. 108) para o desenvolvimento regional, entretanto, possui muitos aspectos citados nas definições de desenvolvimento local; ele o define como

um processo de transformações econômicas, sociais e políticas, [...] cuja dinâmica é imprimida desde "de dentro e por iniciativa própria" dos agentes locais, manifesta nas "mudanças estruturais ou qualitativas" que um desenvolvimento regional sofre a partir de "alterações endógenas" e "em escala cada vez maior".

É possível perceber a existência de pontos em comum, dificultando a diferenciação entre tais abordagens, uma vez que ambos incluem noções como ação endógena, autonomia e mudanças qualitativas nos diversos âmbitos (econômico, social, político). Então é natural que, a fim de garantir a autenticidade das perspectivas, a diferenciação seja resultante dos conceitos de local e região. O local, como explicitado previamente, é definido a partir de um caráter de identidade, por características e aspectos próprios de uma localidade, sejam eles culturais, econômicos, ambientais ou sociais, que levam à coesão e à noção de pertencimento. No entanto, alguns autores utilizam o conceito de local única e exclusivamente baseado na divisão administrativa ou geográfica, considerando, muitas vezes, o local como um município.

Da mesma forma, conforme esclarecem Bassan e Siedenberg (2010), existem diversos conceitos de região; entretanto, a maioria inclui noções naturais ou ambientais (relevo, clima, vegetação), econômicas, sociais e culturais. Bassan e Siedenberg (2010, p. 141) consideram região como

uma porção do espaço com características naturais específicas que, ao longo de seu processo de formação histórico-cultural, foi configurando uma identificação social, econômica e política, a fim de atender às necessidades de sua população, delimitando uma identidade regional própria.

Ultramari e Duarte (2009) apresentam quatro conceitos de região: (a) região é uma parte qualquer da superfície terrestre que pode ser definida por seus diversos aspectos (sociais, políticos ou econômicos); (b) região é uma área que se diferencia do seu entorno por alguma característica própria; (c) região é um simples recorte do território mapeado em escala adequada; (d) região é uma ferramenta metodológica, ou seja, a escolha de uma área geográfica de análise. Além disso, um fenômeno que pode influir na conceituação de região é a globalização, "entendida como a intensificação das relações e dependências dos diferentes locais ou cidades em nível global” (ULTRAMARI; DUARTE, 2009, p. 47). Portanto, as 
interpretações e objetivos de quem utiliza o termo podem estabelecer novas tipologias de definição, alterando o modo de entender os espaços regionais. Segundo a concepção adotada por Ultramari e Duarte (2009), é possível entender que o desenvolvimento regional pode constituir iniciativas mais abrangentes, envolvendo mais de um local. Isso só pode ser afirmado devido à concepção de desenvolvimento local utilizada por tal autor, que considera o município como localidade, ou seja, trata do desenvolvimento municipal quando fala de desenvolvimento local.

Segundo Bassan e Siedenberg (2010), os fatores que caracterizam uma região, definindo sua identidade e unicidade, são os responsáveis pelo seu processo de desenvolvimento, esses autores incluem: (a) formação geomorfológica (relevo, vegetação); (b) formação histórico-cultural (cultura e tradições enraizadas e transmitidas a gerações futuras pelos primeiros habitantes ou colonizadores); (c) formação econômico-social (distribuição espacial da população, origem do processo produtivo, base econômica que identifica a região); (d) aspecto político e administrativo.

Para Bassan e Siedenberg (2010), um processo de crescimento econômico (renda e produtividade) configura-se como pré-condição para levar ao desenvolvimento regional, além de um crescente processo de autonomia regional de decisão, que envolve a definição de políticas específicas, próprias da região. Os autores apontam também como pré-condição para o desenvolvimento a capacidade regional de apropriação de parte do excedente econômico ali gerado, revertendo-o para a região e diversificando, assim, a base econômica, o que confere sustentabilidade ao crescimento no longo prazo.

Bassan e Siedenberg (2010) alertam para o crescente movimento de inclusão social, além do processo de conscientização e mobilização social acerca da sustentabilidade ambiental e dos recursos naturais, e também da identificação da população com sua região, todos esses fatores estão envolvidos no desenvolvimento regional. Para Siedenberg (2010), desenvolvimento regional se refere a um processo de mudanças multifacetado relativo a aspectos sociais e econômicos que ocorrem em determinado espaço e tempo. Multifacetado porque envolve diferentes aspectos, como as características básicas do processo de mudança, os atores e agentes envolvidos, os meios e recursos disponíveis, as relações estabelecidas e os interesses em jogo (SIEDENBERG, 2010). "Desenvolvimento é, ao mesmo tempo, um estado e um processo, ambos complexos" (SIEDENBERG, 2010, p. 171).

A noção de desenvolvimento recebe, ainda, outra definição: territorial. A próxima subseção trata dessa conceituação. 


\subsubsection{Desenvolvimento territorial}

A região foi (re)colocada como objeto de investigação das ciências sociais, resultando no aumento do interesse sobre as questões territoriais, em uma tentativa de pensar o desenvolvimento a partir da perspectiva territorial (DALLABRIDA; SIEDENBERG; FERNÁNDEZ, 2004). Dallabrida, Siedenberg e Fernández (2004, p. 102) definem desenvolvimento territorial como

[...] um estágio do processo de mudança estrutural empreendido por uma sociedade organizada territorialmente, sustentado na potencialização dos capitais tangíveis (ou materiais) e intangíveis (ou imateriais) existentes no local, com vistas à melhoria da qualidade de vida de sua população.

O debate sobre novas formas de organização da produção e explicação dos fatores que têm contribuído para o desenvolvimento de âmbitos espaciais distantes dos grandes centros urbano-industriais tem sido revitalizado pelo aumento, desde o final dos anos 1970, do número de pequenas e médias empresas em meios sociais criativos e inovadores (DALLABRIDA; SIEDENBERG; FERNÁNDEZ, 2004). Os autores explicam tal fenômeno pela conclusão de que as cidades, regiões ou territórios podem tornar-se protagonistas na decisão dos seus destinos, assumindo um papel ativo; ou seja, o desenvolvimento de sistemas territoriais de produção pode ser independente da redistribuição do crescimento econômico das regiões mais industrializadas e urbanizadas.

Para Albuquerque (1998), o conceito de "espaço" como suporte para o desenvolvimento sugere a ideia de homogeneidade, com preocupações acerca da distância, custos de transporte, aglomeração de atividades e polarização do crescimento, com referência a um contexto geográfico dado. Então, a perspectiva do desenvolvimento econômico local e regional é centrada no conceito de "território" como ator do desenvolvimento, compreendendo a complexidade e heterogeneidade do mundo real, "suas características ambientais específicas, os atores sociais e sua mobilização em torno de diversas estratégias e projetos, assim como a existência de recursos estratégicos para o desenvolvimento produtivo e empresarial e o respectivo acesso" (ALBUQUERQUE, 1998, p. 53).

O desenvolvimento territorial é definido por Marques et al. (2007) como uma visão integradora de espaços, atores sociais, agentes, mercados e políticas de intervenção. Os autores defendem o desenvolvimento traduzido em crescimento e geração de riquezas em função da coesão social, como expressão de sociedades nas quais prevaleça a equidade, o respeito à diversidade, à solidariedade, à justiça social, o sentimento de pertencimento e 
inclusão; e da coesão territorial, como expressão de espaços, recursos, sociedades e instituições imersas em regiões, nações ou espaços supranacionais, que os definem como entidades culturais, política e socialmente integradas.

“A expressão novo regionalismo é comumente utilizada para referir-se às abordagens do desenvolvimento que, apesar de sustentarem-se em enfoques em parte contraditórios, centram seu foco na região" (DALLABRIDA; SIEDENBERG; FERNÁNDEZ, 2004, p. 103). Segundo esses autores, as abordagens teóricas contemporâneas que tangenciam o enfoque do desenvolvimento a partir da perspectiva territorial podem ser divididas em duas vertentes do chamado "novo regionalismo": vertente globalista ou vertente regionalista.

A vertente globalista sustenta-se na concepção de homogeneização do espaço local, baseada na crença da possibilidade de competição perfeita entre localidades. Nesse enfoque, "qualquer tentativa de diferenciação local seria freada diante da possibilidade de risco de se ver a comunidade punida pela perda de capital e mão de obra qualificada para uma outra comunidade" (DALLABRIDA; SIEDENBERG; FERNÁNDEZ, 2004, p. 103).

Existem quatro variações de abordagens da vertente globalista reconhecidas pelos principais autores (DALLABRIDA; SIEDENBERG; FERNÁNDEZ, 2004). A primeira é chamada de Escola da Nova Política Urbana ou New Urban Policy School - NUP (COX, 1995). Nesse enfoque as cidades ou comunidades são situadas em termos de suas políticas de desenvolvimento a partir de uma lente econômica geograficamente mais ampla, com foco para as mudanças geradas a nível nacional e internacional pela criação, pelas organizações, de novas divisões de trabalho (COX, 1995). Além disso, as cidades competem entre si por investimentos, já que possuem interesses econômicos específicos. Esse enfoque é baseado nas concessões oferecidas pelos governos e comunidades locais, tais como a flexibilização legal, isenções tributárias e investimentos diretos para atrair novos investimentos (COX, 1995).

A segunda variação defende que caberia às cidades e regiões assumirem as responsabilidades pela geração de renda e emprego através da elaboração e implementação de um comportamento empresarial, buscando captar capital. A política urbana adotaria estratégias de competitividade frente às outras cidades, buscando maior atratividade para o capital internacional, tendo seu sucesso avaliado pela capacidade de criar novas bases para um desenvolvimento econômico local (DALLABRIDA; SIEDENBERG; FERNÁNDEZ, 2004).

A terceira variação estuda o surgimento de redes de cidades e regiões conectadas entre si numa sociedade global baseada no fluxo de informações. Assim, a disputa pelo capital internacional é complementada por estratégias urbanas que buscam também maiores níveis de 
produtividade urbana. Essa depende de fatores como a conectividade, a inovação e a flexibilidade institucional, facilitando a inserção privilegiada das cidades-região (cidades com mais de um milhão de habitantes, conformando grandes aglomerados urbanos) no cenário global (DALLABRIDA; SIEDENBERG; FERNÁNDEZ, 2004).

A quarta variação, segundo Dallabrida, Siedenberg e Fernández (2004), defende o surgimento de uma ordem internacional sem fronteiras nacionais, com um esgotamento do papel do Estado Nacional e de suas políticas de regulação macroeconômica (OHMAE, 1996), ou até seu desaparecimento (STRANGE, 2003), proclamando as vantagens da livre competição entre cidades ou regiões. Nesse sentido, Strange (2003) defende que as fronteiras territoriais já não coincidem com os limites da autoridade política sobre a economia e a sociedade.

A vertente regionalista, por sua vez, ressalta a perspectiva da territorialização do desenvolvimento no contexto da nova economia globalizada, defendendo que a capacidade das cidades/regiões/territórios de atuarem sobre os fatores estruturais aumentou, implicando na maior capacidade de aproveitar os fatores globais em função das especificidades do local (DALLABRIDA; SIEDENBERG; FERNÁNDEZ, 2004). Nesta vertente também existem variações de abordagem, destacadas por Dallabrida, Siedenberg e Fernández (2004):

a) Estudos centrados na problemática da organização industrial: foco no domínio da inovação tecnológica e nas redes institucionais de suporte aos processos de aprendizagem e inovação, alertando para a natureza sistêmica e interatuante de tais processos. Tal enfoque defende a interpretação do processo de inovação entendido como expressão organizacional das dinâmicas de aprendizagem coletiva de determinado território, ou país;

b) Estudos centrados na crise do fordismo: caracterizaram a concepção de novas formas de organização industrial, baseados em modelos de acumulação flexível, mais fáceis de se implementar em aglomerações espaciais por diversos motivos (proximidade levando a maior confiança e troca de informações e experiências, favorecimento de agrupamentos de pequenas e médias empresas no espaço, favorecimento da regulação local através de parcerias);

c) Estudos centrados nos distritos industriais: cada uma das empresas especializase numa única, ou algumas, das fases dos processos produtivos específicos de cada distrito, pertencendo geralmente a um mesmo ramo industrial. No caso de predomínio de pequenas empresas pode ocorrer uma divisão do trabalho entre 
empresas, diversificando o sistema produtivo local e induzindo uma complexidade crescente. O distrito industrial diferencia-se do pólo industrial porque este último constitui-se ao redor de uma ou várias grandes empresas, enquanto no primeiro predominam pequenas e médias empresas;

d) Estudos centrados nos meios inovadores: o conceito de meio inovador pretende apreender as dinâmicas territoriais de inovação, considerando como pressuposto que os mecanismos do desenvolvimento regional residem nas regiões com capacidade para inovação.

Dallabrida, Siedenberg e Fernández (2004) realizam uma análise crítica das abordagens regionalistas do desenvolvimento, sintetizando os desafios da territorialização do desenvolvimento em três dimensões: (1) possibilidade de agravamento das assimetrias e redução de convergências regionais; (2) domínio das empresas transnacionais; e (3) não consolidação da constituição dos sistemas territorializados de pequenas empresas. Entretanto, segundo Dallabrida, Siedenberg e Fernández (2004, p. 118), tais desafios não anulam a defesa do território e seus atores como protagonistas do processo de desenvolvimento local e regional, alertando apenas para a necessidade de revisão de algumas argumentações e de refletir para alcançar respostas mais viáveis a, no mínimo, três questões:

(1) como as regiões periféricas podem afastar-se de seu posicionamento marginal e alcançar novos padrões organizativo-funcionais fundados, como os distritos industriais, por exemplo, no protagonismo e na articulação dos atores territoriais? (2) como aqueles complexos territoriais, que têm alcançado os atributos dos distritos industriais, podem enfrentar suas limitações estruturais ligadas a sua escala e ao conjunto de inércias que bloqueiam sua qualificação, para ingressar nas redes globais controladas pelas empresas transnacionais? e (3) como, em geral, os espaços regionais podem encontrar padrões organizativo-funcionais que lhes permitam inserir em seu âmbito as empresas transnacionais, condicionando seu funcionamento dentro dos territórios e operando com esses macroatores uma lógica não reprodutiva, senão altamente sinergética?

Diante disso, Dallabrida, Siedenberg e Fernández (2004, p. 119, grifo dos autores) destacam algumas interrogações à territorialização do desenvolvimento:

(1) qual a possibilidade de desencadear movimentos de reação dos territórios ou regiões, com relativo grau de protagonismo local? (2) quais características precisam estar presentes em territórios ou regiões, para criar as condições favoráveis a uma reação mais autônoma e protagonista, com maior possibilidade de sucesso? (3) como é possível perceber essas características na realidade de territórios ou regiões fora dos centros mais dinâmicos da economia nacional e mundial? (4) que variáveis/indicadores são mais adequados para mensurar o padrão de competitividade, ou competência territorial desses territórios ou regiões?

O desenvolvimento de algumas abordagens levanta possíveis respostas a tais interrogações, sendo centradas no destaque da organização socioterritorial e da inovação nos processos de desenvolvimento (DALLABRIDA; SIEDENBERG; FERNÁNDEZ, 2004). A 
partir da década de 70 foram desenvolvidas visões sobre a empresa inovadora, tendo como foco a empresa e os fatores internos que influenciam sua capacidade de inovação (DALLABRIDA; SIEDENBERG; FERNÁNDEZ, 2004). Já a partir da década de 80 surgiram estudos defendendo que a concentração espacial e o entorno territorial contribuem para a inovação empresarial (DALLABRIDA; SIEDENBERG; FERNÁNDEZ, 2004).

De acordo com Dallabrida, Siedenberg e Fernández (2004), algumas questões podem ser destacadas no debate a respeito da inovação e suas relações com o território: a discussão sobre o papel das Pequenas e Médias Empresas (PME) e transnacionais na definição de estratégias de desenvolvimento territorial (VÁZQUEZ BARQUERO, 1997); e a necessária (re)consideração do papel do poder público nos processos de desenvolvimento regional, principalmente dos países classificados como "em desenvolvimento". Em face de tantas definições para a noção de desenvolvimento, a comparação e distinção entre elas se mostra útil para a seleção do conceito a ser utilizado neste esforço de pesquisa.

\subsubsection{Comparação dos conceitos de desenvolvimento}

À ideia de desenvolvimento são adicionados muitos adjetivos, sendo analisados três deles neste trabalho, em uma tentativa de selecionar o mais adequado à perspectiva que aqui se procura tratar. A partir da análise das definições encontradas para "desenvolvimento local”, "desenvolvimento regional" e "desenvolvimento territorial", pode-se considerar que as diferenças são sutis, em que se percebe uma diferença geral de tratamento e, muitas vezes, vaga, ao invés de diferenças mais específicas nos conceitos.

Dallabrida e Becker (2010, p. 179) consideram os conceitos de desenvolvimento local e de desenvolvimento regional como sendo sinônimos, definindo-os a partir da perspectiva territorial como

[...] um determinado processo de territorialização ${ }^{3}$ que contempla a dimensão da reterritorialização ${ }^{4}$, capaz de estimular as potencialidades e contribuir para a superação dos desafios locais/regionais, que privilegie a dimensão da inclusividade, capaz de eliminar privações ou não liberdades, capaz de promover os atores/agentes regionais à condição de sujeitos, que envolva os territorializados, os que estão em processo de desterritorialização ${ }^{5}$ e os já desterritorializados, potencializando sua capacidade de auto-organização, implementando uma dinâmica territorial do

\footnotetext{
3 “Territorialização é o processo de apropriação do espaço, seja através de uma ação do setor público ou privado" (DALLABRIDA; BECKER, 2010, p. 178).

4 "Reterritorialização é o processo de assentamento dos desterritorializados, dando-lhes, novamente, o sentido de apropriar-se de algo que perderam ou nunca tiveram" (DALLABRIDA; BECKER, 2010, p. 178).

${ }^{5}$ Desterritorialização é o processo de desapropriação do espaço, em geral imposto (DALLABRIDA; BECKER, 2010).
} 
desenvolvimento mais autônoma, não privatista, menos desigual e segundo a lógica da sociedade.

Dallabrida e Becker (2010) utilizam o conceito de região como parte do espaço nacional que reflete as especificidades sociais em um determinado momento. Já o conceito de território é definido como o "espaço territorializado, apropriado", como "lugar de relações", "espaço de ação e de poder" (DALLABRIDA; BECKER, 2010, p. 178). Assim, a dinâmica territorial do desenvolvimento refere-se às maneiras de os atores locais/regionais organizarem-se para atuarem no processo de desenvolvimento local/regional, que também pode ser entendido como processo de ordenamento/reordenamento do território. Ou seja, a dinâmica envolve as diversas opções dos atores locais para viabilizar o desenvolvimento (DALLABRIDA; BECKER, 2010). O quadro 4 apresenta a comparação dos aspectos do desenvolvimento territorial de acordo com seus autores.

\begin{tabular}{|c|c|c|c|c|}
\hline Autores & $\begin{array}{c}\text { Dallabrida, } \\
\text { Siedenberg e } \\
\text { Fernández (2004) }\end{array}$ & Albuquerque (1998) & $\operatorname{Cox}(1995)$ & $\begin{array}{l}\text { Marques et al. } \\
\quad(2007)\end{array}$ \\
\hline $\begin{array}{l}\text { Percepção de } \\
\text { abrangência }\end{array}$ & $\begin{array}{l}\text { Território como } \\
\text { organização social }\end{array}$ & \begin{tabular}{lr}
\multicolumn{3}{l}{ Território está ligado } \\
à ideia & de \\
homogeneidade, com \\
preocupações & acerca \\
da distância, custos \\
de transporte, \\
aglomeração & de \\
atividades & $\mathrm{e}$ \\
polarização & do \\
crescimento &
\end{tabular} & $\begin{array}{lr}\text { Cidades } & \text { ou } \\
\text { comunidades com } \\
\text { foco para as } \\
\text { mudanças geradas a } \\
\text { nível nacional e } \\
\text { internacional }\end{array}$ & $\begin{array}{l}\text { Território em } \\
\text { função da coesão } \\
\text { social e territorial }\end{array}$ \\
\hline $\begin{array}{l}\text { Esferas } \\
\text { consideradas }\end{array}$ & - & Esfera econômica & Esfera econômica & Esfera econômica \\
\hline $\begin{array}{l}\text { Dinâmica } \\
\text { focalizada }\end{array}$ & 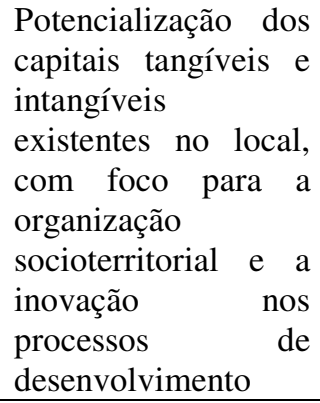 & - & $\begin{array}{l}\text { Baseado nas } \\
\text { concessões oferecidas } \\
\text { pelos governos e } \\
\text { comunidades locais, } \\
\text { tais como a } \\
\text { flexibilização legal, } \\
\text { isenções tributárias e } \\
\text { investimentos diretos } \\
\text { para atrair novos } \\
\text { investimentos }\end{array}$ & $\begin{array}{lr}\text { Dinâmica } & \text { baseada } \\
\text { na integração de } \\
\text { espaços, } r \text { atores } \\
\text { sociais, agentes, } \\
\text { mercados } & \mathrm{e} \\
\text { políticas } & \mathrm{de} \\
\text { intervenção } & \end{array}$ \\
\hline
\end{tabular}

Quadro 4 - Conceitos de desenvolvimento territorial comparados

O desenvolvimento territorial, a partir da exposição aqui realizada, apresenta-se como um conceito voltado, de forma geral, a aspectos geográficos e de dinâmica produtiva e organizativa, mais focado em preocupações quanto à autonomia e protagonismo dos locais/regiões quanto ao seu processo de desenvolvimento. 
Em relação às definições de desenvolvimento regional encontradas, as diferenças frente aos conceitos de desenvolvimento local não ficam claras. Da mesma forma que os conceitos de região e local podem, em ambos os casos, adquirir conotações distintas, conforme o ponto de vista do autor utilizado, as definições de desenvolvimento local e regional também apresentam essa amplitude diante de diferentes autores. Os quadros 5 e 6 apresentam uma síntese dos aspectos característicos desses conceitos, de acordo com seus autores.

\begin{tabular}{|c|c|c|c|c|c|}
\hline Autores & $\begin{array}{l}\text { Becker } \\
\text { (2010a) }\end{array}$ & $\begin{array}{c}\text { Bassan e } \\
\text { Siedenberg } \\
(2010)\end{array}$ & $\begin{array}{c}\text { Ultramari e } \\
\text { Duarte (2009) }\end{array}$ & $\begin{array}{l}\text { Siedenberg } \\
(2010)\end{array}$ & \begin{tabular}{|c|} 
Ramos e \\
Mariño (2004; \\
2010) \\
\end{tabular} \\
\hline $\begin{array}{l}\text { Percepção de } \\
\text { abrangência }\end{array}$ & - & $\begin{array}{lr}\text { Região } & \text { como } \\
\text { resultante } & \text { de } \\
\text { processo } & \text { de } \\
\text { formação } & \\
\text { histórico-cultural, } \\
\text { com } \\
\text { características } \\
\text { naturais } \\
\text { identidade própria }\end{array}$ & $\begin{array}{l}\text { Região é maior } \\
\text { que o local }\end{array}$ & - & $\begin{array}{l}\text { Região como } \\
\text { formação } \\
\text { histórica } \\
\text { social, com } \\
\text { identidade e } \\
\text { consciência } \\
\text { comunitária }\end{array}$ \\
\hline $\begin{array}{l}\text { Esferas } \\
\text { consideradas }\end{array}$ & $\begin{array}{l}\begin{array}{l}\text { Econômica, } \\
\text { social } \\
\text { política }\end{array} \\
\text { e }\end{array}$ & - & $\begin{array}{l}\text { Dimensão } \\
\text { econômica }\end{array}$ & $\begin{array}{l}\text { Aspectos sociais } \\
\text { e econômicos }\end{array}$ & $\begin{array}{l}\text { Econômica, } \\
\text { social, política, } \\
\text { cultural } \\
\text { natural }\end{array}$ \\
\hline $\begin{array}{l}\text { Dinâmica } \\
\text { focalizada }\end{array}$ & $\begin{array}{l}\text { Transforma- } \\
\text { ções } \\
\text { qualitativas } \\
\text { endógenas }\end{array}$ & $\begin{array}{l}\text { Crescimento } \\
\text { econômico } \\
\text { autonomia } \\
\text { regional. } \\
\text { Sustentabilidade }\end{array}$ & - & $\begin{array}{l}\text { Processo } \\
\text { mudança }\end{array}$ & $\begin{array}{l}\text { Transforma- } \\
\text { ções } \\
\text { qualitativas } \\
\text { endógenas }\end{array}$ \\
\hline
\end{tabular}

Quadro 5 - Conceitos de desenvolvimento regional comparados

O que se percebe, a partir dos conceitos analisados, é que as concepções de desenvolvimento regional aparentemente apresentam uma ênfase maior no aspecto econômico, com foco para a capacidade produtiva das regiões.

Dessa forma, a partir da comparação dos conceitos de desenvolvimento definidos pelos autores analisados, optou-se por adotar o conceito de desenvolvimento local no presente esforço de pesquisa. Essa escolha é justificada pela aparente maior abrangência dessa perspectiva, em que o desenvolvimento é considerado como um processo de longo prazo, que envolve mudanças econômicas, sociais, políticas, culturais e ambientais, visando à melhoria das condições de vida da sociedade de maneira sustentável, a partir dos potenciais endógenos da localidade. 


\begin{tabular}{|c|c|c|c|}
\hline 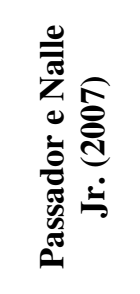 & 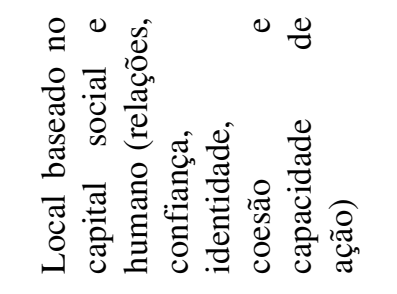 & 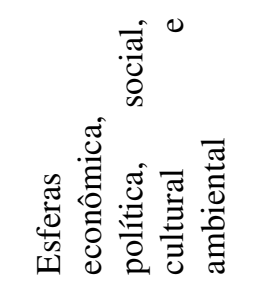 & 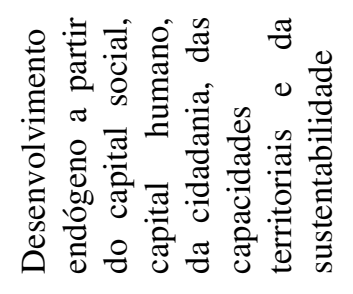 \\
\hline 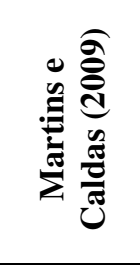 & 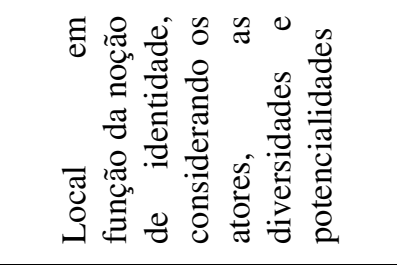 & 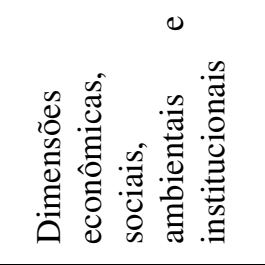 & ' \\
\hline 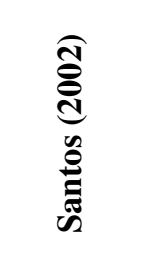 & 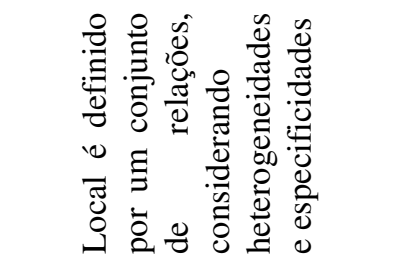 & I & ' \\
\hline 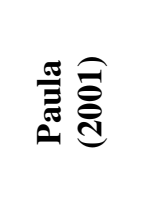 & 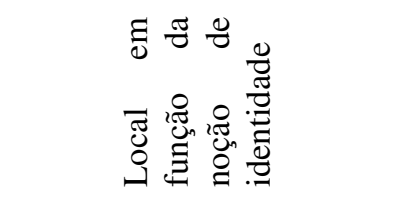 & 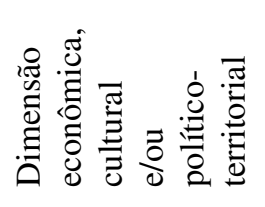 & ' \\
\hline 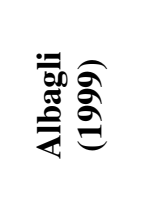 & 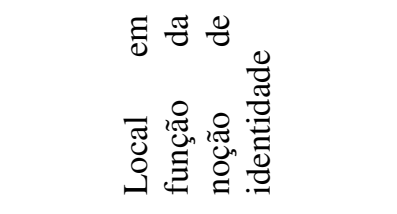 & 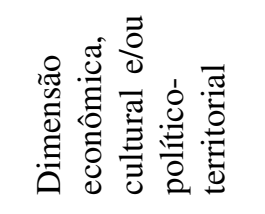 & ' \\
\hline 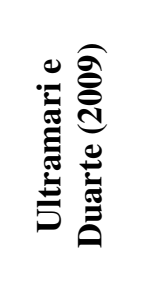 & 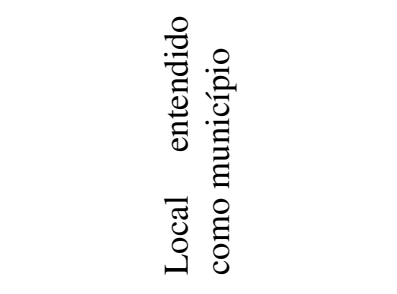 & 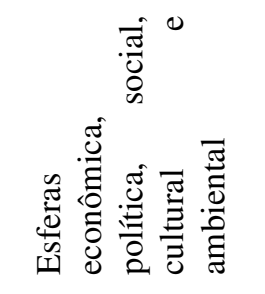 & 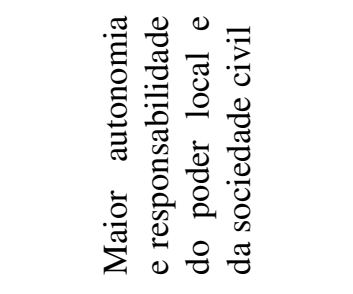 \\
\hline 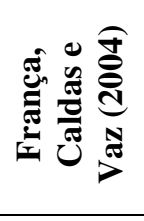 & 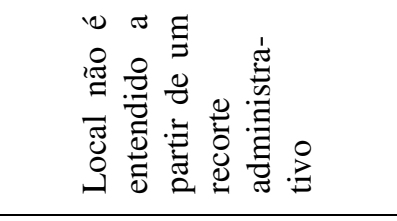 & & ' \\
\hline 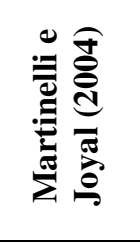 & 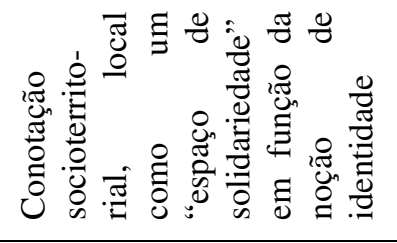 & & 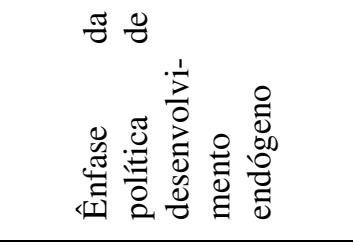 \\
\hline 递 & 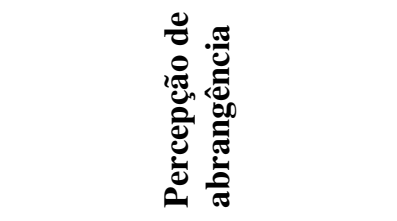 & 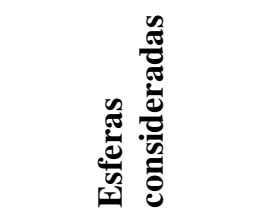 & 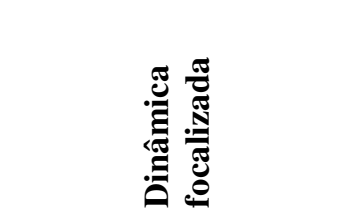 \\
\hline
\end{tabular}


Além disso, o "local", nesta pesquisa, é considerado a partir da formação socioterritorial, baseada na noção de identidade e pertencimento criada em dada localidade, definindo seus limites; isto é, o local pode ser formado por alguns bairros, um município ou um conjunto deles, formando uma região. A perspectiva dos limites do local é dependente do referencial de análise, uma vez que, ao estudar a dinâmica de desenvolvimento de um país, um estado ou um conjunto de estados pode ser considerado como uma localidade para fins de estudo. Da mesma forma, ao analisar um estado, um conjunto de municípios pode ser visto como um local. Assim, o desenvolvimento local foi considerado como o conceito mais amplo e mais adequado a este esforço de pesquisa, exatamente por buscar compreender a dinâmica do desenvolvimento, a partir de sua essência, em uma tentativa de englobar a maior diversidade possível de aspectos dessa dinâmica.

\subsection{ATORES DO DESENVOLVIMENTO}

A partir da abordagem cartesiana, o desenvolvimento adquiriu uma visão fragmentada em termos de instrumentos e ações dos atores envolvidos. Martins, Vaz e Caldas (2010) alertam para o predomínio de uma visão fragmentada na promoção do desenvolvimento, em que um ou poucos instrumentos são selecionados, deixando de explorar complementaridades que poderiam significar novas possibilidades de ação. Sachs (2008) também alerta para a fragmentação predominante no mundo, a despeito do discurso de globalização, representada pelo desequilíbrio e pelas desigualdades. A superposição, ou disjunção e contrariedade das políticas e ações de fomento ao desenvolvimento causam a impressão de desarticulação entre as instituições que deveriam dialogar entre si nos processos de planejamento do desenvolvimento local (ROCHA NETO; BORGES, 2011). As possibilidades de articulação dos diferentes instrumentos de promoção do desenvolvimento precisam ser mais bem entendidas, sendo que tais instrumentos não são universais, isto é, não podem ser replicados em qualquer contexto, mas sim entendidos como parte do repertório à disposição dos atores (MARTINS; VAZ; CALDAS, 2010).

Em uma perspectiva internacional, Tisch e Wallace (1994) apresentam a diversidade de atores em projetos de cooperação para o desenvolvimento: países doadores, países beneficiários de auxílio, fundações doadoras, agências não-governamentais implementadoras, 
empresas de consultoria, organizações beneficiárias de localidades específicas e os indivíduos. Já em nível local, Sachs (2008) enfatiza a necessidade de participação de todos os atores envolvidos no processo de desenvolvimento, que inclui trabalhadores, empregadores, o Estado, a sociedade civil organizada, entre outros.

Os vários atores sociais, por sua vez, devem compreender seus papéis distintos, tanto aqueles embasados no território, quanto os de instituições externas à comunidade (MARTINS; VAZ; CALDAS, 2010). Para garantir que as iniciativas associadas ao desenvolvimento local tenham alguma chance de sucesso são necessárias condições mínimas e quando tais condições existem o desenvolvimento se baseia em decisões tomadas pelos atores locais, que podem decidir nada fazer (MARTINELLI; JOYAL, 2004). Os distintos processos de desenvolvimento local dependem das diferentes dinâmicas de envolvimento político e participação social das comunidades no processo decisório, na resolução de conflitos gerados pelo desenvolvimento passado e nas definições dos rumos do desenvolvimento futuro (BECKER, 2010b).

Para Martinelli e Joyal (2004), todo processo de desenvolvimento local pressupõe a criação de novas instituições para o desenvolvimento, com a participação de gestores públicos e privados; o incentivo a iniciativas empresariais inovadoras; e a melhoria da capacidade da força de trabalho local. Porém, o desenvolvimento não depende somente das diretrizes e intervenções do Estado ou das atividades empresariais, mas sim do conjunto da comunidade, ou seja, gestores públicos, atores privados empresariais e sociedade civil em seu conjunto (ALBUQUERQUE, 1998). Becker (2010b, p. 41) defende que "[...] uma sociedade mais organizada socialmente é uma sociedade mais participativa politicamente. E uma sociedade mais participativa politicamente é uma sociedade muito mais desenvolvida economicamente".

Os processos de desenvolvimento são distintos dinamicamente e as localidades que (re)agem ativamente às oportunidades globais oferecidas pelo processo de desenvolvimento contemporâneo conseguem integrar os interesses locais regionalmente, criando um modelo próprio e específico, inserindo-o na dinâmica global de desenvolvimento. Dessa forma, tais regiões desenvolvem suas potencialidades, em vez de apenas reagirem passivamente e, o desenvolvimento resulta, então, do envolvimento direto dos agentes regionais, econômicos, sociais e políticos na concepção e execução de um projeto próprio (BECKER, 2010b).

O desenvolvimento, então, é uma tarefa coletiva da sociedade, necessitando de consenso de todos os atores sociais envolvidos no processo (MARTINELLI; JOYAL, 2004). Nesse sentido, Albuquerque (1998) afirma que nas estratégias de desenvolvimento local, o 
espaço territorial e a sociedade local são concebidos como agentes de transformação social, reiterando o potencial endógeno de desenvolvimento através de recursos humanos, institucionais, econômicos e culturais.

Para Becker (2010a), o desenvolvimento de uma comunidade emerge da capacidade de criar e da articulação dos seus agentes sociais, econômicos e políticos em torno de um processo de desenvolvimento regionalizado. Além disso, Becker (2010a, p. 89) defende que cada vez mais, as novas combinações de desenvolvimento dependem de iniciativas políticoinstitucionais e menos da regulação do mercado, cada vez mais "as habilidades desenvolvidas pelo conjunto dos agentes econômicos, sociais e políticos são determinantes da dinâmica de desenvolvimento". Assim, o desenvolvimento trata-se de um processo complexo, resultante de múltiplos determinantes e desafios (BECKER, 2010a).

A abordagem conhecida como "Hélice Tripla" ou "Hélice Tríplice" sugere uma proposta intermediária entre o livre mercado e o planejamento centralizado, enfatizando a soma das ações conjuntas dentro e entre as esferas institucionais representadas pela universidade, pela indústria e pelo governo (BRISOLLA et al., 1997). O objetivo é de que a interação fomente a inovação (IPIRANGA; FREITAS; PAULA, 2010), melhorando as condições para sua geração numa sociedade baseada no conhecimento (MELLO, 2004). Com essas relações, a dinâmica da inovação passa a ser responsabilidade das três esferas, não sendo mais exclusiva da indústria ou apenas da universidade através das pesquisas aplicadas. No entanto, nesse contexto de cooperação existe uma série de questões culturais, vantagens e barreiras, políticas governamentais, formas contratuais e arranjos baseados em distintos objetivos e motivações das partes envolvidas (IPIRANGA; FREITAS; PAULA, 2010). Além de estarem submetidas a essa variedade de motivações, as estratégias de inovação na abordagem da Hélice Tríplice são subordinadas às especificidades locais e aos seus distintos desenvolvimentos históricos (MELLO, 2004).

Nesse modelo, a indústria é vista como o local, o governo como a fonte de relações contratuais que garantem relações estáveis e a universidade como a fonte de novos conhecimentos e tecnologias. Assim, a cooperação entre universidade e indústria é facilitada por políticas governamentais de ciência e tecnologia (MELLO, 2004), além dos editais e programas de incentivo à parceria (IPIRANGA; FREITAS; PAULA, 2010).

À medida que o conhecimento torna-se um insumo cada vez mais central para o desenvolvimento, a universidade, enquanto um espaço institucional de geração e transmissão de conhecimentos passa a ser vista como um ator social de destaque (MELLO, 2004). Conforme Brisolla et al. (1997), as universidades, na América Latina, tiveram sua 
contribuição dirigida, principalmente, à formação de recursos humanos. Entretanto, a criação de mecanismos de interação universidade-empresa pode ser estabelecida de diversas formas: acordos de cooperação, criação de empresas que busquem capital de risco, trabalhos de consultoria, contratos de pesquisa cooperativa, implantação de parques tecnológicos e participação de docentes na administração e conselho das empresas (BRISOLLA et al., 1997).

A abordagem da Hélice Tríplice ressalta o imperativo, por parte dos atores institucionais, de se adaptarem às situações em curso, de passarem a assumir novos papéis e novas funções (MELLO, 2004). Esse formato sugere indagações acerca da participação de cada um dos atores nessas relações de cooperação e também a respeito dos benefícios e desvantagens para cada um deles. A maior participação da universidade no desenvolvimento local por meio das relações de cooperação com empresas e governo poderá auxiliar no fortalecimento da mesma, trazendo alguns benefícios listados por Brisolla et al. (1997): maior visibilidade junto à sociedade; ampliação da experiência dos docentes; aumento do volume de recursos financeiros; diversificação das linhas de pesquisa; maior flexibilidade fornecida pelos recursos dos contratos; ampliação dos grupos de pesquisa e o treinamento de pessoal; treinamento de alunos; e atualização de disciplinas. Da mesma forma, Brisolla et al. (1997) cita alguns aspectos negativos da interação para a universidade: redução da oferta de disciplinas ou de publicações; redução da dedicação para com os alunos; foco em problemas de curto prazo no ensino em detrimento de uma formação mais generalista; diminuição da atenção à formação de recursos humanos; perda da pluralidade na escolha de temas de pesquisa. Apesar das diferenças e das barreiras, tanto as universidades, como o governo e a indústria, reconhecem as vantagens dessa cooperação, seja para cada parte envolvida, como para o desenvolvimento local de forma geral, ampliando o interesse nessa dinâmica (IPIRANGA; FREITAS; PAULA, 2010).

Martins, Vaz e Caldas (2010) analisam experiências de desenvolvimento local com participação de diferentes agentes, tais como: governo, comunidades organizadas pela igreja, empresários constituindo associação, ONGs, sindicatos de trabalhadores, cooperativas, movimentos sociais, associação de moradores e setor privado. Em geral, a sociedade civil tem vantagens na condução de processos com o objetivo de construir novos padrões de relacionamento social a partir da alteração da estrutura produtiva; isso se justifica pelo conflito entre a dinâmica dos governos, sujeita ao sistema político e prazos eleitorais, e a lógica de mudança das mentalidades, que envolve mudança cultural de longo prazo (MARTINS; VAZ; CALDAS, 2010). 
Segundo Becker (2010a, p. 75), na dinâmica atual do desenvolvimento, é possível observar duas ordens de determinação, que, em geral, seguem movimentos opostos: "uma, definida pelo primado do econômico, devastando nações e regiões; a outra, perseguida pelas sociedades regionais e nacionais, reagindo à devastação e buscando proteger-se, defendendo suas sociedades da destruição". Nesse contexto, o poder público apresenta-se como mediador entre a esfera econômica e a esfera social. Conforme Becker (2010b, p. 39-40) a reação à devastação e a busca por proteção é resultado

[...] da capacidade organizacional dos agentes regionais (econômicos, sociais, políticos) de superar as contradições e resolver os conflitos através da integração dos interesses locais com os interesses socioambientais regionalizados e destes com os interesses econômico-corporativos transnacionalizados.

Cardoso Junior (2011) enfatiza a importância do Estado para induzir ou catalisar a vontade de desenvolvimento em nível nacional e coletivo, articulando os atores e regiões. Seguindo a mesma opinião, Albuquerque (1998) defende que os poderes públicos devem intervir a fim de permitir as negociações dos diferentes atores sociais em prol de uma meta comum, que é conseguir o desenvolvimento socioeconômico territorialmente equilibrado e ambientalmente sustentável. Já Martinelli e Joyal (2004) enfatizam o papel desse ator no auxílio às populações locais a se emanciparem, desvinculando-se de sua própria influência e das grandes empresas. Ele promove e estimula novas formas de trabalho e produção, impedindo a marginalização de indivíduos e empresas, e os auxiliando a se integrar ao mercado e aos novos processos produtivos. Conforme Cardoso Junior (2011), o Estado é um ator estratégico em qualquer processo de desenvolvimento, já que é o responsável por garantir a segurança interna, por ordenar o uso sustentável do território, por regular, enfim, a atividade econômica e promover políticas públicas. Logo, o setor público tem um papel importante para a integração e cooperação entre os diferentes elementos da comunidade local (MARTINELLI; JOYAL, 2004), embora sua ação isolada não seja suficiente (MARTINS; VAZ; CALDAS, 2010).

Fatores como a necessidade de modelar instituições, combinada com a complexidade crescente e a rápida velocidade das mudanças têm aumentado as demandas dos responsáveis pelo desenvolvimento local. Quanto mais complexas são as situações, mais dependente é o desenvolvimento local da liderança e da capacidade de gestão de redes de indivíduos-chave (SOTARAUTA, 2009). Nesse sentido, as organizações empresariais representam cada vez mais um ator relevante no contexto de desenvolvimento, já que sua relevância e seu poder de influência são significativos em relação aos dos indivíduos isoladamente. 
As organizações empresariais tornam-se centrais nesse contexto, sendo, concomitantemente, causa e efeito das principais mudanças ocorridas nos últimos tempos (AXLEY; MACMAHON, 2006; CLOSS; ANTONELLO, 2010). Elas afetam direta ou indiretamente a vida da maioria da população global, seja pela geração de empregos e renda, pela produção de bens e serviços ou pela criação de subprodutos (intencionais ou não) que resultam tanto em benefícios como em prejuízos à sociedade e ao meio ambiente (AXLEY; MACMAHON, 2006; CLOSS; ANTONELLO, 2010).

Albuquerque (1998) também enfatiza o papel central do desenvolvimento produtivo e empresarial, através de inovação tecnológica, para o desenvolvimento econômico local, colocando as empresas privadas no foco do debate. De acordo com Frey e Frey (2004), elas passaram a assumir parte desse papel devido à inoperância do poder público em resolver questões de ordem social, com a vantagem de não ficarem limitadas às políticas locais, regionais ou nacionais, tendo maior flexibilidade e agilidade no equacionamento e solução de problemas sociais. $\mathrm{O}$ estudo destes autores defende que a responsabilidade social empresarial se reflete numa sociedade mais humana e igualitária, levando, consequentemente, a uma comunidade local mais desenvolvida econômica e socialmente.

Ademais, Oliveira e Wittmann (2010) alertam para a tendência à tomada de consciência dos empresários e gestores públicos para a necessidade de integração dos interesses do mercado e da sociedade a fim de alcançar o sucesso de uma organização. Para os autores, o gerenciamento tornou-se o fator decisivo de produção, uma vez que os recursos tradicionais de produção, como terra, mão de obra e dinheiro, não mais garantem vantagem competitiva a uma nação.

A partir do prisma da qualidade de vida, o Brasil tem muito que melhorar. Para isso, Dowbor (2001) defende que não se trata de atrair mais empresas produtivas com tecnologia avançada e que criem empregos, mas sim de organizar o reequilíbrio social do Brasil. De acordo com Dowbor (2001), parcerias envolvendo o setor estatal, ONG e empresas privadas vêm sendo realizadas. "Surgem com força conceitos como responsabilidade social e ambiental do setor privado. [...] As empresas privadas ultrapassam a visão do assistencialismo, para assumir responsabilidade que lhes confere o poder político efetivo que têm" (DOWBOR, 2001, p. 216).

Nessa nova ordem mundial, em que a complexidade é percebida pela abertura dos mercados e interfaces empresariais, as organizações passam a perceber vários fatores que interferem na competitividade, "pois a concorrência global passou a inserir novos padrões de 
qualidade, produtividade e inovação" (WITTMANN; DOTTO; BOFF, 2004, p. 20). Assim, surge a necessidade de adaptação a fim de compatibilizá-las com padrões mais avançados de competitividade. A busca de uma posição estratégica competitiva compreende, além do atendimento diferenciado às demandas do mercado, o atendimento das demandas sociais e ambientais (OLIVEIRA; WITTMANN, 2010).

Nesse contexto, conforme Oliveira e Wittmann (2010), a gestão, ou competência gerencial, torna-se fator essencial a propostas de mudanças qualitativas e melhoria dos indicadores sociais, reforçando, por sua vez, a importância da administração na sociedade. Em uma sociedade onde a complexidade e as interdependências das organizações são aspectos essenciais, a gestão surge como fator-chave para a melhoria da qualidade de vida e para a solução de problemas complexos.

Segundo Wittmann, Dotto e Boff (2004), entre as alternativas existentes, as alianças, parcerias e redes de cooperação associadas a aglomerados, arranjos produtivos e sistemas locais de produção, constituem estratégias indispensáveis ao sucesso de qualquer negócio, pois aumentam a sinergia entre os envolvidos. Nesse ambiente, as organizações empresariais associam o desenvolvimento individual ao coletivo, pelo aumento da interdependência e compartilhamento de ações coordenadas:

\footnotetext{
nesse cenário, empresas que possuem algum vínculo relacional, privilegiam o aglomerado como alternativa competitiva para se desenvolverem e em contrapartida permitem à região manter uma diversidade de relações sociais, baseadas na complementaridade, interdependência e cooperação (WITTMANN; DOTTO; BOFF, 2004, p. 21).
}

As aglomerações de empresas, chamadas de clusters, têm tido sucesso em vários países, uma vez que são estimuladas a organizarem-se de forma cooperativada, o que proporciona maiores vantagens competitivas (WITTMANN; DOTTO; BOFF, 2004). Para Amato Neto (2000), a emergência de novas formas de organização interfirmas, envolvendo cooperação entre empresas (redes de negócios) e formação de aglomerados, ou a constituição de sistemas locais de produção, oferecem elementos originais e estratégicos ao enfrentamento dos novos desafios. Nesse contexto, "surgem as joint ventures, as redes empresariais, os arranjos locais de produção (ALP), os sistemas locais de produção (SLP), os sistemas locais de inovação e produção (SLI/P), os distritos industriais, os arranjos territoriais e outras formas interativas" (WITTMANN; DOTTO; BOFF, 2004, p. 23, grifo nosso).

Wittmann, Dotto e Boff (2004) defendem que os negócios devem ser analisados sob a perspectiva das empresas e dos países em que estão inseridos, uma vez que os negócios dependem não somente da relação entre o produtor e o consumidor, mas também do esforço dos governos para viabilizar todo o processo produtivo e as relações comerciais. De acordo 
com Wittmann, Dotto e Boff (2004), como a cooperação empresarial e sua interface com o desenvolvimento regional foram intensificadas, em muitos países essa forma de organização da atividade produtiva conta com o apoio de políticas públicas para sua implementação, por meio de apoio à formação de blocos industriais e de portfólio industrial, além de políticas governamentais de comércio, de infraestrutura, de contexto institucional, além de macroeconômicas.

As redes existem em todo lugar e em qualquer escala (BARABÁSI, 2007). Apesar de serem consideradas como os componentes fundamentais das organizações (CASTELLS, 1999), o real impacto da formação de redes empresariais na economia da região é sentido a partir do momento em que elas se reorganizam em grande escala, construindo relacionamentos entre as redes atuantes no mercado (WITTMANN; DOTTO; BOFF, 2004).

No contexto global, é possível perceber a ascendência competitiva de grandes empresas em detrimento de governos, sendo que blocos ou aglomerados de empresas interferem tanto regional como localmente (WITTMANN; DOTTO; BOFF, 2010). Assim, para potencializar o desenvolvimento e integrar governos com empresas, agregando valor do regional ao global e ao local, os mecanismos de gerenciamento devem associar-se ao capital social, criando potencial endógeno para evitar desequilíbrios culturais, sociais e econômicos (SEN, 2000). Para isso, Wittmann, Dotto e Boff (2004) destacam a necessidade de participação de todos os agentes do desenvolvimento, como escolas, universidades, laboratórios, associações e órgãos públicos, conjugando esforços e preservando o modelo de cooperação empresarial.

Nessa mesma direção, Oliveira e Wittmann (2010) alertam para a necessidade de integração dos interesses do mercado e da sociedade a fim de alcançar o sucesso de uma organização, enfatizando o papel essencial do gerenciamento integrado, chamado de Sistema Integrado de Gestão (SIG) pelos autores. Ele é considerado um método gerencial capaz de atender as demandas dos diferentes interessados, contribuindo à melhoria de indicadores econômicos e sociais, internos e externos à organização, constituindo uma "via ética para o desenvolvimento das organizações e, por que não dizer, de regiões e nações", de forma sustentável (OLIVEIRA; WITTMANN, 2010, p. 286).

Os fatores determinantes na competitividade de uma empresa já não se limitam aos fatores estruturais de mercado e concorrência, incluindo variáveis sistêmicas, como macroeconômicas, político-institucionais, legal-regulatórias, infraestruturais, sociais e internacionais. "Ademais, ainda que o mercado seja global, suas fontes de sustentação serão 
regionais, pois carregam a marca da interação com o lugar do qual a organização se serve de seres humanos, energia, matérias-primas, infraestrutura física, tecnológica e institucional" (OLIVEIRA; WITTMANN, 2010, p. 287). Nesse contexto, os autores defendem que a falta de uma abordagem sistêmica de gestão, integrando os diferentes interesses das partes envolvidas, é um dos fatores a inibir a sinergia nos processos econômicos e organizacionais de desenvolvimento.

O local deve ser inserido de maneira autônoma no global, transformando informação (global e local) em conhecimento para obter vantagem competitiva em longo prazo, ligada aos agentes locais. Entretanto, esta dinâmica depende da postura dos agentes sociais, econômicos e políticos ligados ao lugar, em torno de um projeto regionalizado, próprio, específico e, portanto, diferenciado. Essa abordagem dialética engloba a totalidade dos processos de desenvolvimento (OLIVEIRA; WITTMANN, 2010).

Para Oliveira e Wittmann (2010), a gestão integrada consiste em uma alternativa para restabelecer o equilíbrio entre o econômico e o social nas organizações, já que o equilíbrio das demandas e tendências globais com as potencialidades locais é o grande desafio contemporâneo dos agentes dos processos de desenvolvimento. O SIG proposto compreende, além da gestão de sistemas considerados tradicionais (finanças, produção, logística e recursos humanos), a gestão ambiental, a gestão da segurança e saúde do trabalhador e a gestão da responsabilidade social. Logo, a integração desses sistemas procura estabelecer a sustentabilidade do desenvolvimento sob uma perspectiva sistêmica.

Se os princípios do SIG viessem a ser um dos pontos de sustentação e incentivo das administrações públicas e privadas, talvez muitos dos esforços da sociedade, hoje desordenados e mesmo conflitantes, teriam maiores chances de serem compatibilizados e orientados a um desenvolvimento socialmente justo e responsável (OLIVEIRA; WITTMANN, 2010, p. 314).

Diante do exposto, entende-se que cada ator do desenvolvimento local possui um papel distinto nesse fenômeno, sendo crítico o envolvimento e a sinergia entre eles. Entretanto, além dessa integração entre os atores na dinâmica do desenvolvimento, outros aspectos devem ser observados para que as iniciativas tenham maior probabilidade de sucesso. Esses requisitos são tratados no próximo tópico. 


\subsection{REQUISITOS DO DESENVOLVIMENTO}

Em um contexto de complexidade, cuja dinâmica requer a participação dos diversos atores para a implementação de iniciativas equilibradas, muitos aspectos têm sido apontados como requisitos para o desenvolvimento.

Muitos autores (MARTINELLI; JOYAL, 2004; RAMOS; MARIÑO, 2004; SACHS, 2008) enfatizam a necessidade de incluir vertentes como a humana (melhoria de vida das pessoas), a político-social (melhoria da vida da sociedade como um todo) e a sustentabilidade (preocupação com o presente e com o futuro) nas iniciativas de desenvolvimento, estimulando os demais fatores que as afetam (perspectivas sociais, culturais, políticas, morais e éticas). $\mathrm{Na}$ visão de Sachs (2008), o desenvolvimento possui objetivos mais amplos do que apenas a multiplicação da riqueza material, apresentando requisitos para sua efetividade.

Para Ramos e Mariño (2004), os pré-requisitos sociais do desenvolvimento são: integração social (identidade e consciência comunitária); geração e distribuição de capital social; e mobilidade social, assim como a sua projeção sobre a realidade contemporânea, em termos de indicadores empíricos, sociais e econômicos. Entende-se que tais indicadores estão associados à presença dos pré-requisitos em questão, que "são historicamente condicionados pelas configurações originais de ocupação dos territórios e relações sociais ali estabelecidas" (RAMOS; MARIÑO, 2004, p. 79).

Ramos e Mariño (2004) adotam a concepção do desenvolvimento defendida por Becker (2010b), em que o processo de desenvolvimento contemporâneo inclui duas direções, a do processo global corporativo derivado da globalização e incidindo como fator exógeno nas comunidades locais, e do processo de reação à globalização, em termos socioambientais, emanando endogenamente nas comunidades locais. Dessa forma, Ramos e Mariño (2004) defendem que o processo contemporâneo de desenvolvimento sofre interferência de condicionantes como as condições históricas regionais, sociais e físico-naturais, projetando-se sobre o processo de desenvolvimento inclusive sobre sua dinâmica atual. Seguindo a mesma orientação, Sachs (2001) reafirma a capacidade de pensar de forma endógena como determinante para o potencial de um país.

Ao defender o desenvolvimento baseado em potencialidades endógenas, para que as comunidades sejam por ele beneficiadas, diversos fatores devem ser reunidos: o grau de educação da população, a decisão do poder local e dos diferentes níveis de governo, a 
participação da sociedade e a capacidade de atração de novos investimentos externos. Além disso, as vocações da comunidade devem ser identificadas, isto é, as vantagens que uma localidade apresenta em relação a outras, para que uma potencialidade se torne dinâmica (MARTINELLI; JOYAL, 2004).

As iniciativas de desenvolvimento local devem ser estabelecidas a partir de estruturas próprias da região, visando superar seu empobrecimento. Entretanto, é preciso levar em conta a oscilação do mercado, sem se submeter totalmente às suas exigências. Por isso, o empreendedorismo local é central, sendo que se deve avaliar o perfil de empresa que pode surgir em consequência das intervenções no âmbito do planejamento estratégico. Além disso, o poder público, mesmo diante da descentralização administrativa, deve estimular e arbitrar tais relações (MARTINELLI; JOYAL, 2004).

Moraes (2010, p. 280) também defende a necessidade de aproveitar potencialidades endógenas e, apesar das limitações estruturais, a investigação de como os fatores regionais podem ser potencializados torna-se necessária:

\begin{abstract}
para promover o desenvolvimento de um determinado território (seja Estado, região, município ou distrito), é necessário estudar o grau de aproveitamento dos seus recursos e potencialidades endógenas. Fatores regionais que têm influência direta sobre a dinâmica do desenvolvimento regional podem ser potencializados pela capacidade organizativa, técnica e gerencial das administrações locais, pela capacidade de articulação e mobilização dos recursos e pela formação social e da base econômica local-regional.
\end{abstract}

Para alcançar um desenvolvimento autossustentável, ou seja, que além do crescimento econômico, reflita-se na melhoria das condições de vida da população, governo e sociedade devem ser agentes ativos, buscando alternativas de mudanças (MARCUZZO; AREND; RAMOS, 2004). Martinelli e Joyal (2004) também argumentam que para promover o desenvolvimento de maneira adequada e efetiva é necessário investir em vários tipos de capital de maneira equilibrada, incluindo: (a) capital humano, que é o conhecimento e a capacidade de criá-lo; (b) capital social, que está relacionado à capacidade de organização da sociedade, envolvendo confiança, cooperação e bom nível de governo; e (c) capital natural, que diz respeito às condições ambientais e territoriais. Nessa mesma direção, Passador e Nalle Jr. (2007) definem o capital social, o capital humano, a cidadania, as capacidades territoriais e as condições de sustentabilidade como bases do desenvolvimento local, devendo ser determinados endogenamente.

Ramos e Mariño (2004) também apontam o capital social, tanto no seu sentido individual quanto no comunitário, como fator chave para o desenvolvimento. O capital social em nível individual envolve a incorporação dos códigos e informações necessários à 
autopromoção do indivíduo nos campos de poder social; já o capital social em nível comunitário é relativo à capacidade organizacional das comunidades (RAMOS; MARIÑO, 2004). Nesse contexto, enfatiza-se a capacidade de reação e assimilação dinâmica, por parte das comunidades regionais, às forças globais de desenvolvimento capitalista, ou seja, a capacidade de incorporar elementos exógenos às formas regionais próprias, preservando a unidades, as qualidades sociais e físico-naturais regionais (RAMOS; MARIÑO, 2004).

Moraes (2010, p. 271) avalia os propósitos e as potencialidades das políticas públicas como indutoras da formação de capital social, uma vez que, para o autor, o "desenvolvimento local-regional está diretamente ligado às características da organização social e das relações cívicas encontradas em uma região". Para Moraes (2010, p. 271), "capital social significa relações sociais 'institucionalizadas' na forma de normas ou de redes sociais". Para Putnam (2005), capital social é o conjunto de características da organização social, entre elas as redes de relações, normas de comportamento, valores, confiança, obrigações e canais de informação.

Ramos e Mariño (2004, p. 86) ainda afirmam que quanto mais democratizado o capital social individual, maiores as possibilidades de geração e acumulação de capital social comunitário; ou seja, "quanto maiores as condições de participação comunitária dos indivíduos (pelo seu acesso ao capital social), maior o potencial organizacional da comunidade".

A noção de identidade comunitária ou consciência coletiva, frequentemente conceituada como identidade coletiva, é apresentada como outro pré-requisito ao desenvolvimento local (RAMOS; MARIÑO, 2004). A identidade, conforme Castells (1999, p. 41) tem sido a base do significado desde os primórdios da sociedade humana: "em um mundo de fluxos globais de riqueza, poder e imagens, a busca da identidade, coletiva ou individual, atribuída ou construída, torna-se a fonte básica de significado social". Entretanto, a identidade está se tornando a principal, e às vezes única fonte de significado (CASTELLS, 1999). Quanto mais nítida e maior seja a condição de sujeito centrada na formação socioespacial, maiores serão as chances de desenvolvimento democrático local (RAMOS; MARIÑO, 2004).

A noção de mobilidade, se referindo "às mudanças de posição que os indivíduos e os grupos experimentam uns com relação aos outros e com relação a critérios externos", também é apontada por Ramos e Mariño (2004, p. 87) como um pré-requisito ao desenvolvimento, considerando que em uma sociedade democrática (com os pré-requisitos citados acima) as 
distâncias sociais não são tão grandes e há igualdade de oportunidades, permitindo a mobilidade social. Ramos e Mariño (2004, p. 97) lançam a hipótese de que

quanto maiores os graus de exclusão, exploração e dominação não legítima, menores as possibilidades de se desenvolver a consciência comunitária, o capital social e muito menos a mobilidade social, os quais consideramos pré-requisitos ou peças chave para o advento de níveis mais altos de desenvolvimento.

Sen (2000) apresenta um foco voltado às condições básicas para a cidadania, já que defende que o desenvolvimento requer que as principais fontes de privação de liberdade sejam removidas, sejam elas: pobreza e tirania, carência de oportunidades econômicas e destituição social sistemática, negligência dos serviços públicos e intolerância ou interferência excessiva de Estados repressores. Além disso, as liberdades elementares devem ser garantidas: alimentação, nutrição satisfatória, remédios, vestuário, moradia adequada, acesso à água tratada, saneamento básico, saúde e educação (SEN, 2000).

Para Albuquerque (1998), além do apoio político e administrativo dos setores públicos locais, a negociação estratégica entre atores socioeconômicos locais (associações de empresários, entidades financeiras, centros de consultoria para empresas, universidades e institutos de pesquisa e desenvolvimento, entre outros), com o objetivo de incorporar inovações tecnológicas e organizativas no tecido empresarial e produtivo local, é considerada decisiva para o desenvolvimento da localidade.

O tempo também se apresenta como requisito para que as iniciativas de desenvolvimento sejam implementadas. Segundo Martins, Vaz e Caldas (2010), a articulação dos atores sociais pressupõe um prazo de maturação e um custo de organização e de institucionalização; o tempo não é condição suficiente, mas permite reunir capacidades institucionais, formular consensos e construir relações de confiança para viabilizar as ações.

Ainda, segundo Martinelli e Joyal (2004), é importante equilibrar a dinâmica competitiva e a cooperativa no contexto do desenvolvimento local, uma vez que a dinâmica cooperativa é fundamental para formar a comunidade de maneira ponderada e justa, prevalecendo a solidariedade, enquanto a dinâmica competitiva insere a comunidade num processo de desenvolvimento racional, dirigido pelas forças do mercado.

A expressão conhecida como Desenvolvimento Local Integrado e Sustentável (Dlis) é utilizada tanto para se referir a abordagens voltadas para o econômico, como a abordagens mais sistêmicas de desenvolvimento. O Dlis visto a partir dessa abordagem mais sistêmica é considerado uma via possível para a melhoria da qualidade de vida das populações e para a conquista de modos de vida mais sustentáveis (MARTINELLI; JOYAL, 2004). Para Franco (2001), o Dlis permite às comunidades se tornarem mais sustentáveis e capazes de suprir suas 
necessidades imediatas, descobrir suas vocações, desenvolver suas potencialidades e fomentar o intercâmbio externo, aproveitando-se das vantagens locais.

Conforme Sachs (2008), o conceito de desenvolvimento sustentável acrescenta a dimensão da sustentabilidade ambiental à da sustentabilidade social; isto é, ela é baseada na ideia de solidariedade diacrônica com as gerações futuras. Nesse sentido, Paiva (2004, p. 37) enfatiza as desigualdades, afirmando que "a distribuição da propriedade (e, por extensão, da renda) é a condição necessária e quase-suficiente do desenvolvimento capitalista sustentável”. Incluindo a noção de distribuição, Sachs (2008) lista os cinco pilares do desenvolvimento sustentável: social, ambiental, territorial (distribuição espacial dos recursos, das populações e das atividades), econômico e político.

Segundo Sunkel (2001), a noção de desenvolvimento sustentável vincula a temática do desenvolvimento econômico com a do meio ambiente, relacionando três âmbitos: a) o dos comportamentos humanos econômicos e sociais; b) o da evolução da natureza; e c) o da configuração social do território. As formulações conceituais básicas da ecologia e das leis fundamentais da termodinâmica permitem relacionar as diferentes disciplinas científicas que se ocupam desses três âmbitos; uma vez que o enfoque convencional da economia apresenta limitações quanto a essas formulações, que impedem a compreensão do conceito de desenvolvimento sustentável (SUNKEL, 2001).

A primeira e fundamental é a noção de ecossistema, que é entendido como a "unidade de análise que integra as inter-relações entre os elementos vivos (a espécie humana, a flora e a fauna) e os inanimados (os elementos e processos energéticos, físicos e químicos) em uma determinada área" (SUNKEL, 2001, p. 296). Já a biosfera é o conjunto de biomas, que são os conjuntos de ecossistemas de um mesmo tipo, e constitui a unidade ecológica global. Os ecossistemas proporcionam bens e serviços para a sociedade, entretanto, tais bens e serviços são grátis, não têm preço e não implicam gastos. Essa questão é alheia à natureza do enfoque econômico predominante, uma vez que o fluxo circular da economia (fatores de produção transformados em bens e serviços que geram um fluxo de remunerações, que permitem adquirir mais fatores de produção) não leva em consideração a existência inevitável dos fluxos de resíduos e desperdícios, nem dos seus efeitos posteriores, de acordo com a primeira lei da termodinâmica (SUNKEL, 2001).

Tais subprodutos são gerados pelo processo produtivo de uma forma nociva, e a população é levada a consumir esses produtos indesejáveis, ocultando seus efeitos reais sobre a saúde e o bem-estar, gerando custos sociais não considerados e aumentando o montante de 
investimento necessário para o desenvolvimento (SUNKEL, 2001). Essas interferências excessivas podem ser assimiladas até certo ponto pelos ecossistemas (regeneração, autoreprodução), entretanto, se elas excederem certos limites, podem desorganizar os ciclos regeneradores e reprodutivos, produzindo um colapso ecológico, levando à desintegração dos ecossistemas e ao desaparecimento de suas capacidades produtivas. Portanto, o capital ecológico é o elemento crítico para a manutenção, não só do desenvolvimento, mas da própria sobrevivência da localidade, região ou país (SUNKEL, 2001).

Resumidamente, os requisitos do desenvolvimento apontados pelos autores estudados incluem: participação dos diversos atores; ampliação do foco de atuação (incluindo as vertentes: humana, política, social, cultural e ambiental); integração social; dinamização das potencialidades endógenas; empreendedorismo local; poder público arbitrando as relações e incentivando a capacidade produtiva local; investimento em capital humano, social e natural; mobilidade social e igualdade de oportunidades; atendimento às necessidades básicas (alimentação, nutrição satisfatória, remédios, vestuário, moradia adequada, acesso à água tratada, saneamento básico, saúde e educação); disponibilidade de tempo; equilíbrio da dinâmica competitiva e cooperativa; e sustentabilidade.

Diante da apresentação do desenvolvimento local como um fenômeno que envolve distintos atores e está sujeito a uma variedade de requisitos, este trabalho busca verificar se a Complexidade consiste em uma base teórica adequada para a compreensão de sua dinâmica, em uma tentativa de sugerir uma abordagem coerente para o tratamento desse fenômeno. 


\section{PROCEDIMENTOS DE PESQUISA E ANÁLISE DOS RESULTADOS}

O presente trabalho caracteriza-se como uma pesquisa teórica, com o objetivo de verificar se os fundamentos epistemológicos e metodológicos da teoria da complexidade são adequadas para descrever a dinâmica do fenômeno do desenvolvimento local. Segundo Demo (1994, p. 35), a pesquisa teórica é "orientada para a (re)construção de teorias, quadros de referência, condições explicativas da realidade, polêmicas e discussões pertinentes”. Além disso, a teoria configura-se como "um conjunto de princípios fundamentais que se constituem em instrumento científico apropriado na procura e principalmente na explicação dos fatos" (MARCONI; LAKATOS, 2010, p. 98).

Sua importância se deve à formação de quadros teóricos de referência, constituindo contextos essenciais para o pesquisador (DEMO, 2008). Marconi e Lakatos (2010) também alertam para a importância da teoria, defendendo o inter-relacionamento entre teoria e fato, ambos indispensáveis à abordagem científica. "O embasamento teórico é fundamental para o desenvolvimento de qualquer tipo de pesquisa e avanço de qualquer campo da ciência" (PARRA FILHO; SANTOS, 2003, p. 101).

Apesar da pesquisa teórica não implicar imediata intervenção na realidade, seu papel é decisivo para construir condições básicas para a mesma, sendo que o investimento em conhecimento constitui-se como principal instrumento de intervenção competente, determinando sua qualidade (DEMO, 1994). Demo (2008) destaca alguns procedimentos fundamentais para a formação de um quadro teórico de referência, incluindo: domínio dos clássicos de determinada disciplina, domínio da bibliografia fundamental e capacidade crítica.

Este esforço de pesquisa pode ser caracterizado por apresentar natureza descritiva, analisando se os fundamentos epistemológicos da Complexidade podem auxiliar na compreensão do processo do desenvolvimento, conforme o quadro 7; utilizando recursos teóricos para transpor ferramentas conceituais da Complexidade para a descrição da dinâmica do desenvolvimento. Segundo Cervo e Bervian (2002), a pesquisa descritiva observa, registra, analisa e correlaciona fenômenos sem manipulá-los, buscando conhecer um fenômeno, suas relações e conexão com outros, sua natureza e características; ou seja, a pesquisa descritiva trabalha com dados ou fatos da própria realidade.

O foco deste trabalho está na sugestão de uma alternativa para a descrição da dinâmica das relações entre as unidades do problema, e não na descrição dos objetos. Toffler (1995) já 
defendia a necessidade da síntese para superar os desafios impostos pela fragmentação excessiva dos conhecimentos e práticas. Este tipo de fundamentação exige um tipo de apreensão do conhecimento manifestado através da intuição (TERRA, 2010; TERRA; PASSADOR, 2011). Capra (2006) defende a validade e segurança do conhecimento (ou consciência) intuitivo, que se baseia numa experiência da realidade decorrente de um estado ampliado de percepção consciente, tendendo a ser sintetizador, holístico e não-linear, apropriado à construção de um conhecimento integrativo. "A análise é a decomposição de um todo em suas partes. A síntese é a reconstituição do todo decomposto pela análise" (CERVO; BERVIAN, 2002, p. 38). A síntese da totalidade do fenômeno, obtida por meio da integração, é relevante para a construção do conhecimento complexo (TERRA, 2010) e exige o abandono do ideal cartesiano de ciência (DEVLIN, 1996).

\begin{tabular}{|l|c|}
\hline \multicolumn{2}{|c|}{ Fundamentos epistemológicos da complexidade, adotados pelo presente estudo } \\
\hline Foco de estudo & Relações \\
\hline Sujeito/Objeto & Indissociáveis \\
\hline Preceito & Integração $\leftrightarrow$ Desintegração \\
\hline Hemisfério cerebral dominante & Direito $\leftrightarrow$ Esquerdo \\
\hline Conhecimento & Intuitivo \\
\hline Inferência predominante & Dedutiva \\
\hline Causalidade & Recursiva \\
\hline Modelos & Não-lineares \\
\hline Linguagem & Simbólica \\
\hline
\end{tabular}

Quadro 7 - Fundamentos epistemológicos da complexidade adotados pelo presente estudo Fonte: adaptado de Terra, 2010, p. 103.

A epistemologia busca a definição tanto de uma teoria geral do conhecimento como de um estudo mais limitado acerca da criação e estrutura das ciências (SERVA; DIAS; ALPERSTEDT, 2010). Conforme Vergara (2010, p. 2), “epistemologia está referida ao conhecimento, à crença de como ele pode ser transmitido: se de forma tangível, objetiva, ou se mais subjetivamente, mais baseado na experiência pessoal". A postura investigativa da fenomenologia segue a linha da epistemologia antipositivista, que tende a rejeitar a noção de que a ciência pode gerar qualquer tipo de conhecimento objetivo (VERGARA, 2010). Foi Heisenberg que, através do "princípio da incerteza", constatou a indissociabilidade entre observador-observado, reintroduzindo o sujeito no processo de observação científica, em que a singularidade subjetiva e os valores são determinantes para a percepção da realidade (BAUER, 1999).

Moreira (2002) apresenta duas posições epistemológicas possíveis: o positivismo, que advoga que os métodos das ciências naturais devem ser transpostos ao estudo do homem; e o interpretativismo, que defende que as especificidades do ser humano exigem para seu estudo 
um conjunto metodológico diferente, que considere o fato do homem interpretar continuamente o mundo em que vive. Já Donaires (2012), baseado nas diferentes formas de encarar a realidade social, aponta os três paradigmas sociológicos enraizados em três tradições filosóficas: positivismo, interpretativismo e a ciência crítica. O interpretativismo tem como propósito entender e interpretar as ocorrências e estruturas sociais, assim como o significado que as pessoas dão aos fenômenos. A natureza da realidade, ou ontologia, é múltipla, construída por meio da interação humana, sendo holística e divergente no interpretativismo. Já a natureza do conhecimento, ou epistemologia, baseia-se no entendimento dos eventos pelo processo mental de interpretação, que é influenciado e interage com o contexto social. Além disso, o interpretativismo é limitado pelos valores, com um inter-relacionamento entre o conhecedor e o conhecimento (DONAIRES, 2012).

No interpretativismo, portanto, os sistemas são vistos como abstrações conceituais, criados a partir do olhar subjetivo dos participantes humanos que fazem parte do sistema (DONAIRES, 2012). Nesse contexto, seguindo a posição epistemológica do interpretativismo, este trabalho considera a interpretação e a experiência como base fundamental de pesquisa.

Conforme Pádua (2008, p. 31), “a compreensão do método no paradigma da complexidade se refere à atividade pensante e consciente do sujeito e ao reconhecimento da presença (participação) do sujeito em todo o processo de conhecer”. Partindo dos objetivos do trabalho, foi verificada necessidade de adoção de uma perspectiva interpretativa, uma vez que o fenômeno que se busca compreender não poderia ser analisado empiricamente, em um curto espaço de tempo, de acordo com a ciência cartesiana.

De acordo com Furtado (1963), ao tratar de desenvolvimento não se lida com relações estáveis derivadas da observação do mundo real, estas são resultantes de esquemas mais ou menos simplificados da realidade. Assim, é preciso definir até que ponto é possível eliminar as suposições simplificadoras incompatíveis com a realidade sem invalidar a eficácia explicativa do modelo abstrato teórico (FURTADO, 1963). O desenvolvimento local é um fenômeno cujos limites não podem ser definidos objetivamente, exigindo seu estudo por meio da interpretação e, principalmente, das experiências do pesquisador. Logo, a partir desse aspecto, além do caráter descritivo da pesquisa e de indissociabilidade entre sujeito e objeto, característica da Complexidade, foi adotado o método de redução fenomenológica de Husserl, como base para a coleta e análise de evidências. Apesar das contribuições de seus discípulos como Heidegger (2000), Merleau-Ponty (1999) e Vergara (2010), que criticaram a suposta 
capacidade de desligamento dos valores e das concepções prévias do pesquisador, não foi encontrado outro método estruturado de avaliação da realidade.

A fenomenologia constitui a base deste trabalho de pesquisa, já que se busca compreender a essência de um fenômeno assumindo a subjetividade e experiência do pesquisador. Segundo Moreira (2002), a fenomenologia é um dos movimentos filosóficos mais importantes do século XX, tendo como precursor mais importante Edmund Husserl (DONAIRES, 2012). Edmund Husserl (1859-1938) introduziu a fenomenologia como uma perspectiva crítica, uma reação ao positivismo e à negação da subjetividade, a partir de uma vertente conhecida como fenomenologia descritiva ou transcendental (VERGARA, 2010). A base da fenomenologia, que tem uma relação direta com a ciência social interpretativa de Weber, está na intencionalidade, ou seja, no conceito de que toda atividade mental consciente é pensar sobre algo (DONAIRES, 2012).

Fenomenologia é o estudo do fenômeno, ou seja, o estudo de tudo o que aparece, que se manifesta ou se revela por si mesmo, tudo que se torna visível à nossa consciência (MOREIRA, 2002). Segundo Giles (1975, p. 132), a fenomenologia preocupa-se em prover uma descrição pura da realidade: “[...] a fenomenologia se apresenta como um estudo puramente descritivo dos fatos vivenciais do pensamento e do conhecimento oriundo dessa observação". Segundo Donaires (2012), a preocupação central da fenomenologia é a natureza e o conteúdo do pensamento sobre o mundo, em substituição ao próprio mundo no positivismo, ou seja, ela toma como dados primitivos o processo mental dos observadores, e não o mundo externo a eles. O desenvolvimento local é um fenômeno que envolve uma diversidade de variáveis, não pode ser isolado no tempo e espaço, além de caracterizar um processo contínuo e fluido, cuja existência dificilmente pode ser determinada objetivamente através de indicadores quantificáveis. O desenvolvimento envolve noções subjetivas como a ideia de identidade, cultura, valores e a sensação de pertencimento, que não podem ser ignoradas ao estudar o tema. Dessa forma, a fenomenologia, neste trabalho, permite o estudo do desenvolvimento local considerando tais aspectos, admitindo a interpretação do pesquisador sobre o fenômeno. Ela "permite explorar situações, valores e práticas com base na visão de mundo dos próprios sujeitos", admitindo a presença da subjetividade do pesquisador (VERGARA, 2010, p. 76).

Considerando como fenômeno tudo aquilo de que podemos nos aperceber na consciência, de qualquer modo que seja, a fenomenologia será, pois, o estudo dos fenômenos puros, cuja tarefa é o estudo da significação das vivências da consciência (MOREIRA, 2002). Para Dartigues (1992, p. 22), a tarefa da fenomenologia é "analisar as vivências intencionais 
da consciência para perceber como aí se produz o sentido dos fenômenos". De acordo com Martins (1992, p. 50), fenomenologia é o nome de um movimento que busca a investigação direta e a descrição de fenômenos experienciados pela consciência, "sem teorias sobre a sua explicação causal e tão livre quanto possível de pressupostos e de preconceitos".

A fenomenologia pretende ser, por essência, dinâmica, mantendo a consciência sempre aberta. Ou seja, os termos e conceitos não são estáticos, podendo se diferenciar conforme o próprio progresso da análise da consciência e do conhecimento de novos níveis fenomenológicos (GILES, 1975). Assim como o desenvolvimento local não é estático, sua descrição através da análise fenomenológica não o é, sendo apenas uma tentativa de compreensão da essência do fenômeno, que permita o estabelecimento de iniciativas com algum nível de fundamentação teórica.

Toda a orientação da fenomenologia consiste em dirigir o conhecimento para o essencial das coisas. Ela não se orienta para fatos, sejam externos ou internos, mas sim para a realidade da consciência, ou seja, para os objetos enquanto intencionados por e na consciência, para as essências ideais (GILES, 1975). Ao caracterizar a fenomenologia como o estudo das essências, Martins (1992, p. 61) trata de alertar para o significado de essência, diferenciando-o do de "existência": "o mundo é aquilo que nós percebemos, não sendo apenas aquilo que eu penso, mas o que eu vivo". "O método fenomenológico enfoca fenômenos subjetivos na crença de que verdades essenciais acerca da realidade são baseadas na experiência vivida" (MOREIRA, 2002).

Para Giles (1975), a fenomenologia proporciona uma perspectiva intuitiva das essências, atingindo os fenômenos em plena evidência, por meio da intuição. Ele é considerado apropriado a situações em que haja necessidade de maior clareza no fenômeno selecionado (maior profundidade, por exemplo) e em que a experiência vivida compartilhada seja a melhor fonte de dados (MOREIRA, 2002). Assim, o método fenomenológico foi considerado apropriado a esta pesquisa, uma vez que há necessidade de maior profundidade e clareza na descrição da dinâmica envolvida no desenvolvimento local, além de considerar a experiência como a melhor fonte de dados, já que essa dinâmica é percebida à medida que se faz parte do fenômeno em estudo. Portanto, a fenomenologia constitui a postura investigativa deste esforço de pesquisa na tentativa de encontrar a essência do desenvolvimento local na consciência dos pesquisadores e, partindo dessa essência primeira, transpor os princípios e fundamentos da Complexidade para compreender a dinâmica do fenômeno. 
A fenomenologia desafia algumas de nossas convicções básicas sobre nós mesmos e o mundo (DEVLIN, 1996), uma vez que ela "deveria proporcionar um método filosófico que fosse livre por completo de todas as pressuposições que pudesse ter aquele que refletisse" (MOREIRA, 2002, p. 62). Para Husserl, o abandono de pressupostos e julgamentos é inerente ao método fenomenológico; assim, o pesquisador deve desconsiderá-los temporariamente (uma vez que não deixam de existir), sendo este procedimento denominado de redução fenomenológica (VERGARA, 2010).

A redução fenomenológica ou transcendental é também chamada de epoqué ou epoché (suspensão do julgamento, na filosofia grega). Na epoqué, o filósofo não duvida da existência do mundo, mas essa existência é colocada em suspensão, ou seja, suspendemos nossas crenças na tradição e nas ciências, opiniões e crenças acerca da existência externa dos objetos da consciência (MOREIRA, 2002). Por meio da epoché é efetuada uma desconexão do mundo natural que leva à instância primeira do conhecimento, isto é, à consciência pura ou transcendental (ZITKOSKI, 1994). Realizar a epoché, de acordo com Martins (1992, p. 56), significa "colocar em suspensão as nossas crenças sobre a existência do fenômeno que está sendo interrogado”. Ela significa suspender a adesão às verdades de todas as ciências, assim como ao mundo existente, significa colocá-los entre parênteses e suspensos. Dessa forma, o fenomenólogo não fará juízo algum sobre existências situadas no espaço e no tempo (ZITKOSKI, 1994).

O fenomenólogo deve descrever o fenômeno abstraindo hipóteses, pressupostos ou teorias, buscando exclusivamente o que se mostra, analisando sua estrutura e suas conexões intrínsecas (MARTINS, 1992). Segundo Husserl (2001, p. 72), a redução fenomenológica busca captar os tipos de objetos de forma "pura", sem inspiração em "pré-conceitos de um sistema de conceitos científicos antecipadamente admitidos”. A consciência passa a valer como uma região de ser absoluta, fonte última da explicação de todo sentido de ser válido para o conhecimento humano (ZITKOSKI, 1994).

A redução fenomenológica, ou “intuição da essência”, conforme Martins (1992, p. 56), refere-se a uma apreensão direta, imediata e atual, de uma ideia em sua realidade individual, que se dá através da consciência intencional. Pretende-se captar as propriedades abstratas ou gerais das ideias ou formas sobre o fenômeno interrogado (MARTINS, 1992). O objetivo da redução é "encontrar exatamente que partes da experiência são verdadeiramente partes da nossa consciência, diferenciando-as daquelas que são simplesmente supostas" (MARTINS, 1992, p. 59). 
Entretanto, Merleau-Ponty (1999, p. 10) já alertava para a dificuldade de neutralizar todos os valores e preconceitos, afirmando que "o maior ensinamento da redução é a impossibilidade de uma redução completa". Devido ao fluxo temporal em que as reflexões ocorrem, "não existe pensamento que abarque todo o nosso pensamento" (MERLEAUPONTY, 1999, p. 11). Nesse mesmo sentido, Devlin (1996) defende que toda ação, toda abordagem é influenciada por um contexto prévio, uma vez que o observador nunca é totalmente objetivo, sem experiências prévias. Apesar disso, para Devlin (1996) essa condição não deve ser considerada como prejudicial à nossa interpretação do mundo, as experiências prévias são necessárias para que haja interpretação, já que interpretação é sempre relativa a experiências prévias. A maneira de se livrar dos valores, conceitos e preconceitos é estar ciente de sua existência, evitando possíveis distorções (VERGARA, 2010). Neste caso, não se trata de um problema relativo à escolha do método, pois a redução fenomenológica de Husserl é a única proposta estruturada para este tipo de abordagem; mas trata-se, sim, de reconhecer que mesmo ela carrega um forte caráter intencional (contribuição dos seguidores de Husserl). E, dessa forma, a alternativa consiste em explicitar a intencionalidade existente.

De acordo com os objetivos e o problema de pesquisa, foi identificada similaridade com o estudo realizado por Terra (2010), uma vez que se trata de pesquisa teórica, buscando contribuir para a compreensão e descrição da dinâmica de um fenômeno complexo através de mecanismos baseados na intuição que, segundo Husserl (2001), é a única fonte possível do conhecimento sem pressupostos. Os passos de pesquisa sugeridos por Terra e Passador (2011) e por Terra (2010), sendo o primeiro trabalho derivado do segundo, são representados na figura 3.

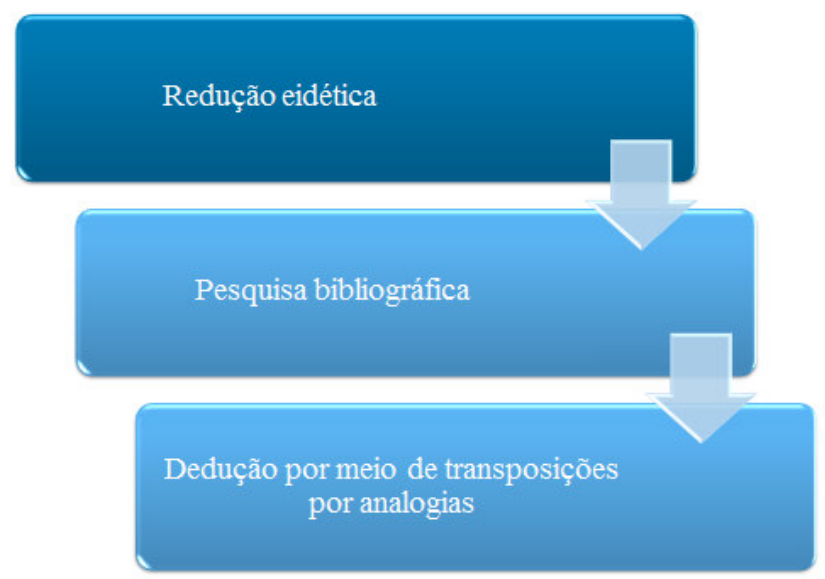

Figura 3 - Etapas do método proposto por Terra (2010) e Terra e Passador (2011) 
Terra e Passador (2011) e Terra (2010) adotam a fenomenologia de Husserl (2001) e a redução eidética, que serão, consequentemente, base deste esforço de pesquisa. Portanto, o método proposto por tais autores foi adotado parcialmente, utilizando-o na análise de um objeto de pesquisa distinto. Para este trabalho, foram utilizadas as duas primeiras etapas, sendo que a última etapa foi adaptada para melhor atender os objetivos deste esforço de pesquisa. Os procedimentos de pesquisa adotados nesta dissertação são representados na figura 4, detalhados nas próximas subseções.

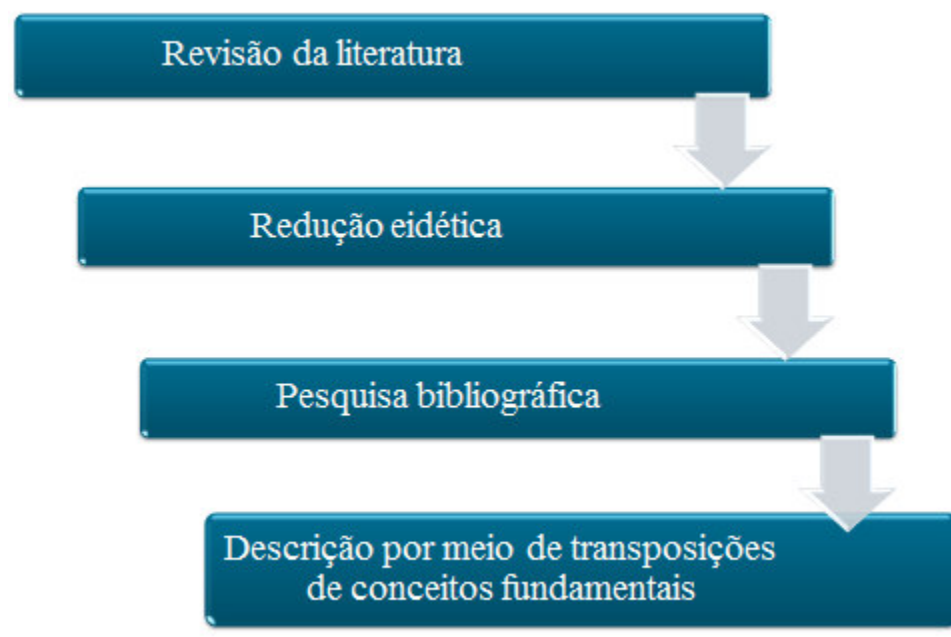

Figura 4 - Procedimentos de pesquisa nesta dissertação

De acordo com a argumentação de Terra (2010), a fim de descrever os conteúdos da consciência de forma acessível, foi adotado um procedimento em que a interpretação da evidência fenomenológica pudesse partir da abordagem teórica que parece adequada para a análise do fenômeno: a Complexidade. O objetivo desta etapa é "possibilitar a classificação e organização da descrição, de forma que esta pudesse ser compreendida e analisada diante de aspectos já familiares ao pesquisador" (TERRA, 2010, p. 107). Foram utilizados conceitos e fundamentos básicos da teoria da complexidade para descrever a dinâmica encontrada na essência primeira do desenvolvimento local, verificando sua adequabilidade para o tratamento de tal fenômeno.

Destaca-se que os procedimentos adotados neste trabalho seguem o método proposto por Terra (2010), com exceção da última etapa, que deixa de utilizar analogias com outros sistemas de áreas consolidadas, para utilizar noções fundamentais, conceitos e definições da abordagem considerada mais adequada para análise do fenômeno em questão. Essa adequação foi necessária à medida que o aprofundamento em assuntos pouco familiares aos 
pesquisadores poderia gerar dificuldades adicionais, além de resultados e análises superficiais, impedindo também que a abordagem tomada como base para este trabalho pudesse ser estudada em sua essência e profundidade adequada.

\subsection{MÉTODO DE COLETA DE EVIDÊNCIAS}

A coleta de evidências deste estudo segue três fases distintas, embora muitas vezes concomitantes, contínuas e não-lineares. Em um primeiro momento, foi realizada a revisão da literatura a respeito dos temas: teoria da complexidade, fenomenologia e desenvolvimento. Essa fase teve como objetivo o aprofundamento em relação aos temas tratados neste estudo, verificando a adequabilidade das escolhas metodológicas e epistemológicas.

Em uma segunda fase, seguindo os passos definidos em Terra (2010) e Terra e Passador (2011), foi utilizado o método fenomenológico de redução eidética, com o objetivo de elaborar, a partir da intuição, um esquema sintético da essência primeira dos aspectos do processo de desenvolvimento local.

Por fim, em uma terceira etapa, foi realizada a pesquisa bibliográfica, buscando aprofundamento em conceitos fundamentais e bases teóricas da Complexidade que pudessem descrever a evidência encontrada a partir do método fenomenológico, a fim de verificar se consiste em abordagem adequada para o estudo do desenvolvimento local. Cada fase tem seus procedimentos detalhados a seguir.

\subsubsection{Fase 1: Revisão da literatura}

A revisão da literatura é geralmente um pré-requisito para a realização de pesquisas científicas na área de ciências sociais aplicadas, sendo menos rigorosa e menos estruturada do que a pesquisa bibliográfica (LIMA; MIOTO, 2007). A revisão da literatura consiste em uma leitura não estruturada, enquanto a pesquisa ou revisão bibliográfica define-se pela estruturação de buscas sistemáticas de conteúdos previamente definidos (LIMA; MIOTO, 2007). Assim, a primeira fase abrange uma busca não estruturada para a melhor compreensão do problema de pesquisa e de seu contexto. 
Inicialmente foi realizada uma revisão da literatura, concretizada através de buscas por autores consagrados da área de desenvolvimento e obras acerca do paradigma da Complexidade acessíveis ao leitor da área de ciências sociais aplicadas. As buscas iniciais utilizaram as bases de dados ISI Web of Science e Scopus, o Sistema Integrado de Bibliotecas da Universidade de São Paulo (SIBiUSP) e o Google. Esta fase ocorreu de maneira contínua e não-linear ao longo do desenvolvimento do trabalho.

O objetivo deste levantamento inicial é o reconhecimento do problema e maior compreensão a respeito da Complexidade, assim como das perspectivas de desenvolvimento. Da mesma forma, essa etapa contribui para destacar autores e conceitos significativos para o problema, utilizados posteriormente para a estratégia de coleta de dados na etapa de pesquisa bibliográfica. É importante enfatizar que, nesta fase, as buscas não foram estruturadas, ou seja, a leitura de uma obra poderia levar à leitura de outras, e estas, por sua vez, de mais obras distintas, não necessariamente na mesma área. Foram privilegiados estudos teóricos, que se aprofundassem nas bases fundamentais de cada tema, expondo conceitos e definições essenciais. Assim, poucas obras especificamente voltadas para aplicações foram incluídas. Excluíram-se obras em idiomas que não o português, o inglês ou o espanhol.

Os critérios de inclusão foram: (CI1) Obras tratando das bases da Complexidade; (CI2) Obras tratando de teorias sobre desenvolvimento, seja ele em sentido macro, ou em nível local, regional ou territorial; (CI3) Obras acerca da fenomenologia.

\subsubsection{Fase 2: Captura da essência do fenômeno}

Concomitantemente à revisão da literatura, a segunda fase foi realizada através do processo de redução eidética, proposta por Husserl (2001). A fenomenologia, originada na filosofia, consiste no estudo do fenômeno, cuja compreensão se dá por meio das essências, ou seja, da redução eidética, que consiste na busca dos atributos sem os quais o objeto não pode ser identificado (VERGARA, 2010). "O programa da Fenomenologia a concebia como uma ciência de rigor, uma ciência eidética pura, uma ciência das essências" (MOREIRA, 2002, p. $83)$.

Para o fenomenólogo, as essências ideais são fenômenos, alcançados pela intuição antes de toda reflexão ou juízo (GILES, 1975). “As essências representam as unidades básicas de entendimento comum de qualquer fenômeno, aquilo sem o que o próprio fenômeno não pode ser pensado" (MOREIRA, 2002, p. 84). Segundo Giles (1975), uma essência pode estar fundamentada em uma singularidade sensível, configurando uma essência material (como, por 
exemplo, livro, árvore), ou categórica, sendo uma essência formal ou categoria (como, por exemplo, unidade, número).

A intuição tem por objeto primordial o universal, que é a forma capaz de se verificar invariavelmente em diferentes indivíduos, à qual corresponde a intuição eidética (GILES, 1975). Apreender a consciência através da redução fenomenológica não é suficiente, é necessário que se apreenda as essências, suas estruturas universais. A redução eidética é a forma como o filósofo se move da consciência dos objetos às essências puras, às estruturas essenciais e invariáveis (MOREIRA, 2002), entretanto, "evidentemente, a nossa evidência só vai tão longe até o ponto em que foi a nossa experiência" (MOREIRA, 2002, p. 89).

Então, busca-se a intuição das essências, também chamada de intuição (ou redução) eidética, que é um recurso metódico de fundamentação rigorosa e última do ser dos fenômenos (ZITKOSKI, 1994). Segundo Husserl (2001, p. 92), "o método da descrição eidética consiste em fazer passar todas essas descrições para a dimensão dos princípios". Para atingir as essências, utiliza-se da imaginação (MOREIRA, 2002) ou de um esforço de pensamento, ao invés de manipulações (DARTIGUES, 1992), verificando quais elementos podem ser removidos sem prejudicar a identidade do objeto de estudo (DARTIGUES, 1992). Se características que não podem ser removidas são encontradas, tais características são eideticamente necessárias ao objeto, evidenciando sua essência (MOREIRA, 2002). Ou seja, o processo intuitivo consiste em imaginar todas as variações possíveis às quais o fenômeno é suscetível, sendo que o invariante define sua essência, ou eîdos (DARTIGUES, 1992; GILES, 1975; ZITKOSKI, 1994).

A partir das características do contexto ambiental, político, social e econômico expostas na introdução deste trabalho, foi realizado o esforço de redução eidética. Assim, a evidência primeira dos aspectos internos e externos do desenvolvimento local, considerado um subsistema do sistema de desenvolvimento mais amplo (nacional, planetário), é apresentada no esboço da figura 5. Esse esboço foi adaptado do trabalho desenvolvido por Terra (2010), que determinou a essência primeira do problema estratégico. Isso foi possível devido às similaridades dos dois estudos.

Considerando que o esboço de Terra (2010) apresenta a essência primeira das organizações, é possível ampliá-lo para os diversos tipos de atores do desenvolvimento, uma vez que a teoria de sistemas amplia o conceito de organização (HOLANDA, 2001).

Num certo sentido, desde o átomo até a galáxia, passando pela molécula, a célula, o organismo e a sociedade, pode ser concebida como sistema, ou seja, associação combinatória 
de elementos diferentes (MORIN, 2011). Conforme Holanda (2001), a teoria de sistemas enquadra num mesmo contexto, por exemplo, um átomo, um cristal, uma molécula ou uma empresa; isto é, tais organismos possuem características comuns, como crescimento, diferenciação, ordem hierárquica, controle, competição etc. Essas características estão presentes tanto em um organismo vivo, como numa empresa, numa sociedade ou nação (HOLANDA, 2001).

Essa ideia é reforçada por Capra (2006, p. 381) na descrição do conceito de “economia", apresentada a partir da concepção sistêmica como "um sistema vivo composto de seres humanos e organizações sociais em contínua ação entre si e com os ecossistemas circundantes de que nossas vidas dependem". A maioria das definições caracteriza as organizações como um indivíduo ou um conjunto de indivíduos inter-relacionados (MORAES, 2001) que se reúnem em função de um objetivo principal, necessitando de gerenciamento para minimizar ou prever problemas.

A teoria das organizações amplia a tipologia das organizações. Houaiss e Villar (2009, p. 1396) definem organização como uma "entidade que serve à realização de ações de interesse social, político etc.; instituição, órgão, organismo, sociedade". Para Ferreira (1986, p. 1232), uma organização constitui-se de uma "associação ou instituição com objetivos definidos", apresentando um conceito mais geral. Nesse sentido, Daft (2002, p. 11) apresenta uma definição mais completa das organizações: "são entidades sociais que são dirigidas por metas, são desenhadas como sistemas de atividades deliberadamente estruturados e coordenados e são ligadas ao ambiente externo". Tal autor enfatiza os relacionamentos presentes em uma organização, resultado da interação entre os indivíduos para realizar funções essenciais seguindo um objetivo (DAFT, 2002). Neste esforço de pesquisa o conceito de "organização" é utilizado seguindo uma interpretação mais ampla, incluindo os diferentes tipos de atores do desenvolvimento.

Dessa forma, partindo da ampliação do conceito de organização, o presente esforço de pesquisa tem como base a essência primeira descrita por Terra (2010), utilizando-a para representar os diversos tipos de atores do desenvolvimento.

De acordo com Beer (1994b), o reconhecimento de um sistema, de suas fronteiras e de seu propósito é altamente subjetivo, dependendo do observador. Isto leva à afirmativa de que não é possível atribuir propósitos, ou mesmo fronteiras, a sistemas como se estes fossem fatos objetivos da natureza. Isso não significa que não se pode comunicar a respeito de sistemas, ou que não seja possível desenvolver afirmações científicas sobre sistemas; mas que deve haver um acordo acerca da natureza, das fronteiras, e dos propósitos de qualquer sistema antes que 
se possa concordar com o que conta como fato (BEER, 1994b). A demarcação das fronteiras do sistema, arbitrária ou não, precisa ser delineada no trabalho científico prático (ASHBY, 1970). Segundo Donaires (2012), a identificação das fronteiras de sistemas não-físicos, como organizações sociais, é um desafio, pois a flexibilidade do sistema depende do desejo dos indivíduos que fazem parte dele ou que fazem uso do sistema. Muitas vezes, essa identificação só é possível por meio de um acordo entre as partes envolvidas, apesar da importância dessa identificação para a geração de modelos úteis (DONAIRES, 2012). Logo, é importante salientar que a abstração deste esforço de pesquisa tem as fronteiras definidas de acordo com a interpretação, estabelecendo os limites com o objetivo de permitir a análise do sistema da melhor forma possível, apesar das limitações cognitivas humanas.

No esboço, os hexágonos em preto representam os seres humanos, cujas inter-relações - apresentadas na mesma cor - ocorrem por meio de trocas tangíveis e intangíveis. Os círculos azuis representam a estrutura física das organizações, e neste caso, são desenhados com linhas descontínuas para indicar sua permeabilidade ao ambiente.

As organizações se relacionam com os seres humanos que as compõem representados dentro dos círculos fronteiriços. Estas organizações são formadas pelas relações entre humanos e estrutura, relacionando-se entre si e com outros humanos e entidades análogas, formando o ambiente, que, neste trabalho, será considerado o sistema em busca do desenvolvimento, em sua multiplicidade de dimensões: política, legal, social, cultural, econômica, ambiental e tecnológica. As setas vermelhas representam as inter-relações entre a organização, os seres humanos e o ambiente - composto por outros sistemas locais em busca do desenvolvimento. No esboço deste trabalho, foram incluídas representações de grupos informais, que também são agentes do desenvolvimento local, embora sem estrutura definida. Grupo, segundo Ferreira (1986, p. 871) é uma "pequena associação ou reunião de pessoas ligadas para um fim comum". Para Michaelis (1998, p. 1057), é um "conjunto de pessoas que têm os mesmos sentimentos, representações e juízos de valor e apresentam os mesmos tipos de comportamento". Houaiss e Villar (2009, p. 992) definem grupo como "conjunto de indivíduos com características, objetivos, interesses comuns". Os grupos são representados no esboço devido à ação de conjuntos de indivíduos para alcançar um objetivo comum que, consequentemente, afetam a dinâmica do desenvolvimento. Assim, os hexágonos pretos com setas mostrando suas relações correspondem a grupos de seres humanos que se reúnem em torno de um mesmo objetivo, sem estrutura formalizada, ou seja, sem o círculo azul ao seu redor. 

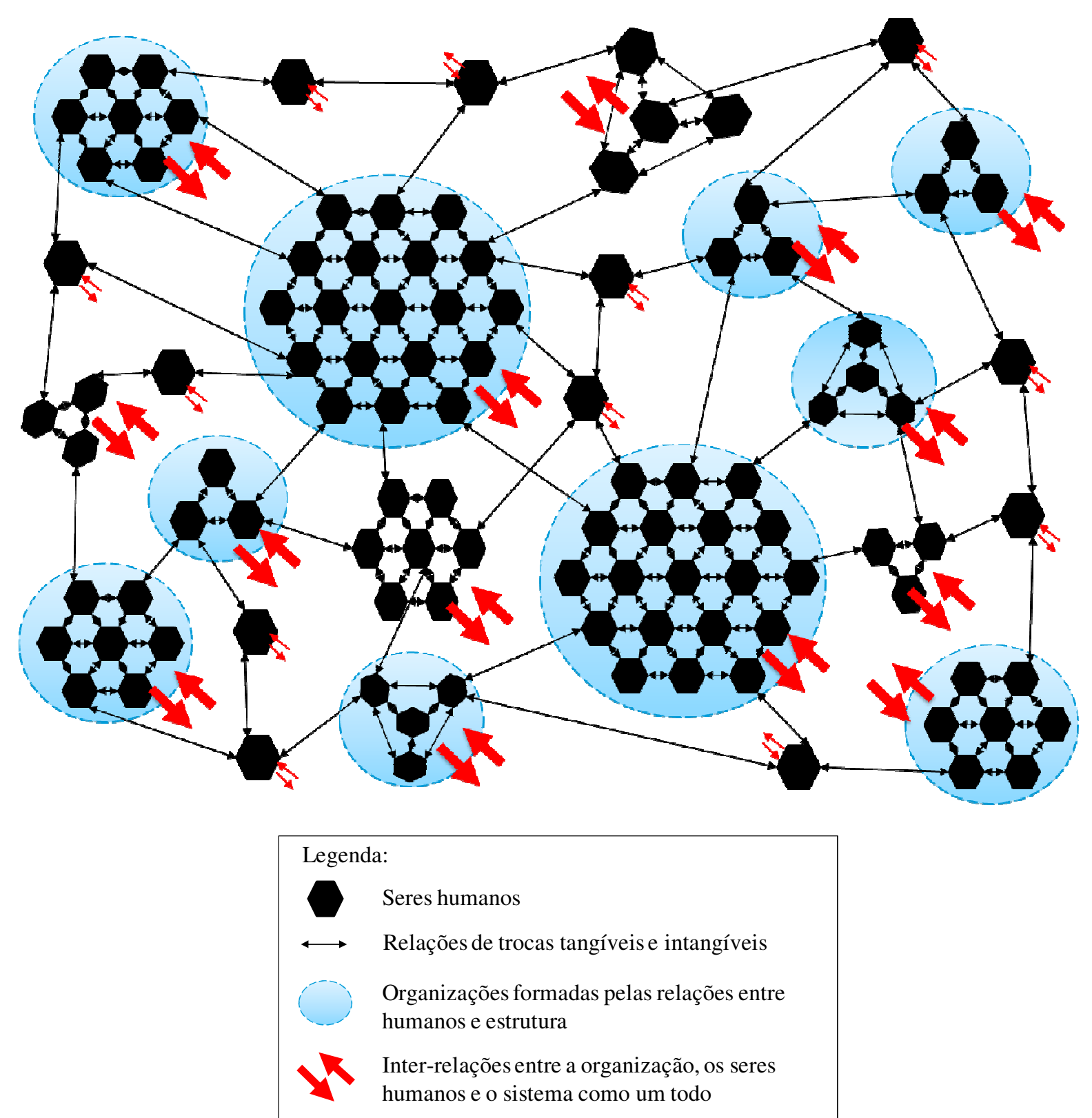

Figura 5 - Esboço da essência primeira do subsistema de desenvolvimento local Fonte: adaptado de Terra (2010).

Como, neste trabalho, busca-se verificar a complexidade envolvida na dinâmica do desenvolvimento local, este é o nível em foco, sendo representado, a título de contextualização, também o sistema maior de que o mesmo é parte, e seus subsistemas. A recursividade ilimitada precisa ser arbitrada na prática pelo observador, definindo os limites de recursão já que os distintos níveis de recursão definem níveis hierárquicos diferentes (DONAIRES, 2012). A figura 6 representa o esboço da essência primeira do desenvolvimento em nível mais macro, embora com limite de recursividade estabelecido, considerando as relações entre os sistemas locais (ou até mesmo entre os sistemas nacionais) de 
desenvolvimento, representadas pelas setas na cor preta, que ocorre por meio de comunicação e troca de materiais. Os círculos tracejados na cor preta representam as fronteiras dos subsistemas de desenvolvimento, que possuem identidade, valores, objetivos e cultura próprios. Além disso, as setas vermelhas, neste caso, configuram as inter-relações entre os subsistemas de desenvolvimento e o sistema planetário, que contemplam energia, elementos orgânicos e inorgânicos, conforme Terra (2010).
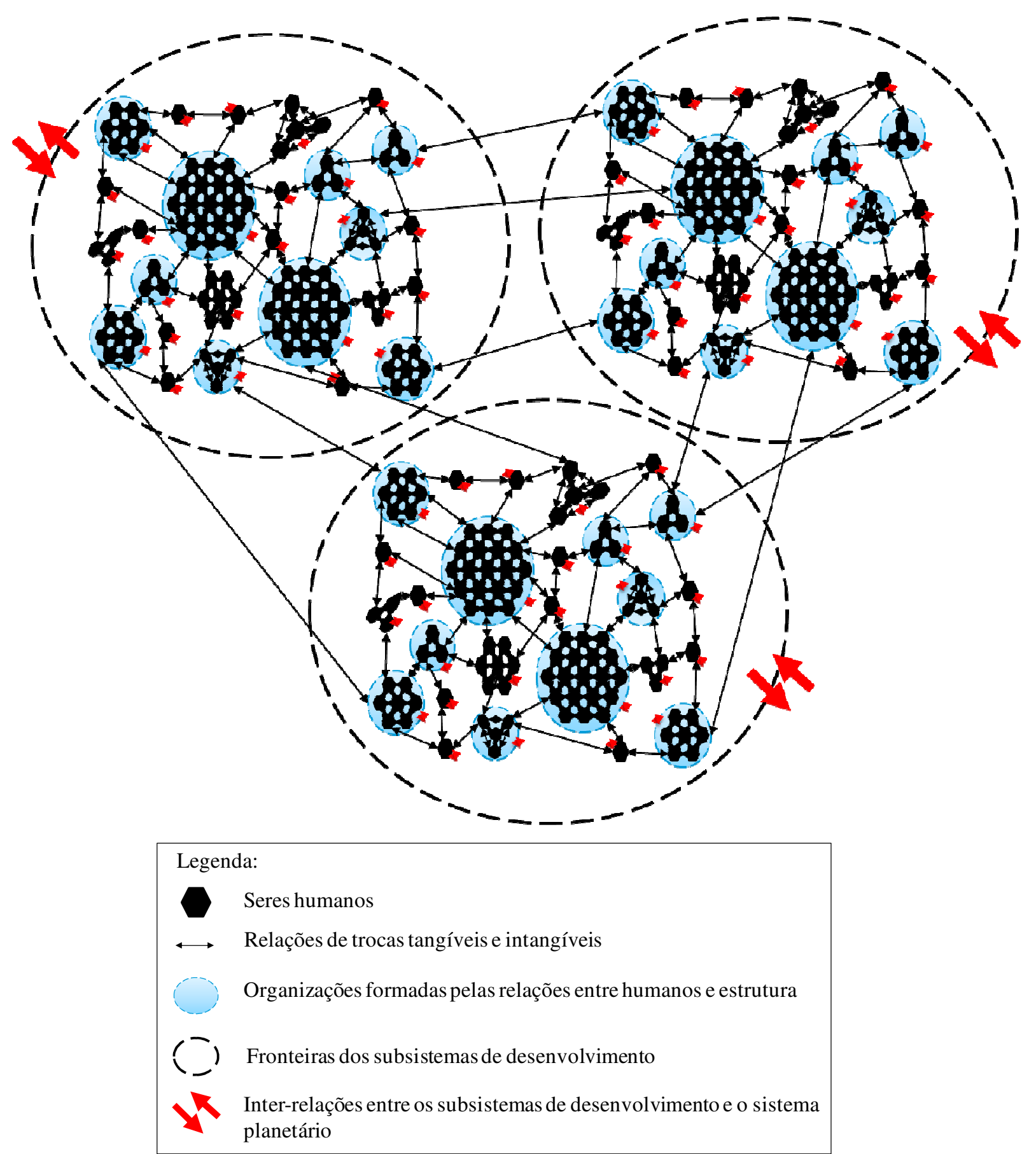

Figura 6 - Esboço da essência primeira do desenvolvimento 
Os esboços ilustrados nas figuras 5 e 6 mostram a evidência primeira dos aspectos internos e externos do desenvolvimento, uma vez que a remoção de qualquer das relações indicadas torna o sistema incompatível com os aspectos essenciais das relações no desenvolvimento. "Se isolássemos uma cidade, ela morreria. Estrutura e função são inseparáveis" (PRIGOGINE, 1996, p. 65).

Se o sistema do desenvolvimento e seus subsistemas deixam de se relacionar com o sistema planetário, o sistema como conhecemos deixa de existir, pois não há mais trânsito de matéria e energia. Tal dinâmica se mostra evidente e necessária para manutenção dos ambientes contemporâneos, conservando sua identidade. Se as organizações e grupos informais deixam de se relacionar entre si e com o ambiente, este último deixa de existir da maneira como o conhecemos, já que as trocas de informações e materiais caracterizam o sistema em busca do desenvolvimento. Se os humanos deixam de se relacionar entre si e com a estrutura física da organização, ocorre o mesmo tipo de desintegração, pois sem as trocas as organizações não têm razão de existir.

Dessa forma, todas as relações propostas são essenciais para que o sistema que compõe o processo de desenvolvimento exista e se mantenha da forma com que ele é percebido pela consciência intuitivamente. Logo, as figuras 5 e 6 apresentam-se como evidência primeira, cada qual em seu respectivo nível, a serem submetidas ao esforço organizador de uma etapa analítica. O resultado dessa etapa é a matéria prima básica para uma etapa posterior.

Segundo sugestão de Terra (2010) e Terra e Passador (2011), é importante ressaltar que a elaboração da descrição da essência primeira do desenvolvimento foi realizada previamente à discussão sobre as diversas perspectivas de desenvolvimento. Essa prática teve o objetivo de minimizar a influência de concepções prévias sobre os conteúdos da consciência, nos quais poderia se basear a construção da essência primeira.

\subsubsection{Fase 3: Pesquisa bibliográfica}

Depois de concluída a construção da evidência primeira e com a revisão da literatura avançada, foi realizada a fase de pesquisa bibliográfica. Esta seguiu as recomendações de Cooper e Schindler (2011), que sugerem a definição clara do problema e o estabelecimento prévio das declarações de busca de conteúdos, para serem usados na descrição da evidência primeira. 
Segundo Lima e Mioto (2007), não é raro que a pesquisa bibliográfica seja caracterizada como revisão da literatura ou revisão bibliográfica. A revisão da literatura é apenas um pré-requisito para a realização da pesquisa, enquanto a pesquisa bibliográfica requer um conjunto ordenado de procedimentos de busca por soluções, atento ao objeto de estudo, e, por isso, não pode ser aleatório (LIMA; MIOTO, 2007).

A pesquisa bibliográfica diz respeito à leitura, seleção, fichamento, organização e arquivamento de um conjunto de conhecimentos de interesse para o pesquisador (FACHIN, 1993); ela abrange toda a bibliografia já tornada pública sobre o tema em estudo, permitindo o exame deste sob novo enfoque ou abordagem (MARCONI; LAKATOS, 2010). A pesquisa bibliográfica pode ser realizada como parte da pesquisa descritiva, ao buscar as contribuições do passado sobre um determinado assunto (CERVO; BERVIAN, 2002, p. 65). Neste esforço de pesquisa, a pesquisa bibliográfica busca literatura a respeito de conceitos e dinâmicas fundamentais da Complexidade, que possam ser utilizados para descrever a dinâmica envolvida na essência primeira do desenvolvimento local.

O fichamento, apresentado por Marconi e Lakatos (2010) como uma das fases da pesquisa bibliográfica, tem como objetivo disponibilizar uma série de informações ao pesquisador, de maneira prática e organizada, consultadas em um grande número de obras (PARRA FILHO; SANTOS, 2003). Essa técnica foi considerada essencial para o esforço de pesquisa, uma vez que, conforme Goldenberg (1999, p. 84), "ao fichar um livro, somos obrigados a ler com profundidade, buscando compreender cada ideia e categoria utilizada". Os fichamentos das obras neste esforço de pesquisa foram realizados conforme sugere Goldenberg (1999): foi realizada uma primeira leitura, com o objetivo de compreender as ideias centrais do(s) autor(es), já anotando os pontos de interesse para a pesquisa, as referências e citações a serem utilizadas no estudo. Posteriormente, quando necessário, realizou-se uma releitura dirigida, buscando assimilar conceitos profundos, pontos de vista críticos e buscar informações adicionais. Neste estudo foram utilizadas fichas contemplando dados de referência bibliográfica, resumo do conteúdo da obra, citações diretas e indiretas, síntese detalhada das ideias de interesse a este trabalho e avaliação crítica das mesmas.

Com base na revisão da literatura realizada previamente, foram destacados os termos e conceitos considerados fundamentais para a teoria da complexidade, a partir da leitura de autores consagrados e obras clássicas nessa área, apresentados no quadro 8. 


\begin{tabular}{|c|c|}
\hline Conceito e Autores & Definição \\
\hline Atratores (Giovannini, 2002a, 2002b) & $\begin{array}{l}\text { O comportamento de sistemas dinâmicos não-lineares pode, em } \\
\text { determinadas condições, possuir um atrator, que é um conjunto } \\
\text { invariante para o qual órbitas próximas convergem depois de } \\
\text { um tempo. }\end{array}$ \\
\hline Auto-organização (Morin, 2010) & $\begin{array}{l}\text { Acontece quando os sistemas se organizam espontaneamente, } \\
\text { sem influência externa. }\end{array}$ \\
\hline $\begin{array}{l}\text { Caos ou dependência sensitiva às condições } \\
\text { iniciais (Fiedler-Ferrara e Prado, 1994; } \\
\text { Giovannini, 2002a, 2002b) }\end{array}$ & $\begin{array}{l}\text { O comportamento caótico resulta das não-linearidades } \\
\text { presentes no sistema, amplificando exponencialmente pequenas } \\
\text { diferenças nas condições iniciais, gerando consequências não- } \\
\text { lineares desproporcionais sobre a evolução do sistema. }\end{array}$ \\
\hline $\begin{array}{l}\text { Emergência (Ashby, 1970; Donaires, 2012; } \\
\text { Giovannini, 2002a, 2002b; Morin, 2010) }\end{array}$ & $\begin{array}{l}\text { Refere-se às propriedades particulares de cada nível } \\
\text { hierárquico, ou seja, elas emergem de cada um deles e fazem } \\
\text { sentido apenas no nível de abstração em que aparecem, sendo } \\
\text { imprevisíveis a partir do conhecimento das partes e de seus } \\
\text { acoplamentos, isto é, propriedades apresentadas pelo todo que } \\
\text { não eram encontradas em nenhuma das partes isoladamente. }\end{array}$ \\
\hline $\begin{array}{l}\text { Estabilidade ou equilíbrio dinâmico } \\
\text { (Giovannini, 2002a, 2002b) }\end{array}$ & $\begin{array}{l}\text { Os sistemas operam nos limites do caos, ou edge of chaos, que } \\
\text { seria onde o sistema alcança um estado de equilíbrio dinâmico } \\
\text { ao redor de um atrator, entre a ordem e o caos, ou estabilidade e } \\
\text { mudança. }\end{array}$ \\
\hline $\begin{array}{l}\text { Identidade (Beer, 1985, 1994a, 1994b; } \\
\text { Donaires, 2012) }\end{array}$ & $\begin{array}{l}\text { O sistema possui uma existência e uma identidade própria que } \\
\text { o define. O objetivo ou propósito do sistema revela aspectos de } \\
\text { sua identidade. }\end{array}$ \\
\hline $\begin{array}{l}\text { Não-linearidade (Bauer, 1999; Giovannini, } \\
\text { 2002a, 2002b) }\end{array}$ & $\begin{array}{l}\text { Sistema não-linear é aquele cujas saídas não podem ser } \\
\text { previstas a partir das condições iniciais ao longo de uma } \\
\text { trajetória reta ou estável, ou seja, um sistema cuja resposta não } \\
\text { é proporcional ao estímulo aplicado, e que permitem várias } \\
\text { soluções. }\end{array}$ \\
\hline $\begin{array}{l}\text { Padrões fractais (Giovannini, 2002a, 2002b; } \\
\text { Morin, 2010, 2011) }\end{array}$ & $\begin{array}{l}\text { O menor ponto da imagem contém a quase totalidade da } \\
\text { informação do objeto representado. }\end{array}$ \\
\hline $\begin{array}{l}\text { Recursividade (Beer, 1985; Morin, 2010, } \\
\text { 2011) }\end{array}$ & $\begin{array}{l}\text { Circuito gerador em que os produtos e os efeitos são, eles } \\
\text { mesmos, produtores e causadores daquilo que produzem, num } \\
\text { ciclo autoconstitutivo, auto-organizador e autoprodutor. O } \\
\text { sistema existe em várias escalas (ou níveis recursivos) e várias } \\
\text { dimensões recursivas, ou seja, ele pertence a várias cadeias de } \\
\text { sistemas. }\end{array}$ \\
\hline $\begin{array}{l}\text { Retroatividade ou retroalimentação (Morin, } \\
\text { 2010) }\end{array}$ & $\begin{array}{l}\text { Feedbacks positivos ou negativos, as múltiplas retroações em } \\
\text { um sistema são inter-relacionadas e sofrem o efeito da } \\
\text { incerteza. }\end{array}$ \\
\hline 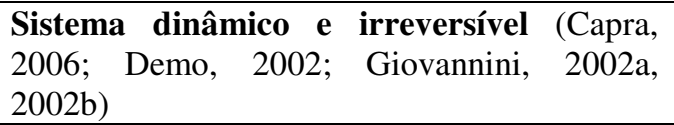 & $\begin{array}{l}\text { A irreversibilidade é determinada pela inserção temporal, ou } \\
\text { seja, qualquer depois é diferente do antes. }\end{array}$ \\
\hline $\begin{array}{l}\text { Variedade (Ashby, 1970; Beer, 1985, 1994a; } \\
\text { Donaires, 2012) }\end{array}$ & $\begin{array}{l}\text { A variedade conta o número de estados possíveis de um } \\
\text { sistema. }\end{array}$ \\
\hline Viabilidade (Beer, 1985; Capra, 2006) & $\begin{array}{l}\text { Um sistema é viável se pode sobreviver de maneira autônoma } \\
\text { em um tipo particular de ambiente. }\end{array}$ \\
\hline
\end{tabular}

Quadro 8 - Conceitos fundamentais da teoria da complexidade resultantes da revisão da literatura

A partir disso, foram definidos previamente os termos para a busca dos conceitos fundamentais em bases de dados, com o objetivo de encontrar atualizações, aprofundamento e críticas às noções centrais dessa abordagem. Assim, essa etapa permitiu a abrangência da produção recente na literatura sobre o tema, somando-se às obras clássicas consultadas. A primeira definição dos termos de busca é apresentada no quadro 9. 


\begin{tabular}{|l|l|}
\hline \multicolumn{1}{|c|}{ Termos de busca } & \multicolumn{1}{c|}{ Tradução (inglês) } \\
\hline Atratores estranhos & Strange attractors \\
\hline Auto-organização & Self-organization \\
\hline Caos & Chaos \\
\hline Dependência sensitiva & Sensitive dependence \\
\hline Emergência & Emergence \\
\hline Equilíbrio dinâmico & Dynamic equilibrium \\
\hline Estabilidade dinâmica & Dynamic stability \\
\hline Fractal & Fractal \\
\hline Identidade & Identity \\
\hline Não-linearidade & Nonlinearity \\
\hline Recursividade & Recursion \\
\hline Retroalimentação & Feedback \\
\hline Sensibilidade às condições iniciais & Sensitivity to initial conditions \\
\hline Sistema dinâmico & Dynamic system \\
\hline Variedade & Variety \\
\hline Viabilidade & Viability \\
\hline Quadro 9 - Proposta inicial dos term & Se busca para pesquisa bibliografica \\
\hline
\end{tabular}

Quadro 9 - Proposta inicial dos termos de busca para pesquisa bibliográfica

Como alguns termos apresentavam uma área comum de significado, eles foram respectivamente reduzidos a um termo mais geral, em uma tentativa de minimizar resultados duplicados nas buscas. O quadro 10 apresenta os termos utilizados para as buscas bibliográficas.

\begin{tabular}{|c|c|c|}
\hline Termos de busca & Termos de busca finais & Tradução (inglês) \\
\hline Atratores estranhos & Atrator & Attractor \\
\hline Auto-organização & Auto-organização & Self-organization \\
\hline Caos & Caos & Chaos \\
\hline Dependência sensitiva & \multirow{2}{*}{ Sensibilidade } & \multirow{2}{*}{ Sensitivity } \\
\hline Sensibilidade às condições iniciais & & \\
\hline Emergência & Emergência & Emergence \\
\hline Fractal & Fractal & Fractal \\
\hline Identidade & Identidade & Identity \\
\hline Não-linearidade & Não-linearidade & Nonlinearity \\
\hline Recursividade & Recursividade & Recursion \\
\hline Retroalimentação & Retroalimentação & Feedback \\
\hline Sistema dinâmico & \multirow{3}{*}{ Dinâmica(o) } & \multirow{3}{*}{ Dynamic } \\
\hline Estabilidade dinâmica & & \\
\hline Equilíbrio dinâmico & & \\
\hline Variedade & Variedade & Variety \\
\hline Viabilidade & Viabilidade & Viability \\
\hline
\end{tabular}

As buscas compreenderam os termos definidos como palavras-chave, tendo como filtro a abordagem da Complexidade, com a utilização dos seguintes termos "teoria da complexidade" e "ciência da complexidade", traduzidos para o inglês, respectivamente, como "complexity theory" e "complexity science". Esses termos de filtro foram escolhidos a partir 
das obras utilizadas na revisão da literatura que se referiam à abordagem. A utilização do termo "complexidade" sozinho gerou uma quantidade muito grande de resultados não necessariamente relacionados à teoria da complexidade, mas sim utilizando o seu significado coloquial representando algo "complicado". Logo, justifica-se a escolha dos termos compostos.

As bases de dados utilizadas foram: ISI Web of Knowledge e Scopus. A justificativa dessa escolha tem base no prestígio dessas bases, o que fica evidenciado pelo fato, por exemplo, da Qualis-CAPES (Coordenação de Aperfeiçoamento de Pessoal de Nível Superior) considerar a indexação dos periódicos em tais bases de dados para classificação nos seus estratos mais elevados: A1, A2, B1, B2 (COORDENAÇÃO DE APERFEIÇOAMENTO DE PESSOAL DE NÍVEL SUPERIOR, 2008). A utilização de palavras-chave no idioma inglês é justificada pela escolha de bases de dados internacionais. Na seleção, optou-se por estudos publicados em periódicos acadêmicos, já que eles são submetidos ao processo de revisão por pares, sendo avaliados detalhadamente. Não foi estabelecida restrição no intervalo de tempo, considerando todos os anos disponíveis na respectiva base de dados. Logo, foram utilizados dois filtros de pesquisa $(\mathrm{F})$ durante as buscas:

F1 - Artigos publicados em periódicos acadêmicos indexados nas bases de dados utilizadas para as buscas; e

F2 - Estudos contendo uma das combinações dos termos de pesquisa definidos previamente nos campos: "título do artigo, resumo, palavras-chave" ("Article Title, Abstract, Keywords", no SCOPUS) e "tópico" ("Topic", no ISI Web of Knowledge, que abrange os mesmos campos utilizados no SCOPUS - título do artigo, resumo, palavras-chave).

O resultado das buscas preliminares com a aplicação dos filtros de pesquisa é mostrado na tabela 1 .

Foram seguidos, também, dois critérios de exclusão (CE):

CE 1 - Estudos em duplicidade (repetidos) nas bases de dados e entre elas;

CE 2 - Estudos em idiomas que não o português, inglês ou espanhol.

Concluída a fase de busca nas bases de dados e aplicados os CE (excluídos 880 artigos), foi realizada a leitura do título, resumo e palavras-chave de cada artigo (total de 968 artigos), selecionando os estudos por meio de dois critérios de inclusão (CI):

CI 1 - Estudos com contribuição teórica abrangendo definições e conceitos elementares da teoria da complexidade; 
CI 2 - Estudos com contribuição teórica contendo críticas à teoria da complexidade e suas definições e conceitos.

\begin{tabular}{lccc}
\hline Termos de busca & ISI Web of Knowledge & Scopus & Total \\
\hline Attractor & 28 & 38 & 66 \\
Chaos & 141 & 180 & 321 \\
Dynamic & 289 & 194 & 483 \\
Emergence & 102 & 153 & 255 \\
\hline Feedback & 49 & 63 & 112 \\
Fractal & 27 & 47 & 74 \\
Identity & 29 & 40 & 69 \\
Nonlinearity & 13 & 23 & 36 \\
Recursion & 19 & 22 & 41 \\
Self-organization & 79 & 109 & 188 \\
Sensitivity & 27 & 25 & 52 \\
Variety & 64 & 72 & 136 \\
Viability & 7 & 8 & 15 \\
Total & $\mathbf{8 7 4}$ & $\mathbf{9 7 4}$ & $\mathbf{1 8 4 8}$ \\
\hline Tabela 1 - Resultado das buscas preliminares nas bases de dados
\end{tabular}

Nos casos em que não foi possível verificar os critérios de inclusão pela leitura dos itens citados, foi realizada a leitura do estudo na íntegra (12 artigos). As buscas resultaram na seleção de 89 artigos para análise, representada na tabela 2.

\begin{tabular}{lccc}
\hline \multicolumn{1}{c}{ Base de dados } & $\begin{array}{c}\text { Selecionados pelos } \\
\text { F }\end{array}$ & $\begin{array}{c}\text { Excluídos } \\
\text { pelos CE }\end{array}$ & $\begin{array}{c}\text { Selecionados } \\
\text { pelos CI }\end{array}$ \\
\hline ISI Web of Knowledge & 874 & 435 & 46 \\
Scopus & 974 & 445 & 43 \\
Total & $\mathbf{1 8 4 8}$ & $\mathbf{8 8 0}$ & $\mathbf{8 9}$ \\
\hline
\end{tabular}

Tabela 2 - Estudos selecionados para análise

A pesquisa bibliográfica, neste esforço de pesquisa, teve o objetivo de verificar o estado da arte da literatura na área da Complexidade, permitindo a análise dos conceitos fundamentais e dos estudos contemporâneos em busca de evoluções, alterações, críticas ou do surgimento de novos conceitos nessa área. Isto é, a pesquisa bibliográfica consistiu na análise do conhecimento contemporâneo acerca do tema. Assim, justificam-se os filtros desta etapa, uma vez que os periódicos garantem a seletividade por estudos com contribuição efetiva para o conhecimento da área. Essa etapa de busca bibliográfica foi realizada durante o mês de maio de 2013. A partir da seleção dos artigos teve início a análise dos mesmos. 


\subsection{PROCEDIMENTO DE ANÁLISE}

A análise dos artigos selecionados na pesquisa bibliográfica estruturada consistiu em um procedimento detalhado de busca das seguintes informações:

1. Dados de referência bibliográfica;

2. Atualização dos conceitos fundamentais da teoria da complexidade já tratados na revisão da literatura;

3. Novos conceitos apresentados como base teórica da Complexidade ou conceitos não abordados na revisão da literatura;

4. Críticas aos conceitos e à teoria da complexidade.

Ainda nesta fase da pesquisa, após análise cuidadosa de cada artigo, 55 trabalhos foram descartados por não apresentarem contribuição significativa a este esforço de pesquisa, totalizando 34 artigos utilizados, relacionados no quadro 11. Dessa forma, foi possível atualizar o conhecimento na área. Destaca-se que os resultados foram incorporados à seção correspondente (seção 3.4. Caos e Complexidade), fornecendo a base para que os conceitos teóricos da Complexidade fossem transpostos na tentativa de compreensão da lógica da dinâmica do desenvolvimento local, verificando a adequabilidade da abordagem.

A última etapa do trabalho consistiu nessa transposição dos aspectos fundamentais da Complexidade para a caracterização do desenvolvimento local, realizada por meio do recurso teórico da dedução. A pesquisa teórica pode ser realizada por dedução, indução ou analogia, tendo o objetivo do enriquecimento do conhecimento científico (PARRA FILHO; SANTOS, 2003). Segundo Martinelli e Ventura (2012), o ponto de partida da abordagem dedutiva é o geral, e o ponto de chegada é o particular, isto é, há uma conexão descendente, baseando-se em uma caracterização geral para, posteriormente, introduzir requisitos adicionais.

Hayek (1955) defende a validade do procedimento dedutivo, afirmando que ao tratar de fenômenos complexos, a questão chave não consiste em descobrir se as hipóteses ou leis para a explicação do fenômeno são verdadeiras, mas se foram selecionadas as explicações apropriadas do rol de afirmações consolidadas e combinadas da maneira correta. Portanto, grande parte dos trabalhos teóricos consolidados pode ser usada para a elaboração de premissas aceitas por meio de padrões dedutivos de argumentação que podem servir como base para explicar fatos observados complexos, ao invés de descobrir novas leis e sua confirmação. Dessa forma se explica o novo pelo familiar, ao contrário da ordem que vai do hipotético ou desconhecido para o conhecido, observável e testável (HAYEK, 1955). 


\begin{tabular}{|c|c|c|c|}
\hline Autoria & Título & Ano & Fonte \\
\hline ABRAHAM, R. H. & The genesis of complexity & 2011 & $\begin{array}{l}\text { World futures: The Journal of } \\
\text { Global Education }\end{array}$ \\
\hline AGAR, M. & $\begin{array}{l}\text { Complexity theory: an exploration and } \\
\text { overview based on John Holland's work }\end{array}$ & 1999 & Field Methods \\
\hline $\begin{array}{l}\text { ALHADEFF- } \\
\text { JONES, M. }\end{array}$ & $\begin{array}{l}\text { Three generations of complexity theories: } \\
\text { nuances and ambiguities }\end{array}$ & 2008 & $\begin{array}{l}\text { Educational Philosophy and } \\
\text { Theory }\end{array}$ \\
\hline BARABÁSI, A.-L. & The architecture of complexity & 2007 & IEEE Control Systems Magazine \\
\hline BLOCH, D. P. & $\begin{array}{l}\text { Complexity, chaos, and nonlinear dynamics: } \\
\text { a new perspective on career development } \\
\text { theory }\end{array}$ & 2005 & $\begin{array}{l}\text { The Career Development } \\
\text { Quarterly }\end{array}$ \\
\hline BOKENO, M. & $\begin{array}{l}\text { Complexity: an alternative paradigm for } \\
\text { teamwork development }\end{array}$ & 2008 & $\begin{array}{l}\text { Development and Learning } \\
\text { Organizations }\end{array}$ \\
\hline $\begin{array}{l}\text { BOUSQUET, A.; } \\
\text { CURTIS, S. }\end{array}$ & $\begin{array}{l}\text { Beyond models and metaphors: complexity } \\
\text { theory, systems thinking and international } \\
\text { relations }\end{array}$ & 2011 & $\begin{array}{l}\text { Cambridge Review of } \\
\text { International Affairs }\end{array}$ \\
\hline BURNES, B. & $\begin{array}{l}\text { Complexity theories and organizational } \\
\text { change }\end{array}$ & 2005 & $\begin{array}{l}\text { International Journal of } \\
\text { Management Reviews }\end{array}$ \\
\hline DENNIS, K. & Time in the age of complexity & 2007 & Time \& Society \\
\hline $\begin{array}{l}\text { GOULIELMOS, A. } \\
\text { M. }\end{array}$ & $\begin{array}{l}\text { Complexity theory: a science where } \\
\text { historical accidents matter }\end{array}$ & 2005 & $\begin{array}{l}\text { Disaster Prevention and } \\
\text { Management }\end{array}$ \\
\hline HORN, J. & Human Research and Complexity Theory & 2008 & $\begin{array}{l}\text { Educational Philosophy and } \\
\text { Theory }\end{array}$ \\
\hline HOWARD, A. & $\begin{array}{l}\text { Paradexity: the convergence of paradox and } \\
\text { complexity }\end{array}$ & 2010 & $\begin{array}{l}\text { Journal of Management } \\
\text { Development }\end{array}$ \\
\hline JOHNSON, J. & $\begin{array}{l}\text { The future of the social sciences and } \\
\text { humanities in the science of complex } \\
\text { systems }\end{array}$ & 2010 & $\begin{array}{l}\text { Innovation: The European Journal } \\
\text { of Social Science Research }\end{array}$ \\
\hline KATOPES, P. & $\begin{array}{l}\text { Resisting chaos: the power of the humanities } \\
\text { as a problem-solving system }\end{array}$ & 2011 & On the Horizon \\
\hline KLIJN, E.-H. & $\begin{array}{l}\text { Complexity theory and public } \\
\text { administration: what's new? }\end{array}$ & 2008 & Public Management Review \\
\hline KOGETSIDIS, H. & $\begin{array}{l}\text { Systems approaches for organisational } \\
\text { analysis }\end{array}$ & 2011 & $\begin{array}{l}\text { International Journal of } \\
\text { Organizational Analysis }\end{array}$ \\
\hline $\begin{array}{l}\text { LARSEN- } \\
\text { FREEMAN, D. }\end{array}$ & $\begin{array}{l}\text { Complex, dynamic systems: a new } \\
\text { transdisciplinary theme for applied } \\
\text { linguistics? }\end{array}$ & 2012 & Language Teaching \\
\hline LINDSAY, V. J. & $\begin{array}{l}\text { The development of international industry } \\
\text { clusters: a complexity theory approach }\end{array}$ & 2005 & $\begin{array}{l}\text { Journal of International } \\
\text { Entrepreneurship }\end{array}$ \\
\hline LONGA, V. M. & A nonlinear approach to translation & 2004 & Target \\
\hline MANSON, S. M. & $\begin{array}{l}\text { Simplifying complexity: a review of } \\
\text { complexity theory }\end{array}$ & 2001 & Geoforum \\
\hline MASON, M. & $\begin{array}{l}\text { What is complexity theory and what are its } \\
\text { implications for educational change? }\end{array}$ & 2008 & $\begin{array}{l}\text { Educational Philosophy and } \\
\text { Theory }\end{array}$ \\
\hline $\begin{array}{l}\text { MATHEWS, K. } \\
\text { M.; WHITE, M. C.; } \\
\text { LONG, R. G. }\end{array}$ & $\begin{array}{l}\text { Why study the complexity sciences in the } \\
\text { social sciences? }\end{array}$ & 1999 & Human Relations \\
\hline MIGUÉLEZ, M. M. & $\begin{array}{l}\text { Paradigmas emergentes y ciencias de la } \\
\text { complejidad }\end{array}$ & 2011 & Opción \\
\hline $\begin{array}{l}\text { MIKULECKY, D. } \\
\text { C. }\end{array}$ & $\begin{array}{l}\text { The emergence of complexity: science } \\
\text { coming of age or science growing old? }\end{array}$ & 2001 & Computers and Chemistry \\
\hline MOWLES, C. & $\begin{array}{l}\text { Post-foundational development management } \\
\text { - power, politics and complexity }\end{array}$ & 2010a & $\begin{array}{l}\text { Public Administration and } \\
\text { Development }\end{array}$ \\
\hline
\end{tabular}




\begin{tabular}{|l|l|l|l|} 
MOWLES, C. & $\begin{array}{l}\text { Successful or not? Evidence, emergence, and } \\
\text { development management }\end{array}$ & $2010 \mathrm{~b}$ & Development in Practice \\
\hline MURRAY, P. J. & Complexity theory and the fifth discipline & 1998 & $\begin{array}{l}\text { Systemic Practice and Action } \\
\text { Research }\end{array}$ \\
\hline NOWOTNY, H. & $\begin{array}{l}\text { The increase of complexity and its reduction: } \\
\text { emergent interfaces between the natural } \\
\text { sciences, humanities and social sciences }\end{array}$ & 2005 & Theory, Culture \& Society \\
\hline PHELAN, S. E. & $\begin{array}{l}\text { A note on the correspondence between } \\
\text { complexity and systems theory }\end{array}$ & 1999 & $\begin{array}{l}\text { Systemic Practice and Action } \\
\text { Research }\end{array}$ \\
\hline $\begin{array}{l}\text { PINA E CUNHA, } \\
\text { M.; REGO, A. }\end{array}$ & Complexity, simplicity, simplexity & 2010 & European Management Journal \\
\hline POSER, H. & Theories of complexity and their problems & 2007 & Frontiers of Philosophy in China \\
\hline PUDDIFOOT, J. E. & $\begin{array}{l}\text { Some problems and possibilities in the study } \\
\text { of dynamical social processes }\end{array}$ & 2000 & $\begin{array}{l}\text { Journal for the Theory of Social } \\
\text { Behaviour }\end{array}$ \\
\hline $\begin{array}{l}\text { RICKLES, D.; } \\
\text { HAWE, P.; } \\
\text { SHIELL, A. }\end{array}$ & A simple guide to chaos and complexity & 2007 & $\begin{array}{l}\text { Journal of Epidemiology \& } \\
\text { Community Health }\end{array}$ \\
\hline $\begin{array}{l}\text { SANGER, M.; } \\
\text { GIDDINGS, M. M. }\end{array}$ & A simple approach to complexity theory & 2012 & Journal of Social Work Education \\
\hline
\end{tabular}

Quadro 11 - Seleção final de artigos para atualização do conhecimento sobre a teoria da complexidade

Assim, a análise dos dados consistiu em um procedimento de inferência baseado em lógica dedutiva, com transposições de conceitos para a essência primeira do desenvolvimento local. Para isso, foram utilizados os conceitos fundamentais da Complexidade encontrados por meio da revisão da literatura e pela pesquisa bibliográfica estruturada, abrangendo, portanto, obras tradicionais e estudos recentes da área. Como os conceitos básicos não são rigidamente definidos em um texto específico acerca da teoria da complexidade (BLOCH, 2005), é provável que outros estudos nessa área isolem uma lista diferente de conceitos, ou utilize definições distintas, apresentadas em uma sequência também diferente.

Ao todo, este esforço de pesquisa envolveu a utilização de 89 livros, 60 artigos científicos, uma tese, duas dissertações e uma revista.

\subsection{ORGANIZAÇÃO DOS RESULTADOS}

Como explicitado previamente, as fases deste trabalho não seguem necessariamente uma ordem linear; os resultados de uma etapa levaram à retroalimentação de etapas anteriores e vice-versa, uma vez que a revisão da literatura ocorreu ao longo de todo o processo de pesquisa, sendo retomada sempre que conceitos ou ideias apresentaram-se como significativos. Devido ao ideal complexo, o presente esforço de pesquisa foi desenvolvido por 
meio de uma concepção em rede, com uma leitura levando a outra, não necessariamente na mesma disciplina, conforme Terra (2010). Portanto, a organização dos resultados preza pela clareza das informações por meio de uma estrutura criada e recriada continuamente. 


\section{DESENVOLVIMENTO LOCAL PELA VISÃO DA TEORIA DA COMPLEXIDADE}

O desenvolvimento tem sido apresentado por diversos autores como um fenômeno ou processo complexo (BECKER, 2010a; CANEVER et al., 2010; CAPRA, 2006; MARTINS; VAZ; CALDAS, 2010; MORAES, 2010; OLIVEIRA; WITTMANN, 2010; SOTARAUTA, 2009; SOTO, 2010). Contudo, poucos trabalhos abordam o fenômeno baseados nos conceitos fundamentais da teoria da complexidade, e os que o fazem, selecionam um ou poucos conceitos para tratar do assunto, como pode ser observado em Mowles (2010a) e Mowles (2010b), que tratam a gestão do desenvolvimento a partir do conceito de emergência. A análise proposta neste esforço de pesquisa é centrada em verificar quais características do desenvolvimento local correspondem aos conceitos fundamentais da teoria da complexidade e, então, quais desses conceitos podem descrever sua dinâmica.

A partir da revisão da literatura e, posteriormente, da pesquisa bibliográfica, foram estabelecidos os principais conceitos/noções considerados fundamentais para a teoria da complexidade. Para facilitar a descrição, os conceitos fundamentais foram transformados para o formato de questões a serem respondidas adicionalmente às questões propostas por Agar (1999), para verificar se o fenômeno que se pretende estudar apresenta algum aspecto que o configura como um sistema complexo e se, portanto, a Complexidade é a abordagem adequada para o seu tratamento. As questões e sua relação com os conceitos fundamentais, além dos autores que tratam dos mesmos estão relacionados no quadro 12.

O fenômeno do desenvolvimento, tanto em nível macro, como em nível local, configura um sistema (questão 1), isto é, um agrupamento de partes em interação (BAUER, 1999; BERTALANFFY et al., 1976; BEER, 1994b; DONAIRES, 2012) que operam juntas para um propósito comum (DONAIRES, 2012). Apesar das partes terem objetivos específicos e distintos, e muitas vezes contraditórios, todas elas buscam a sobrevivência, independente do significado atribuído aos termos "evolução" ou "melhoria" para cada parte. Assim, da mesma forma que o sistema como um todo, os subsistemas também possuem uma identidade própria que os destaca como partes (DONAIRES, 2012). 


\begin{tabular}{|c|c|c|}
\hline Questão para análise & Conceito fundamental & Autores \\
\hline $\begin{array}{l}\text { 1. O fenômeno configura um } \\
\text { sistema? }\end{array}$ & Identidade & Beer, 1985, 1994a, 1994b; Donaires, 2012 \\
\hline $\begin{array}{l}\text { 2. É dinâmico (quando o tempo é } \\
\text { uma variável do sistema)? }\end{array}$ & $\begin{array}{l}\text { Sistema dinâmico e } \\
\text { irreversível }\end{array}$ & $\begin{array}{l}\text { Bloch, 2005; Capra, 2006; Demo, 2002; } \\
\text { Giovannini, 2002a, 2002b; Larsen-Freeman, } \\
2012\end{array}$ \\
\hline 3. Há evidências de co-evolução? & Co-evolução & $\begin{array}{l}\text { Bousquet e Curtis, 2011; Klijn, 2008; } \\
\text { Lindsay, 2005; Murray, 1998; Rickles, Hawe } \\
\text { e Shiell, } 2007\end{array}$ \\
\hline \multirow{2}{*}{$\begin{array}{l}\text { 4. Existe em uma variedade de } \\
\text { dimensões recursivas? }\end{array}$} & Recursividade & $\begin{array}{l}\text { Beer, 1985; Larsen-Freeman, 2012; Morin, } \\
\text { 2010, } 2011\end{array}$ \\
\hline & Variedade & $\begin{array}{l}\text { Ashby, 1970; Beer, 1985, 1994a; Donaires, } \\
2012\end{array}$ \\
\hline $\begin{array}{l}\text { 5. Existe simetria através das } \\
\text { escalas de observação? }\end{array}$ & Padrões fractais & $\begin{array}{l}\text { Bloch, 2005; Giovannini, 2002a, 2002b; } \\
\text { Morin, 2010, } 2011\end{array}$ \\
\hline \multirow[b]{2}{*}{$\begin{array}{l}\text { 6. Há absorção e dissipação de } \\
\text { energia e matéria do ambiente? }\end{array}$} & Viabilidade & Beer, 1985; Capra, 2006 \\
\hline & $\begin{array}{l}\text { Sistema aberto e } \\
\text { dissipativo }\end{array}$ & $\begin{array}{l}\text { Bloch, 2005; Bousquet } \\
\text { Larsen-Freeman, 2012; } \\
\text { Prigogine, } 1996\end{array}$ \\
\hline \multirow[b]{2}{*}{$\begin{array}{l}\text { 7. Existe capacidade de absorção } \\
\text { de instabilidades e ruídos de } \\
\text { origem externa? }\end{array}$} & $\begin{array}{l}\text { Estabilidade ou equilíbrio } \\
\text { dinâmico }\end{array}$ & $\begin{array}{l}\text { Burnes, 2005; Giovannini, 2002a, 2002b; } \\
\text { Lindsay, 2005; Miguélez, } 2011\end{array}$ \\
\hline & Auto-organização & $\begin{array}{l}\text { Bloch, 2005; Bokeno, 2008; Bousquet e } \\
\text { Curtis, 2011; Klijn, 2008; Larsen-Freeman, } \\
\text { 2012; Lindsay, 2005; Miguélez, 2011; Morin, } \\
\text { 2010; Murray, 1998; Rickles, Hawe e Shiell, } \\
2007\end{array}$ \\
\hline 8. Existe aprendizado e adaptação? & Adaptação e aprendizado & $\begin{array}{l}\text { Bloch, 2005; Bousquet e Curtis, 2011; Demo, } \\
\text { 2002; Manson, 2001; Murray, 1998; } \\
\text { Miguélez, 2011 }\end{array}$ \\
\hline $\begin{array}{l}\text { 9. As regras locais produzem algo } \\
\text { maior que sua soma? }\end{array}$ & Emergência & $\begin{array}{l}\text { Agar, 1999; Ashby, 1970; Bloch, 2005; } \\
\text { Bokeno, 2008; Bousquet e Curtis, 2011; } \\
\text { Donaires, 2012; Giovannini, 2002a, 2002b; } \\
\text { Klijn, 2008; Larsen-Freeman, 2012; Longa, } \\
\text { 2004; Manson, 2001; Mason, 2008; } \\
\text { Mikulecky, 2001; Morin, 2010; Murray, 1998 }\end{array}$ \\
\hline $\begin{array}{l}\text { 10. Há evidências de ciclos de } \\
\text { retroalimentação que indicam não- } \\
\text { linearidade? }\end{array}$ & $\begin{array}{l}\text { Retroatividade ou } \\
\text { retroalimentação }\end{array}$ & $\begin{array}{l}\text { Miguélez, 2011; Morin, 2010; Rickles, Hawe } \\
\text { e Shiell, } 2007\end{array}$ \\
\hline \multirow{2}{*}{$\begin{array}{l}\text { 11. Há pontos de alavancagem } \\
\text { (aqueles locais em um sistema em } \\
\text { que uma pequena entrada produz } \\
\text { grandes efeitos devido a } \\
\text { amplificações } \\
\text { retroalimentação)? }\end{array}$} & $\begin{array}{l}\text { Caos ou dependência } \\
\text { sensitiva às condições } \\
\text { iniciais }\end{array}$ & $\begin{array}{l}\text { Bloch, 2005; Fiedler-Ferrara e Prado, 1994; } \\
\text { Giovannini, 2002a, 2002b; Larsen-Freeman, } \\
2012\end{array}$ \\
\hline & Atratores & $\begin{array}{l}\text { Bloch, 2005; Giovannini, 2002a, 2002b; } \\
\text { Puddifoot, } 2000\end{array}$ \\
\hline \multirow[t]{2}{*}{ 12. Há dificuldades de previsão? } & Não-linearidade & $\begin{array}{l}\text { Agar, 1999; Bauer, 1999; Bloch, 2005; } \\
\text { Bokeno, 2008; Giovannini, 2002a, 2002b; } \\
\text { Larsen-Freeman, 2012; Longa, 2004; } \\
\text { Miguélez, 2011; Murray, 1998 }\end{array}$ \\
\hline & Imprevisibilidade & $\begin{array}{l}\text { Bloch, 2005; Fiedler-Ferrara e Prado, 1994; } \\
\text { Giovannini, 2002a, 2002b; Larsen-Freeman, } \\
\text { 2012; Poser, } 2007\end{array}$ \\
\hline
\end{tabular}

Quadro 12 - Relação das questões de análise com os conceitos fundamentais da Complexidade

Considerando a essência primeira do desenvolvimento local, os subsistemas representados pelos hexágonos pretos, representando os seres humanos que atuam na dinâmica do desenvolvimento local por meio de suas ações e decisões individuais, serão 
considerados aqui como o menor nível ou a menor escala a ser analisada, já que a delimitação deve ser esclarecida de acordo com o objetivo do observador (BEER, 1985). Os indivíduos podem influenciar o desenvolvimento local a partir de suas atitudes e decisões, além de incentivar reações em cadeia, por meio, por exemplo, do incentivo da criação de negócios quando do sucesso de um conhecido empreendedor. Os indivíduos influenciam o desenvolvimento local de maneiras variadas: a partir de seu trabalho e seu consumo, contribuindo para a geração de renda e empregos; a partir de suas ações de preservação ambiental e conscientizando outros a fazerem o mesmo; contribuem para a qualificação profissional ao lecionarem e ministrarem treinamentos; podem influenciar posicionamentos políticos por meio de seu direito de voto e manifestações; entre outros exemplos.

Da mesma forma que os seres humanos em um nível micro, os grupos informais são considerados subsistemas (ou partes) do fenômeno, uma vez que a inserção dos indivíduos nesses grupos e as inter-relações entre indivíduo e grupo, e entre grupos distintos, contribuem e influenciam a dinâmica do desenvolvimento local. Tais grupos informais são caracterizados pela rede de relacionamentos formada entre um número de indivíduos, que formam alianças de interesses (sejam profissionais, afetivos, culturais ou ideológicos), compartilhando um objetivo comum. Isso não significa que os indivíduos não possuam outros objetivos específicos que são, muitas vezes, distintos e até contraditórios. Exemplos vão desde os grupos de amizade, cujo objetivo é a inserção social; passando pelos grupos formados no ambiente de trabalho, cujo objetivo é garantir melhores condições de trabalho e remuneração ou a própria proteção da coletividade; até os grupos de afinidade, cujo objetivo é a discussão de ideologias comuns. Logo, é possível afirmar que o indivíduo possui uma identidade própria (caracterizada pela personalidade, história de vida, formação, valores, entre outros aspectos), que o diferencia dos outros seres humanos, com um objetivo próprio, que o caracteriza como um subsistema (formado por partes que não são objeto deste esforço de pesquisa). A reunião ou o conjunto de seres humanos, inter-relacionados entre si devido a interesses comuns, resulta em um grupo informal, cujo propósito é compartilhado, possuindo também uma identidade própria (caracterizada pelos interesses, objetivos, histórico de sua criação e pelo conjunto das identidades dos indivíduos), que resultam na formação de uma identidade do grupo. Então, é possível afirmar que a identidade do grupo influencia a identidade dos indivíduos (que se sentem parte do mesmo) ao mesmo tempo em que a identidade dos indivíduos influencia a identidade do grupo. O nível dos indivíduos e dos grupos informais no desenvolvimento local é representado na figura 7. 


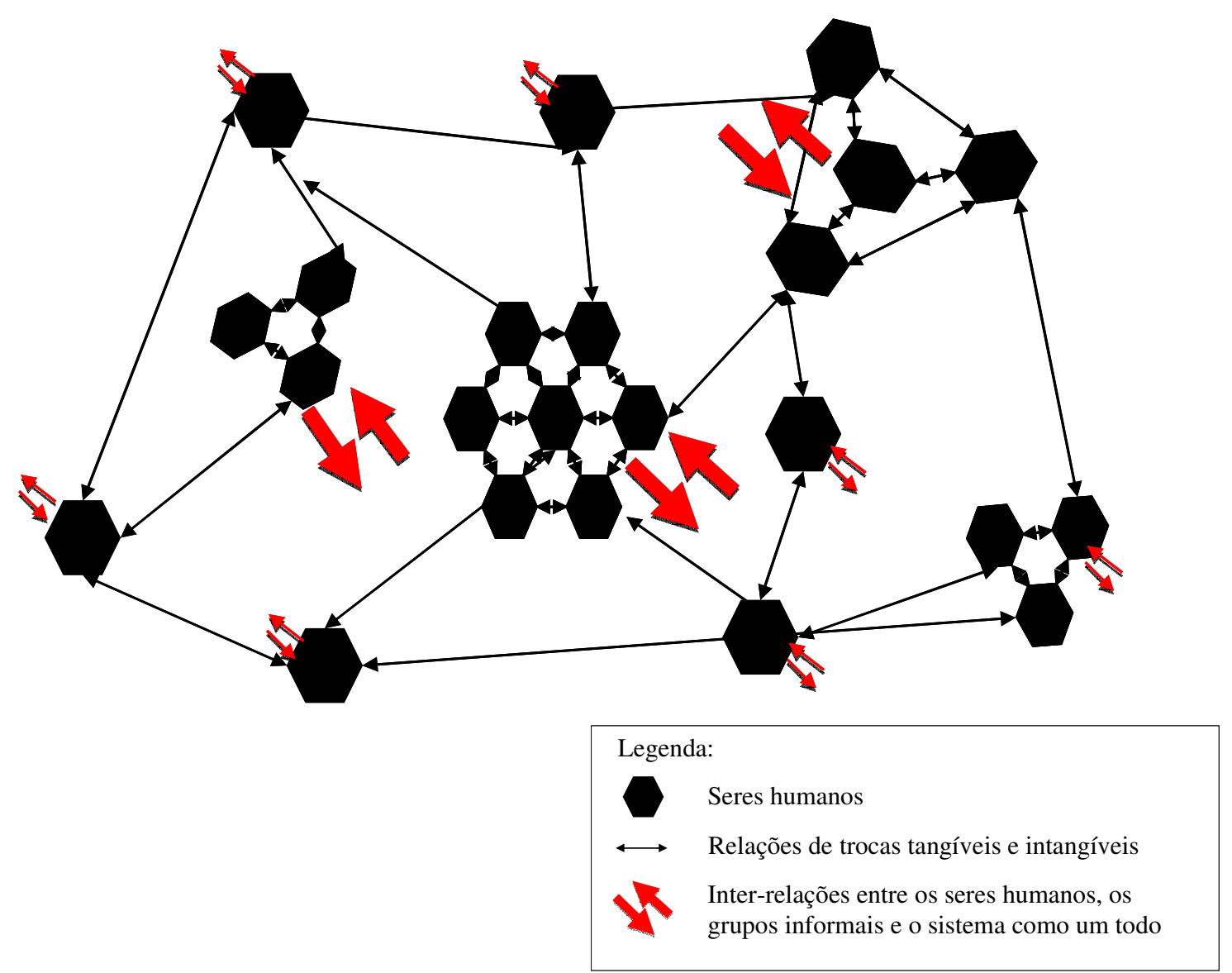

Figura 7 - Indivíduos e grupos informais no desenvolvimento local

A influência dos grupos informais no desenvolvimento local é estabelecida de diversas maneiras, como por exemplo, quando um grupo de trabalhadores se mobiliza buscando melhores condições, essa cultura é incentivada, permitindo que tal busca seja generalizada e até mesmo formalizada por meio dos grupos formais, como sindicatos e associações do setor. Da mesma forma, um grupo de amigos que convida outras pessoas para participarem de seu jogo de futebol semanal está promovendo a prática de esportes e, consequentemente, contribuindo para a melhoria da qualidade de vida nessa localidade.

As organizações, considerando o significado amplo do termo como exposto previamente, também atuam como partes ou subsistemas do desenvolvimento local. Elas remetem a agrupamentos formais de indivíduos em busca de um propósito comum, cuja estrutura pode ser mais ou menos organizada, ou seja, com uma estrutura mínima definida (DAFT, 2002). Assim, as organizações podem remeter a uma igreja, cujo objetivo é pregar uma religião específica; a uma organização empresarial, cujo objetivo pode ser o lucro ou a criação de empregos; a uma ONG, cujo objetivo é o suprimento de necessidades não atendidas pelos serviços públicos; a um órgão público, que busca prover serviços básicos à 
população; entre outros. Portanto, as organizações correspondem a grupos formalizados com identidade própria, que atendem a um propósito comum, embora seus subgrupos informais e os próprios indivíduos mantenham objetivos e identidades específicos concomitantemente. $\mathrm{O}$ nível das organizações no desenvolvimento local é representado na figura 8.
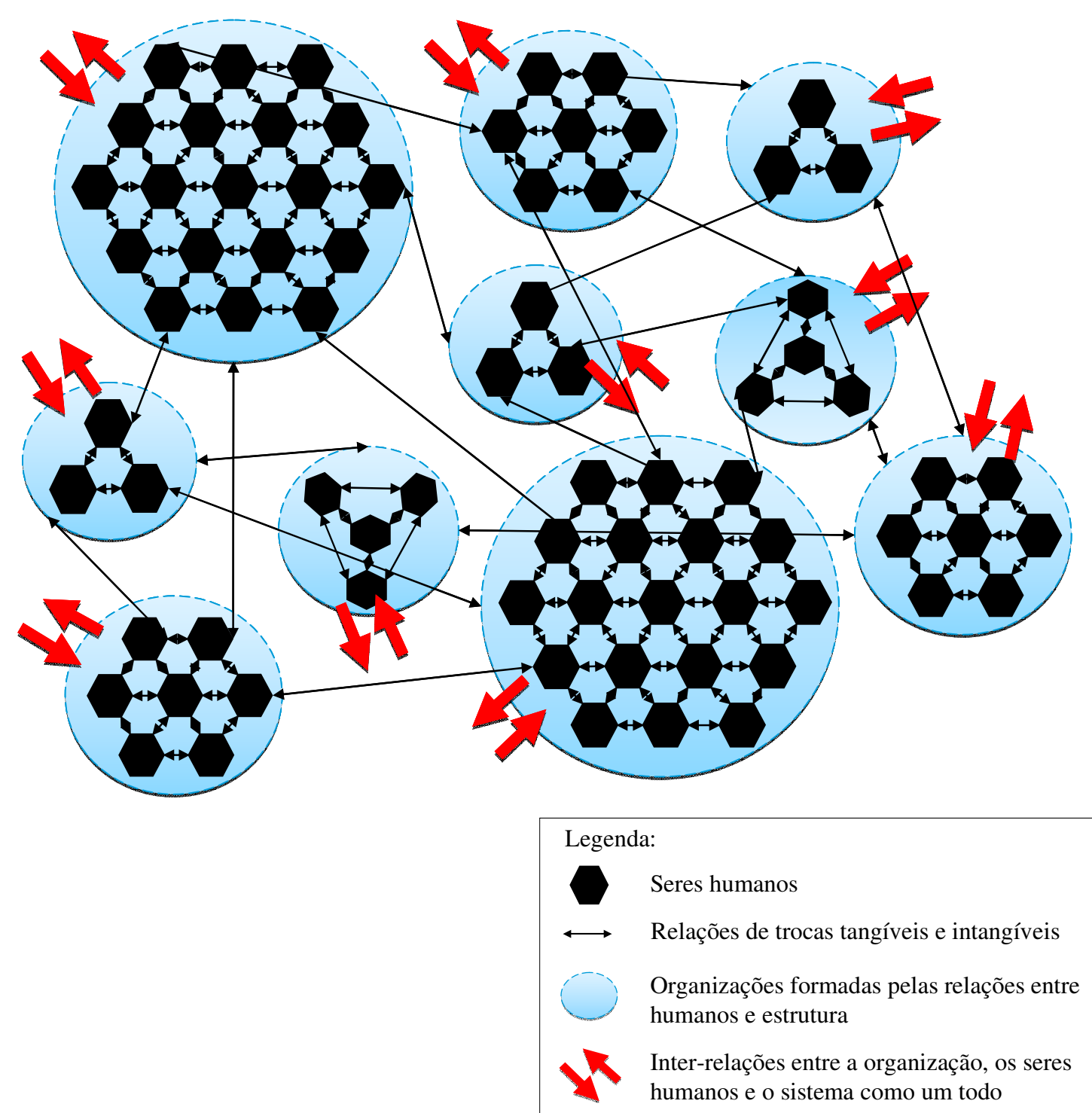

Figura 8 - Organizações no desenvolvimento local

As organizações influenciam o desenvolvimento local a partir do provimento de serviços básicos à população, melhorando suas condições de vida, no caso do serviço público; a partir da defesa dos direitos do cidadão, no caso da organização jurídica; a partir da criação de empregos e de bens e serviços, ao se tratar de uma organização empresarial; a partir da preservação dos recursos ambientais, no caso de uma ONG de preservação; ou no caso de 
uma igreja, pelo fortalecimento da fé e o incentivo da convivência pacífica, prevenindo a violência e condutas criminosas, por exemplo.

A identidade do sistema do desenvolvimento local é então definida a partir das interrelações entre os seus subsistemas e das especificidades locais, como cultura, valores, história, políticas e recursos. Entretanto, os objetivos contraditórios das partes podem levar o sistema ao colapso, ou ao desequilíbrio, exemplificado pelas desigualdades encontradas em certas localidades ou nações. Isso é explicado por Ganzert (2012) devido às diferenças de relevância dos agentes envolvidos, já que os subsistemas mais fracos acabam por estabelecer relações de dependência dos mais relevantes, sendo submetidos aos objetivos destes últimos, que, não necessariamente, visam atender os objetivos dos demais. Ou seja, apesar do objetivo do sistema como um todo ser atendido (sobrevivência do sistema), isso não equivale à “evolução" ou "melhoria" de acordo com o significado atribuído a esses termos por cada parte do sistema. Essa "evolução" ocorre de acordo com o significado e as convicções dos subsistemas mais influentes.

Em nível mais amplo, a dinâmica do desenvolvimento (nacional, internacional, planetário) pode ser descrita pelas inter-relações dos sistemas de desenvolvimento em escala menor, como representado no esboço da essência primeira do desenvolvimento. As redes globais conectam e desconectam indivíduos, grupos e regiões e até países de acordo com sua pertinência para realização dos objetivos processados na rede (CASTELLS, 1999). Portanto, o fenômeno do desenvolvimento, independente da escala observada, pode ser considerado como um sistema, formado por partes em interação visando um propósito comum, a despeito dos distintos propósitos de cada parte individualmente, que mantêm sua identidade, embora contribuam para a formação de uma identidade única do todo.

O desenvolvimento é um fenômeno sujeito à variável do tempo, ou seja, é irreversível e pode ser caracterizado como um sistema dinâmico (questão 2). Significa que, uma vez que mudanças ocorrem em determinada localidade, mesmo que seus efeitos sejam revertidos, ela não será exatamente a mesma, ou seja, mesmo que todos os aspectos materiais retornem à condição anterior à mudança, o aprendizado resultante já configura uma alteração nas perspectivas dessa localidade, sua história terá sido alterada e a experiência estabelece novas considerações quanto ao seu futuro. Logo, o desenvolvimento pode ser considerado um sistema dinâmico. Essa característica implica na impossibilidade de sua compreensão por meio da observação em um único momento no tempo, não sendo possível definir sua evolução até que seu destino seja atingido (AGAR, 1999). 
Nesse contexto, todas as partes influenciam o sistema e também são influenciadas pelo mesmo (MURRAY, 1998), formando uma rede de sistemas em evolução (questão 3). Como detalhado anteriormente, essa evolução não implica progresso, mas simplesmente a impossibilidade de retorno ao estado anterior, devido à "flecha do tempo". Assim, as mudanças levam a estados que podem ou não ser considerados "melhores" para cada parte (MURRAY, 1998), embora todas sejam afetadas direta ou indiretamente, sendo possível afirmar que o desenvolvimento apresenta co-evolução.

Conforme a definição adotada neste esforço de pesquisa, o desenvolvimento local consiste em um processo de longo prazo, que envolve mudanças econômicas, sociais, políticas, culturais e ambientais, visando à melhoria das condições de vida da sociedade de maneira sustentável, a partir dos potenciais endógenos da localidade. Além disso, o "local", nesta pesquisa, é considerado a partir da formação socioterritorial, baseada na noção de identidade e pertencimento criada em dada localidade, definindo seus limites. Portanto, o desenvolvimento implica mudanças nas várias dimensões; e seus subsistemas, que configuram a recursividade, existem e estão submetidos às variações de cada uma dessas dimensões (questão 4). Ou seja, um indivíduo está sujeito às condições sociais, políticas, econômicas, culturais e ambientais, assim como um grupo, uma organização ou uma localidade como um todo. Mudanças em um desses aspectos são refletidas em cada uma das vertentes. Por exemplo, a criação de uma fábrica em determinada localidade reflete na economia, já que cria novos empregos, dinamiza o mercado local, fomenta outros negócios produtores de matéria-prima, entre outros. Essa mudança gera impactos políticos, à medida que a infra-estrutura básica deve ser suficiente para atender as novas demandas, trabalhadores de outras localidades podem ser atraídos para a região, medidas protecionistas podem ser tomadas a fim de privilegiar a produção e o comércio locais, entre outras medidas. A dimensão ambiental também é afetada, já que o destino dos resíduos gerados deve ser controlado, além da utilização dos recursos da região. Além disso, a dimensão cultural sofre mudanças, uma vez que pode haver necessidade de mão-de-obra mais qualificada e adaptada à cultura da organização. Esses são apenas alguns exemplos das consequências que podem ocorrer em cada vertente, deixando evidente a variedade de dimensões recursivas envolvidas no desenvolvimento.

Ao mesmo tempo em que o desenvolvimento abrange essa multiplicidade de dimensões, é possível perceber simetria na essência primeira entre as diferentes escalas de observação (questão 5). Isto é, no nível internacional, a essência do desenvolvimento 
apresenta a configuração de uma rede formada pelas inter-relações entre as partes que, nesse caso, seriam os blocos regionais ou as nações. No nível dos blocos ou das nações individualmente, também é possível perceber essa configuração em rede ao considerar a essência do fenômeno. Isso se repete a cada nível observado, até atingir o nível do ser humano que, por sua vez, também pode ser considerado como um conjunto de subsistemas em interrelação, buscando a sobrevivência. Portanto, o sistema do desenvolvimento pode ser considerado como uma estrutura que apresenta padrões fractais, implicando que a compreensão do sistema em uma escala pode contribuir para a compreensão do sistema nas outras escalas (GIOVANNINI, 2002b).

Todavia, isso não significa que o fenômeno seja o mesmo nos distintos níveis. Não é possível afirmar que o desenvolvimento mundial siga a mesma dinâmica que o municipal, por exemplo. Pelo contrário, devido às propriedades emergentes, em cada nível é possível encontrar especificidades, que não podem ser encontradas nas partes e não necessariamente aparecem no nível acima. Então, é preciso enfatizar uma ressalva quanto à associação dos padrões fractais ao desenvolvimento, já que essa interpretação é coerente diante da análise da essência primeira esboçada neste esforço de pesquisa, isto é, ao interpretar o fenômeno a partir da rede de relações estabelecida, que configura qualquer escala observada.

Porém, ao tratar de um nível de maneira detalhada, essa rede de relações pode apresentar distinções (resultantes das especificidades) frente à outra escala de observação, apresentando diferenças quanto às forças das relações entre as partes, cuja relevância pode mudar de um sistema para outro. As diferenças podem ser notadas também quanto à atitude frente ao associativismo e cooperativismo, por exemplo, que configuram relações mais intensas e em maior número, além de mais bem distribuídas na rede. Além disso, as variáveis envolvidas em cada nível de desenvolvimento, seja ele local, nacional ou internacional, podem não ser as mesmas dos outros níveis, o que garante alguma alteração na dinâmica do fenômeno.

Logo, o conceito de padrões fractais, implicando que a compreensão em uma escala pode contribuir para o conhecimento de outro nível do sistema, utilizado para descrever a dinâmica do desenvolvimento, depende de considerações e relativismo. Este conceito talvez possa contribuir para uma descrição genérica, em um nível de distanciamento considerável do fenômeno, a fim de compreender alguns aspectos gerais. Contudo, algum grau de cautela deve ser considerado ao transpor conhecimentos entre os níveis de observação.

O sistema do desenvolvimento local pode ser considerado um sistema aberto e dissipativo (questão 6), já que absorve e dissipa energia e matéria do ambiente (BLOCH, 
2005; BOUSQUET; CURTIS, 2011; PRIGOGINE, 1996), sendo que as partes e o próprio sistema seriam descaracterizados caso não estabelecessem relações com o ambiente. Essa mesma característica lhe permite certa capacidade de absorção de instabilidades e ruídos de origem externa (questão 7), devido também à circularidade de ação entre as partes do sistema, isto é, cada parte afeta a outra (sendo esse mecanismo considerado como retroalimentação), levando o sistema à sua condição de equilíbrio dinâmico. Ou seja, são necessários ruídos substanciais, aplicados por diversos ciclos, para inviabilizar o equilíbrio do sistema (GIOVANNINI, 2002b). Um exemplo é o próprio Brasil, cujos impactos sofridos devido à crise mundial que teve ascendência na crise do mercado imobiliário americano foram relativamente contidos (CIÊNCIAHOJE, 2012), refletindo sua capacidade de absorção de instabilidades. Assim, as implicações dessa estabilidade dinâmica devem-se, principalmente, ao reforço da importância da compreensão de sua dinâmica antes de atuar sobre o sistema, principalmente antes de dedicar recursos para proteger o sistema, já que ele pode não ser afetado por determinados ruídos externos (GIOVANNINI, 2002b). Portanto, os mecanismos de manutenção da estabilidade dinâmica no sistema do desenvolvimento local devem ser definidos.

Alguns mecanismos enfatizados por autores da área podem ser capazes de contribuir para a manutenção dessa condição de equilíbrio. A endogeneidade, defendida por autores como Ramos e Mariño (2004), Sachs (2001) e Martinelli e Joyal (2004), como foco das iniciativas de desenvolvimento, permite que a localidade possua maior autonomia, sendo menos dependente de relações externas e, consequentemente, estando menos sujeita às instabilidades e ruídos de origem externa.

A abordagem de Passador e Nalle Jr. (2007) apresenta outros mecanismos que contribuem para a manutenção do equilíbrio no desenvolvimento local. Da mesma forma que a endogeneidade, e até incentivando essa abordagem, características culturais e sociais funcionam como mecanismos de manutenção do equilíbrio, já que sociedades com relações de associativismo, cooperação, confiança, vínculos de reciprocidade, solidariedade, capacidade de mobilização e ação em prol do todo, apresentam maior potencial para ação e adaptação, possuem vínculos mais fortes do que de interesses comuns, ou seja, tais sociedades agem em virtude da identificação do sujeito com o todo. Para isso, o capital humano e o capital social, defendidos por Passador e Nalle Jr. (2007), configuram ferramentas para a manutenção do equilíbrio, pois é a partir do fortalecimento destes que as características citadas tornam-se a base do desenvolvimento. Com o incentivo e a formação de uma sociedade mais ativa e 
cooperativa, a capacidade endógena passa a ser mais valorizada nas iniciativas de desenvolvimento local, contribuindo para uma maior capacidade de adaptação e reação aos ruídos externos.

Igualmente, a existência das capacidades territoriais (PASSADOR; NALLE JR., 2007), com a conjugação dos interesses da sociedade, do Estado e do mercado, a difusão de uma cultura empresarial e a incorporação da questão da sustentabilidade, faz com que o território funcione como catalisador das demais variáveis do desenvolvimento, fomentando também a realização do potencial de desenvolvimento endógeno. Nesse mesmo sentido, a cidadania (PASSADOR; NALLE JR., 2007), sendo instrumento que promove a participação e a articulação entre os atores sociais, fortalecendo a coesão da comunidade e melhorando a qualidade das decisões, configura um mecanismo que favorece a autonomia do desenvolvimento, contribuindo para a manutenção do equilíbrio e sobrevivência da localidade de maneira autônoma, embora mantendo relações externas.

À medida que o sistema se aproxima dos limites, são gerados novos comportamentos e configurações, adotando as alternativas que funcionam. Estas assumem a forma de novos atratores estranhos, caracterizando situações de estabilidade dinâmica sujeitas a novas mudanças à medida que o processo continua. Este processo é eficaz, na medida em que, para sobreviver, o sistema não precisa encontrar a melhor alternativa possível, mas sim, aquela que funciona (GIOVANNINI, 2002b). No contexto do desenvolvimento, isso explica a diversidade de localidades que convivem, sobrevivem e se desenvolvem, apresentando especificidades que nem sempre podem ser reaplicadas em outra situação/local. Entretanto, a compreensão da dinâmica do desenvolvimento local pode contribuir para a gestão da complexidade envolvida na criação dessas alternativas.

A partir da sobrevivência das localidades ao longo do tempo é possível perceber a capacidade de adaptação do sistema, sendo que o aprendizado e a adaptação são características intrínsecas ao desenvolvimento (questão 8). O equilíbrio dinâmico é possível à medida que existe o aprendizado com as experiências, incentivado pelos ciclos de retroalimentação, que permitem a avaliação dos resultados de maneira contínua e, dessa forma, o sistema pode se adaptar. Os negócios aprendem para sobreviverem. O poder público aprende a respeito das políticas de incentivo. A sociedade se articula em busca de melhorias a partir das iniciativas de sucesso. Como resultado, o sistema possui capacidade de manter sua identidade e de adaptar sua dinâmica de acordo com seu propósito de sobrevivência.

A formação da identidade do sistema do desenvolvimento deve-se às propriedades emergentes (questão 9), já que as inter-relações entre as partes ou subsistemas produzem um 
sistema cuja identidade e dinâmica não poderia ser prevista a partir do conhecimento das identidades e dinâmicas das partes individuais (AGAR, 1999; ASHBY, 1970; BOKENO, 2008; KLIJN, 2008; LONGA, 2004; MASON, 2008). A identidade não é formada pela superposição das partes, mas pelas suas interações, como é representado na essência primeira por meio das setas bidirecionais. Exemplo disso são os países considerados desenvolvidos, que apresentam desigualdades dentro de seu território; ao considerar as localidades pouco desenvolvidas, não seria possível prever o desenvolvimento do país como um todo. $\mathrm{O}$ contrário também é verdadeiro, já que um observador analisando um negócio de sucesso poderia imaginar que a região seria, como consequência, privilegiada, quando na verdade ele está inserido em uma localidade pouco desenvolvida em termos sociais, por exemplo. Os mecanismos de adaptação e as propriedades emergentes configuram a auto-organização do sistema, que acontece quando os sistemas se organizam espontaneamente, sem influência externa. Os sistemas de desenvolvimento local podem se auto-organizar à medida que suas partes buscam os próprios objetivos atuando no contexto do sistema, isto é, a iniciativa é interna e o sistema pode se adaptar para neutralizar tal influência ou potencializá-la.

O sistema como um todo e cada um de seus subsistemas estão sujeitos à nãolinearidade, percebida devido aos ciclos de retroalimentação que agem nos mesmos (questão 10). A retroalimentação refere-se a uma medição que detecta o desvio do sistema de alguma norma definida, comparando a saída com o resultado esperado. Essa medição, que pode ela mesma ter que sofrer modificações, é retroalimentada para ajustar a entrada para que a transformação leve a uma saída corrigida (BEER, 1994a). Ou seja, a resposta não é necessariamente proporcional ao estímulo aplicado. A retroalimentação positiva de empreendimentos de sucesso incentivando a criação de novos é um exemplo. Esse mesmo exemplo pode ter o resultado inesperado caracterizado pela retroalimentação negativa do sucesso de alguns negócios agirem como desestimulante para a criação de novos negócios, em virtude da dificuldade de competição. As reações da comunidade às políticas públicas são um terceiro exemplo, podendo incentivar novas políticas na mesma direção em caso de reação positiva, ou criando condições para políticas em outra direção, atuando como feedback negativo. Então, o desenvolvimento está sujeito à não-linearidade, sendo impossível estabelecer relações de causa e efeito lineares.

Além da não-linearidade, a dificuldade de previsão (questão 12) relacionada ao desenvolvimento pode ser atribuída também à sensibilidade que esse fenômeno apresenta às condições iniciais (questão 11), isto é, uma pequena entrada produz grandes efeitos 
(FIEDLER-FERRARA; PRADO, 1994; LONGA, 2004; PUDDIFOOT, 2000; SANGER; GIDDINGS, 2012) devido às amplificações de retroalimentação (BOUSQUET; CURTIS, 2011; GIOVANNINI, 2002b). Isso pode ser percebido, por exemplo, em casos em que a articulação de alguns negócios locais resultou na organização de toda uma indústria com poder de impulsionar o desenvolvimento da localidade como um todo, melhorando as condições de vida da população. Outro exemplo pode ser percebido por meio de uma reação da população à alteração no preço do transporte público, podendo resultar tanto em melhores políticas de transporte como na implantação autoritária de medidas restritivas da liberdade democrática da população, por meio de medidas de segurança de inibição de manifestações, alterando todo um regime político.

Ademais, a identidade do local apresenta especificidades que não podem ser reproduzidas, tornando a previsão impossível acerca de todas as consequências de determinada iniciativa. As propriedades emergentes impossibilitam a previsão e o controle, uma vez que mudanças em um subsistema visando à mudança do todo podem não obter o resultado esperado, já que os outros componentes do sistema mudam para se adaptar à intervenção, além de outras mudanças no ambiente. Logo, a imprevisibilidade é característica fundamental do desenvolvimento, sendo que receitas de dinâmicas que resultaram em sucesso em determinada localidade, mesmo que reaplicadas exatamente nos mesmos moldes em outra localidade, não necessariamente produzirão os mesmos efeitos. Um exemplo disso é a aplicação do modelo industrializado de desenvolvimento dos países desenvolvidos nos países periféricos, resultando em maior desigualdade e desequilíbrios.

Diante do exposto, é possível afirmar que o desenvolvimento, nos seus diversos níveis, pode ser considerado como um fenômeno complexo, cujo tratamento pode ser beneficiado pela abordagem da teoria da complexidade. Essa base epistemológica possibilita a compreensão do desenvolvimento local a partir das inter-relações envolvidas na rede que forma o sistema e os subsistemas, permitindo a descrição da dinâmica do fenômeno observado, considerando suas especificidades por meio do conceito de propriedades emergentes e identidade. Além disso, o conceito de recursividade e os padrões fractais possibilitam a abrangência da multiplicidade de dimensões recursivas (política, legal, econômica, social, cultural, tecnológica e ambiental) nos diferentes níveis de observação do fenômeno (local, nacional, internacional). Entretanto, as implicações da noção de padrões fractais devem ser criticadas e reavaliadas em cada nível estudado, já que a compreensão da dinâmica de um nível do desenvolvimento não implica na transposição exata a outros níveis. 
O contexto e os relacionamentos entre o ambiente e o sistema do desenvolvimento também podem ser analisados com o auxílio da noção de sistemas dissipativos e sistemas abertos da Complexidade, possibilitando a consideração das variáveis e ruídos externos que influenciam o desenvolvimento local. O conceito de estabilidade dinâmica também contribui para a compreensão dos mecanismos de manutenção do equilíbrio no sistema, além de permitir avaliar a viabilidade e necessidade de investimento de recursos para proteção do sistema frente a instabilidades. $\mathrm{O}$ fato de o desenvolvimento ser considerado um fenômeno dinâmico também contribui para a adequabilidade da teoria da complexidade como fundamento para seu tratamento, implicando na temporalidade do fenômeno, isto é, a observação em um único momento no tempo não permite sua compreensão.

A teoria da complexidade apresenta-se como abordagem coerente para o tratamento do desenvolvimento local, permitindo a abrangência da multiplicidade de características e dinâmicas envolvidas no fenômeno. 


\section{CONSIDERAÇÕES FINAIS}

Partindo da mudança de paradigma no conhecimento científico, foi organizado um quadro conceitual sobre os paradigmas emergentes ligados à Complexidade, uma vez que o desenvolvimento, em seus diversos níveis (local, regional, nacional, internacional), é apontado como um fenômeno de complexidade inerente.

Foi realizado um esforço a fim de organizar o conhecimento acerca do desenvolvimento e as concepções, processos e variáveis a ele relacionados, com o objetivo de compreender a dinâmica envolvida. Definiu-se um esboço da essência primeira do desenvolvimento, a partir do método de redução eidética, considerando o desenvolvimento local e o desenvolvimento de forma mais ampla. Com base nesse esboço, foram buscados conceitos fundamentais da Complexidade com o objetivo de verificar a adequabilidade da descrição da dinâmica do desenvolvimento local por meio dessa base teórica. A partir do tratamento do fenômeno tomando como base uma abordagem que permita a abrangência da multiplicidade de seus aspectos, tornou-se possível a compreensão, por parte de seus atores e agentes, quanto ao seu papel e suas alternativas de ação integrada.

Diante da relação detalhada da essência primeira do desenvolvimento local aos conceitos fundamentais da Complexidade, as características que este trabalho considera como pertencentes a esse fenômeno são listadas no quadro 13.

\begin{tabular}{|c|c|c|}
\hline Característica & Justificativa & Autores \\
\hline São sistemas & $\begin{array}{l}\text { Consistem de um agrupamento de partes com } \\
\text { identidade própria que operam juntas para um } \\
\text { propósito comum }\end{array}$ & $\begin{array}{l}\text { Beer, 1985, 1994a, 1994b; Donaires, } \\
2012\end{array}$ \\
\hline São dinâmicos & O tempo é uma variável do sistema & $\begin{array}{l}\text { Bloch, 2005; Capra, 2006; } \\
\text { 2002; Giovannini, 2002a, 2002b; } \\
\text { Larsen-Freeman, 2012 }\end{array}$ \\
\hline São abertos & Relacionamento com o ambiente externo & $\begin{array}{l}\text { Bloch, 2005; Bousquet e Curtis, 2011; } \\
\text { Larsen-Freeman, 2012; Manson, 2001; } \\
\text { Prigogine, } 1996\end{array}$ \\
\hline São não-lineares & $\begin{array}{l}\text { Apresentam simultaneamente ciclos de } \\
\text { retroalimentação positivos e negativos }\end{array}$ & $\begin{array}{l}\text { Agar, 1999; Bauer, 1999; Bloch, 2005; } \\
\text { Bokeno, 2008; Giovannini, 2002a, } \\
\text { 2002b; Larsen-Freeman, 2012; Longa, } \\
\text { 2004; Miguélez, 2011; Murray, } 1998\end{array}$ \\
\hline $\begin{array}{l}\text { São adaptativos e } \\
\text { possuem capacidade } \\
\text { de aprendizado }\end{array}$ & $\begin{array}{l}\text { As partes mudam para se adaptar a estímulos } \\
\text { internos ou instabilidades externas, } \\
\text { considerando o histórico de evolução }\end{array}$ & $\begin{array}{l}\text { Bloch, 2005; Bousquet e Curtis, 2011; } \\
\text { Demo, 2002; Manson, 2001; Murray, } \\
\text { 1998; Miguélez, 2011 }\end{array}$ \\
\hline São dissipativos & $\begin{array}{l}\text { Precisam buscar no ambiente energia para } \\
\text { sobreviver e se desenvolver }\end{array}$ & $\begin{array}{l}\text { Bloch, 2005; Bousquet e Curtis, 2011; } \\
\text { Larsen-Freeman, 2012; Manson, 2001; } \\
\text { Prigogine, } 1996\end{array}$ \\
\hline
\end{tabular}

Quadro 13 - Características da Complexidade apresentadas pelo desenvolvimento local 
Em função destas características, os sistemas de desenvolvimento local podem ser compreendidos considerando-se que estão sujeitos aos aspectos da Complexidade listados no quadro 14.

Portanto, é possível afirmar que a Complexidade constitui abordagem adequada para a compreensão da dinâmica do desenvolvimento local.

\begin{tabular}{|l|l|}
\hline \multicolumn{1}{|c|}{ Dinâmica } & \multicolumn{1}{|c|}{ Autores } \\
\hline $\begin{array}{l}\text { Estão sujeitos à dependência sensitiva às condições iniciais e, } \\
\text { portanto, sujeitos à incerteza a partir de um determinado } \\
\text { número de ciclos }\end{array}$ & $\begin{array}{l}\text { Bloch, 2005; Fiedler-Ferrara e Prado, 1994; } \\
\text { Giovannini, 2002a, 2002b; Larsen-Freeman, } \\
2012\end{array}$ \\
\hline $\begin{array}{l}\text { Podem ser vistos como estruturas fractais, com auto- } \\
\text { semelhança entre suas partes, relacionadas segundo leis de } \\
\text { escala (sendo que a compreensão pode ser aplicar a níveis } \\
\text { distintos, com ressalvas às especificidades) }\end{array}$ & $\begin{array}{l}\text { Bloch, 2005; Giovannini, 2002a, 2002b; } \\
\text { Morin, 2010, 2011 }\end{array}$ \\
\hline $\begin{array}{l}\text { Operam em estabilidade dinâmica em torno de atratores } \\
\text { estranhos que podem mudar de posição em função da } \\
\text { capacidade adaptativa }\end{array}$ & $\begin{array}{l}\text { Bloch, 2005; Burnes, 2005; Giovannini, } \\
\text { 2002a, 2002b; Lindsay, 2005; Miguélez, } \\
\text { 2011; Puddifoot, 2000 }\end{array}$ \\
\hline $\begin{array}{l}\text { Podem evoluir autonomamente, sem necessidade de um } \\
\text { estímulo externo, através de processos de geração de de } \\
\text { alternativas que, apesar de não eficientes, são eficazes }\end{array}$ & $\begin{array}{l}\text { Bloch, 2005; Bousquet e Curtis, 2011; Demo, } \\
\text { 2002; Manson, 2001; Murray, 1998; } \\
\text { Miguélez, 2011 }\end{array}$ \\
\hline $\begin{array}{l}\text { Estão sujeitos à imprevisibilidade, devida à não-linearidade, à } \\
\text { sensibilidade às condições iniciais e às propriedades } \\
\text { emergentes }\end{array}$ & $\begin{array}{l}\text { Bloch, 2005; Fiedler-Ferrara e Prado, 1994; } \\
\text { Giovannini, 2002a, 2002b; Larsen-Freeman, } \\
\text { 2012; Poser, 2007 }\end{array}$ \\
\hline & $\begin{array}{l}\text { Bloch, 2005; Bokeno, 2008; Bousquet e } \\
\text { Curtis, 2011; Klijn, 2008; Larsen-Freeman, }\end{array}$ \\
$\begin{array}{l}\text { Podem emergir de processo de auto-organização, se adaptando } \\
\text { ou se estruturando a despeito de influências externas }\end{array}$ & $\begin{array}{l}\text { 2012; Lindsay, 2005; Miguélez, 2011; Morin, } \\
\text { 2010; Murray, 1998; Rickles, Hawe e Shiell, } \\
\text { 2007 }\end{array}$ \\
\hline
\end{tabular}

Quadro 14 - Dinâmicas da Complexidade às quais o desenvolvimento local está sujeito

As limitações deste trabalho estão relacionadas ao fato de que um assunto de tamanha extensão e importância exigiria um esforço de reflexão mais extenso e completo, fora do alcance de uma dissertação de mestrado. Além disso, o próprio fato de lidarmos com a tentativa de descrever a realidade, por meio de teorias científicas, se apresenta como uma limitação:

As teorias científicas não estarão nunca aptas a fornecer uma descrição completa e definitiva da realidade. Serão sempre aproximações da verdadeira natureza das coisas. Em termos claros: os cientistas não lidam com a verdade; eles lidam com descrições da realidade limitadas e aproximadas (CAPRA, 2006, p. 45).

Ao se tratar de sistemas complexos, a identificação do sistema na prática é considerada um desafio, uma vez que o observador possui uma limitação cognitiva, que o obriga a criar simplificações para apreender o objeto de estudo (DONAIRES, 2012). Além de o mundo ser complexo, o cérebro humano não é ferramenta suficiente para dar conta dele, limitando-nos às representações parciais do mundo (DOMINGUES; FERNÁNDEZ, 2011). As limitações 
humanas para lidar com a complexidade derivam de dois aspectos: o primeiro é relacionado à limitação de memória de curto prazo, que pode compreender no máximo dois blocos de informação simultaneamente; e o segundo é relacionado à velocidade de processamento da mente, que requer cerca de cinco segundos para aceitar um novo bloco de informação (DONAIRES, 2012). Para lidar com a complexidade, Donaires (2012) destaca o papel de três técnicas:

1. Decomposição: o problema é decomposto em problemas sucessivamente menores e proporcionalmente mais simples;

2. Abstração: capturar num modelo abstrato somente os elementos importantes para a solução do problema;

3. Hierarquia: classificar e organizar o grande número de abstrações geradas pela decomposição de um sistema complexo.

Logo, na tentativa de descrever um sistema no nível de complexidade dos sistemas socioeconômicos, culturais, tecnológicos, político-legais e ambientais envolvidos no desenvolvimento, para que isso seja possível, foram criadas abstrações conceituais que, em certa medida, são consideradas simplificações da realidade.

Outra limitação encontra-se no fato de que a descrição do fenômeno está sujeita às experiências de quem o descreve, sendo concebida como momentânea. A fenomenologia pretende ser, por essência, dinâmica, mantendo a consciência sempre aberta (GILES, 1975). "O sentido de um fenômeno não deve ser mais concebido, consequentemente, como um sentido eterno, independente das experiências concretas do sujeito" (DARTIGUES, 1992, p. 68-69). Ou seja, os termos e conceitos não são estáticos, podendo ser modificados conforme o próprio progresso da análise da consciência e do conhecimento de novos níveis fenomenológicos (GILES, 1975). Assim, o objetivo deste trabalho não consistiu em estabelecer descrições e explicações eternas, mas sim contribuir para que o desenvolvimento local passe a ser estudado a partir de novos paradigmas, numa tentativa de compreensão do fenômeno buscando maiores possibilidades de ação dos atores envolvidos.

Como os conceitos básicos não são rigidamente definidos em um texto específico acerca da teoria da complexidade (BLOCH, 2005), é provável que outros estudos nessa área isolem uma lista diferente de conceitos, ou utilizem definições distintas, apresentadas em uma sequência também diferente, configurando uma limitação da pesquisa. 
Outrossim, o aprofundamento do conhecimento em áreas de difícil acesso para a formação tradicional do administrador apresentou-se como desafio e possível limitação do estudo.

Conforme explica Vergara (2010), os conhecimentos originados tendo como base a fenomenologia podem ser explorados por outros enfoques de maneira complementar, ou seja, proposições geradas por uma investigação fenomenológica podem ser utilizadas para a geração de hipóteses testadas, por exemplo. Fica como sugestão de estudos futuros a utilização da abordagem aqui sugerida como base para a geração de hipóteses que possam ser testadas.

A abordagem neural e a teoria da informação são apresentadas, adicionalmente à teoria de sistemas e à cibernética, como as principais referências teóricas em que a Complexidade se baseia. Devido à delimitação teórica deste trabalho e às especificidades das mesmas, a abordagem neural e a teoria da informação não são abordadas neste esforço de pesquisa. Logo, sugere-se como perspectiva para estudos futuros o tratamento do desenvolvimento local a partir dessas abordagens, verificando sua compatibilidade.

A originalidade do trabalho consiste na caracterização do fenômeno do desenvolvimento local a partir dos conceitos e princípios da teoria da complexidade, explicando sua relação com o paradigma emergente e considerando a incerteza e a mutabilidade como inerentes e internas ao próprio sistema.

O valor deste esforço de pesquisa reside na sugestão de uma abordagem que possa contribuir para a compreensão da dinâmica específica de comportamento do sistema do desenvolvimento em cada situação, o que gera a possibilidade de busca de resultados determinados na direção da sustentabilidade, uma vez que os atores desse processo podem se posicionar de maneira mais ativa, contribuindo de forma efetiva. Este esforço de pesquisa contribui para a formação do corpo de conhecimento da teoria da complexidade a partir da definição sistemática dos conceitos fundamentais. 


\section{REFERÊNCIAS}

ABRAHAM, R. H. The Genesis of complexity. World Futures: the Journal of Global Education, v. 67, n. 4-5, pp. 380-394, 2011.

AGAR, M. Complexity theory: an exploration and overview based on John Holland's work. Field Methods, v. 11, n. 2, pp. 99-120, 1999.

ALBAGLI, S. Globalização e espacialidade: o novo papel do local. In: CASSIOLATO, J. E.; LASTRES, H. M. M. (Eds.). Globalização e inovação localizada: experiências de sistemas locais no Mercosul e proposições de políticas de C\&T. Brasília: IBICT/MCT, 1999. Cap. 5, p. 181-198.

ALBUQUERQUE, F. Desenvolvimento econômico local e distribuição do progresso técnico: uma resposta às exigências do ajuste estrutural. Fortaleza: BNB, 1998. 151 p.

ALHADEFF-JONES, M. Three generations of complexity theories: nuances and ambiguities. Educational Philosophy and Theory, v. 40, n. 1, pp. 66-82, 2008.

ALMEIDA FILHO, N. O ensino do tema desenvolvimento nas escolas brasileiras: eixos teóricos e proposições derivadas de políticas. In: CARDOSO JUNIOR, J. C.; SIQUEIRA, C. H. R. (Orgs.) Complexidade e desenvolvimento: diálogos para o desenvolvimento. Brasília: Ipea, 2011. Cap. 12, v. 3, p. 227-268.

AMATO NETO, J. Redes de cooperação produtiva e clusters regionais: oportunidades para as pequenas e médias empresas. São Paulo: Atlas, 2000. 163 p.

ARBIX, G.; ZILBOVICIUS, M. Por uma estratégia de civilização. In: ARBIX, G.; ZILBOVICIUS, M.; ABRAMOVAY, R. (Orgs). Razões e ficções do desenvolvimento. São Paulo: Editora UNESP; Edusp, 2001. Cap. 5, p. 55-69.

ASHBY, W. R. Introdução à cibernética. São Paulo: Perspectiva, 1970. 345 p.

AXLEY, S. R.; MCMAHON, T.R. Complexity: a frontier for management education. Journal of Management Education, v. 30, n. 2, pp. 295-315, 2006.

BAGNASCO, A. A teoria do desenvolvimento e o caso italiano. In: ARBIX, G.; ZILBOVICIUS, M.; ABRAMOVAY, R. (Orgs). Razões e ficções do desenvolvimento. São Paulo: Editora UNESP; Edusp, 2001. Cap. 15, p. 349-363.

BARABÁSI, A.-L. The architecture of complexity. IEEE Control Systems Magazine, v. 27, n. 4, pp. 33-42, 2007.

BASSAN, D. S.; SIEDENBERG, D. R. Desenvolver buscando a redução das desigualdades. In: BECKER, D. F.; WITTMANN, M. L. (Orgs). Desenvolvimento regional: abordagens interdisciplinares. 2. ed. Santa Cruz do Sul: EDUNISC, 2010. Cap. 4, p. 137-153. 
BATESON, G. Cybernetic explanation. The American Behavioral Scientist, v. 10, n. 8, pp. 29-32, 1967.

BAUER, R. Gestão da mudança: caos e complexidade nas organizações. São Paulo: Atlas, 1999. $253 \mathrm{p}$.

BECKER, D. F. A contradição em processo: o local e o global na dinâmica do desenvolvimento regional. In: BECKER, D. F.; WITTMANN, M. L. (Orgs).

Desenvolvimento regional: abordagens interdisciplinares. 2. ed. Santa Cruz do Sul: EDUNISC, 2010a. Cap. 2, p. 67-115.

BECKER, D. F. A economia política do (des)envolvimento regional contemporâneo. In: BECKER, D. F.; WITTMANN, M. L. (Orgs). Desenvolvimento regional: abordagens interdisciplinares. 2. ed. Santa Cruz do Sul: EDUNISC, 2010b. Cap. 1, p. 37-66.

BEER, S. Brain of the firm. 2. ed. Chichester: John Wiley \& Sons, 1994a. 417 p.

BEER, S. The heart of enterprise. Chichester: John Wiley \& Sons, 1994b. 582 p.

BEER, S. Diagnosing the system for organizations. Chichester: John Wiley \& Sons, 1985. $152 \mathrm{p}$.

BELLUZZO, L. G. M. Valor e capitalismo: um ensaio sobre a economia política. São Paulo: Brasiliense, 1980. $121 \mathrm{p}$.

BERTALANFFY, L. V. Teoria geral dos sistemas: fundamentos, desenvolvimento e aplicações. 6. ed. Petrópolis: Vozes, 2012. 360 p.

BERTALANFFY, L. V.; ANOHIN, P. K.; RAPOPORT, A.; MACKENZIE, W. J. M.; THOMPSON, J. D. Teoria dos sistemas. 1. ed. Rio de Janeiro: Fundação Getúlio Vargas, 1976. $143 \mathrm{p}$.

BIRKNER, W. M. K. Desenvolvimento regional e descentralização político-administrativa: um estudo comparativo dos casos de Minas Gerais, Ceará e Santa Catarina. Revista de Sociologia e Política, v. 16, n. 30, pp. 297-311, 2008.

BLOCH, D. P. Complexity, chaos, and nonlinear dynamics: a new perspective on career development theory. The Career Development Quarterly, v. 53, n. 3, pp. 194-207, 2005.

BOKENO, M. Complexity: an alternative paradigm for teamwork development.

Development and Learning Organizations, v. 22, n. 6, pp. 7-10, 2008.

BOUSQUET, A.; CURTIS, S. Beyond models and metaphors: complexity theory, systems thinking and international relations. Cambridge Review of International Affairs, v. 24, n. 1, pp. 43-62, 2011.

BRISOLLA, S.; CORDER, S.; GOMES, E.; MELLO, D. As relações universidade-empresagoverno: um estudo sobre a Universidade Estadual de Campinas (UNICAMP). Educação \& Sociedade, v. 18, n. 61, pp. 187-209, 1997. 
BURNES, B. Complexity theories and organizational change. International Journal of Management Reviews, v. 7, n. 2, pp. 73-90, 2005.

CANEVER, M. D.; CARRARO, A.; KOHLS, V. K.; TELES, M. Y. O. Entrepreneurship in the Rio Grande do Sul, Brazil: the determinants and consequences for the municipal development. Revista de Economia e Sociologia Rural, v. 48, n. 1, pp. 85-108, 2010.

CAPRA, F. O ponto de mutação: a ciência, a sociedade e a cultura emergente. São Paulo: Cultrix, 2006. 447 p.

CARDOSO JUNIOR, J. C. Estado, planejamento e políticas públicas: o Brasil em desenvolvimento - um olhar à luz do debate em curso no IPEA ao longo do triênio 20082010. In: CARDOSO JUNIOR, J. C.; SIQUEIRA, C. H. R. (Orgs.) Complexidade e desenvolvimento: diálogos para o desenvolvimento. Brasília: Ipea, 2011. Cap. 2, v. 3, p. 3346.

CARDOSO JUNIOR, J. C.; SIQUEIRA, C. H. R. (Orgs.). Complexidade e desenvolvimento: diálogos para o desenvolvimento. Brasília: Ipea, 2011. v. 3. 275 p.

CASAROTTO FILHO, N.; PIRES, L. H. Redes de pequenas e médias empresas e desenvolvimento local: estratégias para a conquista da competitividade global com base na experiência italiana. São Paulo: Atlas, 1998. 148 p.

CASSANEGO JUNIOR, P. V. Complexidade e organizações: a dinâmica de sistemas complexos adaptativos. In: WITTMANN, M. L. (Org). Administração: teoria sistêmica e complexidade. Santa Maria: UFSM, 2008. Cap. 4, p. 85-97.

CASTELLS, M. A sociedade em rede. 6. ed. São Paulo: Paz e Terra, 1999. 698 p.

CAVALCANTI, M. F.; PAULA, V. A. F. Teoria Geral de Sistemas I. In: MARTINELLI, D. P.; VENTURA, C. A. A.; LIBONI, L. B.; MARTINS, T. M. (Orgs.) Teoria geral dos sistemas. São Paulo: Saraiva, 2012. Cap. 1, p. 1-14.

CERVO, A. L.; BERVIAN, P. A. Metodologia científica. 5. ed. São Paulo: Pearson Prentice Hall, 2002. 241 p.

CIÊNCIAHOJE. Rio de Janeiro: Instituto Ciência Hoje, v. 49, n. 289, 2012.

CLOSS, L. Q.; ANTONELLO, C. S. Aprendizagem transformadora: a reflexão crítica na formação gerencial. Cadernos EBAPE.BR, v. 8, n. 1, pp. 19-37, 2010.

COELHO, F. Desenvolvimento local e construção social: o território como sujeito. In: SILVEIRA, C. M.; REIS, L. C. (Org.). Desenvolvimento local: dinâmicas e estratégias. Rio de Janeiro: DLIS, 2001. p. 57-68.

COOPER, D. R.; SCHINDLER, P. S. Métodos de pesquisa em administração. 10. ed. Porto Alegre: Bookman, 2011. 762 p. 
COORDENAÇÃO DE APERFEIÇOAMENTO DE PESSOAL DE NÍVEL SUPERIOR (CAPES). DIRETORIA DE AVALIAÇÃO (DAV). Documento de área 2009:

Administração, Ciências Contábeis e Turismo. 2008. Disponível em:

http://qualis.capes.gov.br/webqualis/publico/documentosDeArea.seam?conversationPropagati on=begin. Acesso em: 29 jan. 2013.

COSTA, P.; WITTMANN, M. L.; GRZYBOVSKI, D. Reflexões sobre a teoria da complexidade no espaço organizacional. In: WITTMANN, M. L. (Org). Administração: teoria sistêmica e complexidade. Santa Maria: UFSM, 2008. Cap. 3, p. 63-83.

COX, K. R. Globalization, competition and the politics of local economic development. Urban Studies, v. 32, n. 2, pp. 213-224, 1995.

DAFT, R. L. Organizações: teorias e projetos. São Paulo: Pioneira Thomson Learning, 2002.

DALLABRIDA, V. R.; BECKER, D. F. Dinâmica territorial do desenvolvimento. In: BECKER, D. F.; WITTMANN, M. L. (Orgs). Desenvolvimento regional: abordagens interdisciplinares. 2. ed. Santa Cruz do Sul: EDUNISC, 2010. Cap. 6, p. 175-213.

DALLABRIDA, V. R.; SIEDENBERG, D. R.; FERNÁNDEZ, V. R. Desenvolvimento territorial: uma revisão teórica na perspectiva da territorialização do desenvolvimento. In: WITTMANN, M. L.; RAMOS, M. P. (Orgs). Desenvolvimento regional: capital social, redes e planejamento. 1. ed. Santa Cruz do Sul: EDUNISC, 2004. p. 101-133.

DARTIGUES, A. O que é a fenomenologia? 3. ed. São Paulo: Moraes, 1992. 174 p.

DEMO, P. Complexidade e aprendizagem: a dinâmica não linear do conhecimento. São Paulo: Atlas, 2002. 195 p.

DEMO, P. Introdução à metodologia da ciência. 2. ed. São Paulo: Atlas, 2008. 118 p.

DEMO, P. Pesquisa e construção de conhecimento: metodologia científica no caminho Habermas. Rio de Janeiro: Tempo Brasileiro, 1994. 125 p.

DENNIS, K. Time in the age of complexity. Time \& Society, v. 16, n. 2/3, pp. 139-155, 2007.

DEVLIN, K. Good-bye Descartes? Mathematics Magazine, v. 69, n. 5, pp. 344-349, Dec. 1996.

DOMINGUES, I.; FERNÁNDEZ, R. G. Complexidade e pluralismo metodológico. In: CARDOSO JUNIOR, J. C.; SIQUEIRA, C. H. R. (Orgs.) Complexidade e desenvolvimento: diálogos para o desenvolvimento. Brasília: Ipea, 2011. Cap. 3, v. 3, p. 49-63.

DONAIRES, O. S. Teoria Geral de Sistemas II. In: MARTINELLI, D. P.; VENTURA, C. A. A.; LIBONI, L. B.; MARTINS, T. M. (Orgs.) Teoria geral dos sistemas. São Paulo: Saraiva, 2012. Cap. 2, p. 15-34. 
DOWBOR, L. Gestão social e transformação da sociedade. In: ARBIX, G.; ZILBOVICIUS, M.; ABRAMOVAY, R. (Orgs). Razões e ficções do desenvolvimento. São Paulo: Editora UNESP; Edusp, 2001. Cap. 10, p. 197-221.

DOWBOR, L. Globalização e tendências institucionais. In: DOWBOR, L.; IANNI, O.; RESENDE, P. E. A. (Orgs). Desafios da globalização. Petrópolis: Vozes, 1997. Cap. 1, p. 916.

DOWBOR, L.; IANNI, O.; RESENDE, P. E. A. (Orgs). Desafios da globalização. Petrópolis: Vozes, 1997. 302 p.

FACHIN, O. Fundamentos de metodologia. São Paulo: Atlas, 1993. 153 p.

FAORO, R. Os donos do poder. 3. ed. v.1. Porto Alegre: Globo, 1976. 397 p.

FAORO, R. Os donos do poder. 2. ed. v.2. Porto Alegre: Globo, 1975. 353 p.

FERREIRA, A. B. H. Novo dicionário da língua portuguesa. 2. ed. Rio de Janeiro: Nova fronteira, 1986. $1838 \mathrm{p}$.

FERREIRA, M. T. S.; MEIRELES, S. S.; MACEDO, M. A. S.; BARONE, F. M.; SANT'ANNA, P. R.; ZOTES, L. P. Análise do desenvolvimento de Arranjos Produtivos Locais (APLs): um estudo de caso do município de Paraty (RJ). Revista de Administração Pública, v. 45, n. 2, pp. 517-539, 2011.

FIEDLER-FERRARA, N.; PRADO, C. P. C. Caos: uma introdução. São Paulo: Edgard Blücher, 1994. $402 \mathrm{p}$.

FONSECA, I. F.; VILELA, M. V.; SOUSA, P. B.; MIRANDA, S. P.; SILVA, V. M. A. Projeto amanhã: uma experiência de desenvolvimento local por meio da capacitação de jovens rurais. In: PASSADOR, C. S.; PASSADOR, J. L. (Orgs). Gestão pública e desenvolvimento no Século XXI: casos da Companhia de Desenvolvimento dos Vales do São Francisco e do Parnaíba (Codevasf). São Paulo: Annablume; Fapesp, 2007. Cap. 8, p. 191-217.

FRANCO, A. O conceito de capital social e a procura de um índice sistêmico de desenvolvimento local integrado e sustentável. In: SILVEIRA, C. M.; REIS, L. C. (Org.). Desenvolvimento local: dinâmicas e estratégias. Rio de Janeiro: DLIS, 2001. p. 153-162.

FRANÇA, C. L.; CALDAS, E. L.; VAZ, J. C. (Org.) Aspectos econômicos de experiências de desenvolvimento local: um olhar sobre a articulação dos atores. São Paulo: Instituto Pólis, 2004. 80 p. (Publicações Pólis, 46).

FREY, I. A.; FREY, M. R. A responsabilidade social empresarial na gestão dos negócios no contexto dos processos econômico-organizacionais do desenvolvimento regional. In:

WITTMANN, M. L.; RAMOS, M. P. (Orgs). Desenvolvimento regional: capital social, redes e planejamento. 1. ed. Santa Cruz do Sul: EDUNISC, 2004. p. 193-215. 
FURTADO, C. Desenvolvimento e subdesenvolvimento. 2. ed. Rio de Janeiro: Fundo de Cultura, 1963. 270 p.

FURTADO, C. O mito do desenvolvimento econômico. 3. ed. Rio de Janeiro: Paz e Terra, 1974. $117 \mathrm{p}$.

FURTADO, C. Os desafios da nova geração. Revista de Economia Política, v. 24, n. 4, pp. 483-486, 2004.

GANZERT, C. C. Desenvolvimento sistêmico, equidade e interdependência: a busca por um modelo conceitual de gestão do equilíbrio das relações entre agentes econômicos regionais. 2012. 346 p. Tese (Doutorado em Ciências no Programa de Pós-Graduação em Administração de Organizações - Faculdade de Economia, Administração e Contabilidade de Ribeirão Preto, Universidade de São Paulo, Ribeirão Preto, 2012.

GILES, T. R. História do existencialismo e da fenomenologia. São Paulo: EPU, Editora da Universidade de São Paulo, 1975. v.1.302 p.

GIOVANNINI, F. A complexidade e o estudo das organizações: explorando possibilidades. Revista de Administração, v. 37, n. 3, pp. 56-66, 2002a.

GIOVANNINI, F. As organizações e a complexidade: um estudo dos sistemas de gestão da qualidade. 2002b. 218 p. Dissertação (Mestrado em Administração no Programa de PósGraduação em Administração) - Faculdade de Economia, Administração e Contabilidade, Universidade de São Paulo, São Paulo, 2002b.

GLEICK, J. Caos: a criação de uma nova ciência. Rio de Janeiro: Elsevier, 2008. 310 p.

GOLDENBERG, M. A arte de pesquisar: como fazer pesquisa qualitativa em ciências sociais. 3. ed. Rio de Janeiro: Record, 1999. 107 p.

GOULIELMOS, A. M. Complexity theory: a science where historical accidents matter. Disaster Prevention and Management, v. 14, n. 4, pp. 533-547, 2005.

GRAZIANO DA SILVA, J. A nova dinâmica da agricultura brasileira. 2. ed. Campinas : Unicamp. IE, 1996. 217 p.

GRAZIANO DA SILVA, J. O que é questão agrária. 18. ed. São Paulo : Brasiliense, 1994. $106 \mathrm{p}$.

HAYEK, F. A. Degrees of explanation. British journal for the philosophy of science, v. 6, n. 23, pp. 209-225, 1955.

HEIDEGGER, M. Conferências e escritos filosóficos. São Paulo: Nova Cultural, 2000. 304 p.

HOLANDA, V. B. Contabilidade: a cibernética empresarial. Revista Contabilidade \&

Finanças, v. 14, n. 25, pp. 42-59, 2001. 
HORN, J. Human Research and Complexity Theory. Educational Philosophy and Theory, v. 40, n. 1, pp. 130-143, 2008.

HOUAISS, A.; VILLAR, M. S. Dicionário Houaiss da língua portuguesa. Rio de Janeiro: Objetiva, 2009. $1986 \mathrm{p}$.

HOWARD, A. Paradexity: the convergence of paradox and complexity. Journal of Management Development, v. 29, n. 3, pp. 210-223, 2010.

HUSSERL, E. Meditações cartesianas: introdução à fenomenologia. 2. ed. Porto: Rés, 2001. $202 \mathrm{p}$.

IPIRANGA, A. S. R.; FREITAS, A. A. F.; PAIVA, T. A. O empreendedorismo acadêmico no contexto da interação universidade-empresa-governo. Cadernos EBAPE.BR, v. 8, n. 4, pp. 676-693, 2010.

JOHNSON, J. The future of the social sciences and humanities in the science of complex systems. Innovation: The European Journal of Social Science Research, v. 23, n. 2, pp. 115-134, 2010.

KATOPES, P. Resisting chaos: the power of the humanities as a problem-solving system. On the Horizon, v. 19, n. 2, pp. 140-146, 2011.

KLIJN, E.-H. Complexity theory and public administration: what's new? Public Management Review, v. 10, n. 3, pp. 299-317, 2008.

KOGETSIDIS, H. Systems approaches for organizational analysis. International Journal of Organizational Analysis, v. 19, n. 4, pp. 276-287, 2011.

KUHN, T. S. The structure of scientific revolution. 3. ed. Chicago: University of Chicago Press, 1996. 212 p.

LARSEN-FREEMAN, D. Complex, dynamic systems: a new transdisciplinary theme for applied linguistics? Language Teaching, v. 45, n. 2, pp. 202-214, 2012.

LIMA, T. C. S.; MIOTO, R. C. T. Procedimentos metodológicos na construção do conhecimento científico: a pesquisa bibliográfica. Revista Katálysis, v. 10, n. esp., pp. 37-45, 2007.

LINDSAY, V. J. The development of international industry clusters: a complexity theory approach. Journal of International Entrepreneurship, v. 3, n. 1, pp. 71-97, 2005.

LONGA, V. M. A nonlinear approach to translation. Target, v. 16, n. 2, pp. 201-226, 2004.

MAGNOLI, D. Globalização: estado nacional e espaço mundial. 2. ed. reform. São Paulo: Moderna, 2003. 128 p. (Coleção polêmica)

MANSON, S. M. Simplifying complexity: a review of complexity theory. Geoforum, v. 32, pp. 405-414, 2001. 
MARQUES, C. H. S.; LOPES, H. J. A.; BARBOSA, L. F.; COELHO, L. M.; SANTOS, S. R. M. Desenvolvimento territorial: estudo de caso do município de Uruçuí. In: PASSADOR, C. S.; PASSADOR, J. L. (Orgs). Gestão pública e desenvolvimento no Século XXI: casos da Companhia de Desenvolvimento dos Vales do São Francisco e do Parnaíba (Codevasf). São Paulo: Annablume; Fapesp, 2007. Cap. 7, p. 171-189.

MARCHI, J. J.; WITTMANN, M. L. Princípios da teoria da complexidade aplicados à gestão das organizações. In: WITTMANN, M. L. (Org). Administração: teoria sistêmica e complexidade. Santa Maria: UFSM, 2008. Cap. 2, p. 41-61.

MARCONI, M. A.; LAKATOS, E. M. Fundamentos de metodologia científica. 7. ed. São Paulo: Atlas, 2010. 297 p.

MARCUZZO, J. L.; AREND, S. C.; RAMOS, M. P. Contextualização do surgimento da lei de responsabilidade fiscal como instrumento para o desenvolvimento regional. In:

WITTMANN, M. L.; RAMOS, M. P. (Orgs). Desenvolvimento regional: capital social, redes e planejamento. 1. ed. Santa Cruz do Sul: EDUNISC, 2004. p. 159-191.

MARTINELLI, D. P.; JOYAL, A. Desenvolvimento local e o papel das pequenas e médias empresas. Barueri: Manole, 2004. 314 p.

MARTINELLI, D. P.; VENTURA, C. A. A. Metodologias sistêmicas I. In: MARTINELLI, D. P.; VENTURA, C. A. A.; LIBONI, L. B.; MARTINS, T. M. (Orgs.) Teoria geral dos sistemas. São Paulo: Saraiva, 2012. 356 p. Cap. 3, p. 35-50.

MARTINS, J. Um enfoque fenomenológico do currículo: educação como poíesis. São Paulo: Cortez, 1992. 142 p.

MARTINS, R. A.; CALDAS, E. L. Visões do desenvolvimento local: uma análise comparada de experiências brasileiras. Interações, v. 10, n. 2, pp. 207-218, 2009.

MARTINS, R. A.; VAZ, J. C.; CALDAS, E. L. A gestão do desenvolvimento local no Brasil: (des)articulação de atores, instrumentos e território. Revista de Administração Pública, v. 44, n. 3, pp. 559-590, 2010.

MASON, M. What is complexity theory and what are its implications for educational change? Educational Philosophy and Theory, v. 40, n. 1, pp. 35-49, 2008.

MATHEWS, K. M.; WHITE, M. C.; LONG, R. G. Why study the complexity sciences in the social sciences? Human Relations, v. 52, n. 4, pp. 439-462, 1999.

MELLO, J. M. C. A abordagem hélice tríplice e o desenvolvimento regional. In: II Seminário Internacional Empreendedorismo, Pequenas e Médias Empresas e Desenvolvimento Local, 2004, Rio de Janeiro, Anais... Rio de Janeiro,2004.

MERLEAU-PONTY, M. Fenomenologia da percepção. 2. ed. São Paulo: Martins Fontes, 1999. $662 \mathrm{p}$. 
MICHAELIS: moderno dicionário da língua portuguesa. São Paulo: Companhia melhoramentos, 1998. 2259 p.

MIGUÉLEZ, M. M. Paradigmas emergentes y ciencias de la complejidad. Opción, v. 27, n. 65, pp. 45-80, 2011.

MIKULECKY, D. C. The emergence of complexity: science coming of age or science growing old? Computers and Chemistry, v. 25, n. 4, pp. 341-348, 2001.

MIRANDA, M.; MAGALHÃES, P. Discutindo Dlis: reflexões a partir da metrópole. In: SILVEIRA, C. M.; REIS, L. C. (Org.). Desenvolvimento local: dinâmicas e estratégias. Rio de Janeiro: DLIS, 2001. p. 103-112.

MORAES, A. M. P. Iniciação ao estudo de administração. 2. ed. São Paulo: Makron books, 2001. $165 \mathrm{p}$.

MORAES, J. L. A. Capital social: potencialidades dos fatores locais e políticas públicas de desenvolvimento local-regional. In: BECKER, D. F.; WITTMANN, M. L. (Orgs).

Desenvolvimento regional: abordagens interdisciplinares. 2. ed. Santa Cruz do Sul: EDUNISC, 2010. Cap. 10, p. 263-281.

MORGAN, G. Imagens da organização. 1. ed. São Paulo: Atlas, 2009. 421 p.

MORIN, E. A cabeça bem-feita: repensar a reforma, reformar o pensamento. 18. ed. Rio de Janeiro: Bertrand Brasil, 2010. 128 p.

MORIN, E. Introdução ao pensamento complexo. 4. ed. Porto Alegre: Sulina, 2011. 120 p.

MOREIRA, D. A. O método fenomenológico na pesquisa. São Paulo: Pioneira Thomson, 2002. 152 p.

MOTTA, F. C. P.; VASCONCELOS, I. F. G. Teoria geral da administração. 3. ed. São Paulo: Pioneira Thomson Learning, 2008. 428 p.

MOWLES, C. Post-foundational development management - power, politics and complexity. Public Administration and Development, v. 30, n. 2, pp. 149-158, 2010a.

MOWLES, C. Successful or not? Evidence, emergence, and development management. Development in Practice, v. 20, n. 7, pp. 757-770, 2010 b.

MURRAY, P. J. Complexity theory and the fifth discipline. Systemic Practice and Action Research, v. 11, n. 3, pp. 275-293, 1998.

NAVARRO, Z. Desenvolvimento rural no Brasil: os limites do passado e os caminhos do futuro. Revista Estudos Avançados, v. 15, n. 43, pp. 83-100, 2001.

NOWOTNY, H. The increase of complexity and its reduction: emergent interfaces between the natural sciences, humanities and social sciences. Theory, Culture \& Society, v. 22, n. 5, pp. 15-31, 2005. 
NWAUCHE, E. S.; NWOBIKE, J. C. Implementação do direito ao desenvolvimento. Sur Revista Internacional de Direitos Humanos, v. 2, n. 2, pp. 96-117, 2005. ISSN 1806-6445.

OHMAE, K. O fim do Estado-Nação: a ascensão das economias regionais. Rio de Janeiro: Campus, 1996. 214 p.

OLIVEIRA, M. A. F.; WITTMANN, M. L. Sistema integrado de gestão: uma nova abordagem para integrar a competitividade das organizações com o desenvolvimento regional. In: BECKER, D. F.; WITTMANN, M. L. (Orgs). Desenvolvimento regional: abordagens interdisciplinares. 2. ed. Santa Cruz do Sul: EDUNISC, 2010. Cap. 11, p. 285-318.

PÁDUA, E. M. M. Complexidade e meio ambiente: um estudo sobre a contribuição de Edgar Morin. In: PÁDUA, E. M. M.; MATALLO JUNIOR, H. Ciências sociais, complexidade e meio ambiente: interfaces e desafios. Campinas: Papirus, 2008. Cap. 1, p. 15-46.

PAIVA, C. A. Capital social, comunidade, democracia e o planejamento do desenvolvimento no RS: uma avaliação de suas possibilidades à luz de sua história. In: WITTMANN, M. L.; RAMOS, M. P. (Orgs). Desenvolvimento regional: capital social, redes e planejamento. 1. ed. Santa Cruz do Sul: EDUNISC, 2004. p. 37-78.

PARRA FILHO, D.; SANTOS, J. A. Metodologia científica. 6. ed. São Paulo: Futura, 2003. $277 \mathrm{p}$.

PASSADOR, C. S.; NALLE JR., C. Uma proposta de desenvolvimento: capital humano, capital social, territorialidade, cidadania e sustentabilidade. In: PASSADOR, C. S.; PASSADOR, J. L. (Orgs). Gestão pública e desenvolvimento no Século XXI: casos da Companhia de Desenvolvimento dos Vales do São Francisco e do Parnaíba (Codevasf). São Paulo: Annablume; Fapesp, 2007. Cap. 1, p. 17-39.

PAULA, J. Desenvolvimento \& gestão compartilhada. In: SILVEIRA, C. M.; REIS, L. C. (Org.). Desenvolvimento local: dinâmicas e estratégias. Rio de Janeiro: DLIS, 2001. p. 141150.

PHELAN, S. E. A note on the correspondence between complexity and systems theory. Systemic Practice and Action Research, v. 12, n. 3, pp. 237-246, 1999.

PINA E CUNHA, M.; REGO, A. Complexity, simplicity, simplexity. European Management Journal, v. 28, n. 2, pp. 85-94, 2010.

POLANYI, K. A grande transformação: as origens de nossa época. 2. ed. Rio de Janeiro: Elsevier, 2000. 349 p.

POSER, H. Theories of complexity and their problems. Frontiers of Philosophy in China, v. 2, n. 3, pp. 423-436, 2007.

PRADO, E. F. S. Economia, complexidade e dialética. São Paulo: Plêiade, 2009. 165 p.

PRADO JÚNIOR, C. História e desenvolvimento: a contribuição da historiografia para a teoria e prática do desenvolvimento brasileiro. 3. ed. São Paulo: Brasiliense, 2001. 142 p. 
PRIGOGINE, I. O fim das certezas: tempo, caos e as leis da natureza. São Paulo: UNESP, 1996. $199 \mathrm{p}$.

PUDDIFOOT, J. E. Some problems and possibilities in the study of dynamical social processes. Journal for the Theory of Social Behaviour, v. 30, n. 1, pp. 79-97, 2000.

PUTNAM, R. D. Comunidade e democracia: a experiência da Itália moderna. 4. ed. Rio de Janeiro: Fundação Getúlio Vargas, 2005. 257 p.

RAMOS, M. P.; MARIÑO, J. M. F. Condicionantes históricos do desenvolvimento capitalista global em nível regional. In: WITTMANN, M. L.; RAMOS, M. P. (Orgs). Desenvolvimento regional: capital social, redes e planejamento. 1. ed. Santa Cruz do Sul: EDUNISC, 2004. p. 79-99.

RAMOS, M. P.; MARIÑO, J. M. F. Democracia e desenvolvimento: uma discussão teórica conceitual para entender diferenças regionais. In: BECKER, D. F.; WITTMANN, M. L. (Orgs). Desenvolvimento regional: abordagens interdisciplinares. 2. ed. Santa Cruz do Sul: EDUNISC, 2010. Cap. 7, p. 217-228.

RICUPERO, R. A busca de sentido para a economia e o desenvolvimento. In: ARBIX, G.; ZILBOVICIUS, M.; ABRAMOVAY, R. (Orgs). Razões e ficções do desenvolvimento. São Paulo: Editora UNESP; Edusp, 2001. Cap. 4, p. 41-53.

RICKLES, D.; HAWE, P. ; SHIELL, A. A simple guide to chaos and complexity. Journal of Epidemiology \& Community Health, v. 61, pp. 933-937, 2007.

ROBERTSON, R. Globalização: teoria social e cultura global. Petrópolis: Vozes, 1999. 312 p.

ROCHA NETO, J. M.; BORGES, D. F. As assimetrias entre as políticas setoriais e a política de planejamento regional no Brasil. Revista de Administração Pública, v. 45, n. 6, pp. 1639-1654, 2011.

ROSTOW, W. W. Etapas do desenvolvimento econômico: um manifesto não-comunista. 5. ed. Rio de Janeiro: Zahar, 1974. 274 p.

SACHS, I. Desenvolvimento: includente, sustentável, sustentado. Rio de Janeiro: Garamond, 2008. $151 \mathrm{p}$.

SACHS, I. Ecodesenvolvimento: crescer sem destruir. São Paulo: Vértice, 1986. 207 p.

SACHS, I. Repensando o crescimento econômico e o progresso social: o âmbito da política. In: ARBIX, G.; ZILBOVICIUS, M.; ABRAMOVAY, R. (Orgs). Razões e ficções do desenvolvimento. São Paulo: Editora UNESP; Edusp, 2001. Cap. 7, p. 155-163.

SANGER, M.; GIDDINGS, M. M. A simple approach to complexity theory. Journal of Social Work Education, v. 48, n. 2, pp. 1-8, 2012. 
SANTOS, B. S. (Org.) Produzir para viver: os caminhos da produção não capitalista. Rio de Janeiro: Civilização brasileira, 2002. 514 p.

SANTOS, M. Por uma outra globalização: do pensamento único à consciência universal. 6 . ed. Rio de Janeiro: Record, 2001. 174 p.

SEN, A. K. Desenvolvimento como liberdade. São Paulo: Companhia das Letras, 2000. 409 p.

SERVA, M.; DIAS, T.; ALPERSTEDT, G. D. Paradigma da complexidade e teoria das organizações: uma reflexão epistemológica. Revista de Administração de Empresas, v. 50, n. 3, pp. 276-287, 2010.

SIEDENBERG, D. R. A gestão do desenvolvimento: ações e estratégias entre a realidade e a utopia. In: BECKER, D. F.; WITTMANN, M. L. (Orgs). Desenvolvimento regional:

abordagens interdisciplinares. 2. ed. Santa Cruz do Sul: EDUNISC, 2010. Cap. 5, p. 157-173.

SILVEIRA, C. M. Miradas, métodos, redes: o desenvolvimento local em curso. In:

SILVEIRA, C. M.; REIS, L. C. (Org.). Desenvolvimento local: dinâmicas e estratégias. Rio de Janeiro: DLIS, 2001. p. 31-42.

SINGER, P. Globalização e desemprego: diagnóstico e alternativas. 4. ed. São Paulo:

Contexto, 2000. 139 p.

SIQUEIRA, C. H. R. A opacidade do presente: planejamento, conhecimento e desenvolvimento. In: CARDOSO JUNIOR, J. C.; SIQUEIRA, C. H. R. (Orgs.)

Complexidade e desenvolvimento: diálogos para o desenvolvimento. Brasília: Ipea, 2011.

Cap. 1, v. 3, p. 17-32.

SOTARAUTA, M. Power and influence tactics in the promotion of regional development: an empirical analysis of the work of Finnish regional development officers. Geoforum, v. 40, n. 5, pp.895-905, 2009.

SOTO, W. H. G. Considerações finais - A dialética do desenvolvimento regional: capital social, democracia, redes empresariais e dinâmica territorial. In: BECKER, D. F.;

WITTMANN, M. L. (Orgs). Desenvolvimento regional: abordagens interdisciplinares. 2. ed. Santa Cruz do Sul: EDUNISC, 2010. Cap. 15, p. 383-395.

SOUZA, N. J. Desenvolvimento econômico. 2. ed. São Paulo: Atlas, 1995. 242 p.

STIGLITZ, J. E. Globalização: como dar certo. São Paulo: Companhia das Letras, 2007. 523 p.

STRANGE, S. The retreat of the state: the diffusion of power in the world economy. Cambridge: Cambridge University Press, 2003. 218 p.

STREETEN, P. Globalização: ameaça ou oportunidade? In: ARBIX, G.; ZILBOVICIUS, M.; ABRAMOVAY, R. (Orgs). Razões e ficções do desenvolvimento. São Paulo: Editora UNESP; Edusp, 2001. Cap. 6, p. 71-153. 
SUNKEL, O. A sustentabilidade do desenvolvimento atual na América Latina. In: ARBIX, G.; ZILBOVICIUS, M.; ABRAMOVAY, R. (Orgs). Razões e ficções do desenvolvimento. São Paulo: Editora UNESP; Edusp, 2001. Cap. 13, p. 267-309.

TERRA, L. A. A. Dinâmica simbiótica: o problema estratégico visto sob a perspectiva da complexidade. 2010. 190 p. Dissertação (Mestrado em Ciências no Programa de Pós-

Graduação em Administração de Organizações) - Faculdade de Economia, Administração e Contabilidade de Ribeirão Preto, Universidade de São Paulo, Ribeirão Preto, 2010.

TERRA, L. A. A.; PASSADOR, J. L. A fenomenologia como instrumento de construções teóricas em pesquisa sistêmica. In: CONGRESSO BRASILEIRO DE SISTEMAS, 7., 2011, Franca. Anais... Franca: Uni-FACEF, 2011, 1 CD-ROM.

THIOLLENT, M. Problemas de metodologia. In: FLEURY, A. C. C.; VARGAS, N. (Ed.). Organização do trabalho: uma abordagem interdisciplinar: sete estudos sobre a realidade brasileira. São Paulo: Atlas, 1983. Cap. 3, p. 54-83.

TISCH, S. J.; WALLACE, M. B. Dilemmas of development assistance: the what, why and who of foreign aid. Colorado: Westview Press, 1994. 182 p.

TOFFLER, A. A terceira onda. 20. ed. Rio de Janeiro: Record, 1995. 491 p.

ULTRAMARI, C.; DUARTE, F. Desenvolvimento local e regional. 1. ed. Curitiba: Ibpex, 2009. $132 \mathrm{p}$.

VÁZQUEZ BARQUERO, A. Gran empresa y desarollo endógeno. La convergência estratégica de las empresas y territórios ante el desafio dela competência. Revista EURE, v. 23, n. 70, pp. 5-18, 1997.

VEIGA, J. E. A história não os absolverá nem a geografia. Campinas: Armazén do Ipê, 2005a. $130 \mathrm{p}$.

VEIGA, J. E. Desenvolvimento sustentável: o desafio do século XXI. Rio de Janeiro: Garamond, 2005b. 220 p.

VERGARA, S. C. Métodos de pesquisa em administração. 4. ed. São Paulo: Atlas, 2010. $277 \mathrm{p}$.

VERGARA, S. C.: BRANCO, P. D. Em busca da visão de totalidade. Revista de Administração de Empresas, v. 33, n. 6, pp. 20-31, 1993.

WITTMANN, M. L.; DOTTO, D. M. R.; BOFF, V. A. Desenvolvimento regional: análise de processos organizacionais de desenvolvimento integrado. In: BECKER, D. F.; WITTMANN, M. L. (Orgs). Desenvolvimento regional: abordagens interdisciplinares. 2. ed. Santa Cruz do Sul: EDUNISC, 2010. Cap. 12, p. 319-339.

WITTMANN, M. L.; DOTTO, D. M. R.; BOFF, V. A. Estruturas organizacionais em rede e desenvolvimento regional: contextualização e complexidades. In: WITTMANN, M. L.; 
RAMOS, M. P. (Orgs). Desenvolvimento regional: capital social, redes e planejamento. 1. ed. Santa Cruz do Sul: EDUNISC, 2004. p. 11-35.

WITTMANN, M. L.; MAEHLER, A. E. Administração: do pensamento grego à teoria da complexidade. In: WITTMANN, M. L. (Org). Administração: teoria sistêmica e complexidade. Santa Maria: UFSM, 2008. Cap. 1, p. 15-39.

WITTMANN, M. L.; RAMOS, M. P. (Orgs). Desenvolvimento regional: capital social, redes e planejamento. 1. ed. Santa Cruz do Sul: EDUNISC, 2004. 215 p.

ZITKOSKI, J. J. O método fenomenológico de Husserl. Porto Alegre: EDIPUCRS, 1994. $108 \mathrm{p}$. 